2007 ANNUAL REPORT OF

THE BOARDS OF TRUSTEES OF THE

FEDERAL HOSPITAL INSURANCE AND

FEDERAL SUPPLEMENTARY MEDICAL INSURANCE TRUST FUNDS

\title{
COMMUNICATION
}

From

THE BOARDS OF TRUSTEES, FEDERAL HOSPITAL INSURANCE AND FEDERAL SUPPLEMENTARY MEDICAL INSURANCE TRUST FUNDS

Transmitting

THE 2007 ANNUAL REPORT OF THE BOARDS OF TRUSTEES OF THE FEDERAL HOSPITAL INSURANCE AND FEDERAL SUPPLEMENTARY MEDICAL INSURANCE TRUST FUNDS 



\section{LETTER OF TRANSMITTAL}

\section{BOARDS OF TRUSTEES OF THE \\ FEDERAL HOSPITAL INSURANCE AND \\ FEDERAL SUPPLEMENTARY MEDICAL INSURANCE TRUST FUNDS, \\ Washington, D.C., April 23, 2007}

HONORABLE Nancy Pelosi

Speaker of the House of Representatives

Washington, D.C.

HONORABLE Richard B. Cheney

President of the Senate

Washington, D.C.

\section{DEAR MADAM SPEAKER AND MR. CHENEY:}

We have the honor of transmitting to you the 2007 Annual Report of the Boards of Trustees of the Federal Hospital Insurance Trust Fund and the Federal Supplementary Medical Insurance Trust Fund, the 42nd such report.

$$
\text { Respectfully, }
$$

Henry M. Paulson, Jr., Secretary of the Treasury, and Managing Trustee of the Trust Funds.

Michael O. Leavitt, Secretary of Health and Human Services, and Trustee.

John L. Palmer, Trustee.
Elaine L. Chao, Secretary of Labor, and Trustee.

Michael J. Astrue, Commissioner of Social Security, and Trustee.

Thomas R. Saving, Trustee.

Leslie V. Norwalk, Esq., Acting

Administrator of the Centers for

Medicare \& Medicaid Services, and

Secretary, Boards of Trustees. 



\section{CONTENTS}

I. INTRODUCTION

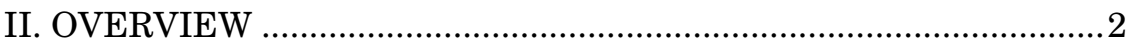

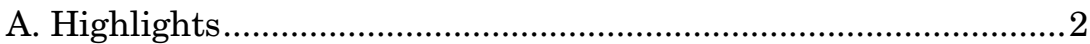

B. Medicare Data for Calendar Year 2006 ....................................

C. Economic and Demographic Assumptions .................................... 6

D. Financial Outlook for the Medicare Program ..............................10

E. Financial Status of the HI Trust Fund ….................................. 15

F. Financial Status of the SMI Trust Fund ....................................20



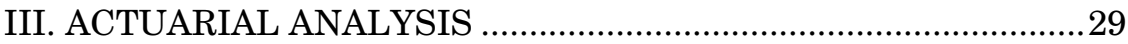

A. Medicare Financial Projections..................................................29

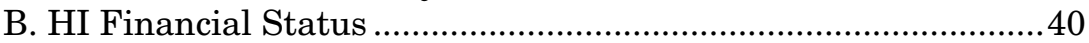

1. Financial Operations in Calendar Year 2006..........................40

2. 10 Year Actuarial Estimates (2007 2016).................................46

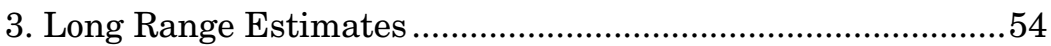







a. 10 Year Actuarial Estimates (2007 2016) ….......................75

b. 75 Year Actuarial Estimates (2007 2081) ….......................77

c. Implications of SMI Cost Growth ........................................78

2. Part B Account ......................................................................... 82

a. Financial Operations in Calendar Year 2006 .....................82

b. 10 Year Actuarial Estimates (2007 2016) ..........................89



3. Part D Account ......................................................................... 106

a. Financial Operations in Calendar Year 2006 ..................107

b. 10 Year Actuarial Estimates (2007 2016) .........................112





A. Hospital Insurance ..................................................................123

B. Supplementary Medical Insurance...........................................136



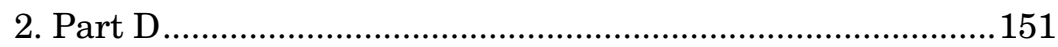

C. Long-Range Medicare Cost Growth Assumptions .....................160



A. Medicare Amendments since the 2006 Report ..........................163

B. Average Medicare Expenditures per Beneficiary …...................165

C. Medicare Cost Sharing and Premium Amounts .........................168

D. Supplementary Assessment of Uncertainty in Part B Cost

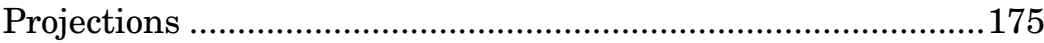

E. Medicare and Social Security Trust Funds and the Federal



F. Fiscal Year Historical Data and Projections through 2016......192



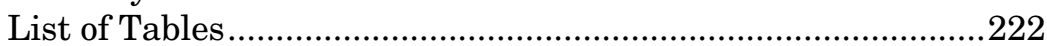

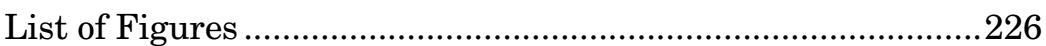

H. Statement of Actuarial Opinion ............................................228 



\section{INTRODUCTION}

The Medicare program has two components. Hospital Insurance (HI), or Medicare Part A, helps pay for hospital, home health, skilled nursing facility, and hospice care for the aged and disabled. Supplementary Medical Insurance (SMI) consists of Medicare Part B and Part D. ${ }^{1}$ Part B helps pay for physician, outpatient hospital, home health, and other services for the aged and disabled who have voluntarily enrolled. Part D initially provided access to prescription drug discount cards and transitional assistance to low-income beneficiaries. In 2006 and later, Part D provides subsidized access to drug insurance coverage on a voluntary basis for all beneficiaries and premium and cost-sharing subsidies for low-income enrollees.

The Medicare Board of Trustees was established under the Social Security Act to oversee the financial operations of the HI and SMI trust funds. ${ }^{2}$ The Board comprises six members. Four members serve by virtue of their positions in the Federal Government: the Secretary of the Treasury, who is the Managing Trustee; the Secretary of Labor; the Secretary of Health and Human Services; and the Commissioner of Social Security. The other two members, John L. Palmer and Thomas R. Saving, are public representatives initially appointed by President William J. Clinton on October 28, 2000, and reappointed by President George W. Bush on April 18, 2006. The Administrator of the Centers for Medicare \& Medicaid Services (CMS) is designated as Secretary of the Board.

The Social Security Act requires that the Board, among other duties, report annually to the Congress on the financial and actuarial status of the HI and SMI trust funds. This 2007 report is the 42 nd to be submitted.

\footnotetext{
${ }^{1}$ Medicare also has a Part C, which provides Part A and Part B coverage and, optionally, Part D coverage through private health insurance plans.

${ }^{2}$ Technically, separate boards are established for HI and SMI. Because both boards have the same membership, for convenience they are collectively referred to as the Medicare Board of Trustees in this report.
} 
Overview

\section{OVERVIEW}

\section{A. HIGHLIGHTS}

The major findings of this report under the intermediate set of assumptions are summarized below.

\section{In 2006}

In 2006, 43.2 million people were covered by Medicare: 36.3 million aged 65 and older, and 7.0 million disabled. Total benefits paid in 2006 were $\$ 402$ billion. Income was $\$ 437$ billion, expenditures were $\$ 408$ billion, and assets held in special issue U.S. Treasury securities grew to $\$ 339$ billion.

\section{Short-Range Results}

The HI trust fund is not adequately financed over the next 10 years under the intermediate assumptions. From the beginning of 2007 to the end of 2016, the assets of the HI trust fund are projected to decrease from $\$ 305$ billion to $\$ 221$ billion, which would be less than the recommended minimum level of 1 year's expenditures.

The SMI trust fund is adequately financed over the next 10 years and beyond because premium and general revenue income for Parts B and $\mathrm{D}$ are reset each year to match expected costs. Progress has been made toward rebuilding Part B assets, following significant declines in 1999-2004. Part B costs have been increasing rapidly, however, having averaged 11.0 percent annually over the last 6 years, and are likely to continue doing so. Under current law, an average annual growth rate of 6.6 percent is projected for the next 10 years. This rate is unrealistically constrained due to multiple years of physician fee reductions that would occur under current law. If Congress continues to override these reductions, as they have for 2003-2007, the Part B growth rate would instead average roughly 8 to 9 percent. For Part D, the average annual increase in expenditures is estimated to be 12.6 percent through 2016 . The U.S. economy is projected to grow by 4.8 percent on average during this period, significantly more slowly than either Part B or Part D.

The difference between Medicare's total outlays and its "dedicated financing sources" is estimated to reach 45 percent of outlays in fiscal year 2013, the seventh year of the projection. As a result, under section 801 of the Medicare Prescription Drug, Improvement, and Modernization Act of 2003 (also known informally as the Medicare 
Highlights

Modernization Act, or MMA), the Board of Trustees is issuing a determination of projected "excess general revenue Medicare funding" in this report. Since this is the second consecutive such finding, a "Medicare funding warning" is triggered, which will require the President to submit to Congress, within 15 days after the release of the Fiscal Year 2009 Budget, proposed legislation to respond to the warning. Congress is then required to consider the legislation on an expedited basis.

\section{Long-Range Results}

Under the intermediate assumptions the HI trust fund is projected to be exhausted in 2019, 1 year later than in last year's report, due to slightly higher projected payroll tax income and slightly lower projected benefits than previously estimated. For the 75-year projection period, the actuarial deficit is little different from that in last year's report, at 3.55 rather than 3.51 percent of taxable payroll.

The HI annual cost rate is projected to increase from 3.01 percent of taxable payroll in 2006 to 11.79 percent in $2081-8.38$ percent of taxable payroll more than the projected income rate for 2081. Expressed in relation to the projected Gross Domestic Product (GDP), HI cost is estimated to rise from the current level of 1.4 percent of GDP to 5.0 percent in 2081.

Part B outlays were 1.3 percent of GDP in 2006 and are projected to grow to about 4.0 percent by 2081 . These cost projections, however, are understated as a result of the substantial reductions in physician payments that would be required under current law. Actual future Part B costs will depend on the steps Congress takes to address the situation but could exceed the current-law projections by 7 to 9 percent in 2010 , growing to roughly 25 to 40 percent for 2030 and later.

Part D outlays are estimated to increase from 0.4 percent of GDP in 2006 to about 2.4 percent by 2081 . Initially, these outlay projections are significantly lower than those shown in last year's report. The primary reason for the reduction is that the 2007 prescription drug plan bid submissions were about 10 percent lower than in 2006. In the long range, the outlay projections return to, and eventually exceed, the prior projected level. 


\section{Overview}

\section{Conclusion}

The financial outlook for the Medicare program continues to raise serious concerns. In particular, a "Medicare funding warning" is triggered by the findings of this report. Total Medicare expenditures were $\$ 408$ billion in 2006 and are expected to increase in future years at a faster pace than either workers' earnings or the economy overall. As a percentage of GDP, expenditures are projected to increase from 3.1 percent in 2006 to 11.3 percent by 2081 (based on our intermediate set of assumptions). Growth of this magnitude, if realized, would substantially increase the strain on the nation's workers, Medicare beneficiaries, and the Federal Budget.

HI tax income is estimated to fall short of HI expenditures in 2007 and is projected to do so in all future years. The HI trust fund does not meet our short-range test of financial adequacy, and fund assets are projected to be exhausted in 2019. In the long range, projected expenditures and scheduled tax income are substantially out of balance, and the trust fund does not meet our test of long-range close actuarial balance. Currently, this imbalance is relatively small, with tax income is estimated to cover 99 percent of costs in 2007, but will grow rapidly in the absence of changes to current law: taxes would cover 79 percent of estimated costs in 2019 , and only 29 percent at the end of the long-range period. Closing deficits of this magnitude will require very substantial increases in tax revenues and/or reductions in expenditures.

The Part B and Part D accounts in the SMI trust fund are adequately financed under current law, since premium and general revenue income are reset each year to match expected costs. Such financing, however, would have to increase rapidly to match expected expenditure growth under current law and to finish rebuilding Part B assets to an appropriate level.

These projections demonstrate the need for timely and effective action to address Medicare's financial challenges. Consideration of such reforms should occur in the relatively near future. The sooner the solutions are enacted, the more flexible and gradual they can be. Moreover, the early introduction of reforms increases the time available for affected individuals and organizations-including health care providers, beneficiaries, and taxpayers-to adjust their expectations. We believe that prompt, effective, and decisive action is necessary to address these challenges-both the exhaustion of the HI trust fund and the anticipated rapid growth in HI, SMI Part B, and SMI Part D expenditures. 


\section{B. MEDICARE DATA FOR CALENDAR YEAR 2006}

HI and SMI have separate trust funds, sources of revenue, and categories of expenditures. Table II.B1 presents Medicare data for calendar year 2006, in total and for each part of the program. The largest category of HI expenditures is inpatient hospital services, while the largest SMI expenditure categories are physician services and prescription drugs.

\begin{tabular}{|c|c|c|c|c|}
\hline & \multirow[b]{2}{*}{$\mathrm{HI}$ or Part A } & \multicolumn{2}{|c|}{ SMI } & \multirow[b]{2}{*}{ Total } \\
\hline & & Part B & Part D & \\
\hline Assets at end of 2005 (billions) & $\$ 285.8$ & $\$ 24.0$ & - & $\$ 309.8$ \\
\hline Total income & $\$ 211.5$ & $\$ 177.3$ & $\$ 48.2$ & $\$ 437.0$ \\
\hline $\begin{array}{l}\text { Payroll taxes } \\
\text { Interest } \\
\text { Taxation of benefits } \\
\text { Premiums } \\
\text { General revenue } \\
\text { Transfers from States } \\
\text { Other }\end{array}$ & $\begin{array}{r}181.3 \\
15.7 \\
10.3 \\
2.6 \\
0.5 \\
-\overline{1.0}\end{array}$ & $\begin{array}{r}\overline{1.8} \\
\overline{-} \\
42.9 \\
132.7 \\
\overline{0.0}\end{array}$ & $\begin{array}{r}0.0 \\
- \\
3.5 \\
39.2 \\
5.5 \\
-\end{array}$ & $\begin{array}{r}181.3 \\
17.5 \\
10.3 \\
48.9 \\
172.4 \\
5.5 \\
1.0\end{array}$ \\
\hline Total expenditures & $\$ 191.9$ & $\$ 169.0$ & $\$ 47.4$ & $\$ 408.3$ \\
\hline $\begin{array}{l}\text { Benefits } \\
\text { Hospital } \\
\text { Skilled nursing facility } \\
\text { Home health care } \\
\text { Physician fee schedule services } \\
\text { Managed care } \\
\text { Prescription drugs } \\
\text { Other }\end{array}$ & $\begin{array}{r}189.0 \\
121.0 \\
19.9 \\
6.0 \\
-\overline{32.9} \\
\overline{9.3}\end{array}$ & $\begin{array}{r}165.9 \\
27.2 \\
- \\
7.2 \\
58.4 \\
31.5 \\
41.7\end{array}$ & $\begin{array}{r}47.1 \\
- \\
- \\
- \\
\frac{47.1}{-}\end{array}$ & $\begin{array}{r}402.0 \\
148.2 \\
19.9 \\
13.1 \\
58.4 \\
64.4 \\
47.1 \\
51.0\end{array}$ \\
\hline Administrative expenses & $\$ 2.9$ & $\$ 3.1$ & $\$ 0.3$ & $\$ 6.3$ \\
\hline Net change in assets & $\$ 19.6$ & $\$ 8.3$ & $\$ 0.8$ & $\$ 28.7$ \\
\hline Assets at end of 2006 & $\$ 305.4$ & $\$ 32.3$ & $\$ 0.8$ & $\$ 338.5$ \\
\hline $\begin{array}{l}\text { Enrollment (millions) } \\
\text { Aged } \\
\text { Disabled } \\
\text { Total }\end{array}$ & $\begin{array}{r}35.9 \\
7.0 \\
42.9\end{array}$ & $\begin{array}{r}34.1 \\
6.1 \\
40.3\end{array}$ & $\begin{array}{r}\mathrm{n} / \mathrm{a} \\
\mathrm{n} / \mathrm{a} \\
27.9\end{array}$ & $\begin{array}{r}36.3 \\
7.0 \\
43.2\end{array}$ \\
\hline Average benefit per enrollee & $\$ 4,410$ & $\$ 4,121$ & $\$ 1,690$ & $\$ 10,221$ \\
\hline
\end{tabular}

For HI, the primary source of financing is the payroll tax on covered earnings. Employers and employees each pay 1.45 percent of wages, while self-employed workers pay 2.9 percent of their net income. Other HI revenue sources include a portion of the Federal income taxes that people pay on their Social Security benefits, and interest paid on the U. S. Treasury securities held in the HI trust fund.

For SMI, transfers from the general fund of the Treasury represent the largest source of income, currently covering about 79 percent of program costs. Also, beneficiaries pay monthly premiums for Parts B and D that finance a portion of the total cost. As with HI, interest is paid on the U. S. Treasury securities held in the SMI trust fund. 
Overview

\section{ECONOMIC AND DEMOGRAPHIC ASSUMPTIONS}

Actual future Medicare expenditures will depend on a number of factors, including the size and composition of the population eligible for benefits, changes in the volume and intensity of services, and increases in the price per service. For HI, future trust fund income will depend on the size and characteristics of the covered work force and the level of workers' earnings. These factors will depend in turn upon future birth rates, death rates, labor force participation rates, wage increases, and many other economic and demographic circumstances affecting Medicare. To illustrate the uncertainty and sensitivity inherent in estimates of future Medicare trust fund operations, projections have been prepared under a "low cost" and a "high cost" set of assumptions as well as under an intermediate set.

Table II.C1 summarizes the key assumptions used in this report. Many of the demographic and economic variables that determine Medicare costs and income are common to the Old-Age, Survivors, and Disability Insurance (OASDI) program and are explained in detail in the report of the OASDI Board of Trustees. These variables include changes in the Consumer Price Index (CPI) and wages, real interest rates, fertility rates, and mortality rates. ("Real" indicates that the effects of inflation have been removed.) The assumptions vary, in most cases, from year to year during the first 5 to 30 years before reaching their so-called "ultimate" values for the remainder of the 75-year projection period. Other assumptions are specific to Medicare.

As with all of the assumptions underlying the Trustees' financial projections, the Medicare-specific assumptions are reviewed annually and updated based on the latest available data and analysis of trends. In addition, the assumptions and projection methodology are subject to periodic review by independent panels of expert actuaries and economists. The most recent such review was conducted by the 2004 Medicare Technical Review Panel, which issued its findings in December 2004. 
Economic and Demographic Assumptions

Table II.C1._Ultimate Assumptions

\begin{tabular}{|c|c|c|c|}
\hline & Intermediate & Low Cost & High Cost \\
\hline \multicolumn{4}{|l|}{ Economic: } \\
\hline \multicolumn{4}{|l|}{ Annual percentage change in: } \\
\hline Gross Domestic Product (GDP) per capita ${ }^{1}$.................. & 4.1 & 3.5 & 4.6 \\
\hline Average wage in covered employment ....................... & 3.9 & 3.4 & 4.4 \\
\hline Consumer Price Index (CPI) ......................... & 2.8 & 1.8 & 3.8 \\
\hline Real-wage differential (percent) & 1.1 & 1.6 & 0.6 \\
\hline Real interest rate (percent) …………………………... & 2.9 & 3.6 & 2.1 \\
\hline \multicolumn{4}{|l|}{ Demographic: } \\
\hline Total fertility rate (children per woman) & 2.00 & 2.30 & 1.70 \\
\hline Average annual percentage reduction in total & & & \\
\hline age-sex adjusted death rates from 2031 to $2081 \ldots \ldots$ & 0.70 & 0.33 & 1.21 \\
\hline \multicolumn{4}{|l|}{ Health cost growth: } \\
\hline \multicolumn{4}{|l|}{ Annual percentage change in per beneficiary } \\
\hline $\begin{array}{l}\text { Medicare expenditures (excluding demographic } \\
\text { impacts) }\end{array}$ & $5.1^{2}$ & 3 & 3 \\
\hline \multicolumn{4}{|c|}{$\begin{array}{l}\text { 'The assumed ultimate increases in per capita GDP and per beneficiary Medicare expenditures can also } \\
\text { be expressed in real terms, adjusted to remove the impact of assumed inflation growth. When adjusted } \\
\text { by the chain-weighted GDP price index, assumed real per capita GDP growth is } 1.5 \text { percent, and real } \\
\text { per beneficiary Medicare cost growth is } 2.5 \text { percent. } \\
{ }^{2} \text { Cost growth assumptions in the last } 50 \text { years of the projection vary year by year and follow a smooth } \\
\text { downward path that generates the same } 75 \text {-year } \mathrm{HI} \text { actuarial balance as a level growth assumption of } \\
\text { GDP plus } 1 \text { percent for the last } 50 \text { years ( } 5.1 \text { percent). }\end{array}$} \\
\hline
\end{tabular}

The assumed long-range rate of growth in annual Medicare expenditures per beneficiary is one of the most critical determinants of the projected cost of Medicare-covered health care services in the more distant future. Prior to last year's report, the increase in average expenditures per beneficiary for the $25^{\text {th }}$ through $75^{\text {th }}$ years of the projection was assumed to equal the growth in per capita GDP plus 1 percentage point. ${ }^{3}$ This assumption was recommended by the 2000 Medicare Technical Review Panel. With the inclusion of infinitehorizon projections starting in the 2004 Trustees Report, per beneficiary expenditures after the $75^{\text {th }}$ year were assumed to increase at the same rate as per capita GDP. The 2004 Technical Review Panel recommended that these assumptions continue to be used, given the limits of current knowledge, but that further research also be conducted.

Starting with last year's report, the Board of Trustees adopted a slight refinement of the long-range growth assumption that provides a more gradual transition from current health cost growth rates, which have been roughly 2 to 3 percentage points above the level of GDP growth, to the ultimate assumed level of GDP plus zero percent just after the $75^{\text {th }}$ year and for the indefinite future. The year-by-year growth assumptions are based on a simplified economic model and

${ }^{3}$ This assumed increase in the average expenditures per beneficiary excludes the impacts of the aging of the population and changes in the gender composition of the Medicare population, which are estimated separately. 


\section{Overview}

are determined in a way such that the 75-year actuarial balance for the HI trust fund is consistent with that generated by the "GDP plus 1 percent" assumption. An independent group of experts in health economics and long-range forecasting reviewed the model and advised that its use for this purpose is appropriate. Consistent with the recommendations of this group and the 2000 and 2004 Technical Panels, further research is being conducted on long-range health cost growth trends.

As in the past, detailed growth rate assumptions are established for the next 10 years by individual type of service (for example, inpatient hospital care, physician services, etc.), reflecting recent trends and the impact of specific statutory provisions. Under the economic model, in 2031 the growth rate for all Medicare services is assumed to be about 1.4 percentage points above the level of GDP growth for that year. This differential gradually declines to about 0.8 percent in 2051 and to 0.2 percent in $2081 .{ }^{4}$ Compared to the assumptions used in several reports prior to last year, the new growth assumption is initially higher but subsequently lower than the constant "GDP plus 1 percent" assumption. Beyond 75 years, the assumed growth rate of GDP plus zero percent is essentially unchanged.

In HI, for the high cost assumptions, the annual increase in aggregate costs (relative to increases in taxable payroll) during the initial 25-year period is assumed to be 2 percentage points greater than under the intermediate assumptions. Under low cost assumptions, the increase during the same period is assumed to be 2 percentage points less than under intermediate assumptions. The 2-percentage-point differentials are assumed to decline gradually until 2056, when the same rate of increase in HI costs (relative to taxable payroll) is assumed for all three sets of assumptions.

Because of its automatic financing provisions for Parts B and D, the SMI trust fund is expected to be adequately financed into the indefinite future, so a long-range analysis using high cost and low cost assumptions has not been conducted. The 2004 Technical Panel recommended refining the presentation of long-range uncertainty through stochastic techniques or long-range high- and low-cost alternatives for Parts A, B, and D. The trustees and their staffs intend to consider alternative methods to illustrate the long-range uncertainty in the Medicare projections.

${ }^{4}$ The cost growth assumptions thus follow a smooth, downward path over the last 50 years of the projection rather than remaining constant. 
While it is reasonable to expect that actual trust fund experience will fall within the range defined by the three alternative sets of assumptions, no assurance can be given in light of the wide variations in experience that have occurred since the beginning of the Medicare program. In general, a greater degree of confidence can be placed in the assumptions and estimates for the earlier years than for the later years. Nonetheless, even for the earlier years, the estimates are only an indication of the expected trend and the general range of future Medicare experience. For simplicity of presentation, much of the analysis in this overview centers on the projections under the intermediate assumptions. 
Overview

\section{FINANCIAL OUTLOOK FOR THE MEDICARE PROGRAM}

This report evaluates the financial status of the HI and SMI trust funds. For HI, the Trustees apply formal tests of financial status for both the short range and the long range; for SMI, the Trustees assess the ability of the trust fund to meet incurred costs over the period for which financing has been set.

HI and SMI are financed in very different ways. Within SMI, Part B and Part D premiums and general revenue financing are reestablished annually to match expected costs for the following year. In contrast, $\mathrm{HI}$ is subject to substantially greater variation in asset growth, since financing is established through statutory tax rates that cannot be adjusted to match expenditures except by enactment of new legislation.

Despite the significant differences in benefit provisions and financing, the two components of Medicare are closely related. Most beneficiaries are enrolled in both HI and SMI Part B, and a majority have enrolled in SMI Part D. Many receive health care services from both HI and SMI in a given year. Thus, efforts to improve and reform either component must necessarily involve the other component as well. In view of the anticipated growth in Medicare expenditures, it is also important to consider the distribution among the various sources of revenues for financing Medicare and the manner in which this distribution will change over time under current law.

In this section, the projected total expenditures for the Medicare program are considered, along with the primary sources of financing. Figure II.D1 shows projected costs as a percentage of GDP. Medicare expenditures represented 3.1 percent of GDP in 2006. Costs increase to about 7.3 percent of GDP by 2035 under the intermediate assumptions and to 11.3 percent of GDP by the end of the 75 -year period. However, it is important to note that, after 2007, Medicare expenditures are understated because of unrealistic substantial reductions in physician payments scheduled under current law. 
Figure II.D1.-Medicare Expenditures as a Percentage of the Gross Domestic Product

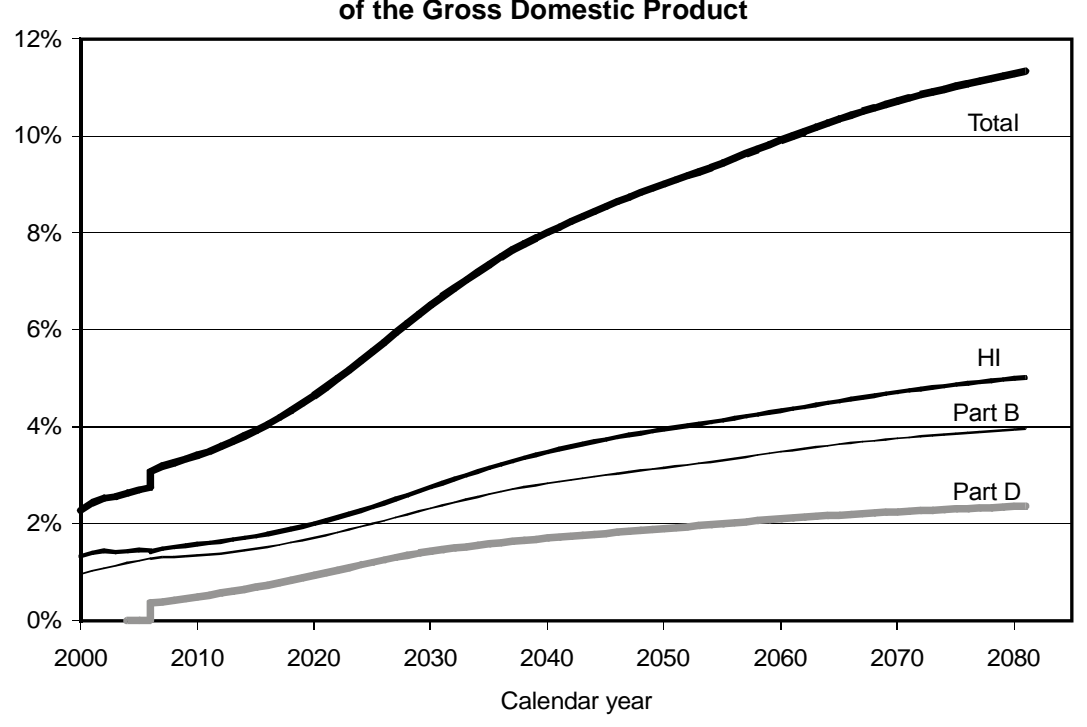

The Medicare projections reflect (i) continuing growth in the volume and intensity of services provided per beneficiary throughout the projection period, (ii) the impact of a large increase in beneficiaries starting in about 2010 as the leading edge of the 1946-65 baby boom generation reaches age 65 and becomes eligible to receive benefits, and (iii) the introduction of the Part D program in 2004, along with the other provisions of the Medicare Modernization Act of 2003, the Deficit Reduction Act of 2005, and the Tax Relief and Health Care Act of 2006. Other key demographic trends are also reflected, including future birth rates at roughly the same level as during the last 2 decades and continuing improvements in life expectancy.

The past and projected amounts of Medicare revenues, under current law, are shown in figure II.D2. Interest income is excluded since it would not be a significant part of program financing in the long range. Medicare revenues-from HI payroll taxes, HI income from the taxation of Social Security benefits, SMI Part D State transfers for certain Medicaid beneficiaries, HI and SMI premiums, and HI and SMI statutory general revenues-are compared to total Medicare expenditures. For the next 3 years, such Medicare revenues are estimated to be slightly above program expenditures, reflecting the automatic financing of SMI Part D plus a surplus in Part B financing (designed to restore assets to a more appropriate level) that is slightly greater than the small but increasing deficit of $\mathrm{HI}$ expenditures over tax income. Thereafter, overall expenditures are projected to exceed 


\section{Overview}

aggregate revenues to an increasing extent, as a result of the projected large financial imbalance in the HI trust fund.

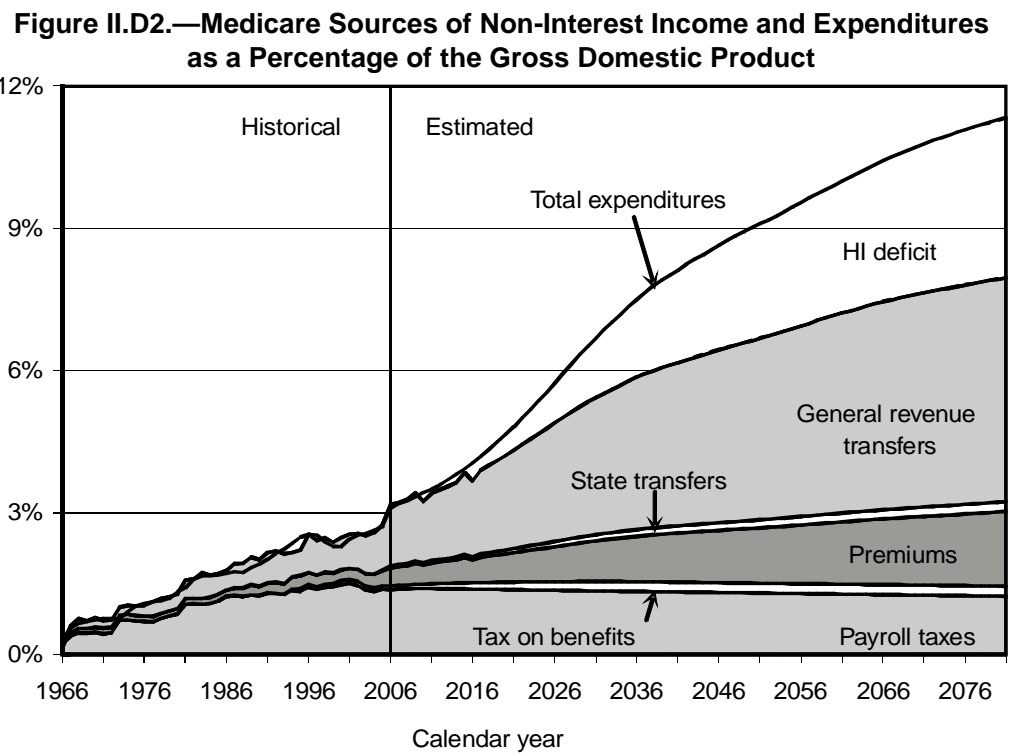

As shown in figure II.D2, payroll tax revenues increased steadily as a percentage of GDP in the historical period, due to increases in the HI payroll tax rate and the limit on taxable earnings, the latter of which was eliminated in 1994. In the future, however, payroll taxes are projected to grow more slowly than GDP. ${ }^{5}$ HI revenue from income taxes on Social Security benefits will likely increase as a share of GDP as additional beneficiaries become subject to such taxes.

By comparison, growth in SMI Part B and Part D premiums and general fund transfers is expected to continue to outpace GDP growth and HI payroll tax growth in the future. This phenomenon occurs primarily because, under current law, SMI revenue increases at the same rate as expenditures, whereas HI revenue does not. Thus, as the HI sources of revenue become increasingly inadequate to cover $\mathrm{HI}$ costs, SMI revenues are projected to represent a growing share of total Medicare revenues. Within the next 10 years, general revenue transfers are expected to constitute the largest single source of income to the Medicare program as a whole-and would add

\footnotetext{
${ }^{5}$ Although total worker compensation is projected to grow at the same rate as GDP, wages and salaries are expected to increase more slowly and fringe benefits (health insurance costs in particular) more rapidly. Thus, earnings are projected to gradually decline as a percentage of GDP. Absent any change to the tax rate scheduled under current law, HI payroll tax revenue would similarly decrease as a percentage of GDP.
} 


\section{Medicare Financial Outlook}

significantly to the Federal Budget pressures. Although a smaller share of the total, SMI premiums would grow just as rapidly as general revenue transfers, thereby also placing a growing burden on beneficiaries.

The interrelationship between the Medicare program and the Federal Budget is an important topic-one that will become increasingly so over time as the general revenue requirements for SMI continue to grow. While these transfers are an important source of financing for the SMI trust fund, and are central to the automatic financial balance of the fund's two accounts, they represent a large and growing requirement for the Federal Budget. SMI general revenues currently equal 1.3 percent of GDP and would increase to an estimated 4.7 percent in 2081 under current law. Moreover, in the absence of corrective legislation, the difference between HI tax revenues and expenditures would be met for a number of years by interest earnings on trust fund assets and by redeeming those assets. Both of these financial resources for the HI trust fund require cash transfers from the general fund of the Treasury, placing a further obligation on the budget. In 2018, these transactions would require general fund transfers equal to 0.4 percent of GDP. (After asset depletion in 2019, no provision exists to use general revenues to cover the HI deficit.) Appendix E describes the interrelationship between the Federal Budget and the Medicare and Social Security trust funds and illustrates the programs' long-range financial outlook from both a "trust fund perspective" and a "budget perspective."

The Medicare Modernization Act requires the Board of Trustees to test whether the difference between program outlays and dedicated financing sources exceeds 45 percent of Medicare outlays. ${ }^{6}$ If this level is attained within the first 7 fiscal years of the projection, a determination of projected "excess general revenue Medicare funding" is required. This determination was made in the 2006 report-the first such finding - since the difference was projected to initially reach the 45-percent level in fiscal year 2012. If such determinations are present in two consecutive Trustees Reports, then a "Medicare funding warning" is triggered. In this year's report, the difference is projected to exceed 45 percent in 2013 , once again inside the first 7 years of the projection period (2007-2013). Therefore, a finding of projected "excess general revenue Medicare funding" is again made in

${ }^{6}$ The dedicated financing sources are HI payroll taxes, the HI share of income taxes on Social Security benefits, Part D State transfers, and beneficiary premiums. These sources are the first four layers depicted in figure II.D2. 
Overview

this report, and a "Medicare funding warning" is triggered. (Section III.A contains additional details on these tests.)

This section has summarized the total financial obligation posed by Medicare and the manner in which it is financed. Under current law, however, the HI and SMI components of Medicare have separate and distinct trust funds, each with its own sources of revenues and mandated expenditures. Accordingly, the financial status of each Medicare trust fund must be assessed separately. The next two sections of the overview present such assessments for the HI trust fund and the SMI trust fund, respectively. 


\section{E. FINANCIAL STATUS OF THE HI TRUST FUND}

\section{10-Year Actuarial Estimates (2007-2016)}

Over the next 10 years, HI expenditures are expected to grow faster than income. Expenditure growth is estimated to average 7.2 percent per year. HI income growth averages 4.9 percent per year over this period. Currently, the HI trust fund is experiencing small annual surpluses of total income over expenditures. If interest earnings and general revenues are excluded from income, then expenditures are expected to exceed tax income in 2007 and thereafter. Therefore, interest and trust fund assets would be needed to pay expenditures in full and on time beginning in 2007. Total expenditures will exceed total income and deficits will begin to emerge in 2011. The HI trust fund is projected to become exhausted in 2019 .

Table II.E1 presents the projected operations of the HI trust fund under the intermediate assumptions for the next decade. At the beginning of 2007, HI assets significantly exceeded annual expenditures. The Board of Trustees has recommended that assets be maintained at a level at least equal to annual expenditures, to serve as an adequate contingency reserve in the event of adverse economic or other conditions.

Based on the 10-year projection shown in table II.E1, the Board of Trustees applies an explicit test of short-range financial adequacy, which is described in section III.B of this report. The HI trust fund does not meet this test because assets are estimated to fall below 100 percent of annual expenditures within the next 10 years.

\begin{tabular}{|c|c|c|c|c|c|}
\hline \multicolumn{6}{|c|}{$\begin{array}{c}\text { Table II.E1.-Estimated Operations of the HI Trust Fund } \\
\text { under Intermediate Assumptions, Calendar Years 2006-2016 } \\
\text { [Dollar amounts in billions] }\end{array}$} \\
\hline Calendar year & Total income $^{1}$ & $\begin{array}{c}\text { Total } \\
\text { expenditures }\end{array}$ & $\begin{array}{l}\text { Change in } \\
\text { fund }\end{array}$ & Fund at year end & $\begin{array}{c}\text { Ratio of assets to } \\
\text { expenditures }\end{array}$ \\
\hline $2006^{3}$ & $\$ 211.5$ & $\$ 191.9$ & $\$ 19.6$ & $\$ 305.4$ & $149 \%$ \\
\hline 2007 & 223.6 & 208.2 & 15.4 & 320.8 & 147 \\
\hline 2008 & 234.3 & 224.2 & 10.1 & 330.9 & 143 \\
\hline 2009 & 247.8 & 240.7 & 7.1 & 337.9 & 137 \\
\hline 2010 & 260.9 & 257.7 & 3.1 & 341.0 & 131 \\
\hline 2011 & 274.4 & 275.1 & -0.7 & 340.4 & 124 \\
\hline 2012 & 287.8 & 293.9 & -6.1 & 334.3 & 116 \\
\hline 2013 & 301.0 & 314.5 & -13.5 & 320.8 & 106 \\
\hline 2014 & 313.9 & 336.4 & -22.5 & 298.3 & 95 \\
\hline 2015 & 327.0 & 359.8 & -32.8 & 265.5 & 83 \\
\hline 2016 & 340.4 & 385.4 & -44.9 & 220.5 & 69 \\
\hline
\end{tabular}

${ }^{1}$ Includes interest income.

${ }^{2}$ Ratio of assets in the fund at the beginning of the year to expenditures during the year.

${ }^{3}$ Figures for 2006 represent actual experience.

Note: Totals do not necessarily equal the sums of rounded components. 


\section{Overview}

A comparison with last year's estimates reveals that actual payroll tax income in 2006 and projected future amounts are slightly higher than previously projected. This results from higher average wages than previously assumed. In addition, projected HI expenditures are slightly lower over the 10-year period. The result is a slower depletion of trust fund assets than previously estimated, as well as increased interest earnings. The cumulative effect of these factors is a higher level of projected $\mathrm{HI}$ assets relative to annual expenditures.

\section{75-Year Actuarial Estimates (2007-2081)}

Each year, 75-year estimates of the financial and actuarial status of the HI trust fund are prepared. Although financial outcomes are inherently uncertain, particularly over periods as long as 75 years, such estimates can indicate whether the trust fund-as seen from today's vantage point-is considered to be in satisfactory financial condition.

Because of the difficulty in comparing dollar values for different periods without some type of relative scale, income and expenditure amounts are shown relative to the earnings in covered employment that are taxable under HI (referred to as "taxable payroll"). The ratio of tax income (including both payroll taxes and income from taxation of Social Security benefits, but excluding interest income) to taxable payroll is called the "income rate," and the ratio of expenditures to taxable payroll is the "cost rate."

Since HI payroll tax rates are not scheduled to change in the future under current law, payroll tax income as a percentage of taxable payroll will remain constant at 2.90 percent. Income from taxation of benefits will increase only gradually as a greater proportion of Social Security beneficiaries become subject to such taxation over time. Thus, the income rate is not expected to increase significantly over current levels. The cost rate, though, will sharply escalate due to retirements of those in the baby boom generation and continuing health services cost growth, as mentioned in the prior section.

Figure II.E1 compares projected income and cost rates under the intermediate assumptions. As indicated, HI expenditures are projected to continue to exceed tax income by a rapidly growing margin. In 2019, for example, taxes would cover only 79 percent of estimated expenditures and, in 2050, only 38 percent. By the end of the 75-year period, HI costs would be over three times the level of scheduled tax revenues-a substantial deficit by any standard. 
The shaded area in figure II.E1 represents the excess of expenditures over tax income that could be met by interest earnings and the redemption of trust fund assets. Both types of transactions occur through transfers from the general fund of the Treasury. Starting in 2007 , the fund is expected to begin using interest earnings to cover the excess of expenditures over tax income. Starting in 2011, trust fund assets will begin to be used also, to cover the excess. In the absence of other changes, this process will continue through 2019, at which time the fund is projected to be exhausted. The HI trust fund's projected year of exhaustion often receives considerable attention. In practice, however, the demands on general revenue (to pay interest and redeem the Treasury bonds held by the trust fund) have already begun, some 12 years before the exhaustion date. By 2018, in the absence of legislation to address the HI deficits, an estimated 19 percent of HI expenditures would have to be met by redeeming assets as opposed to being covered by tax income for that year.



The year-by-year cost rates and income rates shown in figure II.E1 can be summarized into single values representing, in effect, the average value over a given period. Based on the intermediate assumptions, an actuarial deficit of 3.55 percent of taxable payroll is projected for the 75-year period, representing the difference between the summarized income rate of 3.40 percent and the corresponding cost rate of 6.95 percent. Based on this measure, the HI trust fund continues to fail the Trustees' test for long-range financial balance. 


\section{Overview}

The long-range financial imbalance could be addressed in several different ways. In theory, the 2.90-percent payroll tax could be immediately increased to 6.45 percent, or expenditures could be reduced by a corresponding amount. Note, however, that these changes would require an immediate 122-percent increase in the tax rate or an immediate 51-percent reduction in expenditures. ${ }^{7}$ More realistically, the tax and/or benefit changes could be made gradually, rather than immediately, but would ultimately have to reach much more substantial levels to eliminate the deficit throughout the long-range period. At the end of the 75-year period, for example, the tax rate would have to be more than three times its current level, or benefit expenditures would have to be less than one-third of their projected amount (or some combination). These examples illustrate the severe magnitude of the projected long-range deficits for the HI trust fund and the need for reform.

Under the intermediate assumptions, the assets of the HI trust fund would continue decreasing, as a percentage of annual expenditures, from about 147 percent of annual expenditures at the beginning of 2007 until becoming exhausted in 2019, as illustrated in figure II.E2. This date is 1 year later than estimated in the 2006 annual report, due to the slightly higher projected income and lower projected expenditures mentioned earlier.

\footnotetext{
${ }^{7}$ Under either of these two scenarios, tax income would initially be substantially greater than expenditures, and trust fund assets would accumulate rapidly. Subsequently, however, financing would be increasingly inadequate, and assets would be drawn down to cover the difference. At the end of the 75-year period, tax income would cover only about 60 percent of annual expenditures. Level changes in either taxes or benefits, consequently, would not permanently address the long-range financial imbalance and would result in unusual patterns of asset accumulation and redemption.
} 
Figure II.E2.-HI Trust Fund Balance at Beginning of Year as a Percentage of Annual Expenditures

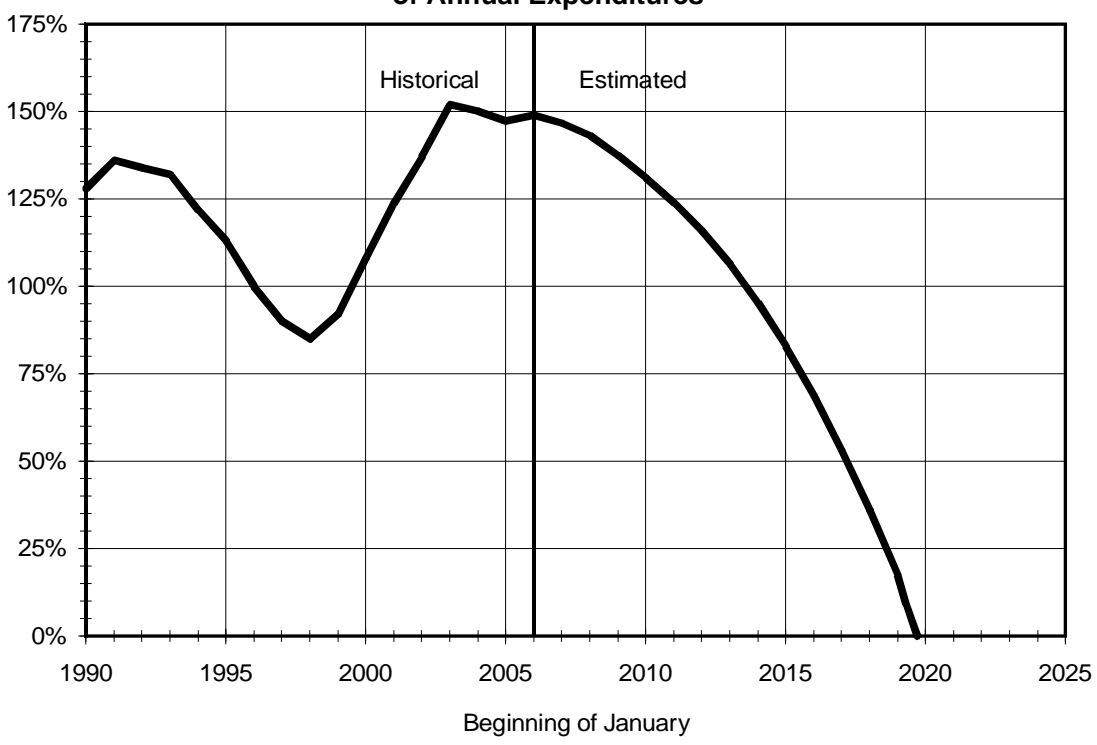

To the extent that actual future conditions vary from the intermediate assumptions, the date of exhaustion could differ substantially in either direction from this estimate. Under the low cost assumptions, trust fund assets would not be depleted until 2042. Under the high cost assumptions, however, asset depletion would occur in 2014. 
Overview

\section{F. FINANCIAL STATUS OF THE SMI TRUST FUND}

SMI differs fundamentally from $\mathrm{HI}$ in regard to the nature of financing and the method by which financial status is evaluated. As a result of the Medicare Modernization Act, SMI is now composed of two parts, Part B and Part D, each with its own separate account within the SMI trust fund. The financial status of the SMI trust fund must be determined by evaluating the financial status of each account separately, since there is no provision in the law for transferring assets between the Part B and Part D accounts. The nature of the financing for both parts of SMI is similar, in that the Part B premium and the Part D premium, and the corresponding transfers from general revenues for each part, are established annually at a level sufficient to cover the following year's estimated expenditures. Thus, each account within SMI is automatically in financial balance under current law. For OASDI and HI, however, financing established many years earlier may prove significantly higher or lower than subsequent actual costs. Moreover, Part B and Part D are voluntary (whereas OASDI and HI are generally compulsory), and income is not based on payroll taxes. These disparities result in a financial assessment that differs in some respects from that for OASDI or HI, as described in the following sections.

\section{10-Year Actuarial Estimates (2007-2016)}

Table II.F1 shows the estimated operations of the Part B account, the Part D account, and the total SMI trust fund under the intermediate assumptions during calendar years 2006 through 2016. For Part B, expenditures grew at an average annual rate of 10.8 percent over the past 5 years, primarily as a result of significant increases in the volume and complexity of most types of covered services. The Part B growth rate exceeded GDP growth by 5.3 percent annually, on average. Part B cost increases are estimated to average about 6.6 percent for the 10-year period 2007 to 2016 , about 1.8 percent per year faster than GDP, in part as a result of unrealistic reductions in physician payments required by current law. Legislative changes to physician payments are likely and could increase the projected Part B growth rates to roughly 8 to 9 percent.

Part B income growth normally matches expenditure growth fairly closely. During the last few years, however, premiums and general revenue financing have been increased at a faster pace than expenditures in an effort to rebuild Part B account assets to an 
adequate contingency reserve. Under current law, assets are projected to fall just within the desired range by the end of 2007 (but would not do so if legislation is enacted to address a scheduled 10 -percent reduction in physician fees for 2008). ${ }^{8}$

As noted, the projected Part B expenditure and income growth is unrealistically low, due to the structure of physician payment updates under current law. Future physician payment increases must be adjusted downward if cumulative past actual physician spending exceeds a statutory target. Prior to the Consolidated Appropriations Resolution (CAR), past spending was already above the target level. CAR raised the physician fee update for 2003, but without raising the target. The Medicare Modernization Act and the Deficit Reduction Act again raised the physician fee schedule updates for 2004, 2005, and 2006 without raising the target. The Tax Relief and Health Care Act raised the physician fee schedule update for 2007, increased the target for 1 year, and specified that the 2008 physician fee schedule conversion factor be computed as if the 2007 physician fee schedule update had not been changed. Together, these factors yield projected physician updates of about -10 percent for 2008 and about -5 percent for at least 8 consecutive years, from 2009 through 2016 .

Given recent history, multiple years of significant reductions in physician payments per service are very unlikely to occur before legislative changes intervene. Scheduled negative physician fee updates in 2003 through 2007 have already been avoided by legislation, and the negative physician fee update scheduled for 2008 is larger than any of those previously avoided. However, these unlikely payment reductions are required under the current-law payment system and are reflected in the Part B projections shown in this report. Therefore, the Part B, total SMI, and total Medicare estimates shown for 2008 and thereafter are likely understated and should be interpreted cautiously.

The Part B projections, in particular, may be understated by 25 to 40 percent in the long range and thus have limited usefulness. At the request of the Trustees, the Office of the Actuary at the Centers for Medicare \& Medicaid Services (CMS) has prepared two illustrative sets of Part B projections under theoretical alternatives to current

${ }^{8}$ The traditional measure used to evaluate the status of the Part B account of the SMI trust fund is defined as the ratio of the excess of Part B assets over Part B liabilities to the next year's Part B incurred expenditures. The desired range for this ratio is 15 to 20 percent, and was developed based on past studies which indicated that this level of excess assets is sufficient to protect against adverse events. 


\section{Overview}

law. These projections are available at http://www.cms.hhs.gov/ ReportsTrustFunds/05_alternativePartB.asp. No endorsement of these alternatives to current law by the Trustees, CMS, or the Office of the Actuary should be inferred.

\begin{tabular}{|c|c|c|c|c|}
\hline Calendar year & Total income $^{1}$ & Total expenditures & Change in fund & Fund at year end \\
\hline $\begin{array}{c}\text { Part B account: } \\
2006^{2} \\
2007 \\
2008 \\
2009 \\
2010 \\
2011 \\
2012 \\
2013 \\
2014 \\
2015 \\
2016\end{array}$ & $\begin{array}{c}\$ 177.3 \\
188.0 \\
198.3 \\
223.5^{3} \\
201.0^{3} \\
232.5 \\
248.6 \\
266.1 \\
284.7 \\
331.8^{3} \\
300.4^{3}\end{array}$ & $\begin{array}{r}\$ 169.0 \\
179.6 \\
190.8 \\
202.9 \\
216.1 \\
229.3 \\
244.4 \\
261.6 \\
279.9 \\
299.5 \\
321.6\end{array}$ & $\begin{array}{r}\$ 8.3 \\
8.4 \\
7.5 \\
20.7 \\
-15.2 \\
3.2 \\
4.2 \\
4.5 \\
4.7 \\
32.3 \\
-21.2\end{array}$ & $\begin{array}{r}\$ 32.3 \\
40.7 \\
48.2 \\
68.8 \\
53.7 \\
56.9 \\
61.1 \\
65.6 \\
70.3 \\
102.5 \\
81.4\end{array}$ \\
\hline $\begin{array}{l}\text { Part D account: } \\
2006^{2} \\
2007 \\
2008 \\
2009 \\
2010 \\
2011 \\
2012 \\
2013 \\
2014 \\
2015 \\
2016\end{array}$ & $\begin{array}{c}48.2 \\
50.1 \\
61.9 \\
69.6^{3} \\
78.7^{3} \\
89.1 \\
101.4 \\
112.0 \\
124.8 \\
139.3^{3} \\
155.7^{3}\end{array}$ & $\begin{array}{r}47.4 \\
50.1 \\
61.9 \\
69.6 \\
78.6 \\
89.0 \\
101.3 \\
111.9 \\
124.8 \\
139.2 \\
155.6\end{array}$ & $\begin{array}{l}0.8 \\
0.0 \\
0.0 \\
0.0 \\
0.0 \\
0.1 \\
0.1 \\
0.1 \\
0.1 \\
0.1 \\
0.1\end{array}$ & $\begin{array}{l}0.8 \\
0.8 \\
0.8 \\
0.9 \\
0.9 \\
1.0 \\
1.0 \\
1.1 \\
1.2 \\
1.3 \\
1.4\end{array}$ \\
\hline $\begin{array}{l}\text { Total SMI: } \\
2006^{2} \\
2007 \\
2008 \\
2009 \\
2010 \\
2011 \\
2012 \\
2013 \\
2014 \\
2015 \\
2016\end{array}$ & $\begin{array}{l}225.5 \\
238.1 \\
260.2 \\
293.1^{3} \\
279.6^{3} \\
321.6 \\
350.0 \\
378.1 \\
409.5 \\
471.1^{3} \\
456.1^{3}\end{array}$ & $\begin{array}{l}216.4 \\
229.7 \\
252.6 \\
272.4 \\
294.7 \\
318.3 \\
345.7 \\
373.5 \\
404.7 \\
438.7 \\
477.2\end{array}$ & $\begin{array}{r}9.1 \\
8.4 \\
7.5 \\
20.7 \\
-15.1 \\
3.3 \\
4.3 \\
4.6 \\
4.8 \\
32.3 \\
-21.1\end{array}$ & $\begin{array}{r}33.1 \\
41.5 \\
49.0 \\
69.7 \\
54.6 \\
57.9 \\
62.1 \\
66.7 \\
71.5 \\
103.8 \\
82.8\end{array}$ \\
\hline
\end{tabular}

Includes interest income.

${ }^{2}$ Figures for 2006 represent actual experience.

${ }^{3}$ Section 708 of the Social Security Act modifies the provisions for the delivery of Social Security benefit checks when the regularly designated day falls on a Saturday, Sunday, or legal public holiday. Delivery of benefit checks normally due January 3,2010 is expected to occur on December 31, 2009. Consequently, the Part B and Part D premiums withheld from the checks and the associated Part B general revenue contributions are expected to be added to the Part B account and Part D account, respectively, on December 31,2009. These amounts are excluded from the premium income and general revenue income for 2010. Similarly, delivery of benefit checks normally due January 3, 2016 is expected to occur on December 31, 2015.

In general, Part B income and outgo will remain in approximate balance as a result of the annual adjustment of premium and general revenue income to match costs. Over temporary periods, it is possible 
for these amounts to differ, sometimes significantly. For example, financing rates for 2004 were set with the intention of increasing the assets in the Part B account of the trust fund to a more adequate level. The subsequent enactment of the MMA, however, increased Part B expenditures significantly above the level anticipated when the financing was set. Moreover, other factors in 2004 also raised costs faster than anticipated. As a result, Part B assets declined by $\$ 4.5$ billion in 2004. This deficit brought the total asset loss during 1999 through 2004 to $\$ 26.8$ billion, leaving assets at the end of 2004 substantially below the normal level that is optimal for the Part B account.

Therefore, the financing rates for 2005, 2006, and 2007 were set with the intention of taking steps toward restoring the assets to a more adequate level. However, the financing rates for 2004, 2005, and 2006 were determined before actual costs were known for these years. In addition, the Deficit Reduction Act (DRA) increased Part B costs for 2006 and later after the 2006 financing had been determined, and the Tax Relief and Health Care Act (TRA) increased the costs for 2007 after the 2007 financing had been determined. Because of higherthan-anticipated 2004 and 2005 costs, the DRA, and the TRA, the increase in the Part B account assets was less than desired in 2005 and 2006, and the asset increase is now expected to be restricted again in 2007. The result is that the Part B assets will likely remain below the desired level. Under current law, correcting this situation would require a 3 -percent increase in the 2008 premium, along with the corresponding general revenue transfers. However, should legislative changes block the negative physician updates that will otherwise occur for 2008 and later under current law, this increase would need to be larger. After 2007, assets held in the Part B account are projected to maintain an adequate contingency reserve for the Part B account of the trust fund, under current law.

The Part D account of the SMI trust fund was established in 2004 for Medicare prescription drug coverage, which began in 2006. For 2004 and 2005, the Transitional Assistance Account handled the transactions for transitional assistance under the prescription drug card program, with any remaining assets transferred to the Part D account in 2006. ${ }^{9}$ Income and expenditures for the Part D account are projected to grow at an average annual rate of 12.6 percent for the 10-year period 2006 to 2016, in part due to expected further increases in enrollment. As with Part B, income and outgo are projected to

${ }^{9}$ For simplicity, the Transitional Assistance Account is treated in this report as if it were included in the Part D account. 


\section{Overview}

remain in balance through the annual adjustment of premium and general revenue income to match costs. As a result of the appropriations process for Part D general revenues, it is not necessary to maintain a contingency reserve in the account (see section III.C3 for further details).

The projected Part D costs shown in this report are significantly lower than those in the 2006 report. The reduction is primarily attributable to the 2007 prescription drug plan bid submissions. The average 2007 plan bid was about 10 percent lower than in 2006. This extraordinary change reflected a number of factors, including a significant drop in plans' expectations for preferred brand name drug use and an associated increase in generic utilization. The decrease is also believed to reflect the substantial competition among Part D plans, together with much slower growth in prescription drug costs, generally, in 2004 through 2006 compared with prior years.

The primary test of financial adequacy for Parts B and D pertains to the level of the financing that has been formally established for a given period (normally, through the end of the current calendar year). As noted, the financial adequacy must be determined for Part B and Part D separately. The financing for each part of SMI is considered satisfactory if it is sufficient to fund all services, including benefits and administrative expenses, provided through a given period. Further, to protect against the possibility that cost increases under either part of SMI will be higher than expected, the accounts of the trust fund need assets adequate to cover a reasonable degree of variation between actual and projected costs. For Part B, the financing established through December 2007 is estimated to be sufficient to cover benefits and administrative costs incurred through that time period. As a result of the current higher-than-anticipated Part B expenditure level and the TRA, however, limited progress is expected in 2007 toward restoring the account balance to a more adequate contingency reserve level. The financing established for Part D is estimated to be sufficient to cover benefits and administrative costs incurred through 2007.

The amount of the contingency reserve needed in Part B is much smaller (both in absolute dollars and as a fraction of annual costs) than in HI or OASDI. This is so because the premium rate and corresponding general revenue transfers for Part B are determined annually based on estimated future costs, while the HI and OASDI payroll tax rates are set in law and are therefore much more difficult to adjust should circumstances change. Part D revenues are also 
established annually to match estimated costs. Moreover, general revenue transfers for Part $\mathrm{D}$ will be made as funds are needed, thereby eliminating the need for a contingency reserve to cover unexpectedly higher costs.

\section{75-Year Actuarial Estimates (2007-2081)}

Figure II.F1 shows past and projected total SMI expenditures and premium income as a percentage of the Gross Domestic Product (GDP). As noted, SMI expenditures are significantly understated as a result of unrealistic physician payment reductions required under the current-law sustainable growth rate system. As a result, the SMI estimates after 2007 should be interpreted cautiously. Annual SMI expenditures grew from about 1.2 percent of GDP in 2005 to 1.6 percent of GDP in 2006 with the commencement of the general prescription drug coverage. Under the intermediate assumptions, SMI expenditures would grow to almost 4 percent of GDP within 25 years and to more than 6 percent by the end of the projection period.

Figure II.F1.-SMI Expenditures and Premiums as a Percentage of the Gross Domestic Product

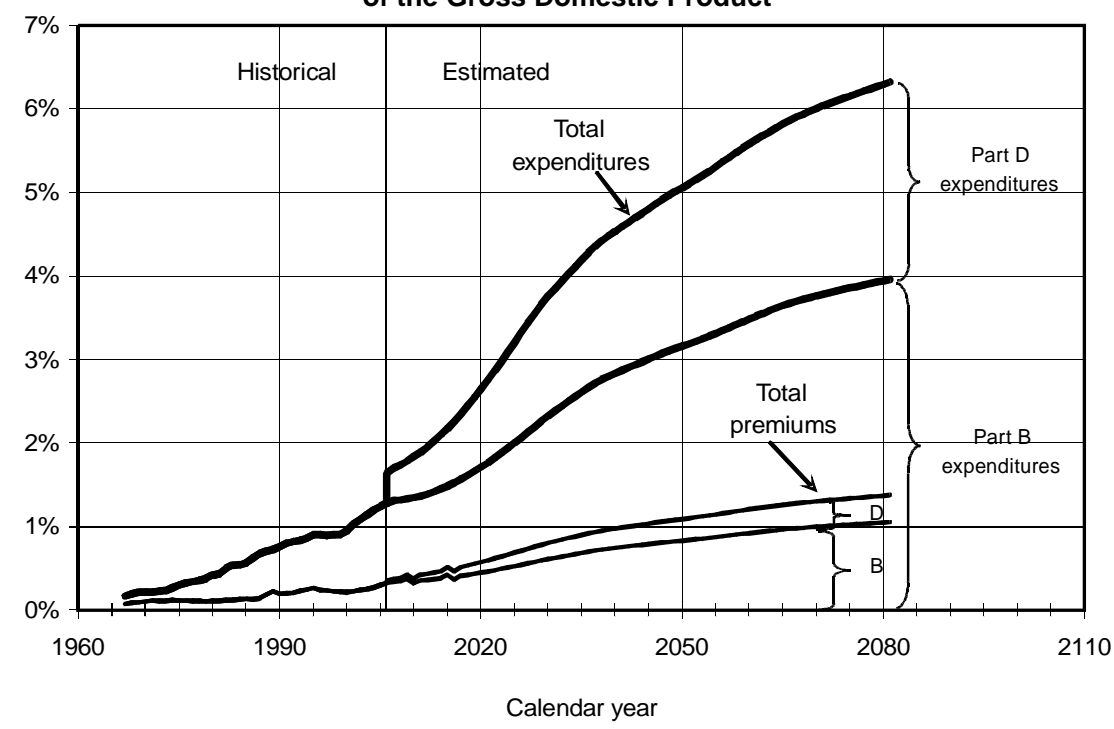

The projected SMI cost under current law would place steadily increasing demands on beneficiaries and society at large. Average per-beneficiary costs for Part B and Part D benefits are projected to increase after 2007 by at least 5 percent annually, despite the significant reductions in Part B physician payments under current 


\section{Overview}

law. The associated beneficiary premiums would increase by approximately the same rate, as would the average levels of beneficiary coinsurance for covered services. In contrast, from one generation to the next, scheduled Social Security benefit levels increase at about the rate of growth in average earnings (estimated at roughly 3.8 percent)..$^{10}$ Over time, the Part B and Part D premiums and coinsurance amounts paid by beneficiaries would typically represent a growing share of their total Social Security and other income. (Beneficiaries who qualify for Medicaid and the Part D low-income subsidy are an important exception to this trend, since they generally pay little or no premiums and cost-sharing amounts.)

Similarly, aggregate SMI general revenue financing for Parts B and $\mathrm{D}$ is expected to increase by roughly 6.5 percent annually, well in excess of the projected 4.4-percent growth in GDP. As a result, if personal and corporate Federal income taxes are maintained at their long-term historical level, relative to the national economy in the future, then SMI general revenue financing would represent a growing share of the total income tax revenue of the Federal Government.

${ }^{10}$ For each generation, after beneficiaries are initially eligible, their benefit level is adjusted to keep up with inflation (estimated at 2.8 percent). 
Conclusion

\section{G. CONCLUSION}

Total Medicare expenditures were $\$ 408$ billion in 2006 and are expected to increase in future years at a faster pace than either workers' earnings or the economy overall. As a percentage of GDP, expenditures are projected to increase from 3.1 percent currently to 11.3 percent by 2081 (based on our intermediate set of assumptions). The level of Medicare expenditures is expected to exceed that for Social Security in 2028 and, by 2081, to be 80 percent more than the cost of Social Security. Growth of this magnitude, if realized, would

place a substantially greater strain on the nation's workers, Medicare beneficiaries, and the Federal Budget.

Total Medicare outlays, less dedicated revenues, are projected to first exceed 45 percent of outlays in 2013. Since this is within the first 7 fiscal years of the projection period, the Board determines that a condition of projected "excess general revenue Medicare funding" exists for the second consecutive year. This determination triggers a "Medicare funding warning," as required by the Medicare Modernization Act.

The HI trust fund ratio is expected to decline steadily after 2006. The trust fund is projected to be exhausted in 2019-1 year later than estimated in last year's report, primarily as a result of slightly higher projected payroll tax income and slightly lower expenditures than previously estimated. The HI trust fund fails to meet our short-range test of financial adequacy.

The long-range financial projections for HI continue to show a substantial financial imbalance. The long-range HI actuarial deficit in this year's report is 3.55 percent of taxable payroll, up slightly from 3.51 percent in last year's report. Tax income is expected to be less than expenditures in all future years, and trust fund assets would begin to decline in 2011. Without legislation to address these deficits, HI would increasingly rely on interest income and the redemption of fund assets, thereby adding to the draw on the Federal Budget. Scheduled HI tax income would cover only 79 percent of estimated expenditures in 2019 and only 38 percent in 2050. By the end of the 75-year period, less than one-third of $\mathrm{HI}$ costs could be paid from $\mathrm{HI}$ tax revenues. Accordingly, bringing the HI program into long-range financial balance would require very substantial increases in revenues and/or reductions in expenditures. As in past reports, the HI trust fund fails to meet our long-range test of close actuarial balance. 


\section{Overview}

The financial outlook for SMI is fundamentally different than for HI, as a result of the statutory differences in how these two components of Medicare are financed. However, rapid expenditure growth is a serious issue for both. The Medicare Modernization Act established a separate account within the SMI trust fund to handle transactions for the new Medicare drug benefit. Because there is no authority to transfer assets between the new Part $\mathrm{D}$ account and the existing Part B account, it is necessary to evaluate each account's financial adequacy separately. Part B assets minus liabilities at the end of 2004 were at their lowest level, relative to annual outlays, in nearly 30 years. Moreover, while the financing established for the Part B account for calendar year 2007 is adequate to cover 2007 expected expenditures, the financial status of the Part B account in 2007 remains below the optimal level. Thus, the Part B financing rates for 2008 will have to be increased-for the fifth year in a row-in an effort to return to an adequate contingency reserve.

No financial imbalance is anticipated for the Part D account, since the general revenue subsidy for this benefit is drawn on a daily, as-needed basis. The projected Part D costs shown in this report are significantly lower than in previous reports, reflecting the latest data on drug cost trends generally and Part D bid levels.

For both the Part B and Part D accounts, income is projected to equal expenditures for all future years-but only because beneficiary premiums and general revenue transfers will be set to meet expected costs each year.

The projections shown in this report continue to demonstrate the need for timely and effective action to address Medicare's financial challenges-both the long-range financial imbalance facing the HI trust fund and the heightened problem of rapid growth in expenditures. We believe that solutions can and must be found to ensure the financial integrity of $\mathrm{HI}$ in the long term and to reduce the rate of growth in Medicare costs. Consideration of such reforms should occur in the relatively near future. The sooner the solutions are enacted, the more flexible and gradual they can be. Moreover, the early introduction of reforms increases the time available for affected individuals and organizations-including health care providers, beneficiaries, and taxpayers-to adjust their expectations. We believe that prompt, effective, and decisive action is necessary to address these challenges. 


\section{ACTUARIAL ANALYSIS}

\section{A. MEDICARE FINANCIAL PROJECTIONS}

Medicare is the nation's second largest social insurance program, exceeded only by Social Security (OASDI). Although Medicare's two components-Hospital Insurance and Supplementary Medical Insurance-are very different from each other in many key respects, it is important to consider the overall cost of Medicare and the manner in which that cost is financed. By reviewing Medicare's total expenditures, the financial obligation posed by the program can be assessed. Similarly, the sources and relative magnitudes of $\mathrm{HI}$ and SMI revenues are an important policy matter. It should be noted that the Part B expenditures, and therefore the SMI and total Medicare expenditures, are substantially understated because projected current-law physician payment updates are unrealistically reduced under the sustainable growth rate system. Consequently, the estimates after 2007 should be used cautiously in evaluating the financial obligation posed by Medicare.

The issues of Medicare's total cost to society and how that cost is met are different from the question of the financial status of the Medicare trust funds. The latter focuses on whether a specific trust fund's income and expenditures are in balance. As discussed later in this section, such an analysis must be performed for each trust fund individually. The separate HI and SMI financial projections prepared for this purpose, however, can be usefully combined for the broader purposes outlined above. To that end, this section presents information on combined HI and SMI costs and revenues. Sections III.B and III.C of this report present detailed assessments of the financial status of the HI trust fund and the SMI trust fund, respectively.

\section{10-year Actuarial Estimates (2007-2016)}

Table III.A1 shows past and projected Medicare income, expenditures, and trust fund assets in dollar amounts for calendar years. ${ }^{11}$ Projections are shown under the intermediate set of assumptions for the short-range projection period 2007 through 2016 based on current law (including the unrealistic reductions in physician payment rates). A more detailed breakdown of

\footnotetext{
${ }^{11}$ Amounts are shown on a "cash" basis, reflecting actual expenditures made during the year, even if the payments were for services performed in an earlier year. Similarly, income figures represent amounts actually received during the year, even if incurred in an earlier year.
} 
Actuarial Analysis

expenditures and income for HI and SMI is provided in tables III.B4 and III.C1, respectively.

Table III.A1.-Total Medicare Income, Expenditures, and Trust Fund Assets during Calendar Years 1970-2016

\begin{tabular}{|c|c|c|c|c|}
\hline Calendar year & Total income & Total expenditures & $\begin{array}{c}\text { Net change in } \\
\text { assets }\end{array}$ & $\begin{array}{c}\text { Assets at end of } \\
\text { year }\end{array}$ \\
\hline \multicolumn{5}{|l|}{ Historical data: } \\
\hline 1970 & $\$ 8.2$ & $\$ 7.5$ & $\$ 0.7$ & $\$ 3.4$ \\
\hline 1975 & 17.7 & 16.3 & 1.3 & 12.0 \\
\hline 1980 & 37.0 & 36.8 & 0.1 & 18.3 \\
\hline 1985 & 76.5 & 72.3 & 4.2 & 31.4 \\
\hline 1990 & 126.3 & 111.0 & 15.3 & 114.4 \\
\hline 1995 & 175.3 & 184.2 & -8.9 & 143.4 \\
\hline 2000 & 257.1 & 221.8 & 35.3 & 221.5 \\
\hline 2001 & 273.3 & 244.8 & 28.5 & 250.0 \\
\hline 2002 & 284.8 & 265.7 & 19.1 & 269.1 \\
\hline 2003 & 291.6 & 280.8 & 10.8 & 280.0 \\
\hline 2004 & 317.7 & 308.9 & 8.8 & 288.8 \\
\hline 2005 & 357.5 & 336.4 & 21.0 & 309.8 \\
\hline 2006 & 437.0 & 408.3 & 28.7 & 338.5 \\
\hline \multicolumn{5}{|c|}{ Intermediate estimates: } \\
\hline 2007 & 461.7 & 437.9 & 23.8 & 362.2 \\
\hline 2008 & 494.4 & 476.8 & 17.7 & 379.9 \\
\hline 2009 & $540.9^{1}$ & 513.1 & 27.8 & 407.7 \\
\hline 2010 & $540.5^{1}$ & 552.5 & -12.0 & 395.6 \\
\hline 2011 & 595.9 & 593.4 & 2.6 & 398.2 \\
\hline 2012 & 637.7 & 639.6 & -1.8 & 396.4 \\
\hline 2013 & 679.1 & 688.0 & -8.9 & 387.4 \\
\hline 2014 & 723.4 & 741.1 & -17.7 & 369.7 \\
\hline 2015 & $798.1^{1}$ & 798.5 & -0.4 & 369.3 \\
\hline 2016 & $796.5^{1}$ & 862.5 & -66.0 & 303.3 \\
\hline
\end{tabular}

Note: Totals do not necessarily equal the sums of rounded components.

As indicated in table III.A1, Medicare expenditures have increased rapidly during most of the program's history and are expected to continue doing so in the future. Health care cost increases, including those for Medicare, Medicaid, and private health insurance, are affected by the following factors:

- Growth in the number of beneficiaries;

- Increases in the prices paid per service, which reflect both higher wages for health care workers and inflation in the goods and services purchased by health care providers;

- Increases in the average number of services per beneficiary ("utilization"); and

- Increases in the average complexity of services ("intensity"). 


\section{Financial Projections}

Medicare expenditures are projected to increase at an average annual rate of 7.8 percent during 2007-2016. The average growth rate reflects the continuing impact of each of the factors listed above, together with the effects of the provisions of the Medicare Modernization Act, the Deficit Reduction Act, and the Tax Relief Act, and the unrealistic physician payment reductions.

Through most of Medicare's history, trust fund income has kept pace with increases in expenditures. ${ }^{12}$ In the future, however, Medicare income is projected to increase less rapidly than expenditures, primarily because HI payroll tax revenues would not keep pace with HI benefits under current law. In contrast to the growth factors listed above for health care costs, HI payroll taxes increase only as a function of the number of workers and increases in their average earnings. Moreover, with past declines in birth rates, continuing improvements in life expectancy, and prevailing rates of disability incidence, the number of workers is expected to grow slowly while the number of beneficiaries increases much more rapidly.

Past excesses of income over expenditures have been invested in U.S. Treasury securities, with total fund assets accumulating to $\$ 339$ billion at the end of calendar year 2006. Combined assets are projected to continue increasing until reaching about $\$ 398$ billion in 2011 and to begin declining thereafter. ${ }^{13}$

\section{75-year Actuarial Estimates (2007-2081)}

Expressing Medicare expenditures as a percentage of GDP gives a relative measure of the size of the Medicare program compared to the general economy. The projection of this measure affords the public an idea of the relative financial resources that will be necessary to pay for Medicare services. However, after 2007, the projected SMI Part B and total Medicare expenditures are unrealistically low because of the current-law physician payment reductions. Should these payment rates, by new legislation, be prevented from declining, the overall Medicare costs shown in this section would be increased-possibly by 10 to 15 percent for 2030 and later (and by lower percentages prior to 2030), depending on the specific changes enacted.

${ }^{12}$ This balance resulted from periodic increases in HI payroll tax rates and other HI financing, from annual increases in SMI premium and general revenue financing rates (to match the following year's estimated expenditures), and from frequent legislation designed to slow the rate of growth in expenditures.

${ }^{13}$ See sections III.B and III.C regarding the asset projections for HI and SMI, separately. 


\section{Actuarial Analysis}

Table III.A2 shows past and projected Medicare expenditures expressed as a percentage of GDP. ${ }^{14}$ Medicare expenditures represented 0.7 percent of GDP in 1970 and had grown to 2.7 percent of GDP by 2005, reflecting rapid increases in the factors affecting health care cost growth, as mentioned previously. Starting in 2006, Medicare provided subsidized access to prescription drug coverage through Part D, increasing projected Medicare expenditures to 3.1 percent of GDP.

Continuing rapid growth is expected thereafter, with total Medicare expenditures projected to reach about 11.3 percent of GDP by 2080 . For comparison, projected Medicare costs would exceed those for Social Security in 2028 and would continue to grow more rapidly until, in 2081, the expenditure level for Medicare would be 80 percent more than that for Social Security. Another comparison would be that over the last 50 years, total Federal income tax receipts have averaged 11 percent of GDP.

As indicated, part of the projected substantial increase is attributable to the new prescription drug benefit in Medicare. In its first (partial) year of operation, this benefit increased aggregate Medicare costs by over one-eighth. ${ }^{15}$ With continuing faster growth in drug costs, relative to the traditional HI and SMI Part B expenditures, this new benefit is projected to increase costs by roughly one-fourth for 2020 and later. ${ }^{16}$

The cost projections shown in table III.A2 for total Medicare, as well as for Parts A, B, and D, are somewhat different than those in the 2006 annual report. These differences arise for a number of reasons, which are described in sections III.B and III.C.

\footnotetext{
${ }^{14}$ In contrast to the expenditure amounts shown in table III.A1, historical and projected expenditures are shown on an incurred basis. Incurred amounts relate to the expenditures for services performed in a given year, even if those expenditures are paid in a later year.

${ }^{15}$ Although the Part D drug benefit became available on January 1, 2006, beneficiaries had until May $15^{\text {th }}$ to enroll. About 62 percent of the ultimate number of enrollees had enrolled as of January $1^{\text {st }}$.

${ }^{16}$ Costs beyond the first 25 years for HI, SMI Part B, and SMI Part D are each based on the assumption that age-sex-adjusted per beneficiary expenditures will increase at the rate determined by the economic model mentioned earlier. This rate is about 1.4 percent faster than the per capita GDP in 2031, decelerating to about the same rate as per capita GDP by 2081 .
} 
Financial Projections

Table III.A2.-HI and SMI Incurred Expenditures as a Percentage of the Gross Domestic Product

\begin{tabular}{|c|c|c|c|c|}
\hline \multirow[b]{2}{*}{ Calendar year } & \multirow{2}{*}{$\begin{array}{c}\text { HI } \\
\text { Part A }\end{array}$} & \multicolumn{2}{|c|}{ SMI } & \multirow[b]{2}{*}{ Total } \\
\hline & & Part B & Part D & \\
\hline \multicolumn{5}{|l|}{ Historical data: } \\
\hline 1970 & $0.52 \%$ & $0.22 \%$ & - & $0.74 \%$ \\
\hline 1975 & 0.73 & 0.30 & - & 1.03 \\
\hline 1980 & 0.91 & 0.41 & - & 1.32 \\
\hline 1985 & 1.12 & 0.56 & - & 1.68 \\
\hline 1990 & 1.14 & 0.76 & - & 1.90 \\
\hline 1995 & 1.58 & 0.90 & - & 2.48 \\
\hline 2000 & 1.33 & 0.95 & - & 2.28 \\
\hline 2001 & 1.40 & 1.03 & - & 2.43 \\
\hline 2002 & 1.44 & 1.08 & - & 2.52 \\
\hline 2003 & 1.42 & 1.14 & - & 2.56 \\
\hline 2004 & 1.43 & 1.19 & $0.00 \%$ & 2.63 \\
\hline 2005 & 1.46 & 1.23 & 0.01 & 2.70 \\
\hline 2006 & 1.43 & 1.28 & 0.37 & 3.07 \\
\hline \multicolumn{5}{|c|}{ Intermediate estimates: } \\
\hline 2007 & 1.49 & 1.31 & 0.39 & 3.18 \\
\hline 2008 & 1.52 & 1.32 & 0.42 & 3.25 \\
\hline 2009 & 1.55 & 1.33 & 0.45 & 3.33 \\
\hline 2010 & 1.58 & 1.35 & 0.49 & 3.41 \\
\hline 2011 & 1.60 & 1.36 & 0.52 & 3.49 \\
\hline 2012 & 1.63 & 1.39 & 0.57 & 3.59 \\
\hline 2013 & 1.67 & 1.42 & 0.60 & 3.69 \\
\hline 2014 & 1.71 & 1.45 & 0.64 & 3.81 \\
\hline 2015 & 1.75 & 1.48 & 0.69 & 3.92 \\
\hline 2020 & 2.00 & 1.71 & 0.93 & 4.64 \\
\hline 2025 & 2.35 & 2.00 & 1.20 & 5.55 \\
\hline 2030 & 2.75 & 2.32 & 1.43 & 6.51 \\
\hline 2035 & 3.15 & 2.61 & 1.58 & 7.34 \\
\hline 2040 & 3.48 & 2.83 & 1.70 & 8.01 \\
\hline 2045 & 3.74 & 3.00 & 1.80 & 8.54 \\
\hline 2050 & 3.95 & 3.16 & 1.90 & 9.00 \\
\hline 2055 & 4.13 & 3.31 & 2.00 & 9.44 \\
\hline 2060 & 4.33 & 3.48 & 2.10 & 9.91 \\
\hline 2065 & 4.53 & 3.64 & 2.18 & 10.35 \\
\hline 2070 & 4.71 & 3.76 & 2.24 & 10.72 \\
\hline 2075 & 4.87 & 3.85 & 2.30 & 11.02 \\
\hline 2080 & 5.00 & 3.94 & 2.35 & 11.29 \\
\hline
\end{tabular}

The 75-year projection period fully allows for the presentation of future developments that are expected to occur, such as the impact of a large increase in enrollees that will begin within the next 10 years. This increase in the number of beneficiaries will occur because the relatively large number of persons born during the period between the end of World War II and the mid-1960s (known as the baby boom generation) will reach eligibility age and begin to receive benefits. Moreover, as the average age of Medicare beneficiaries increases, these individuals will experience greater health care utilization and costs, thereby adding further to growth in program expenditures. Table III.A3 shows past and projected enrollment in the Medicare program. 
Actuarial Analysis

Table III.A3.-Medicare Enrollment [In thousands]

\begin{tabular}{|c|c|c|c|c|c|}
\hline \multirow[b]{2}{*}{ Calendar year } & \multirow{2}{*}{$\begin{array}{c}\mathrm{HI} \\
\text { Part A }\end{array}$} & \multicolumn{2}{|c|}{ SMI } & \multirow[b]{2}{*}{ Part $C^{1}$} & \multirow[b]{2}{*}{ Total $^{2}$} \\
\hline & & Part B & Part D & & \\
\hline \multicolumn{6}{|l|}{ Historical data: } \\
\hline 1970 & 20,104 & 19,496 & - & - & 20,398 \\
\hline 1975 & 24,481 & 23,744 & - & - & 24,864 \\
\hline 1980 & 28,002 & 27,278 & - & - & 28,433 \\
\hline 1985 & 30,621 & 29,869 & - & 842 & 31,081 \\
\hline 1990 & 33,747 & 32,567 & - & 1,181 & 34,251 \\
\hline 1995 & 37,175 & 35,641 & - & 2,714 & 37,594 \\
\hline 2000 & 39,257 & 37,335 & - & 6,233 & 39,688 \\
\hline 2001 & 39,669 & 37,667 & - & 5,608 & 40,103 \\
\hline 2002 & 40,065 & 37,982 & - & 5,005 & 40,508 \\
\hline 2003 & 40,738 & 38,584 & - & 4,655 & 41,188 \\
\hline 2004 & 41,485 & 39,123 & 1,217 & 4,683 & 41,902 \\
\hline 2005 & 42,181 & 39,698 & 1,841 & 5,084 & 42,588 \\
\hline 2006 & 42,852 & 40,271 & 27,854 & 6,550 & 43,249 \\
\hline \multicolumn{6}{|c|}{ Intermediate estimates: } \\
\hline 2007 & 43,772 & 40,726 & 30,957 & 7,644 & 44,160 \\
\hline 2008 & 44,679 & 41,480 & 32,299 & 8,571 & 45,057 \\
\hline 2009 & 45,655 & 42,294 & 33,679 & 9,414 & 46,022 \\
\hline 2010 & 46,581 & 43,055 & 35,036 & 10,122 & 46,936 \\
\hline 2011 & 47,647 & 43,901 & 36,511 & 10,717 & 47,992 \\
\hline 2012 & 49,054 & 45,082 & 38,266 & 11,323 & 49,390 \\
\hline 2013 & 50,587 & 46,404 & 39,448 & 11,891 & 50,915 \\
\hline 2014 & 52,067 & 47,693 & 40,589 & 12,462 & 52,388 \\
\hline 2015 & 53,571 & 48,999 & 41,748 & 13,002 & 53,884 \\
\hline 2016 & 55,118 & 50,349 & 42,942 & 13,565 & 55,426 \\
\hline 2020 & 61,927 & 56,342 & 48,203 & 15,924 & 62,216 \\
\hline 2025 & 71,001 & 64,449 & 55,228 & 19,193 & 71,283 \\
\hline 2030 & 78,813 & 71,528 & 61,283 & 22,308 & 79,098 \\
\hline 2035 & 83,640 & 75,937 & 65,026 & 3 & 83,930 \\
\hline 2040 & 86,578 & 78,675 & 67,306 & 3 & 86,872 \\
\hline 2045 & 88,702 & 80,578 & 68,955 & 3 & 89,000 \\
\hline 2050 & 91,140 & 82,802 & 70,846 & 3 & 91,441 \\
\hline 2055 & 93,927 & 85,305 & 73,006 & 3 & 94,229 \\
\hline 2060 & 97,283 & 88,386 & 75,607 & 3 & 97,587 \\
\hline 2065 & 100,285 & 91,110 & 77,929 & 3 & 100,583 \\
\hline 2070 & 103,056 & 93,651 & 80,069 & 3 & 103,345 \\
\hline 2075 & 105,651 & 96,009 & 82,068 & 3 & 105,926 \\
\hline 2080 & 108,366 & 98,477 & 84,158 & 3 & 108,623 \\
\hline \multicolumn{6}{|c|}{$\begin{array}{l}{ }^{1} \text { Number of beneficiaries enrolled in a Medicare Advantage plan. Figures from the early 1980s to } 1997 \\
\text { represent those enrolled in a risk HMO, and figures from } 1998 \text { to } 2003 \text { represent those enrolled in a } \\
\text { Medicare+Choice plan. In order to enroll in a Medicare Advantage plan, a beneficiary must be enrolled in } \\
\text { both Part A and Part B. Therefore, Part C enrollment is a subset of both Part A and Part B enrollment. } \\
{ }^{2} \text { Number of beneficiaries with } \mathrm{HI} \text { and/or SMl coverage. } \\
{ }^{3} \text { Enrollment in Medicare Advantage plans is not explicitly projected beyond } 2030 \text {. }\end{array}$} \\
\hline
\end{tabular}

The past and projected amounts of Medicare revenues as a percentage of total non-interest Medicare income are shown in Table III.A4, based on the intermediate assumptions. Interest income is excluded, since, under current law, it would not be a significant part of program financing in the long range. 
Financial Projections

\begin{tabular}{|c|c|c|c|c|c|}
\hline $\begin{array}{c}\text { Calendar } \\
\text { year }\end{array}$ & Payroll taxes & $\begin{array}{l}\text { Tax on } \\
\text { benefits }\end{array}$ & Premiums $^{1}$ & $\begin{array}{c}\text { State } \\
\text { transfers }\end{array}$ & $\begin{array}{l}\text { General } \\
\text { revenue }\end{array}$ \\
\hline \multicolumn{6}{|c|}{ torical data: } \\
\hline 1970 & $61.8 \%$ & $0.0 \%$ & $13.7 \%$ & $0.0 \%$ & $24.6 \%$ \\
\hline 1980 & 68.0 & 0.0 & 8.6 & 0.0 & 23.4 \\
\hline 1990 & 62.2 & 0.0 & 9.8 & 0.0 & 27.9 \\
\hline 2000 & 59.8 & 3.6 & 9.1 & 0.0 & 27.6 \\
\hline 2006 & 43.3 & 2.5 & 11.7 & 1.3 & 41.2 \\
\hline \multicolumn{6}{|c|}{ rmediate estimates: } \\
\hline 2010 & 43.1 & 2.9 & 12.3 & 1.5 & 40.2 \\
\hline 2020 & 32.7 & 3.7 & 14.2 & 1.9 & 47.4 \\
\hline 2030 & 25.3 & 3.7 & 15.7 & 2.4 & 53.0 \\
\hline 2040 & 21.7 & 3.4 & 16.7 & 2.4 & 55.8 \\
\hline 2050 & 19.7 & 3.1 & 17.4 & 2.5 & 57.3 \\
\hline 2060 & 17.9 & 2.9 & 18.2 & 2.6 & 58.5 \\
\hline 2070 & 16.5 & 2.8 & 18.9 & 2.6 & 59.2 \\
\hline 2080 & 15.6 & 2.7 & 19.7 & 2.6 & 59.4 \\
\hline
\end{tabular}

${ }^{1}$ Includes premium revenue from $\mathrm{HI}$ and both accounts in the SMI trust fund.

Note: Due to rounding, the sum of these percentages may not exactly equal 100 percent.

In 2006, HI payroll taxes represented 43 percent of total non-interest income to the Medicare program. General revenues (primarily those for SMI) were the next largest source of overall financing, at 41 percent. Beneficiary premiums (again, primarily for SMI) were third, at 12 percent. Under current law, HI tax revenues are projected to fall increasingly short of HI expenditures after 2006. In contrast, SMI premium and general revenues will keep pace with SMI expenditure growth, and, once fully phased down ${ }^{17}$, state payments (on behalf of Medicare beneficiaries who also qualify for full Medicaid benefits) will grow with Part D expenditures. Consequently, in the absence of legislation, HI tax income would represent a declining portion of total Medicare revenues. In 2018, for example, just prior to the projected exhaustion of the HI trust fund, currently scheduled HI payroll taxes would represent about 34 percent of total non-interest Medicare income. General revenues and beneficiary premiums would equal about 46 and 14 percent, respectively. ${ }^{18}$

The Medicare Modernization Act (MMA) requires an expanded analysis of the combined expenditures and dedicated revenues of the $\mathrm{HI}$ and SMI trust funds. In particular, a determination must be made as to whether projected annual "general revenue funding" exceeds 45 percent of total Medicare outlays within the next 7 fiscal years

\footnotetext{
${ }^{17}$ State payments amounted to 90 percent of their projected foregone prescription drug costs in 2006, with this percentage phasing down over a 10 -year period to 75 percent in 2015.

${ }^{18}$ The general revenue share of total Medicare revenues cannot be directly compared to the difference between outlays and dedicated revenues as a share of outlays (described previously). Although somewhat similar in magnitude, the former measure does not reflect the HI deficit, whereas the latter measure does.
} 


\section{Actuarial Analysis}

(2007-2013). For this purpose, general revenue funding is defined in the law as total Medicare outlays minus dedicated Medicare financing sources. Dedicated Medicare financing sources include HI payroll taxes; income from taxation of Social Security benefits; State transfers for the prescription drug benefit; premiums paid under Parts A, B, and D; and any gifts received by the Medicare trust funds. The test is applied using incurred expenditures and revenues to avoid temporary distortions arising from the payment of Medicare Advantage capitation amounts in September when the normal October payment date is a Saturday or Sunday. Figure III.A1 shows the projected difference between total Medicare outlays and dedicated funding sources as a percentage of total outlays over the long-range projection period.

In the 2006 report, it was estimated that "general revenue funding" would exceed 45 percent in 2012 , which was within the first 7 fiscal years. Therefore, a determination of "excess general revenue funding" was made. As indicated in figure III.A1, the difference between annual outlays and dedicated financing is now expected to first exceed 45 percent of total expenditures in 2013 under the intermediate assumptions. Since this estimate is within the 7-year test period prescribed in the law, a determination of projected "excess general revenue Medicare funding" is made for the second consecutive year in this report. Since it has been determined in two consecutive reports that the difference between Medicare outlays and dedicated financing sources is projected to reach 45 percent within the first 7 years, a "Medicare funding warning" is triggered, indicating that a trust fund's financing is inadequate or that the general revenues provided under current law are becoming unduly large. This finding requires the President to submit to Congress, within 15 days after the date of the next budget submission, proposed legislation to respond to the warning. ${ }^{19}$ Congress is then required to consider this legislation on an expedited basis. This new requirement will help call attention to Medicare's impact on the Federal Budget.

${ }^{19}$ The next such budget submission will be the President's Fiscal Year 2009 Budget, which will be released in early February 2008. 


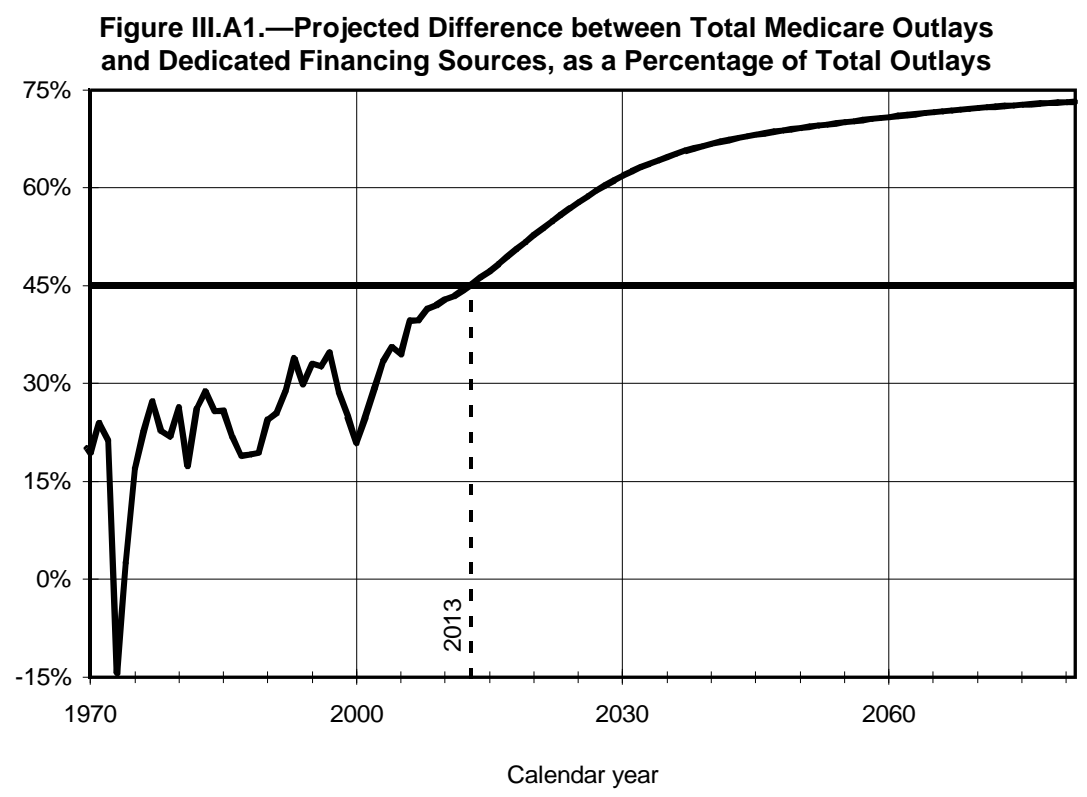

As is also indicated in figure III.A1, the difference between outlays and dedicated funding sources is projected to continue growing throughout the 75 -year period, reaching 63 percent of total outlays in 2031 and 73 percent in 2081. Although the law characterizes this difference as "general revenue funding," it is important to recognize that current law provides for general revenue transfers only for certain purposes related to Parts A, B, and D, as follows:

- Financing specified portions of SMI Part B and SMI Part D expenditures;

- Reimbursing the HI trust fund for the costs of certain uninsured beneficiaries;

- Paying interest on invested assets of the trust funds; and

- Redeeming the special Treasury securities held as assets by the trust funds.

The difference between outlays and dedicated funding sources, as shown in figure III.A1, will reflect all of these general revenue transfers, plus the imbalance between $\mathrm{HI}$ expenditures and dedicated revenues after $\mathrm{HI}$ asset exhaustion in 2019, for which there is no provision under current law to cover the shortfall. In particular, 


\section{Actuarial Analysis}

transfers from the general fund of the Treasury could not be made for this purpose without new legislation.

The MMA also requires that projected growth in the difference between outlays and dedicated revenues be compared with other health spending growth rates. Table III.A5 contains this comparison.

\begin{tabular}{|c|c|c|c|c|c|}
\hline \multirow[b]{2}{*}{ Calendar year } & \multicolumn{5}{|c|}{ Average annual growth in: } \\
\hline & $\begin{array}{c}\text { Incurred outlays } \\
\text { minus dedicated } \\
\text { revenues }\end{array}$ & $\begin{array}{c}\text { Incurred } \\
\text { Medicare outlays }\end{array}$ & GDP & $\begin{array}{c}\text { National health } \\
\text { expenditures }\end{array}$ & $\begin{array}{c}\text { Private health } \\
\text { insurance }^{1}\end{array}$ \\
\hline 2001 & $29.7 \%$ & $10.2 \%$ & $3.2 \%$ & $8.6 \%$ & $9.6 \%$ \\
\hline 2002 & 22.0 & 7.2 & 3.4 & 9.1 & 10.5 \\
\hline 2003 & 23.1 & 6.2 & 4.7 & 8.1 & 9.6 \\
\hline 2004 & 16.6 & 9.8 & 6.9 & 7.2 & 7.9 \\
\hline 2005 & 6.1 & 9.2 & 6.3 & 6.9 & 6.6 \\
\hline 2006 & 38.5 & 21.0 & 6.3 & 6.8 & 4.8 \\
\hline 2007 & 10.7 & 8.5 & 4.6 & 6.6 & 6.7 \\
\hline 2008 & 9.5 & 7.3 & 5.0 & 7.0 & 7.0 \\
\hline 2009 & 9.4 & 7.7 & 5.2 & 7.3 & 7.3 \\
\hline 2010 & 9.8 & 7.6 & 5.1 & 6.9 & 6.7 \\
\hline 2011 & 8.8 & 7.4 & 5.1 & 6.8 & 6.5 \\
\hline 2012 & 10.1 & 7.8 & 4.9 & 7.0 & 6.5 \\
\hline 2013 & 10.3 & 7.8 & 4.7 & 7.0 & 6.7 \\
\hline 2014 & 10.2 & 7.7 & 4.6 & 6.9 & 6.3 \\
\hline 2015 & 10.0 & 7.8 & 4.7 & 6.8 & 6.0 \\
\hline 2016 & 10.7 & 8.0 & 4.7 & 6.8 & 5.8 \\
\hline $2017-2031$ & 8.0 & 9.9 & 4.5 & - & - \\
\hline 2032-2056 & 5.5 & 5.9 & 4.4 & - & - \\
\hline $2057-2081$ & 5.0 & 5.1 & 4.4 & - & - \\
\hline
\end{tabular}

As shown in table III.A5, the gap between outlays and dedicated revenues, and Medicare outlays, both increased substantially when the prescription drug benefit was fully implemented in 2006. In addition, the outlay gap will increase faster than outlays throughout the 75-year period, since the dedicated sources of income to the HI trust fund will cover a decreasing percentage of HI outlays.

In addition to projected Medicare outlay growth, table III.A5 shows projected growth in GDP, total expenditures on health care in the U.S., and private health insurance expenditures. Each of the health expenditure categories is expected to increase more rapidly than GDP, continuing a longstanding trend. Private health insurance expenditures equal the total premiums earned by private health insurers, including benefits incurred and the net cost of insurance. The net cost of insurance includes administrative costs, additions to reserves, rate credits and dividends, premium taxes, and profits or 


\section{Financial Projections}

losses. Comparisons between aggregate Medicare and private health insurance cost growth are affected by several factors:

- The number of Medicare beneficiaries is currently increasing by about 1.5 percent per year, and this growth rate will approximately double after 2010 when the post-World War II baby boom generation reaches eligibility age. In recent years, the number of individuals with private health insurance has declined and is projected to increase only slowly in the future.

- The benefits covered by Medicare and private health insurance plans can vary. In particular, though most prescription drugs are currently covered by Medicare, this was not the case prior to 2006. Moreover, many Medicare beneficiaries who had private drug insurance coverage (such as Medigap policies) switched to the subsidized Part D coverage in 2006, thereby accelerating Medicare outlay growth while slowing private health insurance growth.

- The use of health care services differs significantly between Medicare beneficiaries (who are generally over 65) and individuals with private health insurance (who are predominantly below age 65). The former group, for example, has a higher incidence of hospitalization, skilled nursing care, and home health care. For the latter group, physician services represent a greater proportion of their total health care needs. Different cost growth trends by type of service will affect overall growth rates, reflecting the distribution of services for each category of people.

A number of research studies have attempted to control for some or all of these differences in comparing growth trends. Over long historical periods, average, demographically adjusted, per capita growth rates have been similar for Medicare and private health insurance. For shorter periods, however, the rates of growth have often diverged substantially. More information on past and projected national and private health expenditures, and comparisons to Medicare growth rates, is available in the sources cited in table III.A5.

Under current law, the HI and SMI trust funds are separate and distinct, each with its own sources of financing. There are no provisions for using HI revenues to finance SMI expenditures, or vice versa, or for lending assets between the two trust funds. Moreover, the benefit provisions, financing methods, and, to a lesser degree, eligibility rules are very different between these Medicare components. In particular, both accounts of the SMI trust fund are 
Actuarial Analysis

automatically in financial balance under current law, whereas the HI fund is not.

For these reasons, the financial status of the Medicare trust funds can be evaluated only by separately assessing the status of each fund. The following two sections of this report present such assessments for $\mathrm{HI}$ and SMI, respectively.

\section{B. HI FINANCIAL STATUS}

\section{Financial Operations in Calendar Year 2006}

The Federal Hospital Insurance Trust Fund was established on July 30,1965 as a separate account in the U.S. Treasury. All the HI financial operations are handled through this fund.

A statement of the revenue and expenditures of the fund in calendar year 2006, and of its assets at the beginning and end of the calendar year, is presented in table III.B1.

The total assets of the trust fund amounted to $\$ 285.8$ billion on January 1, 2006. During calendar year 2006, total revenue amounted to $\$ 211.5$ billion, and total expenditures were $\$ 191.9$ billion. Total assets thus increased by $\$ 19.6$ billion during the year, to $\$ 305.4$ billion on December 31, 2006. 
HI Financial Status

Table III.B1.-Statement of Operations of the HI Trust Fund during Calendar Year 2006

[In thousands]

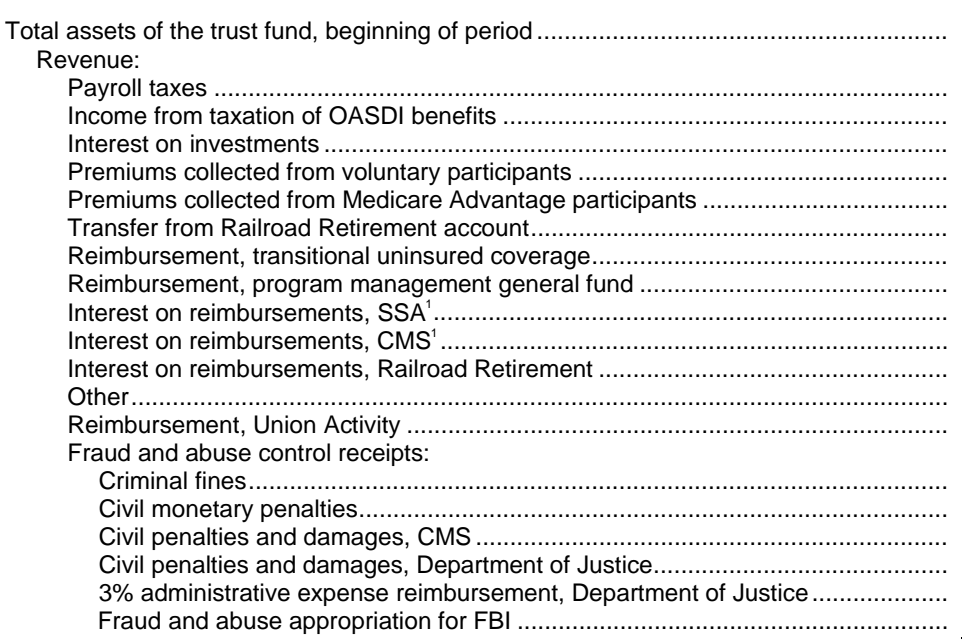

Total revenue.

Expenditures:

Net benefit payments

Administrative expenses:

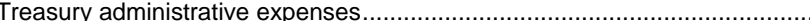

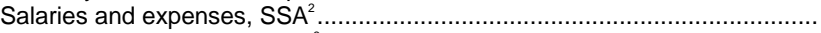

Salaries and expenses, $\mathrm{CMS}^{3}$

Salaries and expenses, Office of the Secretary, HHS

Medicare Payment Advisory Commission ....................................................

Fraud and abuse control expenses:

HHS Medicare integrity program .................................................... $\quad 732,757$

HHS Office of Inspector General ............................................................ 184,189

Department of Justice ..................................................................... 43,814

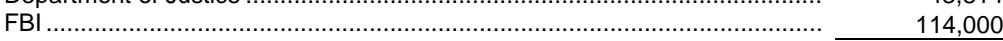

Total expenditures................................................................................... $\$ 191,932,792$

Net addition to the trust fund .................................................................

Total assets of the trust fund, end of period.................................................... \$305,351,908

${ }^{1} \mathrm{~A}$ positive figure represents a transfer to the $\mathrm{HI}$ trust fund from the other trust funds. A negative figure represents a transfer from the $\mathrm{HI}$ trust fund to the other funds.

${ }^{2}$ For facilities, goods, and services provided by SSA.

${ }^{3}$ Includes administrative expenses of the intermediaries.

Note: Totals do not necessarily equal the sums of rounded components.

\section{a. Revenues}

The trust fund's primary source of income consists of amounts appropriated to it, under permanent authority, on the basis of taxes paid by workers, their employers, and individuals with self-employment income, in work covered by HI. Included in HI are 


\section{Actuarial Analysis}

workers covered under the OASDI program, those covered under the Railroad Retirement program, and certain Federal, State, and local employees not otherwise covered under the OASDI program.

HI taxes are payable on a covered individual's total wages and self-employment income, without limit. For calendar years prior to 1994, taxes were computed on a person's annual earnings up to a specified maximum annual amount, called the maximum tax base. The maximum tax bases for 1966-1993 are presented in table III.B2. (Legislation enacted in 1993 removed the limit on taxable income beginning in calendar year 1994.)

The HI tax rates applicable in each of the calendar years 1966 and later are also shown in table III.B2. For 2008 and thereafter, the tax rates shown are the rates scheduled in current law.

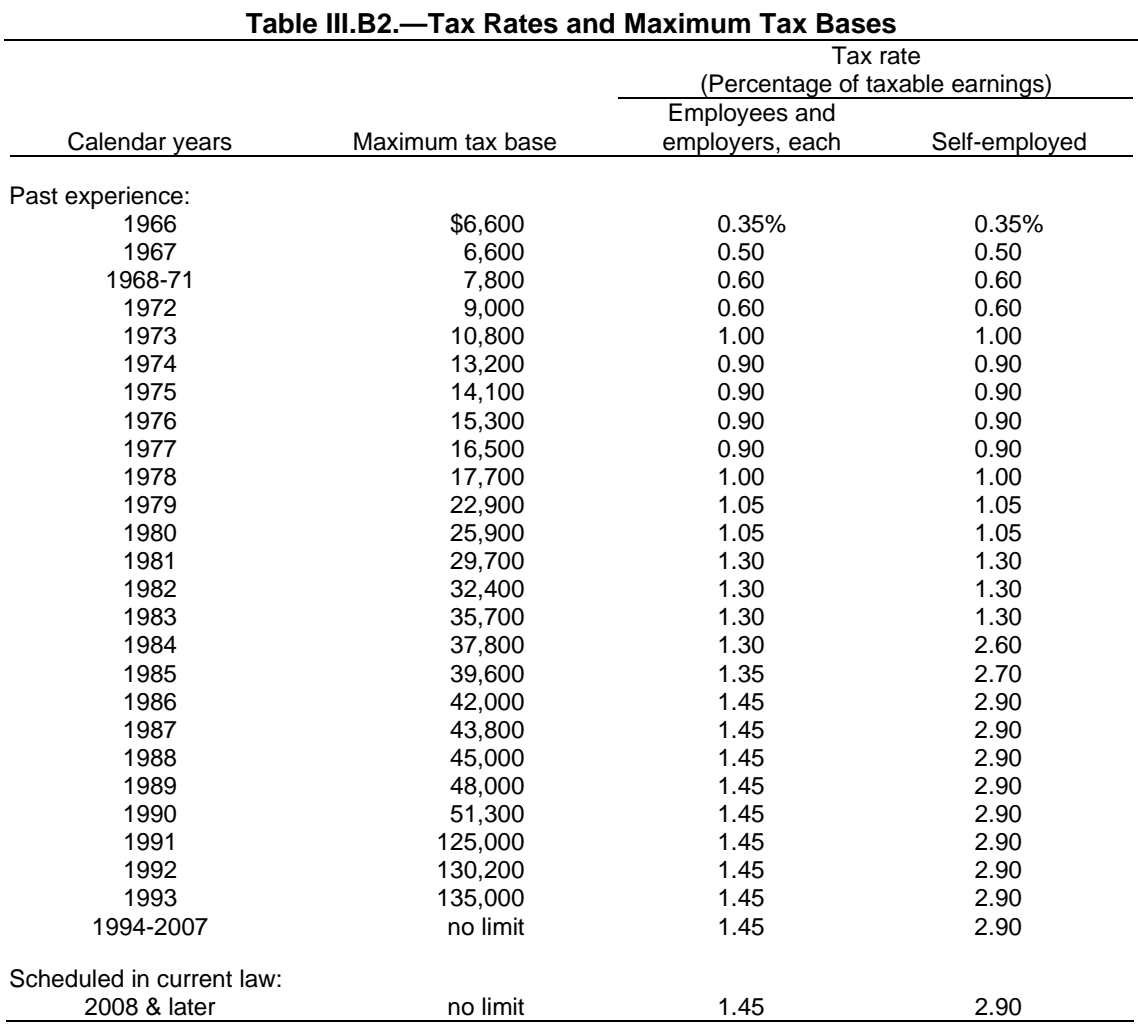

Total HI payroll tax income in calendar year 2006 amounted to $\$ 181.3$ billion-an increase of 5.8 percent over the amount of $\$ 171.4$ billion for the preceding 12 -month period. This increase in tax 
income resulted from an increase in the number of workers and their earnings.

Up to 85 percent of an individual's or couple's OASDI benefits may be subject to Federal income taxation if their income exceeds certain thresholds. The income tax revenue attributable to the first 50 percent of OASDI benefits is allocated to the OASI and DI trust funds. The revenue associated with the amount between 50 and 85 percent of benefits is allocated to the HI trust fund. Income from the taxation of OASDI benefits amounted to $\$ 10.3$ billion in calendar year 2006.

Another substantial source of trust fund income is interest credited from investments in government securities held by the fund. In calendar year 2006, $\$ 15.7$ billion in interest was credited to the fund. The trust fund's investment procedures are described later in this section.

Section 1818 of the Social Security Act provides that certain persons not otherwise eligible for HI protection may obtain coverage by enrolling in HI and paying a monthly premium. Premiums collected from such voluntary participants in fiscal year 2006 amounted to about $\$ 2.6$ billion.

The Railroad Retirement Act provides for a system of coordination and financial interchange between the Railroad Retirement program and the HI trust fund. This financial interchange requires a transfer that would place the HI trust fund in the same position in which it would have been if railroad employment had always been covered under the Social Security Act. In accordance with these provisions, a transfer of $\$ 440$ million in principal and about $\$ 17$ million in interest from the Railroad Retirement program's Social Security Equivalent Benefit Account to the HI trust fund balanced the two systems as of September 30, 2005. This amount, together with interest to the date of transfer totaling about $\$ 14$ million, was transferred to the trust fund in June 2006.

Two sections of the statute authorize HI benefits for certain uninsured persons aged 65 and over. Entitlement to HI benefits was provided to almost all persons aged 65 and over, or near that age, when the HI trust fund first began operations. Legislation in 1982 added similar transitional entitlement for those Federal employees who would retire before having had a chance to earn sufficient quarters of Medicare-qualified Federal employment. The costs of this coverage, including administrative expenses, are reimbursed from the 


\section{Actuarial Analysis}

general fund of the Treasury. In calendar year 2006, such reimbursement amounted to $\$ 408$ million: $\$ 407$ million for estimated benefit payments and $\$ 1$ million for administrative expenses. The $\$ 407$ million for benefit payments consisted of \$201 million for non-Federal uninsured and \$206 million for Federal uninsured beneficiaries.

The Health Insurance Portability and Accountability Act of 1996 established a health care fraud and abuse control account within the HI trust fund. Monies derived from the fraud and abuse control program are transferred from the general fund of the Treasury to the HI trust fund. During calendar year 2006, the trust fund was credited with about $\$ 495$ million in receipts from this program.

\section{b. Expenditures}

Expenditures for HI benefit payments and administrative expenses are paid out of the trust fund. All expenses incurred by the Department of Health and Human Services, the Social Security Administration, the Department of the Treasury (including the Internal Revenue Service), and the Department of Justice in administering $\mathrm{HI}$ are charged to the trust fund. Such administrative duties include payment of benefits, the collection of taxes, fraud and abuse control activities, and experiments and demonstration projects designed to determine various methods of increasing efficiency and economy in providing health care services, while maintaining the quality of such services, under HI and SMI.

In addition, Congress has authorized expenditures from the trust funds for construction, rental and lease, or purchase contracts of office buildings and related facilities for use in connection with the administration of HI. These costs are included in trust fund expenditures. The net worth of facilities and other fixed capital assets, however, is not carried in the statement of trust fund assets presented in this report, since the value of fixed capital assets does not represent funds available for benefit or administrative expenditures and is not, therefore, considered in assessing the actuarial status of the funds.

Of the $\$ 191.9$ billion in total HI expenditures, $\$ 189.0$ billion represented net benefits paid from the trust fund for health services. ${ }^{20}$

${ }^{20}$ Net benefits equal the total gross amounts initially paid from the trust fund during the year, less recoveries of overpayments identified through fraud and abuse control activities. 
Net benefit payments increased 5.0 percent in calendar year 2006 over the corresponding amount of $\$ 180.0$ billion paid during the preceding calendar year. This increase reflected the impact of the Deficit Reduction Act as well as an abrupt decrease during the year in the number of hospital admissions-which, after increasing by about 2 percent on average in past years, appears to have decreased by 4 percent in 2006. Additional information on HI benefits by type of service is available in section IV.A.

The $\$ 2.9$ billion of the remaining expenditures was for net HI administrative expenses, after adjustments to the preliminary allocation of administrative costs among the Social Security and Medicare trust funds and the general fund of the Treasury. This amount includes $\$ 1.1$ billion for the health care fraud and abuse control program.

\section{c. Actual experience versus prior estimates}

Table III.B3 compares the actual experience in calendar year 2006 with the estimates presented in the 2005 and 2006 annual reports. A number of factors can contribute to differences between estimates and subsequent actual experience. In particular, actual values for key economic and other variables can differ from assumed levels, and legislative and regulatory changes may be adopted after a report's preparation. The comparison in table III.B3 indicates that actual HI tax income in 2006 was slightly higher than estimated in the 2005 and 2006 reports, primarily because actual wage growth was higher than earlier estimates for the last few years. Actual HI benefit payments in calendar year 2006 were somewhat lower than the amounts projected in the 2005 and 2006 reports primarily as a result of slower growth in inpatient hospital expenditures than had been estimated. This slower growth, in turn, largely resulted from a decrease in the number of hospitalizations in 2006 compared to prior years.

Table III.B3.-Comparison of Actual and Estimated Operations of the HI Trust Fund, Calendar Year 2006 [Dollar amounts in millions]

\begin{tabular}{|c|c|c|c|c|c|}
\hline \multirow[b]{3}{*}{ Item } & \multirow[b]{3}{*}{$\begin{array}{c}\text { Actual } \\
\text { amount }\end{array}$} & \multicolumn{4}{|c|}{$\begin{array}{l}\text { Comparison of actual experience with estimates for } \\
\text { calendar year } 2006 \text { published in- }\end{array}$} \\
\hline & & \multicolumn{2}{|c|}{2006 report } & \multicolumn{2}{|c|}{2005 report } \\
\hline & & $\begin{array}{c}\text { Estimated } \\
\text { amount }{ }^{1}\end{array}$ & $\begin{array}{c}\text { Actual as } \\
\text { percentage } \\
\text { of estimate }\end{array}$ & $\begin{array}{c}\text { Estimated } \\
\text { amount }^{1}\end{array}$ & $\begin{array}{c}\text { Actual as } \\
\text { percentage } \\
\text { of estimate }\end{array}$ \\
\hline $\begin{array}{l}\text { Payroll taxes } \\
\text { Benefit payments }\end{array}$ & $\begin{array}{r}\$ 181,274 \\
188,989\end{array}$ & $\begin{array}{r}\$ 180,820 \\
197,309\end{array}$ & $\begin{array}{c}100 \% \\
96\end{array}$ & $\begin{array}{r}\$ 178,053 \\
191,583\end{array}$ & $\begin{array}{c}102 \% \\
99\end{array}$ \\
\hline
\end{tabular}


Actuarial Analysis

\section{d. Assets}

The portion of the trust fund that is not needed to meet current expenditures for benefits and administration is invested, on a daily basis, in interest-bearing obligations of the U.S. Government. The Social Security Act authorizes the issuance of special public-debt obligations for purchase exclusively by the trust fund. The law requires that these special public-debt obligations bear interest, at a rate based on the average market yield (computed on the basis of market quotations as of the end of the calendar month immediately preceding the date of such issue), on all marketable interest-bearing obligations of the United States forming a part of the public debt that are not due or callable until after 4 years from the end of that month. Currently, all invested assets of the HI trust fund are in the form of such special-issue securities. ${ }^{21}$ Table V.F9, presented in appendix F, shows the assets of the HI trust fund at the end of fiscal years 2005 and 2006 .

\section{10-Year Actuarial Estimates (2007-2016)}

While the previous section addressed the transactions of the HI trust fund during the preceding fiscal year, this section presents estimates of the trust fund's operations and financial status for the next 10 years. The long-range actuarial status of the trust fund is discussed in the next section. In both this and the following section, no changes are assumed to occur in the present statutory provisions and regulations under which HI operates.

The estimates shown in this section provide detailed information concerning the short-range financial status of the trust fund. The estimated levels of future income and outgo, annual differences between income and outgo, and annual trust fund balances are explained and examined. Two particularly important indicators of solvency for the HI trust fund-the estimated year of exhaustion and the test of short-range financial adequacy—are also discussed.

To illustrate the sensitivity of future costs to different economic and demographic trends, estimates are shown under three alternative sets of assumptions, which are intended to portray a reasonable range of possible future trends. Due to the uncertainty inherent in such projections, however, the actual operations of the HI trust fund in the future could differ significantly from these estimates.

\footnotetext{
${ }^{21}$ Investments may also be made in obligations guaranteed as to both principal and interest by the United States, including certain federally sponsored agency obligations.
} 
Figure III.B1 shows past and projected income and expenditures for the HI trust fund. Following the Balanced Budget Act of 1997, the fund experienced annual surpluses in the range of $\$ 21$ billion to $\$ 36$ billion through 2003. This difference decreased to between $\$ 13$ billion and $\$ 16$ billion in 2004 and 2005, but then reached $\$ 20$ billion in 2006. It is expected to decrease in the future until expenditures exceed income in 2011 and later. The assumptions underlying these estimates are discussed in section IV.A of this report.

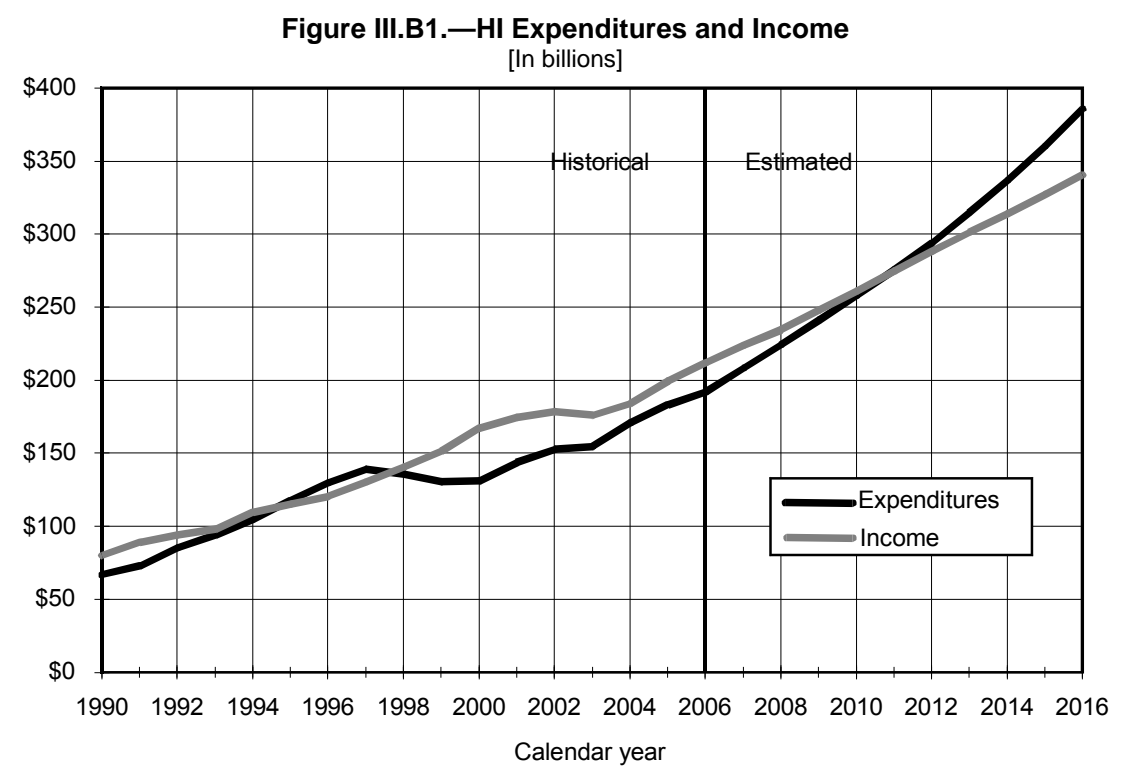

The expected operations of the HI trust fund during calendar years 2007 to 2016, together with the past experience, are shown in table III.B4. The estimates shown in this table are based on the intermediate set of assumptions. The assumptions underlying the intermediate projections are presented in section IV.A of this report. 
Table III.B4.-Operations of the HI Trust Fund during Calendar Years 1970-2016

\begin{tabular}{|c|c|c|c|c|c|c|c|c|c|c|c|c|c|}
\hline \multirow[b]{2}{*}{$\begin{array}{c}\begin{array}{c}\text { Calendar } \\
\text { year }\end{array} \\
\end{array}$} & \multicolumn{8}{|c|}{ Income } & \multicolumn{3}{|c|}{ Expenditures } & \multicolumn{2}{|c|}{ Trust fund } \\
\hline & $\begin{array}{c}\text { Payroll } \\
\text { taxes }\end{array}$ & $\begin{array}{c}\text { Income } \\
\text { from } \\
\text { taxation of } \\
\text { benefits }\end{array}$ & $\begin{array}{c}\text { Railroad } \\
\text { Retirement } \\
\text { f } \text { account } \\
\text { transfers }\end{array}$ & $\begin{array}{c}\text { Reimburse- } \\
\text { ment for } \\
\text { uninsured } \\
\text { persons }\end{array}$ & $\begin{array}{c}\text { Premiums } \\
\text { from } \\
\text { voluntary } \\
\text { enrollees }\end{array}$ & $\begin{array}{c}\text { Payments } \\
\text { for military } \\
\text { wage } \\
\text { credits }\end{array}$ & $\begin{array}{l}\text { Interest } \\
\text { and } \\
\text { other }^{1,2}\end{array}$ & Total & $\begin{array}{c}\text { Benefit } \\
\text { payments }^{2,3}\end{array}$ & $\begin{array}{l}\text { Adminis- } \\
\text { trative } \\
\text { expenses }\end{array}$ & Total & $\begin{array}{c}\text { Net } \\
\text { change }\end{array}$ & $\begin{array}{l}\text { Fund at } \\
\text { end of year }\end{array}$ \\
\hline \multicolumn{14}{|c|}{ Historical data: } \\
\hline 1970 & $\$ 4.9$ & - & $\$ 0.1$ & $\$ 0.9$ & - & $\$ 0.0$ & $\$ 0.2$ & $\$ 6.0$ & $\$ 5.1$ & $\$ 0.2$ & $\$ 5.3$ & $\$ 0.7$ & $\$ 3.2$ \\
\hline 1975 & 11.5 & - & 0.1 & 0.6 & $\$ 0.0$ & 0.0 & 0.7 & 13.0 & 11.3 & 0.3 & 11.6 & 1.4 & 10.5 \\
\hline 1980 & 23.8 & - & 0.2 & 0.7 & 0.0 & 0.1 & 1.1 & 26.1 & 25.1 & 0.5 & 25.6 & 0.5 & 13.7 \\
\hline 1985 & 47.6 & - & 0.4 & 0.8 & 0.0 & $-0.7^{5}$ & 3.4 & 51.4 & 47.6 & 0.8 & 48.4 & $4.8^{6}$ & 20.5 \\
\hline 1990 & 72.0 & - & 0.4 & 0.4 & 0.1 & $-1.0^{7}$ & 8.5 & 80.4 & 66.2 & 0.8 & 67.0 & 13.4 & 98.9 \\
\hline 1995 & 98.4 & $\$ 3.9$ & 0.4 & 0.5 & 1.0 & 0.1 & 10.8 & 115.0 & 116.4 & 1.2 & 117.6 & -2.6 & 130.3 \\
\hline 2000 & 144.4 & 8.8 & 0.5 & 0.5 & 1.4 & 0.0 & 11.7 & 167.2 & $128.5^{8}$ & 2.6 & 131.1 & 36.1 & 177.5 \\
\hline 2001 & 152.0 & 7.5 & 0.5 & 0.5 & 1.4 & $-1.2^{9}$ & 14.0 & 174.6 & $141.2^{8}$ & 2.2 & 143.4 & 31.3 & 208.7 \\
\hline 2002 & 152.7 & 8.3 & 0.4 & 0.4 & 1.6 & 0.0 & 15.1 & 178.6 & $149.9^{8}$ & 2.6 & 152.5 & 26.1 & 234.8 \\
\hline 2003 & 149.2 & 8.3 & 0.4 & 0.4 & 1.6 & 0.0 & 15.8 & 175.8 & $152.1^{8}$ & 2.5 & 154.6 & 21.2 & 256.0 \\
\hline 2004 & 156.5 & 8.6 & 0.4 & 0.4 & 1.9 & 0.2 & 16.0 & 183.9 & 167.6 & 3.0 & 170.6 & 13.3 & 269.3 \\
\hline 2005 & 171.4 & 8.8 & 0.4 & 0.3 & 2.4 & 0.0 & 16.1 & 199.4 & 180.0 & 2.9 & 182.9 & 16.4 & 285.8 \\
\hline 2006 & 181.3 & 10.3 & 0.5 & 0.4 & 2.6 & 0.0 & 16.4 & 211.5 & 189.0 & 2.9 & 191.9 & 19.6 & 305.4 \\
\hline \multicolumn{14}{|c|}{ Intermediate estimates: } \\
\hline 2007 & 192.3 & 10.7 & 0.5 & 0.5 & 2.8 & 0.0 & 16.8 & 223.6 & 205.2 & 3.1 & 208.2 & 15.4 & 320.8 \\
\hline 2008 & 201.0 & 12.1 & 0.5 & 0.5 & 3.0 & 0.0 & 17.2 & 234.3 & 221.1 & 3.1 & 224.2 & 10.1 & 330.9 \\
\hline 2009 & 212.6 & 13.7 & 0.5 & 0.3 & 3.2 & 0.0 & 17.6 & 247.8 & 237.6 & 3.2 & 240.7 & 7.1 & 337.9 \\
\hline 2010 & 223.4 & 15.3 & 0.5 & 0.3 & 3.4 & 0.0 & 17.9 & 260.9 & 254.5 & 3.3 & 257.7 & 3.1 & 341.0 \\
\hline 2011 & 234.9 & 17.1 & 0.6 & 0.3 & 3.6 & 0.0 & 18.0 & 274.4 & 271.7 & 3.3 & 275.1 & -0.7 & 340.4 \\
\hline 2012 & 246.1 & 19.1 & 0.6 & 0.3 & 3.8 & 0.0 & 17.9 & 287.8 & 290.4 & 3.4 & 293.9 & -6.1 & 334.3 \\
\hline 2013 & 257.1 & 21.5 & 0.6 & 0.3 & 4.0 & 0.0 & 17.4 & 301.0 & 310.9 & 3.6 & 314.5 & -13.5 & 320.8 \\
\hline 2014 & 268.4 & 23.8 & 0.6 & 0.3 & 4.3 & 0.0 & 16.5 & 313.9 & 332.8 & 3.7 & 336.4 & -22.5 & 298.3 \\
\hline 2015 & 280.4 & 26.1 & 0.6 & 0.3 & 4.5 & 0.0 & 15.0 & 327.0 & 356.0 & 3.8 & 359.8 & -32.8 & 265.5 \\
\hline 2016 & 293.1 & 28.6 & 0.7 & 0.3 & 4.8 & 0.0 & 13.0 & 340.4 & 381.4 & 3.9 & 385.4 & -44.9 & 220.5 \\
\hline
\end{tabular}


'Other income includes recoveries of amounts reimbursed from the trust fund that are not obligations of the trust fund, receipts from the fraud and abuse control program, and a small amount of miscellaneous income. These amount to $\$ 0.6$ billion each year for the 10-year projection period.

${ }^{2}$ Values after 2005 include additional premiums for Medicare Advantage (MA) plans that are deducted from beneficiaries' Social Security checks. These additional premiums are beneficiary obligations and occur when a beneficiary chooses an MA plan whose monthly plan payment exceeds the benchmark amount. Beneficiaries subject to such premiums may choose to either reimburse the plans directly or have the premiums deducted from their Social Security checks. The premiums deducted from the Social Security checks are transferred to the $\mathrm{HI}$ and SMI trust funds and then transferred from the trust funds to the plans.

${ }^{3}$ Includes costs of Peer Review Organizations from 1983 through 2001 (beginning with the implementation of the prospective payment system on October 1, 1983) and costs of Quality Improvement Organizations beginning in 2002.

${ }^{4}$ Includes costs of experiments and demonstration projects. Beginning in 1997, includes fraud and abuse control expenses, as provided for by Public Law 104-191.

${ }^{5}$ Includes the lump-sum general revenue adjustment of $-\$ 0.8$ billion, as provided for by section 151 of Public Law $98-21$

${ }^{6}$ Includes repayment of loan principal, from the OASI trust fund, of $\$ 1.8$ billion.

${ }^{7}$ Includes the lump-sum general revenue adjustment of $-\$ 1.1$ billion, as provided for by section 151 of Public Law $98-21$

${ }^{8}$ For 1998 to 2003, includes monies transferred to the SMI trust fund for home health agency costs, as provided for by Public Law 105-33.

Includes the lump-sum general revenue adjustment of $-\$ 1.2$ billion, as provided for by section 151 of Public Law 98-2

Note: Totals do not necessarily equal the sums of rounded components. 


\section{Actuarial Analysis}

The increases in estimated income shown in table III.B4 primarily reflect increases in payroll tax income to the trust fund. As noted previously, the main source of $\mathrm{HI}$ financing is the payroll tax on covered earnings paid by employees, employers, and self-employed workers. While the payroll tax rate is scheduled to remain constant, covered earnings are assumed to increase every year through 2016 under the intermediate assumptions. These increases in taxable earnings are due primarily to projected increases both in the number of HI workers covered and in the average earnings of these workers.

Over the next 10 years, most of the smaller sources of financing for the HI trust fund are projected to increase as well. More detailed descriptions of these sources of income can be found in section III.B1.

Interest earnings have been a significant source of income to the trust fund for many years, surpassed only by payroll taxes. As the trust fund levels off in the near future, and subsequently begins to decline (as income falls short of expenditures), interest earnings will follow the same pattern.

Benefit expenditures are projected to increase each year from 2007 to 2016. For the entire short-range period and beyond, benefits are expected to increase at a faster rate than income.

Since future economic, demographic, and health care usage and cost experience may differ considerably from the intermediate assumptions on which the cost estimates shown in table III.B4 were based, projections have also been prepared on the basis of two different sets of assumptions, labeled "low cost" and "high cost." The three sets of assumptions were selected to illustrate the sensitivity of costs to different economic and demographic trends, and to provide an indication of the uncertainty associated with HI financial projections. The low cost and high cost alternatives provide for a fairly wide range of possible experience. While actual experience may be expected to fall within the range, no assurance can be made that this will be the case, particularly in light of the wide variations in experience that have occurred in the past. The assumptions used in preparing projections under the low cost and high cost alternatives, as well as under the intermediate assumptions, are discussed more fully in section IV.A of this report.

The estimated operations of the HI trust fund during calendar years 2006 to 2016, under all three alternatives, are summarized in table III.B5. The trust fund ratio, defined as the ratio of assets at the beginning of the year to expenditures during the year, was 
149 percent for 2006 . Under the intermediate assumptions, the trust fund ratio is projected to steadily decline to a level of 69 percent by 2016. Beyond the 10-year short-term projection period, the ratio would continue to decline, with the fund becoming exhausted in 2019 under the intermediate assumptions.

Under the low cost alternative, exhaustion would occur in 2042, while under the high cost alternative, exhaustion would occur in 2014, within the 10-year period. Without corrective legislation, therefore, the assets of the HI trust fund would be exhausted within the next 7 to 12 years under the high cost and intermediate assumptions. The fact that exhaustion would occur under a fairly broad range of future economic conditions, and is expected to occur in the not-distant future, indicates the importance of promptly addressing the HI trust fund's financial imbalance. 
Actuarial Analysis

Table III.B5.-Estimated Operations of the HI Trust Fund during Calendar Years 2006-2016, under Alternative Sets of Assumptions [Dollar amounts in billions]

\begin{tabular}{|c|c|c|c|c|c|}
\hline $\begin{array}{c}\text { Calendar } \\
\text { year }\end{array}$ & Total income & $\begin{array}{c}\text { Total } \\
\text { expenditures }\end{array}$ & $\begin{array}{l}\text { Net increase } \\
\text { in fund }\end{array}$ & $\begin{array}{c}\text { Fund at } \\
\text { end of year }\end{array}$ & $\begin{array}{c}\text { Ratio of assets to } \\
\text { expenditures }{ }^{1} \\
\text { (percent) }\end{array}$ \\
\hline \multicolumn{6}{|l|}{ Intermediate: } \\
\hline $2006^{2}$ & $\$ 211.5$ & $\$ 191.9$ & $\$ 19.6$ & $\$ 305.4$ & $149 \%$ \\
\hline 2007 & 223.6 & 208.2 & 15.4 & 320.8 & 147 \\
\hline 2008 & 234.3 & 224.2 & 10.1 & 330.9 & 143 \\
\hline 2009 & 247.8 & 240.7 & 7.1 & 337.9 & 137 \\
\hline 2010 & 260.9 & 257.7 & 3.1 & 341.0 & 131 \\
\hline 2011 & 274.4 & 275.1 & -0.7 & 340.4 & 124 \\
\hline 2012 & 287.8 & 293.9 & -6.1 & 334.3 & 116 \\
\hline 2013 & 301.0 & 314.5 & -13.5 & 320.8 & 106 \\
\hline 2014 & 313.9 & 336.4 & -22.5 & 298.3 & 95 \\
\hline 2015 & 327.0 & 359.8 & -32.8 & 265.5 & 83 \\
\hline 2016 & 340.4 & 385.4 & -44.9 & 220.5 & 69 \\
\hline \multicolumn{6}{|l|}{ Low cost: } \\
\hline $2006^{2}$ & 211.5 & 191.9 & 19.6 & 305.4 & 149 \\
\hline 2007 & 224.8 & 202.5 & 22.3 & 327.6 & 151 \\
\hline 2008 & 236.7 & 214.0 & 22.8 & 350.4 & 153 \\
\hline 2009 & 249.7 & 224.9 & 24.8 & 375.2 & 156 \\
\hline 2010 & 262.8 & 235.6 & 27.2 & 402.4 & 159 \\
\hline 2011 & 276.6 & 245.8 & 30.8 & 433.2 & 164 \\
\hline 2012 & 291.0 & 257.0 & 34.0 & 467.3 & 169 \\
\hline 2013 & 305.7 & 269.4 & 36.3 & 503.6 & 173 \\
\hline 2014 & 320.9 & 282.4 & 38.5 & 542.1 & 178 \\
\hline 2015 & 336.0 & 295.4 & 40.7 & 582.8 & 184 \\
\hline 2016 & 352.0 & 309.2 & 42.8 & 625.6 & 188 \\
\hline \multicolumn{6}{|l|}{ High cost: } \\
\hline $2006^{2}$ & 211.5 & 191.9 & 19.6 & 305.4 & 149 \\
\hline 2007 & 220.4 & 213.8 & 6.5 & 311.9 & 143 \\
\hline 2008 & 227.1 & 233.6 & -6.5 & 305.4 & 133 \\
\hline 2009 & 241.8 & 255.8 & -13.9 & 291.4 & 119 \\
\hline 2010 & 251.4 & 277.8 & -26.4 & 265.0 & 105 \\
\hline 2011 & 266.2 & 306.1 & -39.9 & 225.1 & 87 \\
\hline 2012 & 286.4 & 342.7 & -56.4 & 168.7 & 66 \\
\hline 2013 & 302.1 & 380.6 & -78.5 & 90.3 & 44 \\
\hline $2014^{3}$ & 315.1 & 417.9 & -102.8 & -12.6 & 22 \\
\hline $2015^{3}$ & 327.1 & 457.3 & -130.2 & -142.8 & -3 \\
\hline $2016^{3}$ & 337.1 & 501.1 & -164.0 & -306.8 & -28 \\
\hline
\end{tabular}

Ratio of assets in the fund at the beginning of the year to expenditures during the year.

${ }^{2}$ Figures for 2006 represent actual experience.

${ }^{3}$ Estimates for 2014 and later are hypothetical, since the $\mathrm{HI}$ trust fund would be exhausted in those years.

Note: Totals do not necessarily equal the sums of rounded components.

The Board of Trustees has established an explicit test of short-range financial adequacy. The requirements of this test are as follows: (i) If the HI trust fund ratio is at least 100 percent at the beginning of the projection period, then it must be projected to remain at or above 100 percent throughout the 10-year projection period; (ii) alternatively, if the fund ratio is initially less than 100 percent, it must be projected to reach a level of at least 100 percent within 5 years (and the trust fund not be depleted at any time during this period), and then remain at or above 100 percent throughout the rest 
of the 10-year period. This test is applied to trust fund projections made under the intermediate assumptions.

Failure of the trust fund to meet this test is an indication that HI solvency over the next 10 years is in question and that action is needed to improve the short-range financial adequacy of the fund. As can be seen from table III.B5, the HI trust fund does not meet this short-range test. The trust fund ratio, which was above the 100 -percent level at the beginning of 2006, is projected to decrease through 2016, becoming less than 100 percent by 2014. Accordingly, the financing for $\mathrm{HI}$ is not considered adequate in the short-range projection period (2007-2016).

The ratios of assets in the $\mathrm{HI}$ trust fund at the beginning of a calendar year to total expenditures during that year are shown in table III.B6 for selected historical years.

Table III.B6.-Ratio of Assets at the Beginning of the Year to Expenditures

\begin{tabular}{cc}
\multicolumn{2}{c}{ during the Year for the HI Trust Fund } \\
\hline Calendar year & Ratio \\
\hline 1967 & $28 \%$ \\
1970 & 47 \\
1975 & 79 \\
1980 & 52 \\
1985 & 32 \\
1990 & 128 \\
1995 & 113 \\
2000 & 108 \\
2001 & 124 \\
2002 & 137 \\
2003 & 152 \\
2004 & 150 \\
2005 & 147 \\
2006 & 149 \\
\hline
\end{tabular}

Figure III.B2 shows the historical trust fund ratios and the projected ratios under the three sets of assumptions. The labels "I," "II," and "III" indicate projections under the low cost, intermediate, and high cost alternatives, respectively. Figure III.B2 indicates the declining growth of assets (as a percentage of expenditures) in the immediate future, except under conditions of exceptionally robust economic growth and modest health care cost increases, as assumed in the low cost alternative. 


\section{Actuarial Analysis}

Figure III.B2.-HI Trust Fund Balance at Beginning of Year as a Percentage

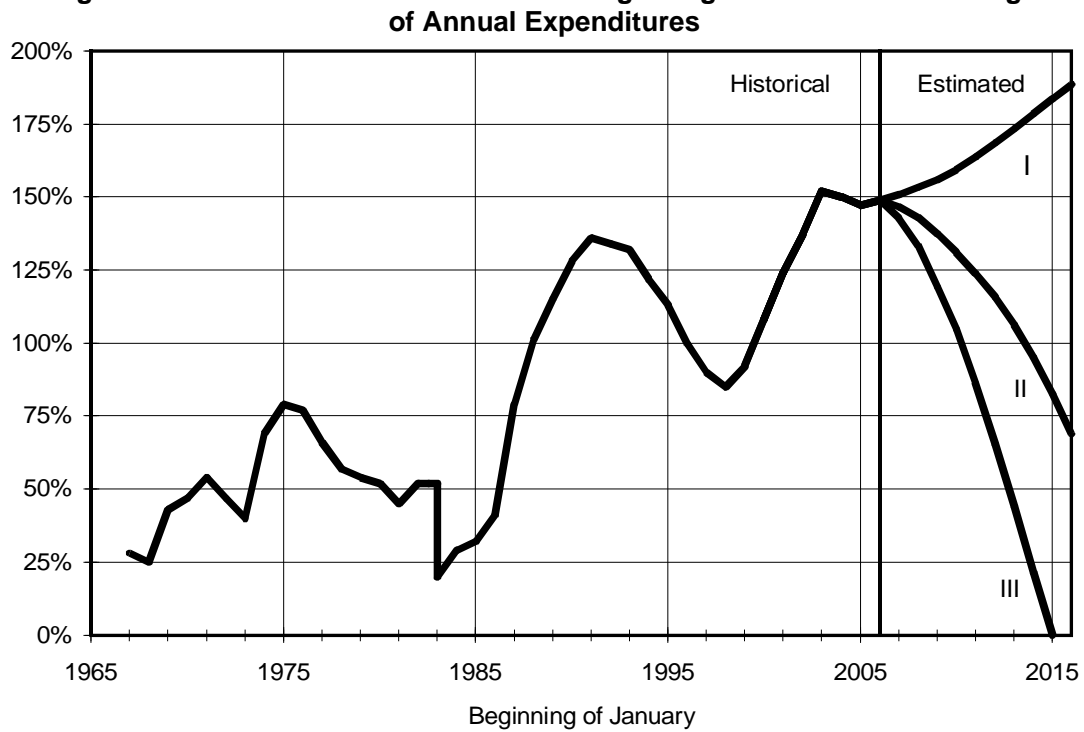

The Trustees have recommended that $\mathrm{HI}$ trust fund assets be maintained at a level of at least 100 percent of annual expenditures. Such a level is estimated to provide a cushion of roughly 5 years or more in the event that income falls short of expenditures, thereby allowing time for policy makers to devise and implement legislative corrections. Thus, while the short-range test is stringent, it is intended to ensure that health care benefits continue to be available without interruption to the millions of aged and disabled Americans who rely on such coverage.

\section{Long-Range Estimates}

Section III.B2 presented HI expected operations over the next 10 years. In this section, the long-range actuarial status of the trust fund is examined under the three alternative sets of assumptions. The assumptions used in preparing projections are summarized in section IV.A of this report. Since the vast majority of total HI costs are related to insured beneficiaries, and since general revenue appropriations and premium payments are expected to support the uninsured segments (those paying the HI premium and those receiving HI coverage through special statutes requiring general revenue transfers to cover their costs), the remainder of this section will focus on the financing for insured beneficiaries only. 
The long-range actuarial status of the HI trust fund is measured by comparing, on a year-by-year basis, the income (from payroll taxes and from taxation of OASDI benefits) with the corresponding incurred costs, expressed as percentages of taxable payroll. ${ }^{22}$ These percentages are referred to as "income rates" and "cost rates," respectively.

The historical and projected HI costs under the intermediate assumptions, expressed as percentages of taxable payroll, and the income rates under current law for selected years over the 75-year period, are shown in table III.B7. The ratio of expenditures to taxable payroll has generally increased over time, rising from 0.94 percent in 1967 to 3.40 percent in 1996, reflecting both the higher rate of increase in medical care costs than in average earnings subject to HI taxes, and the more rapid increase in the number of HI beneficiaries than in the number of covered workers. Cost rates declined significantly between 1996 and 2000 to 2.60 percent, due to favorable economic performance, the impact of the Balanced Budget Act of 1997, and efforts to curb fraud and abuse in the Medicare program. The cost rate increased to 2.78 in 2001, 2.93 in 2002, and 2.95 in 2003 as a result of the Benefits Improvement and Protection Act of 2000 and the 2001 economic recession. In 2004 and 2005, the cost rate increased to 2.99 percent and 3.07 percent, respectively, in part as a result of the Medicare Modernization Act of 2003. In 2006, the cost rate decreased to 3.01 percent due to slower inpatient hospital growth.

\footnotetext{
${ }^{22}$ Taxable payroll is the total amount of wages, salaries, tips, self-employment income, and other earnings subject to the HI payroll tax.
} 
Actuarial Analysis

\begin{tabular}{|c|c|c|c|}
\hline Calendar year & Cost rates $^{2}$ & Income rates & Difference $^{3}$ \\
\hline $\begin{array}{r}\text { Historical data: } \\
1967 \\
1970 \\
1975 \\
1980 \\
1985 \\
1990 \\
1995 \\
2000 \\
2001 \\
2002 \\
2003 \\
2004 \\
2005 \\
2006\end{array}$ & $\begin{array}{l}0.94 \% \\
1.20 \\
1.69 \\
2.19 \\
2.62 \\
2.70 \\
3.30 \\
2.60 \\
2.78 \\
2.93 \\
2.95 \\
2.99 \\
3.07 \\
3.01\end{array}$ & $\begin{array}{l}1.00 \% \\
1.20 \\
1.80 \\
2.10 \\
2.70 \\
2.90 \\
3.01 \\
3.05 \\
3.05 \\
3.05 \\
3.05 \\
3.05 \\
3.06 \\
3.06\end{array}$ & $\begin{array}{l}+0.06 \% \\
0.00 \\
+0.11 \\
-0.09 \\
+0.08 \\
+0.20 \\
-0.29 \\
+0.45 \\
+0.27 \\
+0.12 \\
+0.10 \\
+0.06 \\
-0.01 \\
+0.05\end{array}$ \\
\hline $\begin{array}{c}\text { Intermediate estimat } \\
2007 \\
2008 \\
2009 \\
2010 \\
2011 \\
2012 \\
2013 \\
2014 \\
2015 \\
2016 \\
2020 \\
2025 \\
2030 \\
2035 \\
2040 \\
2045 \\
2050 \\
2055 \\
2060 \\
2065 \\
2070 \\
2075 \\
2080\end{array}$ & $\begin{array}{r}3.11 \\
3.16 \\
3.22 \\
3.28 \\
3.33 \\
3.40 \\
3.48 \\
3.57 \\
3.65 \\
3.74 \\
4.21 \\
4.99 \\
5.91 \\
6.82 \\
7.60 \\
8.23 \\
8.77 \\
9.26 \\
9.79 \\
10.34 \\
10.85 \\
11.31 \\
11.71\end{array}$ & $\begin{array}{l}3.09 \\
3.09 \\
3.11 \\
3.12 \\
3.13 \\
3.15 \\
3.16 \\
3.17 \\
3.19 \\
3.20 \\
3.25 \\
3.30 \\
3.34 \\
3.36 \\
3.36 \\
3.37 \\
3.37 \\
3.37 \\
3.38 \\
3.39 \\
3.40 \\
3.40 \\
3.41\end{array}$ & $\begin{array}{l}-0.02 \\
-0.07 \\
-0.11 \\
-0.16 \\
-0.20 \\
-0.25 \\
-0.32 \\
-0.39 \\
-0.46 \\
-0.54 \\
-0.96 \\
-1.69 \\
-2.57 \\
-3.46 \\
-4.23 \\
-4.87 \\
-5.40 \\
-5.89 \\
-6.41 \\
-6.95 \\
-7.45 \\
-7.91 \\
-8.30\end{array}$ \\
\hline
\end{tabular}

'Under the intermediate assumptions.

${ }^{2}$ Estimated costs attributable to insured beneficiaries only, on an incurred basis. Benefits and administrative costs for noninsured persons are expected to be financed through general revenue transfers and premium payments, rather than through payroll taxes. Gratuitous credits for military service for 1957-2001 are included in taxable payroll.

${ }^{3}$ Difference between the income rates and cost rates. Negative values represent deficits.

After 2006, the income rates under current law are projected to be insufficient, by a growing margin, to support the projected costs. By the end of the long-range projection period, HI tax income is estimated to cover less than one-third of the cost. As a result, the trust fund is seriously out of financial balance in the long range, and substantial reform will be required.

Figure III.B3 shows the year-by-year costs as a percentage of taxable payroll for each of the three sets of assumptions. The labels "I," "II," and "III" indicate projections under the low cost, intermediate, and 
high cost alternatives, respectively. The income rates are also shown, but only for the intermediate assumptions in order to simplify the graphical presentation-and because the variation in the income rates by alternative is very small (by 2081, the annual income rates under the low cost and high cost alternatives differ by less than 0.4 percent of taxable payroll).

Figure III.B3.-Estimated HI Cost and Income Rates as a Percentage of Taxable Payroll

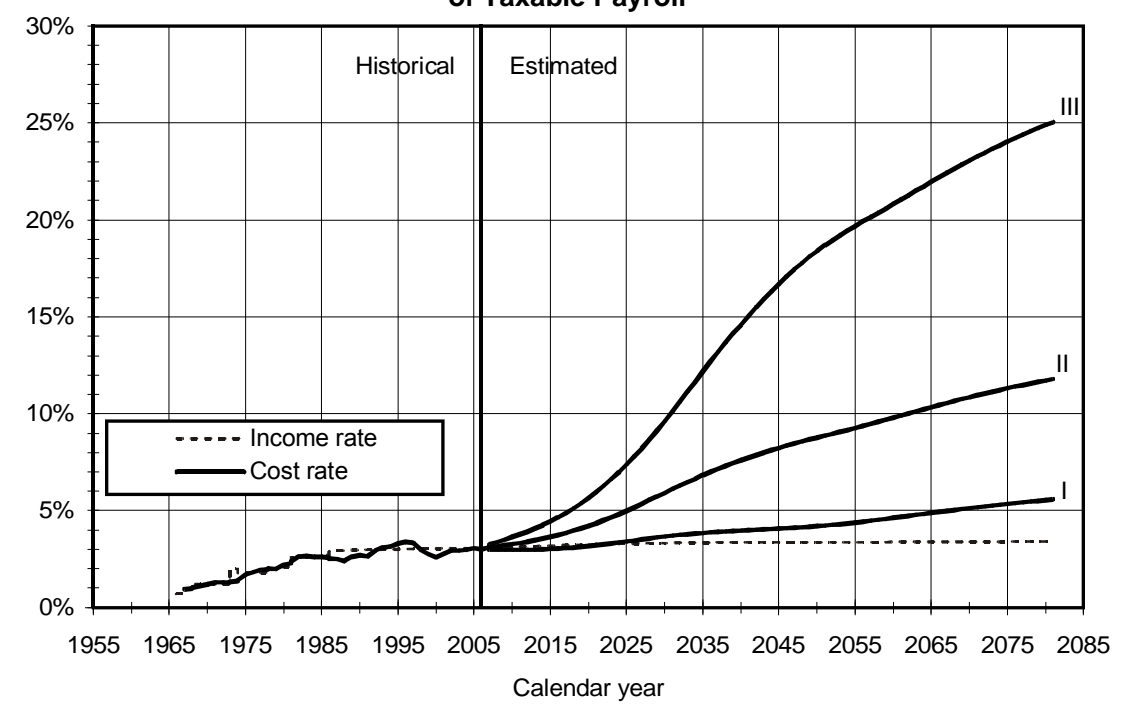

Figure III.B3 further reinforces the financial imbalance projected under the intermediate assumptions. After 2006, cost rates are projected to exceed income rates under current law by a steadily and rapidly growing margin. By the end of the 75-year period, this differential would be more than 8 percent of taxable payroll and would continue to worsen thereafter. Under the more favorable economic and demographic conditions assumed in the low cost assumptions, HI costs would exceed scheduled income by 2022 , with a more modest but steadily growing deficit thereafter. The high cost projections illustrate the severe financial imbalance that could occur if future economic conditions resemble those of the 1973-95 period, if HI expenditure growth accelerates toward pre-1997 levels, and if fertility rates decline to the levels currently experienced in key European countries such as the United Kingdom. ${ }^{23}$

\footnotetext{
${ }^{23}$ Actual experience during these periods was similar on average to the high cost economic and programmatic assumptions for the future.
} 


\section{Actuarial Analysis}

Costs beyond the initial 25-year projection period for the intermediate estimate are based upon the assumption that average HI expenditures per beneficiary will increase at a rate determined by the economic model described in sections II.C and IV.C. This rate is about 1.4 percent faster than the Gross Domestic Product (GDP) per capita in 2031 , slowing down to about 0.2 percent faster by 2081 . Therefore, changes in the next 50 years of the projection period reflect both the impact of the changing demographic composition of the population and average benefits that increase more rapidly than average wages. Beyond the initial 25-year projection period, the low cost and high cost alternatives assume that HI cost increases, relative to taxable payroll increases, are initially 2 percentage points less rapid and 2 percentage points more rapid, respectively, than the results under the intermediate assumptions. The initial 2-percentage-point differentials are assumed to gradually decrease until the year 2056, when HI cost increases (relative to taxable payroll) are assumed to be the same as under the intermediate assumptions.

The cost rates and income rates are shown over a 75-year valuation period in order to fully present the future economic and demographic developments that may reasonably be expected to occur, such as the impact of the large shift in the demographic composition of the population that will take place beginning in the next decade. As figure III.B3 indicates, estimated HI expenditures, expressed as percentages of taxable payroll, increase rapidly beginning around 2010. This rapid increase in costs occurs in part because the relatively large number of persons born during the period between the end of World War II and the mid-1960s (known as the baby boom generation) will reach eligibility age and begin to receive benefits, while the relatively smaller number of persons born during later years will comprise the labor force. During the last 25 years of the projection period, the demographic impacts moderate somewhat. ${ }^{24}$

For the most part, current benefits are paid for by current workers. Consequently, the baby boom generation will be financed by the relatively small number of persons born after the baby boom. Figure III.B4 shows the projected ratio of workers per HI beneficiary from 2006 to 2081.

${ }^{24} \mathrm{HI}$ costs as a percentage of taxable payroll are projected to continue to increase due to demographic changes, reflecting assumed further improvements in life expectancy and assumed birth rates that are at roughly the same level as those experienced during the last 2 decades. 
Figure III.B4.-Workers per HI Beneficiary

[Based on intermediate assumptions]

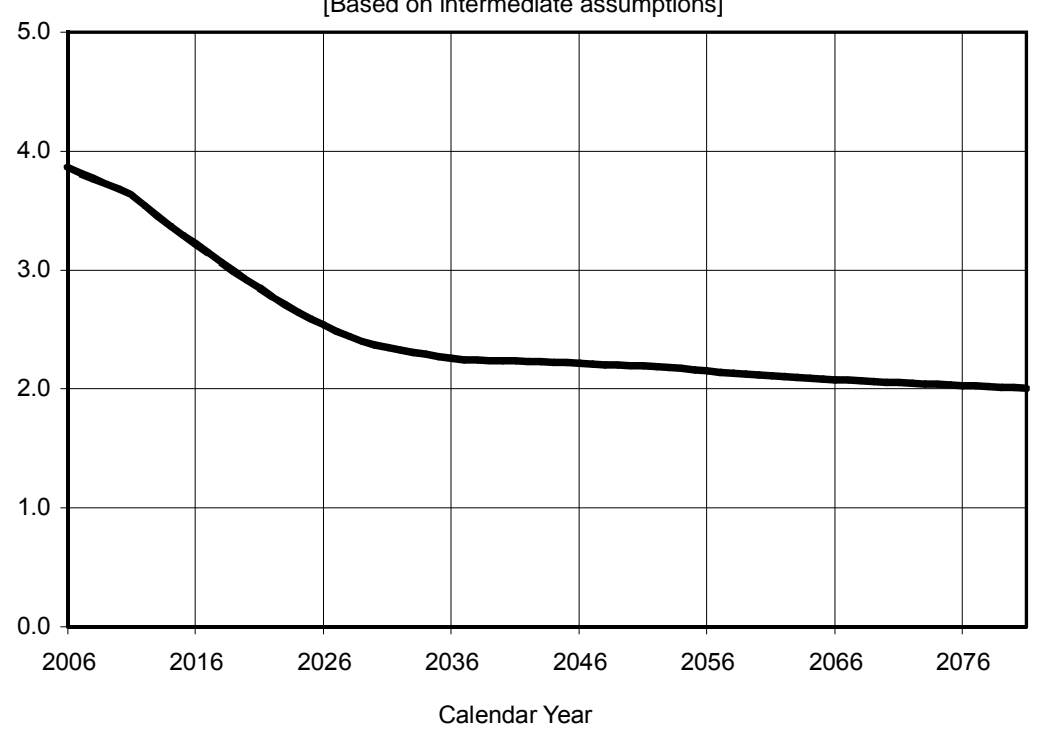

As figure III.B4 indicates, while every beneficiary in 2006 had about 3.9 workers to pay for his or her HI benefit, in 2030 there would be only about 2.4 workers. This ratio would then continue to decline until there are only 2.0 workers per beneficiary by 2080 .

While year-by-year comparisons of revenues and costs are necessary to measure the adequacy of $\mathrm{HI}$ financing, the financial status of the trust fund is often summarized, over a specific valuation period, by a single measure known as the actuarial balance. The actuarial balance of the HI trust fund is defined as the difference between the summarized income rate for the valuation period and the summarized cost rate for the same period.

The summarized income rates, cost rates, and actuarial balance are based upon the present values of future income, costs, and taxable payroll. The present values are calculated, as of the beginning of the valuation period, by discounting the future annual amounts of income and outgo at the assumed rates of interest credited to the HI trust fund. The summarized income and cost rates over the projection period are then obtained by dividing the present value of income and cost, respectively, by the present value of taxable payroll. The difference between the summarized income rate and cost rate over the long-range projection period, after an adjustment to take into account the fund balance at the valuation date and a target trust 


\section{Actuarial Analysis}

fund balance at the end of the valuation period, is the actuarial balance.

In keeping with a decision by the Board of Trustees that it is advisable to maintain a balance in the trust fund equal to a minimum of 1 year's expenditures, the target trust fund balance is equal to the following year's estimated costs at the end of the 75-year projection period. It should be noted that projecting an end-of-period target trust fund balance does not necessarily ensure that the trust fund will maintain such a balance on a year-by-year basis.

The actuarial balance can be interpreted as the percentage that could be added to the current-law income rates and/or subtracted from the current-law cost rates immediately and throughout the entire valuation period in order for the financing to support HI costs and provide for the targeted trust fund balance at the end of the projection period. The income rate increase according to this method is 3.55 percent of taxable payroll. However, if no changes were made until the year the trust fund would be exhausted, then the required increase would be 4.59 percent of taxable payroll under the intermediate assumptions. If changes were instead made year by year, as needed to balance each year's costs and tax revenues, then the changes would be minimal through about 2010, but would grow rapidly thereafter to more than 8 percent of taxable payroll by the end of the projection period.

The actuarial balances under all three alternative sets of assumptions, for the next 25, 50, and 75 years, are shown in table III.B8. The summarized income rate for the entire 75 -year period under the intermediate assumptions is 3.40 percent of taxable payroll. The summarized HI cost rate under the intermediate assumptions, for the entire 75-year period, is 6.95 percent. As a result, the HI trust fund fails to meet the Trustees' long-range test of close actuarial balance by a wide margin. (Section V.G contains the definition of this test.) 
HI Financial Status

Table III.B8.-HI Actuarial Balances under Three Sets of Assumptions

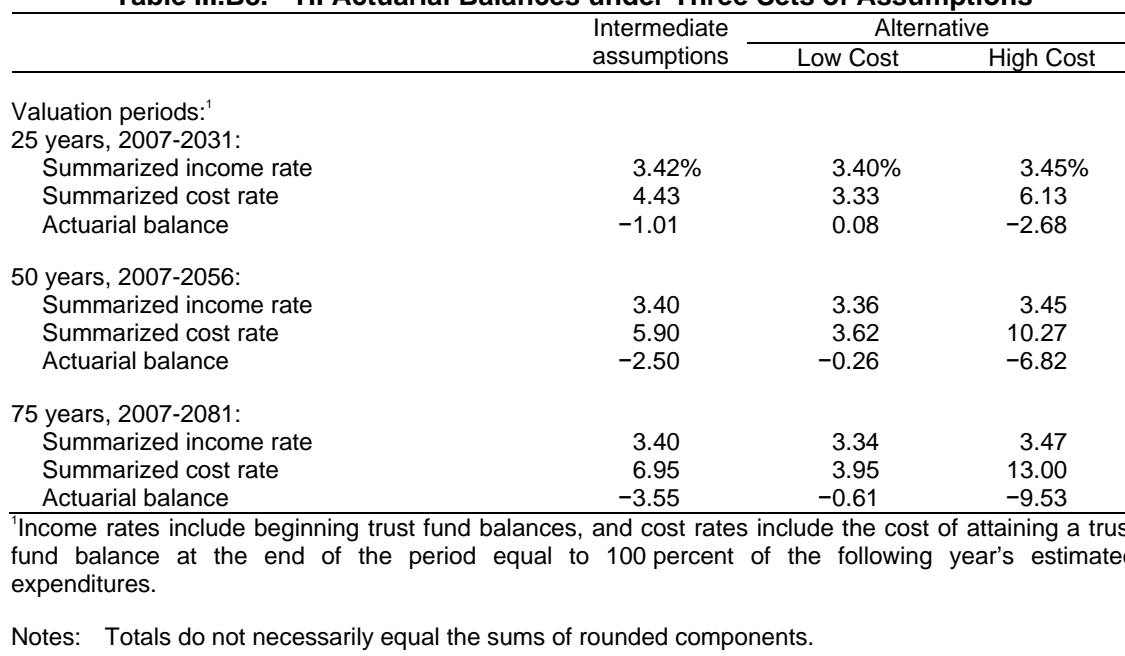

The divergence in outcomes among the three alternatives is reflected both in the estimated operations of the trust fund on a cash basis (as discussed in section III.B2) and in the 75-year summarized costs. The variations in the underlying assumptions can be characterized as (i) moderate in terms of magnitude of the differences on a year-byyear basis, and (ii) persistent over the duration of the projection period. Under the low cost alternative, the summarized cost rate for the 75-year valuation period is 3.95 percent of taxable payroll, and the summarized income rate is 3.34 percent of taxable payroll, meaning that $\mathrm{HI}$ income rates provided in current law would not be adequate on average under the low cost alternative. ${ }^{25}$ Under the high cost alternative, the summarized cost rate for the 75-year projection period is 13.00 percent of taxable payroll, nearly four times the summarized income rate of 3.47 percent of taxable payroll.

As suggested earlier, past experience has indicated that economic and demographic conditions that are as financially adverse as those assumed under the high cost alternative can, in fact, occur. None of the alternative projections should be viewed as unlikely or unrealistic. The wide range of results under the three alternatives is indicative of the uncertainty of HI's future cost and its sensitivity to future economic and demographic conditions. Accordingly, it is important that an adequate balance be maintained in the HI trust

${ }^{25} \mathrm{As}$ seen in figure III.B3, however, this balance would reflect a significant period of slight surpluses followed by a period of growing deficits. Under such a scenario, trust fund assets would initially build up to large levels but would then be drawn down rapidly and be exhausted before the end of the projection period. 


\section{Actuarial Analysis}

fund, as a reserve for contingencies, and that financial imbalances be addressed promptly through corrective legislation.

Table III.B9 shows the long-range actuarial balance under the intermediate projections with its component parts-the present values of tax income, expenditures, and asset requirement of the $\mathrm{HI}$ program over the next 75 years. The estimates are for the "open-group" population-all persons who will participate during the period as either taxpayers or beneficiaries, or both-and consist of payments from, and on behalf of, employees now in the workforce, as well as those who will enter the workforce over the next 75 years. The estimates also include expenditures attributable to these current and future workers, in addition to current beneficiaries.

Table III.B9._Components of 75-Year HI Actuarial Balance under Intermediate Assumptions (2007-2081)

\footnotetext{
Present value as of January 1, 2007 (in billions):

a. Payroll tax income .................................................................. $\$ 9,725$

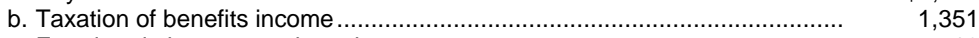

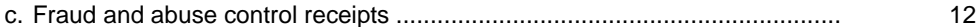

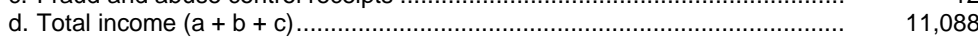

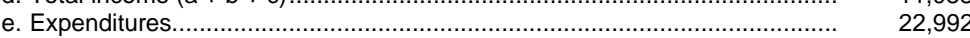

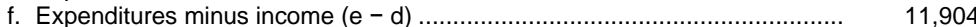

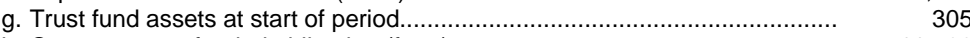

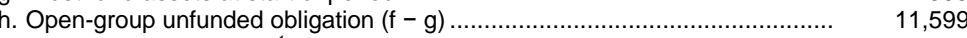

i. Ending target trust fund ${ }^{1}$.................................................................... 300

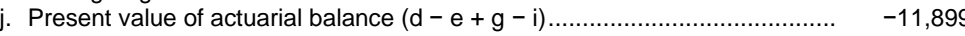

k. Taxable payroll ..................................................................................... $\quad 335,342$

Percent of taxable payroll:

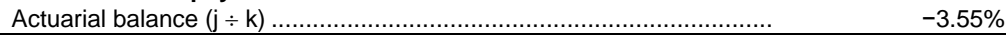

${ }^{1}$ The calculation of the actuarial balance includes the cost of accumulating a target trust fund balance equal to 100 percent of annual expenditures by the end of the period.

Note: Totals do not necessarily equal the sums of rounded components.
}

The present value of future expenditures less future tax income, decreased by the amount of HI trust fund assets on hand at the beginning of the projection, amounts to $\$ 11.6$ trillion. This value is referred to as the 75-year "unfunded obligation" for the HI trust fund and is 5 percent larger than last year's value of $\$ 11.0$ trillion. The primary reasons for the increase are (i) the later valuation date, and (ii) the addition of a large deficit year to the calculation. Other reasons for the change are discussed in more detail later in this section. The unfunded obligation (adjusted for the ending target trust fund) can be expressed as a percentage of the present value of future taxable payroll to calculate the traditional actuarial balance of the HI program. Under the intermediate assumptions, the present value of the actuarial deficit is $\$ 11.9$ trillion. Dividing by the present value of 
future taxable payroll (estimated to be $\$ 335$ trillion) results in the actuarial balance of -3.55 percent shown in table III.B9.

Figure III.B5 shows the present values, as of January 1, 2007, of cumulative HI taxes less expenditures (plus the 2007 trust fund) through each of the next 75 years. These values are estimated under current-law legislated expenditures and tax rates.

Figure III.B5.-Present Value of Cumulative HI Taxes Less Expenditures through Year Shown, Evaluated under Current Law Tax Rates and Legislated Expenditures



The cumulative annual balance of the trust fund is highest at the beginning of 2006, reflecting the beginning trust fund assets of about $\$ 0.3$ trillion. The cumulative present value then turns downward over the projection period, reflecting the anticipated shortfall of tax revenues, relative to expenditures, in 2007 and later. The trust fund is projected to become exhausted in 2019, at which time cumulative expenditures would have exceeded cumulative tax revenues by enough to equal the initial fund assets accumulated with interest. The continuing decline in the line thereafter further illustrates the unsustainable difference between the HI expenditures promised under current law and the financing currently scheduled to support these expenditures. As noted previously, over the full 75-year period, the fund has a projected present value unfunded obligation of $\$ 11.6$ trillion. This unfunded obligation indicates that if $\$ 11.6$ trillion were added to the trust fund at the beginning of 2007 , the program could meet the projected cost of current-law expenditures over the 


\section{Actuarial Analysis}

next 75 years. More realistically, additional annual revenues and/or reductions in expenditures, with a present value totaling $\$ 11.6$ trillion, would be required to reach financial balance.

The estimated unfunded obligation of $\$ 11.6$ trillion and the closely associated present value of the actuarial deficit ( $\$ 11.9$ trillion) are useful indicators of the sizable responsibility facing the American public. In other words, increases in revenues and/or reductions in benefit expenditures-equivalent to a lump-sum amount today of more than $\$ 11$ trillion-would be required to bring the HI trust fund into long-range financial balance. At the same time, long-range measures expressed in dollar amounts, even when expressed as present values, can be difficult to interpret. For this reason, the Board of Trustees has customarily emphasized relative measures such as the income rate and cost rate comparisons shown earlier in this section.

Consistent with the practice of previous reports, this report focuses on the 75-year period from 2007 to 2081 for the evaluation of the long-run financial status of the HI program on an open-group basis (i.e., including past, current, and future participants). Table III.B10 shows that the present value of open-group unfunded obligations for the program over that period is $\$ 11.6$ trillion, which is equivalent to 3.5 percent of taxable payroll or 1.6 percent of GDP. Some experts, however, have expressed concern that overemphasis on summary measures (such as the actuarial balance and open-group unfunded obligations) can obscure the underlying year-by-year patterns of the long-range financial deficits. If legislative solutions were designed only to eliminate the overall actuarial deficit, without consideration of such year-by-year patterns, then a substantial financial imbalance could still remain at the end of the period, and the long-range sustainability of the program could still be in doubt.

Reflecting these same concerns, the Medicare Trustees Report has traditionally focused on the projected year-by-year pattern of HI income versus expenditures and placed less emphasis on summary measures. As noted previously in this section, the scheduled tax revenues for HI represent less than one-third of projected expenditures at the end of the 75-year projection period, and the projected financial imbalance worsens throughout this period.

Concern has also been expressed that limiting the projections to 75 years understates the magnitude of the long-range unfunded 
obligations for HI, because summary measures reflect the full amount of taxes paid by the next two or three generations of workers, but not the full amount of their benefits. One approach to addressing the limitations of 75-year summary measures is to extend the projection horizon indefinitely, so that the projected large deficits after the first 75 years are reflected in the overall results. ${ }^{26}$ Such extended projections can also help indicate whether the HI financial imbalance would be improving or continuing to worsen beyond the normal 75-year period. Accordingly, table III.B10 presents estimates of HI unfunded obligations that extend to the infinite horizon. The extension assumes that the current-law HI program and the demographic and economic trends used for the 75-year projection continue indefinitely except that average HI expenditures per beneficiary will increase at the same rate as GDP per capita beginning in about 2081. Extending the calculations beyond 2081 adds $\$ 17.9$ trillion in unfunded obligations to the amount estimated through 2081. That is, over the infinite horizon, the HI unfunded obligations are projected to be $\$ 29.5$ trillion. This amount represents 5.8 percent of the present value of future HI taxable payroll over the infinite horizon, or 2.6 percent of GDP.

Table III.B10.-Unfunded HI Obligations from Program Inception through the Infinite Horizon

[Present values as of January 1, 2007; dollar amounts in trillions]

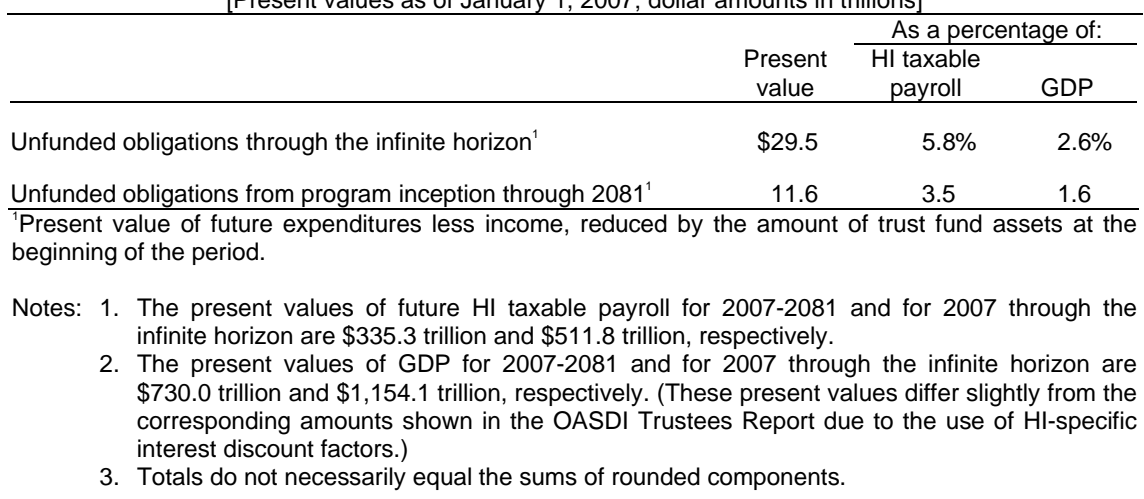

${ }^{26}$ The calculation of present values, in effect, applies successively less weight to future amounts over time, through the process of interest discounting. For example, the weights associated with the $25^{\text {th }}, 75^{\text {th }}$, and $200^{\text {th }}$ years of the projection would be about 27 percent, 2 percent, and 0.0015 percent, respectively, of the weight for the first year. In this way, a finite summary measure can be calculated for an infinite projection period. 


\section{Actuarial Analysis}

The projected HI unfunded obligation over the infinite horizon can be separated into the portions associated with current participants versus future participants. The first line of table III.B11 shows the present value of future expenditures less future taxes for all current participants, including both beneficiaries and covered workers. Subtracting the current value of the HI trust fund (the accumulated value of past HI taxes less outlays) gives a "closed group" unfunded obligation of $\$ 11.8$ trillion. The remaining $\$ 18.0$ trillion of the total unfunded obligation is the projected difference between taxes and expenditures for future participants.

The year-by-year HI deficits described previously in this section have shown that HI taxes will not be adequate to finance the program on a "pay-as-you-go" basis (whereby payroll taxes from today's workers are used to provide benefits to today's beneficiaries). ${ }^{27}$ The unfunded obligations shown in table III.B11 further indicate that workers' HI taxes are not adequate to cover their own future costs when they become eligible for HI benefits-and that this situation has occurred for workers in the past and will continue to be true for future workers under current law. In practice, the projected HI deficits could be addressed by raising additional revenue or reducing benefits (or some combination of these actions). The impact of such changes on the unfunded obligation amounts for current versus future participants would depend on the specific policies selected.

\footnotetext{
${ }^{27}$ As noted previously, small amounts of income are also received in the form of income taxes on OASDI benefits, interest, and general revenue reimbursements for certain uninsured beneficiaries.
} 
Table III.B11._Unfunded HI Obligations for Current and Future Program Participants through the Infinite Horizon

[Present values as of January 1, 2007; dollar amounts in trillions]

\begin{tabular}{|c|c|c|c|}
\hline & $\begin{array}{c}\text { Present } \\
\text { value }\end{array}$ & $\begin{array}{c}\text { As a percen } \\
\text { HI taxable } \\
\text { payroll }\end{array}$ & age of: \\
\hline Future expenditures less income for current participants.............. & $\$ 11.8$ & $2.3 \%$ & $1.0 \%$ \\
\hline $\begin{array}{l}\text { Less current trust fund } \\
\qquad \text { (income minus expenditures to date for past and current participants) ....... }\end{array}$ & 0.3 & 0.1 & 0.0 \\
\hline 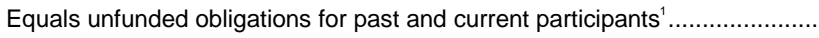 & . 11.4 & 2.2 & 1.0 \\
\hline Plus expenditures less income for future participants for the infinite horizon. & . 18.0 & 3.5 & 1.6 \\
\hline Equals unfunded obligations for all participants for the infinite future ... & 29.5 & 5.8 & 2.6 \\
\hline
\end{tabular}

${ }^{1}$ This concept is also referred to as the closed-group unfunded obligation.

Notes: 1 . The estimated present value of future $\mathrm{HI}$ taxable payroll for 2007 through the infinite horizon is $\$ 511.8$ trillion.

2. The estimated present value of GDP for 2007 through the infinite horizon is $\$ 1,154.1$ trillion. See note 2 in table III.B10.

3. Totals do not necessarily equal the sums of rounded components.

The remainder of this section describes the changes in long-range HI actuarial projections made since the prior year's annual report to Congress was released. Figure III.B6 compares the year-by-year HI cost and income rates for the current annual report with the corresponding projections from the 2006 report.

Figure III.B6.-Comparison of HI Cost and Income Rate Projections: Current versus Prior Year's Reports

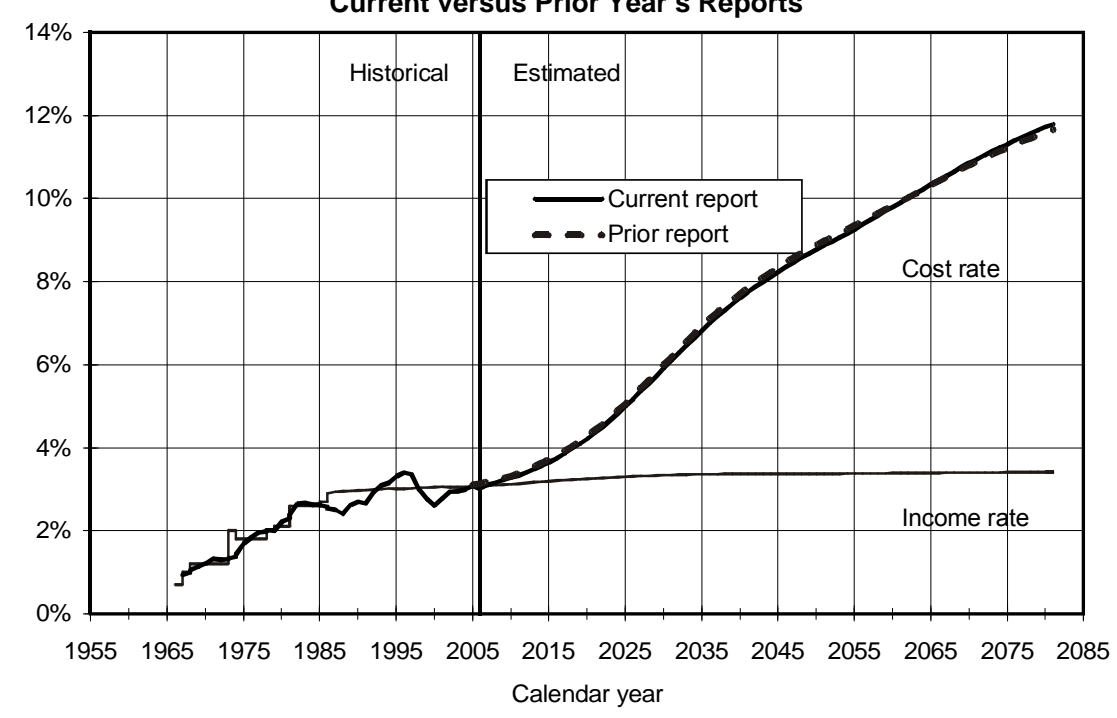

As figure III.B6 indicates, the intermediate HI cost rate projections in this year's report are nearly identical to those in the 2006 reportvery slightly lower for most of the projection period and very slightly 


\section{Actuarial Analysis}

higher in the last decade of the projection period. The projected income rates are not perceptibly different in the chart.

The minimal cost differentials described above reflect projected rates of increase in HI costs that are basically the same as those from last year's report. For both reports, the growth rates are drawn from a simplified economic model that produces a smoother transition from the current faster rates of growth to the ultimate assumption for the infinite horizon based on the GDP increase plus zero percent. The detailed reasons for the change in the actuarial deficit are described below.

As mentioned earlier, the 75-year HI actuarial balance, under the intermediate assumptions, is estimated to be -3.55 percent of taxable payroll. The actuarial balance under the intermediate assumptions as shown in the 2006 annual report was -3.51 percent. The major reasons for the change in the 75-year actuarial balance are summarized in table III.B12. In more detail, these changes consist of the following:

(1) Change in valuation period: Changing the valuation period from 2006-2080 to 2007-2081 adds a large deficit year to the calculation of the actuarial balance. The effect on the actuarial balance is -0.11 percent of taxable payroll.

(2) Updating the projection base: The actual cost as a percentage of payroll for 2006 was lower than estimated in last year's report. The difference was primarily attributable to incurred $\mathrm{HI}$ expenditures that were about 3 percent lower than estimated, as a result of an abrupt decline in the number of inpatient hospital admissions. This decline is believed to be a one-time random fluctuation, and the incidence of admissions is assumed to return to the average trend level in 2007. The net effect of the 2006 actual experience and the assumed return to usual assumed rates results in a total average change in the actuarial balance of +0.06 percent of taxable payroll.

(3) Managed care assumptions: The projected rate of growth in enrollment in Medicare Advantage (MA) plans is now somewhat lower compared to last year's rate of growth, based on data on such enrollees for 2006. In addition, a more refined calculation of the relationship between the utilization rate of those who switch to MA plans compared to those who remain in fee for service was used. The net 
effect of these changes results in a -0.03 -percent change in the actuarial balance.

(4) Hospital assumptions: Minor changes in the hospital assumptions described in section IV.A result in a +0.02 -percent change in the actuarial balance.

(5) Other provider assumptions: The primary change for other providers was the relationship between the hospital market basket and the skilled nursing facility and home health agency market baskets. This change, which was based on the most recent historical experience, results in a -0.03-percent difference in the actuarial balance.

(6) Economic and demographic assumptions: Changes to the economic and demographic assumptions result in a change of +0.05 percent in the actuarial balance. The primary change is faster assumed economic growth in the short range.

Table III.B12.-Change in the 75-Year Actuarial Balance since the 2006 Report

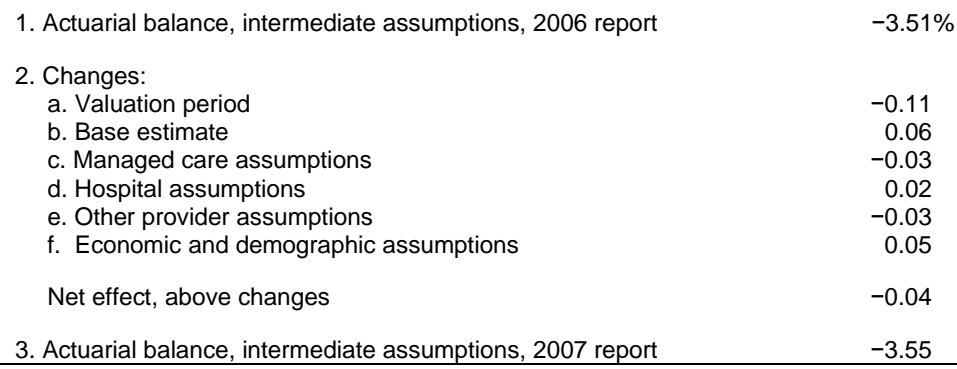

\section{Long-Range Sensitivity Analysis}

This section presents estimates that illustrate the sensitivity of the long-range cost rate and actuarial balance of $\mathrm{HI}$ to changes in selected individual assumptions. The estimates based on the three alternative sets of assumptions (that is, intermediate, low cost, and high cost) demonstrate the effects of varying all of the principal assumptions simultaneously in order to portray a generally more optimistic or pessimistic future, in terms of the projected financial status of the HI trust fund. In the sensitivity analysis presented in this section, the intermediate set of assumptions is used as the reference point, and one assumption at a time is varied within that alternative.

Each table that follows shows the effects of changing a particular assumption on the HI summarized income rates, summarized cost 


\section{Actuarial Analysis}

rates, and actuarial balances (as defined earlier in this report) for 25-year, 50-year, and 75-year valuation periods. Because the income rate varies only slightly with changes in assumptions, it is not considered in the discussion of the tables. The change in each of the actuarial balances is approximately equal to the change in the corresponding cost rate, but in the opposite direction. For example, a lower projected cost rate would result in an improvement or increase in the corresponding projected actuarial balance.

\section{a. Real-Wage Differential}

Table III.B13 shows the estimated HI income rates, cost rates, and actuarial balances on the basis of the intermediate assumptions, with various assumptions about the real-wage differential. These assumptions are that the ultimate real-wage differential will be 0.6 percentage point (as assumed for the high cost alternative), 1.1 percentage points (as assumed for the intermediate assumptions), and 1.6 percentage points (as assumed for the low cost alternative). In each case, the ultimate annual increase in the Consumer Price Index (CPI) is assumed to be 2.8 percent (as assumed for the intermediate assumptions), yielding ultimate percentage increases in average annual wages in covered employment of 3.4, 3.9, and 4.4 percent under the three illustrations, respectively.

Past increases in real earnings have exhibited substantial variation. During 1951-1970, real earnings grew by an average of 2.2 percent per year. During 1972-1996, however, the average annual increase in real earnings amounted to only 0.53 percent. ${ }^{28}$ Poor performance in real-wage growth would be a matter of some concern; as shown in table III.B13, projected HI costs are fairly sensitive to the assumed growth rates in real wages. For the 75-year period 2007-2081, the summarized cost rate decreases from 7.33 percent (for a real-wage differential of 0.6 percentage point) to 6.66 percent (for a differential of 1.6 percentage points). The HI actuarial balance over this period shows a corresponding improvement for faster rates of growth in real wages.

\footnotetext{
${ }^{28}$ This period was chosen because it begins and ends with years in which the economy reached full employment. The period thus allows measurement of trend growth over complete economic cycles.
} 


\begin{tabular}{|c|c|c|c|}
\hline \multirow[b]{2}{*}{ Valuation period } & \multicolumn{3}{|c|}{ Ultimate percentage increase in wages-CPI ${ }^{1}$} \\
\hline & $3.4-2.8$ & $3.9-2.8$ & $4.4-2.8$ \\
\hline \multicolumn{4}{|l|}{ Summarized income rate: } \\
\hline 25-year: $2007-2031$ & $3.46 \%$ & $3.42 \%$ & $3.40 \%$ \\
\hline 50-year: $2007-2056$ & 3.44 & 3.40 & 3.36 \\
\hline 75-year: 2007-2081 & 3.45 & 3.40 & 3.36 \\
\hline \multicolumn{4}{|l|}{ Summarized cost rate: } \\
\hline 25-year: 2007-2031 & 4.61 & 4.43 & 4.34 \\
\hline 50-year: $2007-2056$ & 6.19 & 5.90 & 5.71 \\
\hline 75-year: 2007-2081 & 7.33 & 6.95 & 6.66 \\
\hline \multicolumn{4}{|l|}{ Actuarial balance: } \\
\hline 25-year: 2007-2031 & -1.15 & -1.01 & -0.95 \\
\hline 50-year: $2007-2056$ & -2.74 & -2.50 & -2.35 \\
\hline 75 -year: $2007-2081$ & -3.89 & -3.55 & -3.30 \\
\hline
\end{tabular}

The sensitivity of the HI actuarial balance to different real-wage assumptions is significant, but not as substantial as one might intuitively expect. Higher real-wage differentials immediately increase both HI expenditures for health care and wages for all workers. Though there is a full effect on wages and payroll taxes, the effect on benefits is only partial, since not all health care costs are wage-related. Thus, the HI cost rate decreases with increasing real-wage differentials, because the higher real-wage levels increase the taxable payroll to a greater extent than they increase HI benefits. In particular, each 0.5-percentage-point increase in the assumed real-wage differential increases the long-range HI actuarial balance, on average, by about 0.30 percent of taxable payroll.

\section{b. Consumer Price Index}

Table III.B14 shows the estimated HI income rates, cost rates, and actuarial balances on the basis of the intermediate alternative, with various assumptions about the rate of increase for the CPI. These assumptions are that the ultimate annual increase in the CPI will be 1.8 percent (as assumed for the low cost alternative), 2.8 percent (as assumed for the intermediate assumptions), and 3.8 percent (as assumed for the high cost alternative). In each case, the ultimate real-wage differential is assumed to be 1.1 percent (as assumed for the intermediate assumptions), yielding ultimate percentage increases in average annual wages in covered employment of $2.9,3.9$, and 4.9 percent under the three illustrations. 


\section{Actuarial Analysis}

\begin{tabular}{|c|c|c|c|}
\hline \multirow[b]{2}{*}{ Valuation period } & \multicolumn{3}{|c|}{ Ultimate percentage increase in wages-CPI ${ }^{1}$} \\
\hline & $2.9-1.8$ & $3.9-2.8$ & $4.9-3.8$ \\
\hline \multicolumn{4}{|l|}{ Summarized income rate: } \\
\hline 25-year: $2007-2031$ & $3.43 \%$ & $3.42 \%$ & $3.40 \%$ \\
\hline 50-year: $2007-2056$ & 3.41 & 3.40 & 3.37 \\
\hline 75-year: 2007-2081 & 3.41 & 3.40 & 3.37 \\
\hline \multicolumn{4}{|l|}{ Summarized cost rate: } \\
\hline 25-year: 2007-2031 & 4.44 & 4.43 & 4.40 \\
\hline 50-year: $2007-2056$ & 5.91 & 5.90 & 5.85 \\
\hline 75-year: 2007-2081 & 6.96 & 6.95 & 6.90 \\
\hline \multicolumn{4}{|l|}{ Actuarial balance: } \\
\hline 25-year: 2007-2031 & -1.01 & -1.01 & -1.00 \\
\hline 50-year: $2007-2056$ & -2.50 & -2.50 & -2.49 \\
\hline 75-year: $2007-2081$ & -3.55 & -3.55 & -3.53 \\
\hline
\end{tabular}

The cost rate remains about the same with greater assumed rates of increase in the CPI. Over the 75-year projection period, for example, the cost rate decreases from 6.96 percent (for CPI increases of 1.8 percent) to 6.90 percent (for CPI increases of 3.8 percent). The relative insensitivity of projected HI cost rates to different levels of general inflation occurs because inflation is assumed to affect both the taxable payroll of workers and medical care costs about equally. ${ }^{29}$ In practice, differing rates of inflation could occur between the economy in general and the medical-care sector. The effect of such a difference can be judged from the sensitivity analysis shown in the subsequent section on miscellaneous health care cost factors. An increase of 1 percentage point in the rate of change assumed for the CPI increases the long-range actuarial balance, on average, by about 0.01 percent of taxable payroll.

\section{c. Real-Interest Rate}

Table III.B15 shows the estimated HI income rates, cost rates, and actuarial balances under the intermediate alternative, with various assumptions about the annual real-interest rate for special public-debt obligations issuable to the trust fund. These assumptions are that the ultimate annual real-interest rate will be 2.1 percent (as assumed for the high cost alternative), 2.9 percent (as assumed for the intermediate assumptions), and 3.6 percent (as assumed for the low cost alternative). In each case, the ultimate annual increase in

\footnotetext{
${ }^{29}$ The slight sensitivity shown in the table results primarily from the fact that the fiscal year 2007 payment rates for all providers have already been set before the actual CPI is known.
} 
the CPI is assumed to be 2.8 percent (as assumed for the intermediate assumptions), resulting in ultimate annual yields of 4.9 , 5.7, and 6.4 percent under the three illustrations.

\begin{tabular}{|c|c|c|c|}
\hline \multirow[b]{2}{*}{ Valuation period } & \multicolumn{3}{|c|}{ Ultimate annual real-interest rate } \\
\hline & 2.1 percent & 2.9 percent & 3.6 percent \\
\hline \multicolumn{4}{|l|}{ Summarized income rate: } \\
\hline 25-year: 2007-2031 & $3.41 \%$ & $3.42 \%$ & $3.43 \%$ \\
\hline 50-year: $2007-2056$ & 3.39 & 3.40 & 3.41 \\
\hline 75-year: 2007-2081 & 3.39 & 3.40 & 3.40 \\
\hline \multicolumn{4}{|l|}{ Summarized cost rate: } \\
\hline 25 -year: $2007-2031$ & 4.50 & 4.43 & 4.38 \\
\hline 50-year: $2007-2056$ & 6.14 & 5.90 & 5.69 \\
\hline 75-year: 2007-2081 & 7.41 & 6.95 & 6.56 \\
\hline \multicolumn{4}{|l|}{ Actuarial balance: } \\
\hline 25-year: 2007-2031 & -1.09 & -1.01 & -0.94 \\
\hline 50-year: $2007-2056$ & -2.75 & -2.50 & -2.28 \\
\hline 75-year: $2007-2081$ & -4.02 & -3.55 & -3.16 \\
\hline
\end{tabular}

For all periods, the cost rate decreases with increasing real-interest rates. Over 2007-2081, for example, the summarized HI cost rate would decline from 7.41 percent (for an ultimate real-interest rate of 2.1 percent) to 6.56 percent (for an ultimate real-interest rate of 3.6 percent). Thus, each 1.0-percentage-point increase in the assumed real-interest rate increases the long-range actuarial balance, on average, by about 0.57 percent of taxable payroll. The fact that the HI actuarial balance is sensitive to the interest assumption is not an indication of the actual role that interest plays in the financing. In reality, interest finances only a minimal portion of the HI cost. The sensitivity of the actuarial balance to the interest assumption is implicit in the present-value method used to determine the actuarial balance, since the present-value calculations are very sensitive to the interest rates used to discount future amounts to their present equivalent values.

\section{d. Health Care Cost Factors}

Table III.B16 shows the estimated HI income rates, cost rates, and actuarial balances on the basis of the intermediate set of assumptions, with two variations on the relative annual growth rate in the aggregate cost of providing covered health care services to HI beneficiaries. These assumptions are that the ultimate annual growth rate in such costs, relative to the growth in taxable payroll, will be 1 percentage point slower than the intermediate assumption, the same as the intermediate assumption, and 1 percentage point faster 


\section{Actuarial Analysis}

than the intermediate assumption. In each case, the taxable payroll will be the same as assumed for the intermediate assumptions.

As noted previously, factors such as wage and price increases may simultaneously affect HI tax income and the costs incurred by hospitals and other providers of medical care to HI beneficiaries. (The sensitivity of the trust fund's financial status to these factors is evaluated in sections III.B4a and III.B4b.) Other factors, such as the utilization of services by beneficiaries or the relative complexity of the services provided, can affect provider costs without affecting HI tax income. The sensitivity analysis shown in table III.B16 illustrates the financial effect of any combination of these factors that results in aggregate provider costs increasing by 1 percentage point faster or slower than the intermediate assumptions, relative to growth in taxable payroll under the intermediate assumptions.

\begin{tabular}{|c|c|c|c|}
\hline \multirow[b]{2}{*}{ Valuation period } & \multicolumn{3}{|c|}{ Annual cost/payroll relative growth rate } \\
\hline & -1 percentage point & 0 percentage point & +1 percentage point \\
\hline \multicolumn{4}{|l|}{ Summarized income rate: } \\
\hline 25-year: 2007-2031 & $3.42 \%$ & $3.42 \%$ & $3.42 \%$ \\
\hline 50-year: 2007-2056 & 3.40 & 3.40 & 3.40 \\
\hline 75-year: 2007-2081 & 3.40 & 3.40 & 3.40 \\
\hline \multicolumn{4}{|l|}{ Summarized cost rate: } \\
\hline 25-year: 2007-2031 & 3.85 & 4.43 & 5.12 \\
\hline 50-year: 2007-2056 & 4.51 & 5.90 & 7.84 \\
\hline 75-year: 2007-2081 & 4.77 & 6.95 & 10.50 \\
\hline \multicolumn{4}{|l|}{ Actuarial balance: } \\
\hline 25-year: 2007-2031 & -0.43 & -1.01 & -1.70 \\
\hline 50-year: 2007-2056 & -1.11 & -2.50 & -4.44 \\
\hline 75-year: 2007-2081 & -1.37 & -3.55 & -7.11 \\
\hline
\end{tabular}

As illustrated in table III.B16, the financial status of the HI trust fund is extremely sensitive to the relative growth rates for health care service costs versus taxable payroll. For the 75-year period, the cost rate increases from 4.77 percent (for an annual cost/payroll growth rate of 1 percentage point less than the intermediate assumptions) to 10.50 percent (for an annual cost/payroll growth rate of 1 percentage point more than the intermediate assumptions). Each 1.0-percentage-point increase in the assumed cost/payroll relative growth rate decreases the long-range actuarial balance, on average, by about 2.87 percent of taxable payroll. 
SMI Financial Status

\section{SMI FINANCIAL STATUS}

\section{Total SMI}

The Federal Supplementary Medical Insurance Trust Fund was established on July 30,1965 as a separate account in the U.S. Treasury. All the financial operations of SMI are handled through this fund. Beginning in 2004, the trust fund consists of two separate accounts-one for Part B and one for Part D. The purpose of the two accounts is to ensure that funds from one part are not used to finance the other.

In order to evaluate the financial status of the SMI trust fund, each account needs to be assessed individually, since the financing rates for each part are established separately, their program benefits are quite different in nature, and there is no provision for transferring assets. Sections III.C2 and III.C3 will discuss the financial status of Parts B and D individually. The purpose of this section is to present the expected operations of the SMI trust fund in total, combining the expected operations for Parts B and D, and to discuss the implications of continuing rapid SMI cost growth. It is important to note that projected SMI expenditures are substantially understated because projected physician payment updates are unrealistically reduced under the current-law sustainable growth rate system. Despite the extremely low probability of the current-law physician updates actually occurring, these understated benefit expenditure estimates and associated financing are a result of current law, which is assumed to be unchanged throughout the projections. ${ }^{30}$

\section{a. 10-Year Actuarial Estimates (2007-2016)}

Future operations of the SMI trust fund are projected using the Trustees' economic and demographic assumptions, as detailed in the OASDI Trustees Report, as well as other assumptions unique to SMI. Section IV.B presents an explanation of the effects of the Trustees' intermediate assumptions, and of the other assumptions unique to SMI, on the estimates in this report. In addition, although Part B financing rates have been set only through December 31,2007, it is assumed that financing for future periods will be determined

\footnotetext{
${ }^{30}$ Part B projections under illustrative alternatives to the current sustainable growth rate system are shown on the CMS website at http://www.cms.hhs.gov/ ReportsTrustFunds/05_alternativePartB.asp. No endorsement of these alternatives by the Board of Trustees, CMS, or the Office of the Actuary should be inferred.
} 


\section{Actuarial Analysis}

according to the statutory provisions described in section III.C2 for Part B and section III.C3 for Part D.

Table III.C1 shows the estimated operations of the SMI trust fund under the intermediate assumptions on a calendar-year basis through 2016. The estimates are based on current law, including physician payment updates of -10 percent in 2008 and -5 percent in each of the years 2009 through 2016. This table combines the operations of the Part B and Part D accounts to present the expected operations of the trust fund in total.

\begin{tabular}{|c|c|c|c|c|c|c|c|c|c|c|}
\hline \multirow[b]{2}{*}{$\begin{array}{c}\text { Calendar } \\
\text { year }\end{array}$} & \multicolumn{5}{|c|}{ Income } & \multicolumn{3}{|c|}{ Expenditures } & \multicolumn{2}{|c|}{ Trust fund } \\
\hline & $\begin{array}{c}\text { Premium } \\
\text { income }^{1}\end{array}$ & $\begin{array}{l}\text { General } \\
\text { revenue }^{2}\end{array}$ & $\begin{array}{c}\text { Transfers } \\
\text { from } \\
\text { States } \\
\end{array}$ & $\begin{array}{c}\text { Interest } \\
\text { and } \\
\text { other }^{3,4}\end{array}$ & Total & $\begin{array}{c}\text { Benefit } \\
\text { payments }\end{array}$ & $\begin{array}{c}\text { Adminis- } \\
\text { trative } \\
\text { expense }\end{array}$ & Total & $\begin{array}{c}\text { Net } \\
\text { change }\end{array}$ & $\begin{array}{c}\text { Balance } \\
\text { at end of } \\
\text { year }^{6}\end{array}$ \\
\hline \multicolumn{11}{|c|}{ Historical data: } \\
\hline 1970 & $\$ 1.1$ & $\$ 1.1$ & - & $\$ 0.0$ & $\$ 2.2$ & $\$ 2.0$ & $\$ 0.2$ & $\$ 2.2$ & $-\$ 0.0$ & $\$ 0.2$ \\
\hline 1975 & 1.9 & 2.6 & - & 0.1 & 4.7 & 4.3 & 0.5 & 4.7 & -0.1 & 1.4 \\
\hline 1980 & 3.0 & 7.5 & - & 0.4 & 10.9 & 10.6 & 0.6 & 11.2 & -0.4 & 4.5 \\
\hline 1985 & 5.6 & 18.3 & - & 1.2 & 25.1 & 22.9 & 0.9 & 23.9 & 1.2 & 10.9 \\
\hline 1990 & 11.3 & 33.0 & - & 1.6 & 45.9 & 42.5 & 1.5 & 44.0 & 1.9 & 15.5 \\
\hline 1995 & 19.7 & 39.0 & - & 1.6 & 60.3 & 65.0 & 1.6 & 66.6 & -6.3 & 13.1 \\
\hline 2000 & 20.6 & 65.9 & - & 3.4 & 89.9 & $88.9^{8}$ & 1.8 & 90.7 & -0.8 & 44.0 \\
\hline 2001 & 22.8 & 72.8 & - & 3.1 & 98.6 & $99.7^{8}$ & 1.7 & 101.4 & -2.8 & 41.3 \\
\hline 2002 & 25.1 & 78.3 & - & 2.8 & 106.2 & $111.0^{8}$ & 2.2 & 113.2 & -7.0 & 34.3 \\
\hline 2003 & 27.4 & 86.4 & - & 2.0 & 115.8 & $123.8^{8}$ & 2.3 & 126.1 & -10.3 & 24.0 \\
\hline 2004 & 31.4 & 100.9 & - & 1.5 & 133.8 & 135.4 & 2.9 & 138.3 & -4.5 & 19.4 \\
\hline 2005 & 37.5 & 119.2 & - & 1.4 & 158.1 & 150.3 & 3.2 & 153.5 & 4.6 & 24.0 \\
\hline 2006 & 46.3 & 171.9 & $\$ 5.5$ & 1.8 & 225.5 & 213.0 & 3.4 & 216.4 & 9.1 & 33.1 \\
\hline \multicolumn{11}{|c|}{ Intermediate estimates: } \\
\hline 2007 & 51.0 & 178.4 & 6.6 & 2.1 & 238.1 & 225.9 & 3.8 & 229.7 & 8.4 & 41.5 \\
\hline 2008 & 55.8 & 194.8 & 6.9 & 2.6 & 260.2 & 248.7 & 4.0 & 252.6 & 7.5 & 49.0 \\
\hline 2009 & $64.5^{7}$ & $218.2^{7}$ & 7.4 & 3.0 & 293.1 & 268.3 & 4.1 & 272.4 & 20.7 & 69.7 \\
\hline 2010 & $60.5^{7}$ & $207.9^{7}$ & 8.0 & 3.2 & 279.6 & 290.5 & 4.2 & 294.7 & -15.1 & 54.6 \\
\hline 2011 & 71.0 & 238.5 & 8.6 & 3.5 & 321.6 & 313.9 & 4.4 & 318.3 & 3.3 & 57.9 \\
\hline 2012 & 77.3 & 259.6 & 9.3 & 3.7 & 350.0 & 341.2 & 4.5 & 345.7 & 4.3 & 62.1 \\
\hline 2013 & 83.5 & 280.4 & 10.2 & 4.0 & 378.1 & 368.8 & 4.7 & 373.5 & 4.6 & 66.7 \\
\hline 2014 & 90.0 & 304.0 & 11.2 & 4.3 & 409.5 & 399.9 & 4.9 & 404.7 & 4.8 & 71.5 \\
\hline 2015 & $104.3^{7}$ & $350.0^{7}$ & 12.2 & 4.6 & 471.1 & 433.7 & 5.0 & 438.7 & 32.3 & 103.8 \\
\hline 2016 & $98.3^{7}$ & $339.3^{7}$ & 13.6 & 4.9 & 456.1 & 472.0 & 5.2 & 477.2 & -21.1 & 82.8 \\
\hline
\end{tabular}

${ }^{1}$ Premiums for Part D include amounts withheld from Social Security benefit checks or other Federal payments, as well as premiums paid directly to Part D plans by enrollees.

${ }^{2}$ Includes Part B general fund matching payments, Part D subsidy costs, and certain interest-adjustment items.

${ }^{3}$ Other income includes recoveries of amounts reimbursed from the trust fund that are not obligations of the trust fund and other miscellaneous income.

${ }^{4}$ See footnote 2 of table III.B4.

${ }^{5}$ Includes costs of Peer Review Organizations from 1983 through 2001, and costs of Quality Improvement Organizations beginning in 2002. Values after 2005 include additional premiums collected from beneficiaries and transferred to managed care plans, in which the monthly plan cost exceeds the benchmark amount, and Part D drug premiums to Medicare Advantage plans and private drug plans.

${ }^{6}$ The financial status of SMI depends on both the assets and the liabilities of the trust fund (see table III.C12).

${ }^{7}$ Section 708 of the Social Security Act modifies the provisions for the delivery of Social Security benefit checks when the regularly designated day falls on a Saturday, Sunday, or legal public holiday. Delivery 
of benefit checks normally due January 3, 1999 occurred on December 31, 1998. Consequently, the Part B premiums withheld from the checks ( $\$ 1.5$ billion) and the associated general revenue contributions ( $\$ 4.7$ billion) were added to the SMI trust fund on December 31, 1998. These amounts are excluded from the premium income and general revenue income for 1999. January 3, 2010 will fall on a Sunday, and therefore the delivery of the Social Security checks is expected to occur on December 31, 2009. Likewise, January 3, 2016 will fall on a Sunday, and therefore the delivery of the Social Security checks is expected to occur on December 31, 2015.

${ }^{8}$ Benefit payments less monies transferred from the $\mathrm{HI}$ trust fund for home health agency costs, as provided for by the Balanced Budget Act of 1997.

Note: Totals do not necessarily equal the sums of rounded components.

\section{b. 75-Year Actuarial Estimates (2007-2081)}

Table III.C2 shows the estimated SMI incurred expenditures under the intermediate assumptions expressed as a percentage of GDP, for selected years over the calendar-year period 2006-2080. As noted, these current-law costs are understated, possibly by 15 to 25 percent after 2030, depending on what action Congress takes to address the substantial physician payment reductions required under current law. The 75-year projection period fully allows for the presentation of future trends that may reasonably be expected to occur, such as the impact of the large increase in enrollees after 2010 when the baby boom generation will reach eligibility age and begin to receive benefits.

\begin{tabular}{cc}
$\begin{array}{c}\text { Table III.C2.-SMI Expenditures (Incurred Basis) as a Percentage } \\
\text { of the Gross Domestic Product }\end{array}$ \\
\hline Calendar year & \multicolumn{1}{c}{ SMl expenditures as a percentage of GDP } \\
\hline 2006 & $1.64 \%$ \\
2007 & 1.70 \\
2008 & 1.74 \\
2009 & 1.78 \\
2010 & 1.83 \\
2011 & 1.89 \\
2012 & 1.95 \\
2013 & 2.02 \\
2014 & 2.10 \\
2015 & 2.17 \\
2020 & 2.64 \\
2025 & 3.20 \\
2030 & 3.75 \\
2035 & 4.19 \\
2040 & 4.53 \\
2045 & 4.80 \\
2050 & 5.05 \\
2055 & 5.31 \\
2060 & 5.58 \\
2065 & 5.82 \\
2070 & 6.00 \\
2075 & 6.15 \\
2080 & 6.29 \\
\hline
\end{tabular}




\section{Actuarial Analysis}

\section{c. Implications of SMI Cost Growth}

The SMI trust fund is adequately financed because beneficiary premiums and general revenue contributions, for both Part B and Part D, are established annually to cover the expected costs for the upcoming year. Should actual costs exceed those anticipated when the financing is determined, future rates can include adjustments to recover the shortfall. Likewise, should actual costs be less than those anticipated, the savings would be passed along in lower future rates. As long as the financing rates are reasonably set, both parts of the SMI trust fund will remain financially solvent under current law.

However, a critical issue for the SMI program is the impact of the rapid growth of SMI costs, which places steadily increasing demands on beneficiaries and taxpayers. This section compares the past and projected growth in SMI costs with GDP growth and assesses the implications of the rapid growth on beneficiaries and the budget of the Federal Government. These implications are significantly understated because projected physician payment updates are unrealistically reduced under the current-law sustainable growth rate system.

Table III.C3 compares the growth in SMI expenditures with that of the economy as a whole. Based on our current-law estimates, SMI costs will continue to outpace growth in GDP. Compared to the last 10 years, the growth differential in the next 25 years is generally estimated to be somewhat slower, reflecting the net effects of (i) the increase in the SMI population as the baby boom generation turns age 65, enrolls, and is eligible to receive benefits, (ii) the faster growth trend associated with the new Part D prescription drug benefit, and (iii) the negative physician payment updates that would occur under current law during 2008-2016. The introduction of the full drug benefit in 2006 caused a one-time very large increase in the growth rate. 
SMI Financial Status

\begin{tabular}{|c|c|c|c|c|c|c|c|}
\hline \multirow[b]{2}{*}{$\begin{array}{c}\text { Calendar } \\
\text { years }\end{array}$} & \multicolumn{3}{|c|}{ SMI } & \multicolumn{3}{|c|}{ U.S. Economy } & \multirow[b]{2}{*}{$\begin{array}{c}\text { Growth } \\
\text { differential }^{1}\end{array}$} \\
\hline & $\begin{array}{l}\text { Beneficiary } \\
\text { population }\end{array}$ & $\begin{array}{c}\text { Per capita } \\
\text { expenditures }\end{array}$ & $\begin{array}{c}\text { Total } \\
\text { expenditures }\end{array}$ & $\begin{array}{c}\text { Total } \\
\text { population } \\
\end{array}$ & $\begin{array}{l}\text { Per capita } \\
\text { GDP }\end{array}$ & Total GDP & \\
\hline \multicolumn{8}{|c|}{ Historical data: } \\
\hline 1968-1986 & 2.8 & 13.8 & 17.0 & 1.0 & 8.2 & 9.2 & 7.1 \\
\hline $1986-1996$ & 1.7 & 8.0 & 9.8 & 1.1 & 4.7 & 5.8 & 3.8 \\
\hline $1996-2006$ & 1.1 & $10.7^{2}$ & $11.9^{2}$ & 1.0 & 4.4 & 5.4 & $6.2^{2}$ \\
\hline \multicolumn{8}{|c|}{ Intermediate estimates: } \\
\hline 2007-2016 & 2.3 & 5.8 & 8.2 & 0.8 & 4.0 & 4.8 & 3.2 \\
\hline $2017-2031$ & 2.5 & 5.6 & 8.3 & 0.6 & 3.8 & 4.5 & 3.6 \\
\hline $2032-2056$ & 0.7 & 5.1 & 5.8 & 0.4 & 4.1 & 4.4 & 1.3 \\
\hline $2057-2081$ & 0.6 & 4.5 & 5.1 & 0.3 & 4.1 & 4.4 & 0.7 \\
\hline
\end{tabular}

Since SMI per capita benefits are expected to continue to grow faster than per capita GDP, the premiums and coinsurance amounts paid by beneficiaries would generally represent a growing share of their total income. Figure III.C1 compares past and projected growth in average benefits for SMI versus Social Security. Amounts are also shown for the average SMI premium payments and average cost-sharing payments. (Each of these SMI amounts increased in 2006 with the introduction of the Part D prescription drug benefit, as discussed below.) To facilitate comparison across long time periods, all values are shown in constant 2006 dollars.

Over time, the average Social Security benefit tends to increase at about the rate of growth in average earnings. As noted previously, health care costs generally reflect increases in the earnings of health care professionals, other medical cost inflation, and growth in the utilization and intensity of services. As indicated in figure III.C1, average SMI benefits in 1970 were only about one-twelfth the level of average Social Security benefits but had grown to more than one-third by 2005 . Under the intermediate projections, SMI benefits would continue increasing at a faster rate and would exceed the average Social Security retired worker benefit after 2052 .

Average beneficiary premiums and cost-sharing payments for SMI will increase at about the same rate as average SMI benefits. ${ }^{31}$ Thus, a growing proportion of beneficiaries' Social Security and other income would generally be required over time to pay total out-ofpocket costs for SMI, including both premiums and cost-sharing

\footnotetext{
${ }^{31} \mathrm{As}$ a result, the ratio of average SMI out-of-pocket payments to average SMI benefits is projected to be nearly constant over time.
} 


\section{Actuarial Analysis}

amounts. Most SMI enrollees have other income in addition to Social Security benefits. Other possible sources include earnings from employment, employer-sponsored pension benefits, and investment earnings. For simplicity, the comparisons in figure III.C1 are relative to Social Security benefits only; a comparison of average SMI premiums and cost-sharing amounts to average total beneficiary income would lead to similar conclusions. For illustration, the average Part B plus Part D premium in 2010 is estimated to equal 12 percent of the average Social Security benefit but would increase to an estimated 28 percent in 2080. Similarly, an average costsharing amount in 2010 would be equivalent to 18 percent of the Social Security benefit, increasing to 44 percent in 2080 .

It is important to note that the availability of SMI Part B and Part D benefits greatly reduces the costs that beneficiaries would otherwise face for health care services. The introduction of the prescription drug benefit increased beneficiaries' costs for SMI premiums and cost sharing, but reduced their costs for previously uncovered services by substantially more. The purpose of the illustrations in figure III.C1 is to highlight the impact of rapid cost growth for a given SMI benefit package.

Figure III.C1.-Comparison of Average Monthly SMI Benefits, Premiums, and Cost-Sharing to the Average Monthly Social Security Benefit [Amounts in constant 2006 dollars]

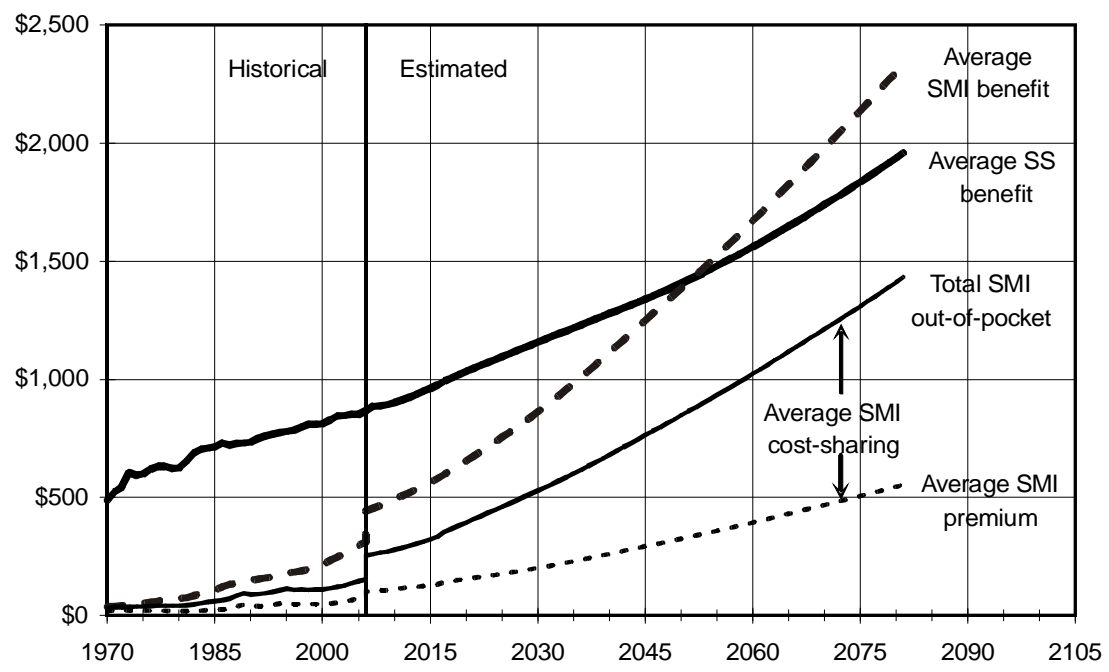

The Social Security benefits shown in figure III.C1 are based on the average OASI benefit amount for all retired workers; individual 
retirees may receive significantly more or less than the average, depending on their past earnings. The value of SMI benefits to individual enrollees, and their cost-sharing payments, varies even more substantially, depending on their income, assets, and use of covered health services in a given year. In particular, Part B premiums and cost-sharing amounts for beneficiaries with very low incomes are paid by Medicaid, and (except for nominal copayments) the corresponding Part D amounts are paid through the Medicare low-income drug subsidy. Moreover, Part B beneficiaries with very high incomes pay a higher income-related premium beginning in 2007. For purposes of illustration, the average SMI benefit value and cost-sharing liability for all beneficiaries are shown. Results for individual beneficiaries can vary substantially from these illustrations. Further information on the nature of this comparison, and on the variations from the illustrative average results, is available at http://www.cms.hhs.gov/ReportsTrustFunds/ 04_Beneficiaryoop.asp.

Another way to evaluate the implications of rapid SMI growth is to compare the government contributions to the SMI trust fund with total Federal income taxes (personal and corporate income taxes). Table III.C4 indicates that SMI general revenues in fiscal year 2006 were equivalent to about 11.4 percent of total Federal income taxes collected in that year, reflecting the addition of the prescription drug benefit. Should such taxes in the future maintain their historical average level of the last 50 years, relative to the national economy, then SMI general revenue financing in 2080 would represent about 41 percent of total income taxes, based on the intermediate projections.

Table III.C4.-SMI General Revenues as a Percentage

of Personal and Corporate Federal Income Taxes

Fiscal year Percentage of income taxes

$\begin{array}{cc}\text { Historical data: } & \\ 1970 & 0.8 \% \\ 1980 & 2.2 \\ 1990 & 5.9 \\ 2000 & 5.4 \\ 2006 & 11.4 \\ & \\ \text { Intermediate estimates: } & 12.4 \\ 2010 & 17.3 \\ 2020 & 24.6 \\ 2030 & 29.8 \\ 2040 & 33.2 \\ 2050 & 36.6 \\ 2060 & 39.4 \\ 2070 & 41.3 \\ 2080 & \end{array}$


Actuarial Analysis

These examples illustrate the significant impact that SMI expenditure growth has had to date on beneficiaries and the Federal Budget. Under current law, the projected SMI expenditure increases associated with the cost of providing health care generally, plus the impact of the baby boom generation reaching eligibility age, would continue to exert growing pressure, despite being understated due to the unrealistic current-law physician payment reductions. This outlook reinforces the Trustees' recommendation for development and enactment of reforms to reduce the rate of growth in SMI expenditures.

\section{Part B Account}

\section{a. Financial Operations in Calendar Year 2006}

A statement of the revenue and expenditures of the Part B account of the SMI trust fund in calendar year 2006, and of its assets at the beginning and end of the fiscal year, is presented in table III.C5. 
Table III.C5.-Statement of Operations of the Part B Account in the SMI Trust Fund during Calendar Year 2006 [In thousands]

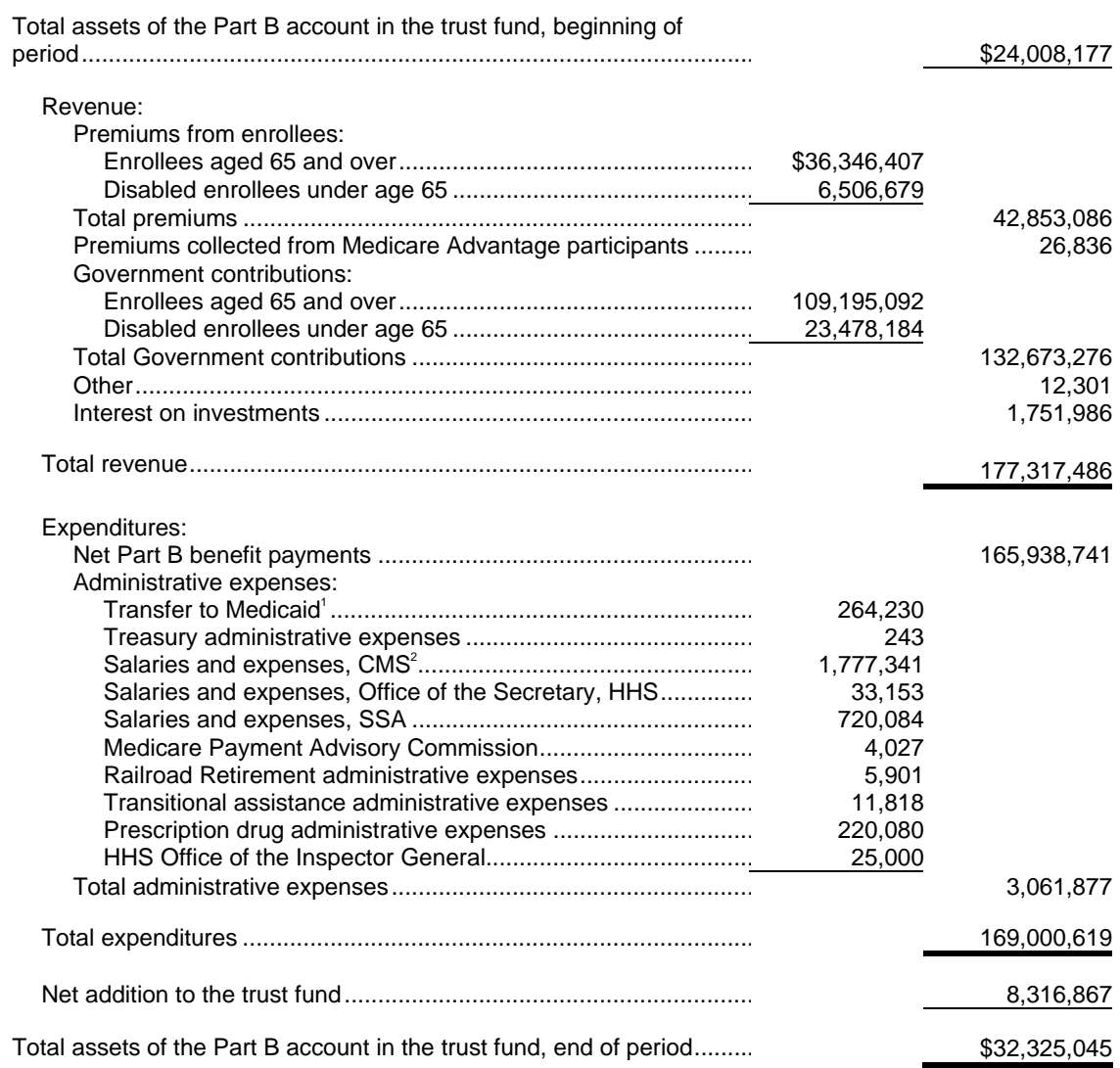

Net addition to the trust fund

Total assets of the Part B account in the trust fund, end of period.........

${ }^{\bar{T}}$ Represents amount transferred from the Part B account in the SMI trust fund to Medicaid to pay the Part B premium for certain qualified individuals, as legislated by the Balanced Budget Act of 1997.

${ }^{2}$ Includes administrative expenses of the carriers and intermediaries.

Note: Totals do not necessarily equal the sums of rounded components.

The total assets of the account amounted to $\$ 24.0$ billion on December 31, 2005. During calendar year 2006, total revenue amounted to $\$ 177.3$ billion, and total expenditures were $\$ 169.0$ billion. Total assets thus increased $\$ 8.3$ billion during the year, to $\$ 32.3$ billion as of December 31, 2006. The increase in assets occurred because the Part $\mathrm{B}$ financing was set to intentionally increase the assets in the Part B account of the SMI trust fund to a more adequate level. The actual increase was lower than intended, because payments to physicians were increased by the Deficit Reduction Act after the calendar year 2006 financing had been determined. 


\section{Actuarial Analysis}

\section{(1) Revenues}

The major sources of revenue for the Part B account are (i) contributions of the Federal Government that are authorized to be appropriated and transferred from the general fund of the Treasury, and (ii) premiums paid by eligible persons who are voluntarily enrolled. Eligible persons aged 65 and over have been able to enroll in Part B since its inception in July 1966. Since July 1973, disabled persons who are under age 65 and who have met certain eligibility requirements have also been able to enroll.

Of the total Part B revenue, $\$ 42.9$ billion represented premium payments by (or on behalf of) aged and disabled enrollees-an increase of 14.2 percent over the amount of $\$ 37.5$ billion for the preceding year. This increase resulted from the growth in the number of persons enrolled in Part B and the 13.2-percent increase in the Part B premium to $\$ 88.50$ for calendar year 2006 .

Premiums paid for fiscal years 1967 through 1973 were matched by an equal amount of government contributions. Beginning July 1973, the amount of government contributions corresponding to premiums paid by each of the two groups of enrollees is determined by applying a "matching ratio," prescribed in the law for each group, to the amount of premiums received from that group. The ratio is equal to (i) twice the monthly actuarial rate applicable to the particular group of enrollees, minus the standard monthly premium rate, divided by (ii) the standard monthly premium rate.

Standard monthly premium rates and actuarial rates are promulgated each year by the Secretary of Health and Human Services. Past monthly premium rates and actuarial rates are shown in table III.C6, together with the corresponding percentages of Part B costs covered by the premium rate. Estimated future premium amounts under the intermediate set of assumptions appear in section V.C. 


\section{SMI Financial Status}

Table III.C6.-Standard Part B Monthly Premium Rates, Actuarial Rates, and Premium Rates as a Percentage of Part B Cost

\begin{tabular}{|c|c|c|c|c|c|}
\hline & & Monthly act & tuarial rate & $\begin{array}{c}\text { Premium ra } \\
\text { percentage of }\end{array}$ & $\begin{array}{l}\text { tes as a } \\
\text { Part B cost }\end{array}$ \\
\hline & $\begin{array}{c}\text { Standard } \\
\text { monthly } \\
\text { premium rate } \\
\end{array}$ & $\begin{array}{c}\text { Enrollees aged } \\
65 \text { and over }\end{array}$ & $\begin{array}{c}\text { Disabled } \\
\text { enrollees under } \\
\text { age } 65\end{array}$ & $\begin{array}{c}\text { Enrollees aged } \\
65 \text { and over }\end{array}$ & $\begin{array}{c}\text { Disabled } \\
\text { enrollees } \\
\text { under age } 65\end{array}$ \\
\hline July 1966-March 1968 & $\$ 3.00$ & - & - & $50.0 \%$ & - \\
\hline April 1968-June 1970 & 4.00 & - & - & 50.0 & - \\
\hline $\begin{array}{c}12-\text { month period ending Jur } \\
1971 \\
1972 \\
1973 \\
1974^{2} \\
1975 \\
1976 \\
1977 \\
1978 \\
1979 \\
1980 \\
1981 \\
1982 \\
1983\end{array}$ & $\begin{array}{r}\text { ne } 30 \text { of } \\
5.30 \\
5.60 \\
5.80 \\
6.30 \\
6.70 \\
6.70 \\
7.20 \\
7.70 \\
8.20 \\
8.70 \\
9.60 \\
11.00 \\
12.20\end{array}$ & $\begin{array}{r}- \\
- \\
\$ 6.30 \\
6.70 \\
7.50 \\
10.70 \\
12.30 \\
13.40 \\
13.40 \\
16.30 \\
22.60 \\
24.60\end{array}$ & $\begin{array}{r}- \\
- \\
\$ 14.50 \\
18.00 \\
18.50 \\
19.00 \\
25.00 \\
25.00 \\
25.00 \\
25.50 \\
36.60 \\
42.10\end{array}$ & $\begin{array}{l}50.0 \\
50.0 \\
50.0 \\
50.0 \\
50.0 \\
44.7 \\
33.6 \\
31.3 \\
30.6 \\
32.5 \\
29.4 \\
24.3 \\
24.8\end{array}$ & $\begin{array}{l}- \\
- \\
21.7 \% \\
18.6 \\
18.1 \\
18.9 \\
15.4 \\
16.4 \\
17.4 \\
18.8 \\
15.0 \\
14.5\end{array}$ \\
\hline July 1983-December 1983 & 12.20 & 27.00 & 46.10 & 22.6 & 13.2 \\
\hline $\begin{array}{c}\text { Calendar year } \\
1984 \\
1985 \\
1986 \\
1987 \\
1988 \\
1989 \\
1990 \\
1991 \\
1992 \\
1993 \\
1994 \\
1995 \\
1996 \\
1997 \\
1998 \\
1999 \\
2000 \\
2001 \\
2002 \\
2003 \\
2004 \\
2005 \\
2006 \\
2007\end{array}$ & $\begin{array}{l}14.60 \\
15.50 \\
15.50 \\
17.90 \\
24.80 \\
31.90^{3} \\
28.60 \\
29.90 \\
31.80 \\
36.60 \\
41.10 \\
46.10 \\
42.50 \\
43.80 \\
43.80 \\
45.50 \\
45.50 \\
50.00 \\
54.00 \\
58.70 \\
66.60 \\
78.20 \\
88.50 \\
93.50\end{array}$ & $\begin{array}{r}29.20 \\
31.00 \\
31.00 \\
35.80 \\
49.60 \\
55.80 \\
57.20 \\
62.60 \\
60.80 \\
70.50 \\
61.80 \\
73.10 \\
84.90 \\
87.60 \\
87.90 \\
92.30 \\
91.90 \\
101.00 \\
109.30 \\
118.70 \\
133.20 \\
156.40 \\
176.90 \\
187.00\end{array}$ & $\begin{array}{r}54.30 \\
52.70 \\
40.80 \\
53.00 \\
48.60 \\
34.30 \\
44.10 \\
56.00 \\
80.80 \\
82.90 \\
76.10 \\
105.80 \\
105.10 \\
110.40 \\
97.10 \\
103.00 \\
121.10 \\
132.20 \\
123.10 \\
141.00 \\
175.50 \\
191.80 \\
203.70 \\
197.30\end{array}$ & $\begin{array}{l}25.0 \\
25.0 \\
25.0 \\
25.0 \\
25.0 \\
25.0^{4} \\
25.0 \\
23.9 \\
26.2 \\
26.0 \\
33.3 \\
31.5 \\
25.0 \\
25.0 \\
24.9 \\
24.6 \\
24.8 \\
24.8 \\
24.7 \\
24.7 \\
25.0 \\
25.0 \\
25.0 \\
25.0\end{array}$ & $\begin{array}{l}13.4 \\
14.7 \\
19.0 \\
16.9 \\
25.5 \\
40.7^{4} \\
32.4 \\
26.7 \\
19.7 \\
22.1 \\
27.0 \\
21.8 \\
20.2 \\
19.8 \\
22.6 \\
22.1 \\
18.8 \\
18.9 \\
21.9 \\
20.8 \\
19.0 \\
20.4 \\
21.7 \\
23.7\end{array}$ \\
\hline $\begin{array}{l}\text { 'The amount shown for eacl } \\
\text { Part B enrollees. It does no } \\
\text { the income-related monthly } \\
2007 \text {, and the premium su } \\
\text { reflect a reduction in premic } \\
\text { amounts are described in m } \\
{ }^{2} \text { In accordance with limitati } \\
\text { Stabilization program, the } \\
\$ 6.10 \text {, respectively. Effectiv } \\
{ }^{3} \text { This rate includes the } \$ 4.0 \\
\text { under the Medicare Catastr } \\
{ }^{4} \text { The premium rates as a pe } \\
\text { portion of the standard mon }\end{array}$ & $\begin{array}{l}\text { hear represer } \\
\text { t reflect other a } \\
\text { adjustment an } \\
\text { rcharge to be } \\
\text { um for benefici } \\
\text { tore detail in se } \\
\text { ions on the co } \\
\text { standard prem } \\
\text { e September } 1 \\
00 \text { catastrophic } \\
\text { ophic Coverag } \\
\text { ercentage of Pa } \\
\text { thly premium ra }\end{array}$ & $\begin{array}{l}\text { nts the standard } \\
\text { amounts that cert } \\
\text { mount to be paid } \\
\text { paid by benefici } \\
\text { iaries who are af } \\
\text { ection V.C. } \\
\text { sts of health car } \\
\text { ium rates for J } \\
973 \text {, the rate inc } \\
\text { coverage montl } \\
\text { e Act of } 1988 \text { (su } \\
\text { art B cost for cale } \\
\text { ate. }\end{array}$ & $\begin{array}{l}\text { Part B premium } \\
\text { tain beneficiaries } \\
\text { by beneficiaries } \\
\text { iaries who enroll } \\
\text { ffected by the ho } \\
\text { re imposed unde } \\
\text { uly and August } \\
\text { reased to } \$ 6.30 \text {. } \\
\text { hly premium that } \\
\text { ubsequently repe } \\
\text { endar year } 1989\end{array}$ & $\begin{array}{l}\text { paid by, or on be } \\
\text { are required to } \\
\text { with high incom } \\
\text { late. In addition } \\
\text { Id-harmless prov } \\
\text { r Phase III of th } \\
1973 \text { were set a } \\
\text { was paid by mc } \\
\text { aled). } \\
\text { apply to the non }\end{array}$ & $\begin{array}{l}\text { half of, most } \\
\text { pay, such as } \\
\text { ie, starting in } \\
\text {, it does not } \\
\text { vision. These } \\
\text { he Economic } \\
\text { at } \$ 5.80 \text { and } \\
\text { ost enrollees } \\
\text {-catastrophic }\end{array}$ \\
\hline
\end{tabular}




\section{Actuarial Analysis}

Figure III.C2 is a graphical representation of the monthly per capita financing rates, for financing periods since 1983, for enrollees aged 65 and over and for disabled individuals under age 65 . The graph shows the portion of the financing contributed by the beneficiaries and by general revenues. As indicated, general revenue financing is the largest income source for Part B.

Figure III.C2.-Part B Aged and Disabled Monthly Per Capita Trust Fund Income

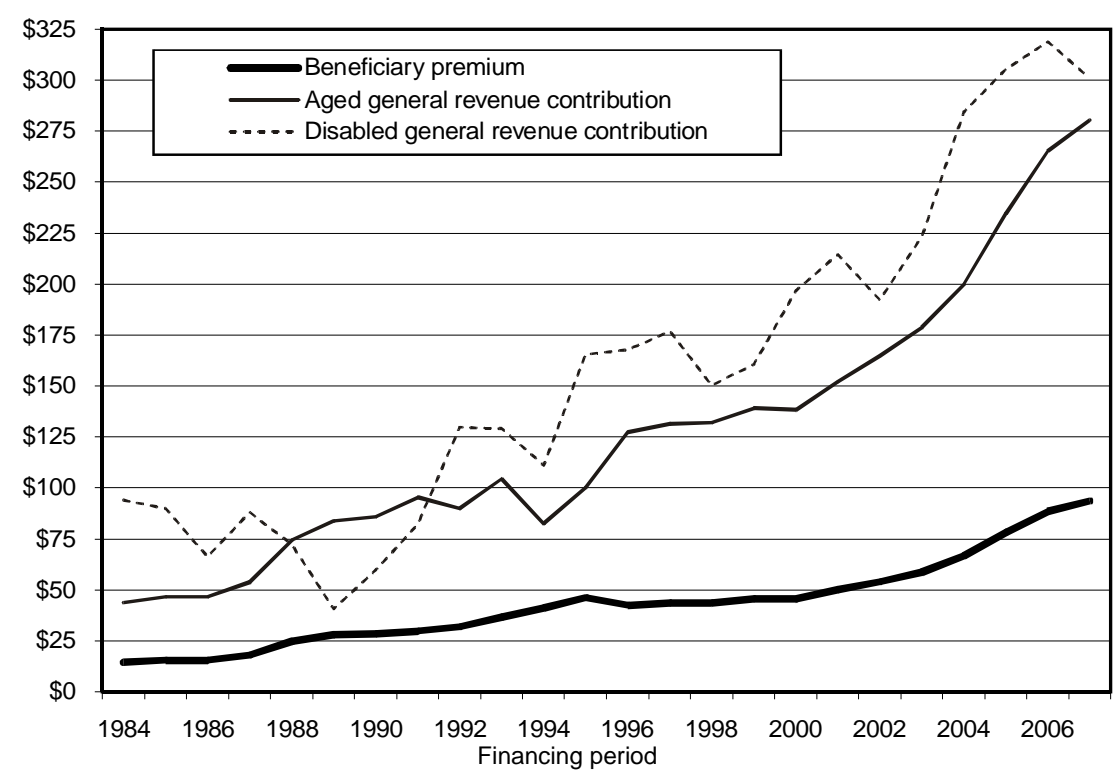

Note: The amounts shown do not include the catastrophic coverage monthly premium rate for 1989.

In calendar year 2006, contributions received from the general fund of the Treasury amounted to $\$ 132.7$ billion, which accounted for 74.8 percent of total revenue.

Another source of Part $B$ revenue is interest received on investments held by the Part B account. The investment procedures of the Part B account are described later in this section. In calendar year 2006, $\$ 1.8$ billion of revenue consisted almost entirely of interest on the investments of the account.

The Managing Trustee may accept and deposit in the Part B account unconditional money gifts or bequests made for the benefit of the fund. Contributions in the amount of $\$ 12$ million were made in calendar year 2006. 


\section{(2) Expenditures}

Expenditures for Part B benefit payments and administrative expenses are paid out of the account. All expenses incurred by the Department of Health and Human Services, the Social Security Administration, and the Department of the Treasury in administering Part B are charged to the account. Such administrative duties include payment of benefits, the fraud and abuse control activities, and experiments and demonstration projects designed to determine various methods of increasing efficiency and economy in providing health care services, while maintaining the quality of these services.

In addition, Congress has authorized expenditures from the trust funds for construction, rental and lease, or purchase contracts of office buildings and related facilities for use in connection with the administration of Part B. Such costs are included in the account expenditures. The net worth of facilities and other fixed capital assets, however, is not carried in the statement of Part B assets presented in this report, since the value of fixed capital assets does not represent funds available for benefit or administrative expenditures and is not, therefore, pertinent in assessing the actuarial status of the funds.

Of the $\$ 169.0$ billion in total Part B expenditures, $\$ 165.9$ billion represented net benefits paid from the account for health services. ${ }^{32}$ Net benefits increased $\mathbf{1 1 . 2}$ percent over the corresponding amount of $\$ 149.2$ billion paid during the preceding calendar year. This increase reflects (i) the impact of the Deficit Reduction Act, which increased payments to physicians in 2006, and (ii) sizable increases in certain other Part B benefit categories. Additional information on Part B benefits by type of service is available in section IV.B1.

The remaining $\$ 3.1$ billion of expenditures was for administrative expenses made up of (i) the net Part B administrative expenses, after adjustments to the preliminary allocation of administrative costs among the Social Security and Medicare trust funds and the general fund of the Treasury, (ii) the net transitional drug assistance administrative expenses, and (iii) certain other net Part D administrative expenses. The start-up administrative expenses for

\footnotetext{
${ }^{32}$ Net benefits equal the total gross amounts initially paid from the trust fund during the year less recoveries of overpayments identified through fraud and abuse control activities.
} 


\section{Actuarial Analysis}

transitional assistance and Part D are paid out of the Part B account, as specified by the MMA.

(3) Actual experience versus prior estimates

Table III.C7 compares the actual experience in calendar year 2006 with the estimates presented in the 2005 and 2006 annual reports. A number of factors can contribute to differences between estimates and subsequent actual experience. In particular, actual values for key economic and other variables can differ from assumed levels, and legislative and regulatory changes may be adopted after a report's preparation. Table III.C7 indicates that actual Part B benefit payments were higher than estimated in the 2005 report mainly due to the impact of the Deficit Reduction Act of 2005, and lower than estimated in the 2006 report reflecting somewhat lower-thanexpected growth in expenditures in 2006 (11.2 percent versus 14.3 percent). Actual premiums and actual government contributions were nearly identical to those estimated in the 2006 report. Actual premiums and actual government contributions, however, were slightly higher than estimated in the 2005 report because the financing rates for calendar year 2006 had not yet been determined at the time the 2005 report was released.

Table III.C7.-Comparison of Actual and Estimated Operations of the Part B Account in the SMI Trust Fund, Calendar Year 2006 [Dollar amounts in millions]

\begin{tabular}{|c|c|c|c|c|c|}
\hline \multirow[b]{3}{*}{ Item } & \multirow[b]{3}{*}{$\begin{array}{l}\text { Actual } \\
\text { amount }\end{array}$} & \multicolumn{4}{|c|}{$\begin{array}{l}\text { Comparison of actual experience with estimates for } \\
\text { calendar year } 2006 \text { published in: }\end{array}$} \\
\hline & & \multicolumn{2}{|c|}{2006 report } & \multicolumn{2}{|c|}{2005 report } \\
\hline & & $\begin{array}{l}\text { Estimated } \\
\text { amount }^{1}\end{array}$ & $\begin{array}{l}\text { Actual as a } \\
\text { percentage } \\
\text { of estimate }\end{array}$ & $\begin{array}{l}\text { Estimated } \\
\text { amount }^{1}\end{array}$ & $\begin{array}{l}\text { Actual as a } \\
\text { percentage } \\
\text { of estimate }\end{array}$ \\
\hline Premiums from enrollees & $\$ 42,853$ & $\$ 42,987$ & $100 \%$ & $\$ 42,316$ & $101 \%$ \\
\hline Government contributions & 132,673 & 132,771 & 100 & 130,003 & 102 \\
\hline Benefit payments & 165,939 & 170,646 & 97 & 158,279 & 105 \\
\hline
\end{tabular}

"Under the intermediate assumptions.

\section{(4) Assets}

The portion of the Part B account that is not needed to meet current expenditures for benefits and administration is invested in interest-bearing obligations of the U.S. Government.

The Social Security Act authorizes the issuance of special public-debt obligations for purchase exclusively by the account. The law requires that these special public-debt obligations shall bear interest, at a rate based on the average market yield (computed on the basis of market quotations as of the end of the calendar month immediately preceding 
the date of such issue), on all marketable interest-bearing obligations of the United States forming a part of the public debt that are not due or callable until after 4 years from the end of that month. Since the inception of the SMI trust fund, the assets have always been invested in special public-debt obligations..$^{33}$ Table V.F10, presented in appendix F, shows the assets of the Part B account at the end of fiscal years 2005 and 2006 .

\section{b. 10-Year Actuarial Estimates (2007-2016)}

Future operations of the Part B account are projected using the Trustees' economic and demographic assumptions, as detailed in the OASDI Trustees Report, as well as other assumptions unique to Part B. Section IV.B1 presents an explanation of the effects of these assumptions on the estimates in this report. It is also assumed that financing for future periods will be determined according to the statutory provisions described in section III.C2a, although Part B financing rates have been set only through December 31, 2007. In addition, for the benefit expenditure estimates and associated financing, it is assumed that current statutory provisions are maintained, despite the extremely low probability of the current-law physician payment updates actually occurring. As noted, the Part B expenditures are substantially understated because projected current-law physician payment rates are unrealistically reduced under the sustainable growth rate system-by about 10 percent in 2008 and 5 percent in each subsequent year through 2016. In practice, Congress is virtually certain to prevent some or all of these scheduled reductions through new legislation, as it has for 2003 through 2007. Depending on the specific legislated changes, Part B costs and revenues could be about 15 to 25 percent higher in 2016 than shown here under current law.

Table III.C8 shows the estimated operations of the Part B account under the intermediate assumptions on a calendar-year basis through 2016. As noted previously, the estimates for 2008 and later should be interpreted cautiously, given the likelihood of further legislation addressing physician payments.

\footnotetext{
${ }^{33}$ Investments may also be made in obligations guaranteed as to both principal and interest by the United States, including certain federally sponsored agency obligations.
} 


\section{Actuarial Analysis}

\begin{tabular}{|c|c|c|c|c|c|c|c|c|c|}
\hline \multirow[b]{2}{*}{$\begin{array}{c}\text { Calendar } \\
\text { year }\end{array}$} & \multicolumn{4}{|c|}{ Income } & \multicolumn{3}{|c|}{ Expenditures } & \multicolumn{2}{|c|}{ Account } \\
\hline & $\begin{array}{c}\text { Premium } \\
\text { income }\end{array}$ & $\begin{array}{l}\text { General } \\
\text { revenue }^{1}\end{array}$ & $\begin{array}{c}\text { Interest } \\
\text { and other, }\end{array}$ & Total & $\begin{array}{c}\text { Benefit } \\
\text { payments }^{3,4}\end{array}$ & $\begin{array}{l}\text { Adminis- } \\
\text { trative } \\
{ }^{4} \text { expenses }\end{array}$ & Total & $\begin{array}{c}\text { Net } \\
\text { change }\end{array}$ & $\begin{array}{l}\text { Balance } \\
\text { at end } \\
\text { of year }\end{array}$ \\
\hline \multicolumn{10}{|c|}{ Historical data: } \\
\hline 1970 & $\$ 1.1$ & $\$ 1.1$ & $\$ 0.0$ & $\$ 2.2$ & $\$ 2.0$ & $\$ 0.2$ & $\$ 2.2$ & $-\$ 0.0$ & $\$ 0.2$ \\
\hline 1975 & 1.9 & 2.6 & 0.1 & 4.7 & 4.3 & 0.5 & 4.7 & -0.1 & 1.4 \\
\hline 1980 & 3.0 & 7.5 & 0.4 & 10.9 & 10.6 & 0.6 & 11.2 & -0.4 & 4.5 \\
\hline 1985 & 5.6 & 18.3 & 1.2 & 25.1 & 22.9 & 0.9 & 23.9 & 1.2 & 10.9 \\
\hline 1990 & 11.3 & 33.0 & 1.6 & 45.9 & 42.5 & 1.5 & 44.0 & 1.9 & 15.5 \\
\hline 1995 & 19.7 & 39.0 & 1.6 & 60.3 & 65.0 & 1.6 & 66.6 & -6.3 & 13.1 \\
\hline 2000 & 20.6 & 65.9 & 3.4 & 89.9 & $88.9^{7}$ & 1.8 & 90.7 & -0.8 & 44.0 \\
\hline 2001 & 22.8 & 72.8 & 3.1 & 98.6 & $99.7^{7}$ & 1.7 & 101.4 & -2.8 & 41.3 \\
\hline 2002 & 25.1 & 78.3 & 2.8 & 106.2 & $111.0^{7}$ & 2.2 & 113.2 & -7.0 & 34.3 \\
\hline 2003 & 27.4 & 86.4 & 2.0 & 115.8 & $123.8^{7}$ & 2.3 & 126.1 & -10.3 & 24.0 \\
\hline 2004 & 31.4 & 100.4 & 1.5 & 133.3 & 135.0 & 2.9 & 137.9 & -4.5 & 19.4 \\
\hline 2005 & 37.5 & 118.1 & 1.4 & 157.0 & 149.2 & 3.2 & 152.4 & 4.6 & 24.0 \\
\hline 2006 & 42.9 & 132.7 & 1.8 & 177.3 & 165.9 & 3.1 & 169.0 & 8.3 & 32.3 \\
\hline \multicolumn{10}{|c|}{ Intermediate estimates: } \\
\hline 2007 & 46.9 & 138.9 & 2.1 & 188.0 & 176.7 & 3.0 & 179.6 & 8.4 & 40.7 \\
\hline 2008 & 50.3 & 145.4 & 2.6 & 198.3 & 187.7 & 3.1 & 190.8 & 7.5 & 48.2 \\
\hline 2009 & $57.4^{6}$ & $163.2^{6}$ & 3.0 & 223.5 & 199.6 & 3.2 & 202.9 & 20.7 & 68.8 \\
\hline 2010 & $51.5^{6}$ & $146.2^{6}$ & 3.2 & 201.0 & 212.8 & 3.4 & 216.1 & -15.2 & 53.7 \\
\hline 2011 & 59.7 & 169.3 & 3.4 & 232.5 & 225.8 & 3.5 & 229.3 & 3.2 & 56.9 \\
\hline 2012 & 63.8 & 181.1 & 3.7 & 248.6 & 240.8 & 3.6 & 244.4 & 4.2 & 61.1 \\
\hline 2013 & 68.3 & 193.8 & 4.0 & 266.1 & 257.8 & 3.8 & 261.6 & 4.5 & 65.6 \\
\hline 2014 & 73.1 & 207.3 & 4.3 & 284.7 & 276.0 & 3.9 & 279.9 & 4.7 & 70.3 \\
\hline 2015 & $85.4^{6}$ & $241.8^{6}$ & 4.6 & 331.8 & 295.4 & 4.1 & 299.5 & 32.3 & 102.5 \\
\hline 2016 & $77.2^{6}$ & $218.3^{6}$ & 4.9 & 300.4 & 317.3 & 4.2 & 321.6 & -21.2 & 81.4 \\
\hline
\end{tabular}

${ }^{1}$ General fund matching payments, plus certain interest-adjustment items.

${ }^{2}$ Other income includes recoveries of amounts reimbursed from the trust fund that are not obligations of the trust fund and other miscellaneous income.

${ }^{3}$ See footnote 2 of table III.B4.

${ }^{4}$ Includes costs of Peer Review Organizations from 1983 through 2001, and costs of Quality Improvement Organizations beginning in 2002

${ }^{5}$ The financial status of Part B depends on both the assets and the liabilities of the trust fund (see table III.C12).

${ }^{6}$ Section 708 of the Social Security Act modifies the provisions for the delivery of Social Security benefit checks when the regularly designated day falls on a Saturday, Sunday, or legal public holiday. Delivery of benefit checks normally due January 3, 2010 will occur on December 31, 2009. Consequently, the Part B premiums withheld from the checks and the associated general revenue contributions will be added to the SMI trust fund on December 31, 2009. Likewise, January 3, 2016 will fall on a Sunday, and therefore delivery of the majority of Social Security checks is expected to occur on December 31, 2015.

${ }^{7}$ Benefit payments less monies transferred from the HI trust fund for home health agency costs, as provided for by the Balanced Budget Act of 1997.

Note: Totals do not necessarily equal the sums of rounded components.

As shown in table III.C8, the account is estimated to increase during 2007 to an estimated $\$ 40.7$ billion by the end of the year. The beneficiary premiums and actuarial rates for calendar year 2007 were promulgated with specific margins to increase the size of the Part B account. However, actual program expenditures for calendar year 2006 were higher than expected, at the time the financing was set, producing a higher projection base for estimating 2007 expenditures. In addition, the Tax Relief and Health Care Act raised the physician 
payment update to 0.0 percent for 2007 after the financing rates had been determined for 2007. (In the absence of this legislation, the update would have been -5.0 percent.) The legislation and higher projection base result in a smaller-than-targeted projected increase in the account in 2007.

Actual deficits in the Part B account in 2003 and 2004 drew down account assets to a level that is well below the range preferred for contingency purposes. As a result, beneficiary premiums and matching general revenue financing were increased substantially for 2005, 2006, and 2007. For 2008, the projections are based on an assumed physician payment update of -9.9 percent, as would be required under current law, and a 4.5-percent increase in income. Accordingly, the account is projected to increase to $\$ 48.2$ billion by the end of 2008, with the inclusion of a relatively small additional financing margin to restore contingency reserves to the preferred level. After 2008, the financing margins are set in such a way that the account assets will increase with the estimated expenditures plus a margin, so that the preferred contingency level will be maintained. For 2008, however, should legislation to prevent the scheduled reduction in physician fees be enacted after the Part $B$ financing is established for the year-as has happened for 4 of the last 5 yearsthen the increase in assets would be much smaller, and the reserve adequacy would remain below the optimal level.

The statutory provisions governing Part B financing have changed over time. Most recently, the Balanced Budget Act of 1997 provided for the permanent establishment of the standard Part B premium at the level of about 25 percent of average expenditures for beneficiaries 65 and over. Figure III.C3 shows historical and projected ratios of premium income to Part B expenditures. 


\section{Actuarial Analysis}

Figure III.C3.-Premium Income as a Percentage of Part B Expenditures



The amount and rate of growth of benefit payments have been a source of some concern for many years. In table III.C9, amounts of payments are considered in the aggregate, on a per capita basis, and relative to the Gross Domestic Product (GDP). Rates of growth are shown historically and for the next 10 years, based on the intermediate estimates under current law, which is likely to change to prevent scheduled reductions in physician fees.

Part B benefit growth has averaged 11.0 percent annually over the past 6 years. During 2006, Part B benefits grew 11.2 percent on an aggregate basis and increased to 1.25 percent of GDP. These large increases arose, in part, due to 18-percent growth in outpatient hospital expenditures in 2006 and nearly 11-percent growth in nonhospital intermediary expenditures. For 2007, benefits are expected to grow 6.5 percent on an aggregate basis and 5.3 percent on a per capita basis, and to increase from 1.25 to 1.27 percent of GDP. 
SMI Financial Status

Table III.C9._Growth in Part B Benefits (Cash Basis) through December 31, 2016

\begin{tabular}{cccccc}
\hline Calendar year & $\begin{array}{c}\text { Aggregate benefits } \\
\text { [billions] }\end{array}$ & $\begin{array}{c}\text { Percent } \\
\text { change }\end{array}$ & $\begin{array}{c}\text { Per capita } \\
\text { benefits }\end{array}$ & $\begin{array}{c}\text { Percent } \\
\text { change }\end{array}$ & $\begin{array}{c}\text { Part B benefits as a } \\
\text { percentage of GDP }\end{array}$ \\
\hline $\begin{array}{c}\text { Historical data: } \\
1970\end{array}$ & & & & & \\
1975 & $\$ 2.0$ & $5.9 \%$ & $\$ 101$ & $3.5 \%$ & $0.19 \%$ \\
1980 & 4.3 & 28.8 & 180 & 24.6 & 0.26 \\
1985 & 10.6 & 22.1 & 390 & 19.3 & 0.38 \\
1990 & 22.9 & 16.7 & 768 & 14.5 & 0.54 \\
1995 & 42.5 & 10.9 & 1,304 & 9.1 & 0.73 \\
2000 & 65.0 & 10.8 & 1,823 & 9.2 & 0.88 \\
2001 & 88.9 & 10.1 & 2,381 & 9.2 & 0.91 \\
2002 & $99.7^{1}$ & 12.1 & 2,646 & 11.1 & 0.98 \\
2003 & 111.0 & 11.3 & 2,922 & 10.4 & 1.06 \\
2004 & $123.8^{1}$ & 11.6 & 3,209 & 9.8 & 1.13 \\
2005 & 135.0 & 9.0 & 3,450 & 7.5 & 1.15 \\
2006 & 149.2 & 10.6 & 3,759 & 9.0 & 1.20 \\
& 165.9 & 11.2 & 4,121 & 9.6 & 1.25 \\
Intermediate & & & & & \\
2007 & 176.7 & 6.5 & 4,338 & 5.3 & 1.27 \\
2008 & 187.7 & 6.2 & 4,524 & 4.3 & 1.29 \\
2009 & 199.6 & 6.4 & 4,720 & 4.3 & 1.30 \\
2010 & 212.8 & 6.6 & 4,942 & 4.7 & 1.32 \\
2011 & 225.8 & 6.1 & 5,143 & 4.1 & 1.34 \\
2012 & 240.8 & 6.6 & 5,340 & 3.8 & 1.36 \\
2013 & 257.8 & 7.1 & 5,556 & 4.0 & 1.39 \\
2014 & 276.0 & 7.0 & 5,787 & 4.2 & 1.42 \\
2015 & 295.4 & 7.0 & 6,029 & 4.2 & 1.45 \\
2016 & 317.3 & 7.4 & 6,303 & 4.5 & 1.49 \\
\hline
\end{tabular}

'See footnote 7 of table III.C8.

The projected growth in Part B benefits slows dramatically during the next 10 years under current law. This is principally because the physician fee schedule payment updates are determined based on the sustainable growth rate system (SGR). The SGR requires that future physician payment increases be adjusted for past actual physician spending relative to a target spending level. The cumulative implications of past physician spending being over the target levels, exacerbated by the physician updates legislated in the Medicare Modernization Act, the Deficit Reduction Act, and the Tax Relief and Health Care Act (TRA), yield projected physician payment updates of about -10 percent for 2008 and about -5 percent annually for at least 8 consecutive years, beginning in 2009. Multiple years of significant reductions in physician payments per service are extremely unlikely to occur before legislative changes intervene, but these payment reductions are required under the current-law SGR system and are included in the physician fee schedule projections. Consequently, the current-law Part B projections shown in this report are expected to substantially understate actual future expenditures in 2008 and later. The degree of understatement depends on the specific actions subsequently taken by Congress but could be 7 to 9 percent in 2010, increasing to roughly 25 to 40 percent for 2030 and later. 


\section{Actuarial Analysis}

Reflecting the recent actual experience and the impact of the TRA, the estimated Part B costs shown in this annual report are lower than those in the 2006 annual report. The costs are projected to be lower throughout the entire 10-year period. Despite the unrealistic statutory reductions to physician payments, Part B costs in the 2007 annual report are expected to continue increasing faster than GDP, as indicated in table III.C9.

Since future economic, demographic, and health care usage and cost experience may vary considerably from the intermediate assumptions on which the preceding cost estimates were based, estimates have also been prepared using two alternative sets of assumptions: low cost and high cost. The estimated operations of the Part B account for all three alternatives are summarized in table III.C10. The assumptions underlying the intermediate assumptions are presented in substantial detail in section IV.B1. The assumptions used in preparing estimates under the low cost and high cost alternatives are also summarized in that section. 
SMI Financial Status

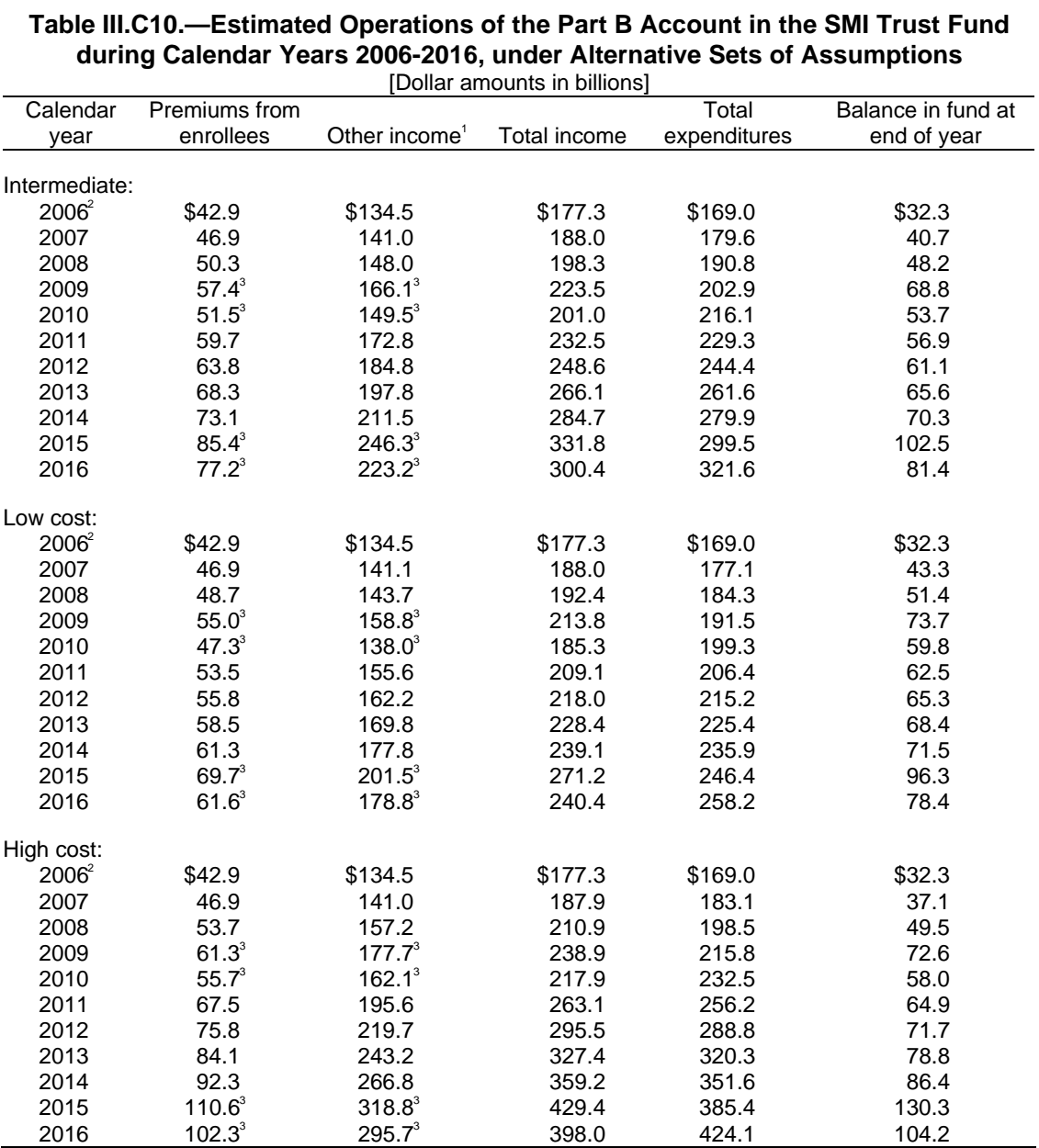

${ }^{1}$ Other income contains government contributions and interest.

${ }^{2}$ Figures for 2006 represent actual experience.

${ }^{3}$ See footnote 6 of table III.C8.

Note: Totals do not necessarily equal the sums of rounded components.

The three sets of assumptions were selected in order to indicate the general range in which the cost might reasonably be expected to fall. The low and high cost alternatives provide for a fairly wide range of possible experience. Actual experience under current law is expected to fall within the range, but no assurance can be given that this will be the case, considering the wide variations in experience that have occurred since Part B began. Although physician fees would be reduced substantially by the SGR system under current law, actual changes in utilization and/or intensity of physician and other Part B services could readily result in current-law costs as high or low as the 


\section{Actuarial Analysis}

alternative projections. Moreover, actual costs could fall outside of this range as a result of new legislation, particularly in light of the very low probability of the current-law physician payment updates actually occurring. In addition to the alternative projections shown here, a supplementary assessment of the possible range of Part B expenditures is shown in section V.D, based on a statistical analysis of past variation in Part B expenditure growth rates.

Part B expenditures are estimated to grow significantly faster than GDP under the intermediate and high cost assumptions. Based on the low cost assumptions, expenditures would increase more slowly than GDP in 2007 through 2015.

The alternative projections shown in table III.C10 illustrate two important aspects of the financial operations of the Part B account:

- Despite the widely differing assumptions underlying the three alternatives, the balance between Part B income and expenditures remains relatively stable. Under the low cost assumptions, for example, by 2016 both income and expenditures would be around 20 percent lower than projected under the intermediate assumptions. The corresponding amounts under the high cost assumptions would be around 30 percent higher than the intermediate estimates.

This result occurs because the premiums and general revenue contributions underlying Part B financing are reestablished annually to match each year's anticipated incurred benefit costs and other expenditures. Thus, Part B income will automatically track Part B expenditures fairly closely, regardless of the specific economic and other conditions.

- As a result of the close matching of income and expenditures described above, projected account assets show stable patterns of change under all three sets of assumptions. The annual adjustment of premiums and general revenue contributions permits the maintenance of a Part B account balance that, while relatively small, is sufficient to guard against chance fluctuations.

It should be noted, however, that continued enactment of legislation to prevent a reduction in physician fees, after financing for a year has been set, jeopardizes the adequacy of Part B assets. Such legislative actions in recent years have contributed to a substantial decline in Part B assets, which, minus corresponding liabilities, in 2004 reached their lowest level relative to annual 
expenditures in nearly 30 years. Efforts to restore assets to a more appropriate level have required premium and general revenue increases of 13.4 percent, 17.4 percent, 13.2 percent, and 5.6 percent in 2004 through 2007 , respectively, with only moderate progress made in increasing asset adequacy.

Adequacy of Part B Financing Established for Calendar Year 2007

The traditional concept of financial adequacy, as it applies to Part B, is closely related to the concept as it applies to many private group insurance plans. Part B is somewhat similar to yearly renewable term insurance, with financing from premium income paid by the enrollees and from income contributed from general revenue by the Federal Government. Consequently, the income during a 12-month period for which financing is being established should be sufficient to cover the costs of services expected to be rendered during that period (including associated administrative costs), even though payment for some of these services will not be made until after the period closes. The portion of income required to cover those benefits not paid until after the end of the year is added to the account. Thus, the assets that are in the account at any time should be no less than the costs of the benefits and the administrative expenses incurred but not yet paid.

Since the income per enrollee (premium plus government contribution) is established prospectively each year, it is subject to projection error. Additionally, legislation enacted after the financing has been established, but effective for the period for which financing has been set, may affect costs. Account assets, therefore, should be maintained at a level that is adequate to cover not only the value of incurred but unpaid expenses but also a reasonable degree of variation between actual and projected costs (in case actual costs exceed projected).

The actuarial status or financial adequacy of the Part B account is traditionally evaluated over the period for which the enrollee premium rates and level of general revenue financing have been established. The primary tests are that (i) the assets and income for years for which financing has been established should be sufficient to meet the projected benefits and associated administrative expenses incurred for that period; and (ii) the assets should be sufficient to cover projected liabilities that have not yet been paid as of the end of the period. If these adequacy tests are not met, Part B can still continue to operate if the account remains at a level adequate to permit the payment of claims as presented. However, to protect 


\section{Actuarial Analysis}

against the possibility that costs will be higher than assumed, assets should be sufficient to include contingency levels that cover a reasonable degree of variation between actual and projected costs.

The traditional tests of asset adequacy described above have been augmented by a supplementary assessment of uncertainty using statistical methods, as shown in section V.D of this report.

As noted above, the tests of financial adequacy for Part B rely on the incurred experience of the account, including a liability for the costs of services performed in a year but not yet paid. Table III.C11 shows the estimated transactions of the account on an incurred basis. The incurred experience must be viewed as an estimate, even for historical years. ${ }^{34}$

\begin{tabular}{|c|c|c|c|c|c|c|c|c|}
\hline \multirow[b]{2}{*}{$\begin{array}{l}\text { Financing } \\
\text { period }\end{array}$} & \multicolumn{4}{|c|}{ Income } & \multicolumn{3}{|c|}{ Expenditures } & \multirow[b]{2}{*}{$\begin{array}{c}\text { Net } \\
\text { operations } \\
\text { in year }\end{array}$} \\
\hline & $\begin{array}{c}\text { Premium } \\
\text { income }\end{array}$ & $\begin{array}{l}\text { General } \\
\text { revenue }\end{array}$ & $\begin{array}{l}\text { Interest } \\
\text { and other }\end{array}$ & Total & $\begin{array}{c}\text { Benefit } \\
\text { payments }\end{array}$ & $\begin{array}{c}\text { Adminis- } \\
\text { trative } \\
\text { expenses }\end{array}$ & Total & \\
\hline \multicolumn{9}{|c|}{ Historical data: } \\
\hline \multicolumn{9}{|c|}{ 12-month period ending June 30 , } \\
\hline 1970 & $\$ 936$ & $\$ 936$ & $\$ 12$ & $\$ 1,884$ & $\$ 1,928$ & $\$ 213$ & $\$ 2,141$ & $-\$ 257$ \\
\hline 1975 & 1,887 & 2,396 & 105 & 4,388 & 3,957 & 438 & 4,395 & -7 \\
\hline 1980 & 2,823 & 6,627 & 421 & 9,871 & 9,840 & 645 & 10,485 & -614 \\
\hline \multicolumn{9}{|c|}{ Calendar year } \\
\hline 1985 & 5,613 & 18,243 & 1,248 & 25,104 & 22,750 & 986 & 23,736 & 1,368 \\
\hline 1990 & 11,320 & 33,035 & 1,558 & 45,913 & 42,578 & 1,541 & 44,119 & 1,794 \\
\hline 1995 & 19,717 & 45,743 & 1,739 & 67,199 & 64,918 & 1,607 & 66,525 & 674 \\
\hline 2000 & 20,555 & 65,898 & 3,450 & 89,903 & $89,757^{1}$ & 1,770 & 91,526 & $-1,623$ \\
\hline 2001 & 22,764 & 72,793 & 3,071 & 98,629 & $100,286^{1}$ & 2,008 & 102,294 & $-3,665$ \\
\hline 2002 & 25,066 & 78,338 & 2,792 & 106,196 & $112,223^{1}$ & 2,196 & 114,419 & $-8,223$ \\
\hline 2003 & 27,402 & 86,402 & 1,992 & 115,796 & $122,094^{1}$ & 2,318 & 124,412 & $-8,616$ \\
\hline 2004 & 31,435 & 100,418 & 1,495 & 133,347 & 136,993 & 2,893 & $139,886^{2}$ & $-6,539$ \\
\hline 2005 & 37,535 & 118,091 & 1,365 & 156,992 & 149,515 & 3,185 & 152,700 & 4,291 \\
\hline 2006 & 42,853 & 132,673 & 1,791 & 177,317 & 166,004 & 3,035 & 169,039 & 8,279 \\
\hline \multicolumn{9}{|c|}{ Intermediate estimates: } \\
\hline 2007 & 46,940 & 138,942 & 2,083 & 187,965 & 178,678 & 2,957 & 181,636 & 6,330 \\
\hline
\end{tabular}

The liability outstanding at any time, for the cost of services performed for which no payment has been made, is referred to as "benefits incurred but unpaid." Estimates of the amount of benefits incurred but unpaid as of the end of each financing period, and of the

${ }^{34}$ Part B experience is substantially more difficult to determine on an incurred basis than on a cash basis. Payment for some services is reported only on a cash basis, and the incurred experience must be inferred from the cash payment information. Moreover, for recent time periods, the tabulations of bills are incomplete due to normal processing time lags. 
administrative expenses related to processing these benefits, appear in table III.C12. In some years, account assets have not been as large as liabilities. Nonetheless, the fund has remained positive, allowing claims to be paid.

Table III.C12.-Summary of Estimated Part B Assets and Liabilities as of the End of the Financing Period, for Periods through December 31, 2007 [Dollar amounts in millions]

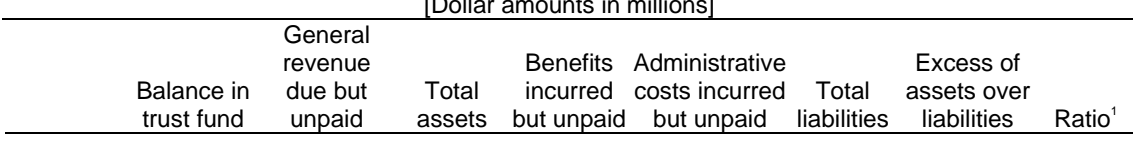

Historical data:

As of June 30,

$\begin{array}{lrrrrrrrr}1970 & \$ 57 & \$ 15 & \$ 72 & \$ 567 & - & \$ 567 & -\$ 495 & -0.21 \% \\ 1975 & 1,424 & 67 & 1,491 & 1,257 & \$ 14 & 1,271 & - & 0.04 \\ 1980 & 4,657 & - & 4,657 & 2,621 & 188 & 2,809 & 1,848 & 0.15\end{array}$

As of December 31 ,

$\begin{array}{lllllllll}1985 & 10,924 & - & 10,924 & 3,142 & -38 & 3,104 & 7,820 & 0.28\end{array}$



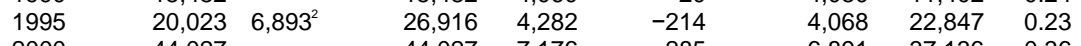

$\begin{array}{lllllllll}2000 & 44,027 & - & 44,027 & 7,176 & -285 & 6,891 & 37,136 & 0.36\end{array}$

$\begin{array}{lllllllll}2001 & 41,889 & 620 & 42,509 & 7,799 & - & 7,799 & 34,711 & 0.30\end{array}$

$\begin{array}{lllllllll}2002 & 34,301 & - & 34,301 & 9,053 & - & 9,053 & 25,248 & 0.20\end{array}$



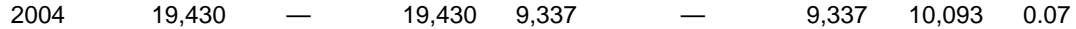

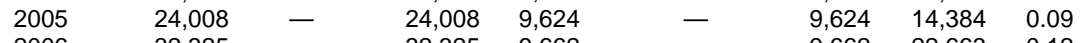

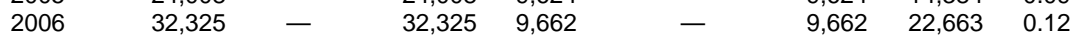

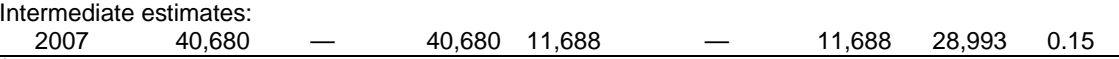

${ }^{1}$ Ratio of the excess of assets over liabilities to the following year's total incurred expenditures.

${ }^{2}$ This amount includes both the principal of $\$ 6,736$ million and the accumulated interest through December 31, 1995 for the shortfall in the fiscal year 1995 appropriation for government contributions. Normally, this transfer would have been made on December 31, 1995 and, therefore, would have been reflected in the trust fund balance. However, due to absence of funding, the transfer of the principal and the appropriate interest was delayed until March 1, 1996.

The amount of assets minus liabilities can be compared with the estimated incurred expenditures for the following calendar year to form a relative measure of the Part B account's financial status. The last column in table III.C12 shows such ratios for past years and the estimated ratio at the end of 2007. Past studies have indicated that a ratio of roughly 15-20 percent is sufficient to protect against unforeseen contingencies, such as unusually large increases in Part B expenditures. At the end of 2006, the Part B reserve ratio was 12 percent, or below normal requirements.

Part B financing has been established through December 31, 2007. The financing for calendar year 2007 was designed with specific margins to increase the excess of assets over liabilities as a percentage of incurred expenditures for the following year. However, actual program expenditures for 2006 were higher than expected at 


\section{Actuarial Analysis}

the time financing was set, producing a higher projection base for estimating 2007 expenditures. In addition, the Tax Relief and Health Care Act (TRA) increased physician payments for 2007 after the financing had been determined. The effects of the TRA, together with the higher projection base, result in estimated 2007 incurred expenditures that are higher than expected when the financing was set. As a result, the calendar year 2007 incurred income is expected to exceed incurred expenditures by $\$ 6.3$ billion, as shown in table III.C11, and the excess of assets over liabilities is expected to increase from $\$ 22.7$ billion at the end of December 2006 to $\$ 29.0$ billion at the end of December 2007, under the intermediate assumptions, as indicated in table III.C12. This excess as a percentage of incurred expenditures for the following year is expected to increase from 12.5 percent as of December 31, 2006 to 15.2 percent as of December 31, 2007. Thus, while the ratio at the end of 2007 is expected to fall within the desired range for the first time since 2002, the TRA and higher-than-anticipated expenditures have again limited the intended growth in the net asset ratio. It should also be noted that the 15.2-percent estimate assumes that physician fees would be reduced by about 10 percent in 2008, as required under current law. If this reduction were overridden by legislation, the Part B reserve ratio would be reduced.

Since the financing rates are set prospectively, the actuarial status of the Part B account could be affected by variations between assumed cost increases and subsequent actual experiences. To test the status of the account under varying assumptions, a lower growth range projection and an upper growth range projection were prepared by varying the key assumptions through the period for which the financing has been set. These two alternative sets of assumptions provide a range of financial outcomes within which the actual experience of Part B might reasonably be expected to fall. The values for the lower and upper growth range assumptions were determined from a statistical analysis of the historical variation in the respective increase factors. Section V.D of this report describes the statistical methodology in more detail and also extends the analysis through 2015.

This sensitivity analysis differs from the low cost and high cost projections discussed previously in this section in that this analysis examines the variation in the projection factors in the period for which the financing has been established (2007 for this report). The low cost and high cost projections, on the other hand, illustrate the 
financial impact of slower or faster growth trends throughout the short-range projection period.

Table III.C13 indicates that, under the lower growth range scenario, account assets would exceed liabilities at the end of December 2007 by a margin equivalent to 20.5 percent of the following year's incurred expenditures. Under the upper growth range scenario, account assets would still exceed liabilities by the end of December 2007, but only by a margin of 9.7 percent of the following year's incurred expenditures. Therefore, under either scenario, assets would be sufficient to cover outstanding liabilities. However, if the higher growth range scenario were actually to materialize, then subsequent financing rates would have to be adjusted upward to a greater degree than already anticipated to increase the excess of assets over liabilities in order to maintain an appropriate contingency level in the account. Figure III.C4 shows this ratio for historical years and for projected years under the intermediate scenario, as well as under the lower growth range (optimistic) and the upper growth range (pessimistic) cost sensitivity scenarios.

\begin{tabular}{|c|c|c|c|}
\hline As of December 31, & 2005 & 2006 & 2007 \\
\hline \multicolumn{4}{|c|}{ Intermediate scenario: } \\
\hline Assets & $\$ 24,008$ & $\$ 32,325$ & $\$ 40,680$ \\
\hline Liabilities & 9,624 & 9,662 & 11,688 \\
\hline Assets less liabilities & 14,384 & 22,663 & 28,993 \\
\hline Ratio $^{1}$ & $8.5 \%$ & $12.5 \%$ & $15.2 \%$ \\
\hline \multicolumn{4}{|c|}{ Low range scenario: } \\
\hline Assets & $\$ 24,008$ & $\$ 32,325$ & $\$ 46,647$ \\
\hline Liabilities & 9,624 & 9,220 & 11,041 \\
\hline Assets less liabilities & 14,384 & 23,105 & 35,607 \\
\hline Ratio $^{1}$ & $8.7 \%$ & $13.5 \%$ & $20.5 \%$ \\
\hline \multicolumn{4}{|c|}{ Upper range scenario: } \\
\hline Assets & $\$ 24,008$ & $\$ 32,325$ & $\$ 33,116$ \\
\hline Liabilities & 9,624 & 10,073 & 12,513 \\
\hline Assets less liabilities & 14,384 & 22,252 & 20,602 \\
\hline Ratio $^{1}$ & $8.3 \%$ & $11.5 \%$ & $9.7 \%$ \\
\hline
\end{tabular}




\section{Actuarial Analysis}

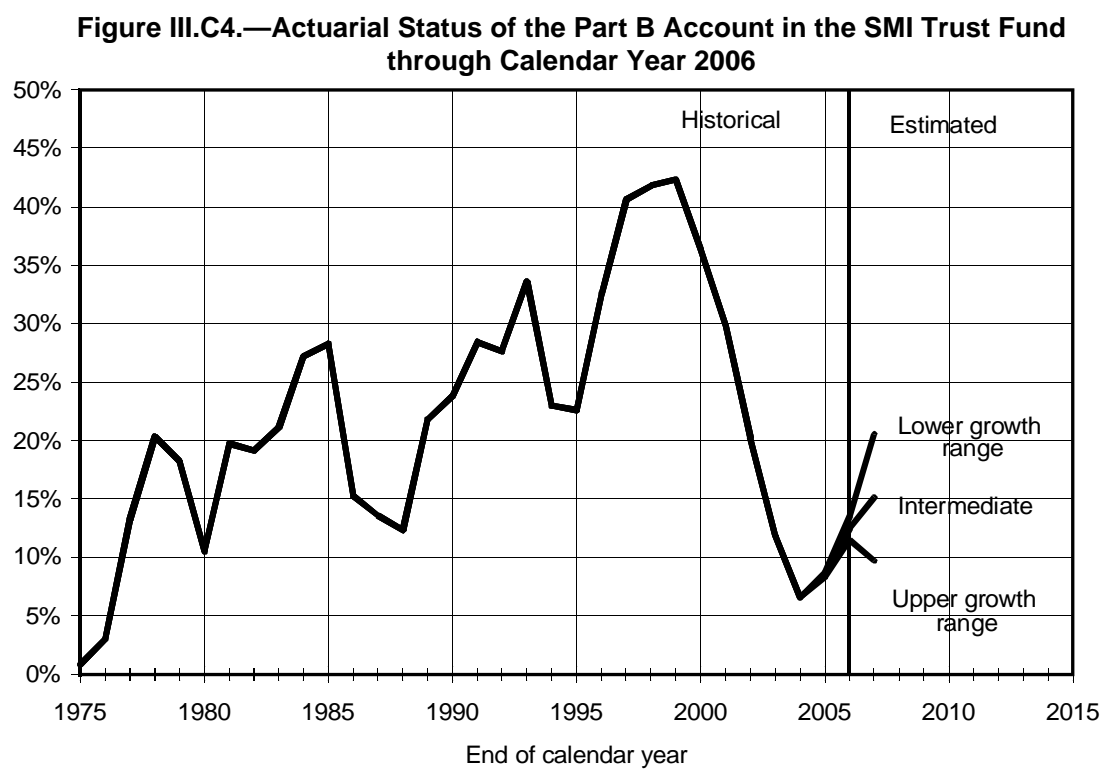

Note: The actuarial status of the Part B account in the SMI trust fund is measured by the ratio of (i) assets minus liabilities at the end of the year to (ii) the following year's incurred expenditures.

Based on the tests described above, the Trustees conclude that the financing established for the Part B account for calendar year 2007 is adequate to cover 2007 expected expenditures and to restore the financial status of the Part B account in 2007 to a satisfactory level. Because the net trust fund ratio would still be at the lower end of the desirable range, the Part B financing rates for 2008 would have to be increased slightly above the estimated expenditure increase. Should the scheduled 2008 physician payment update of about -10 percent be legislatively avoided, however, then the future Part B financing rates would have to be increased by a larger percentage, to reflect the change in physician expenditures.

\section{c. Long-Range Estimates}

In section III.C2b, the expected operations of the Part B account over the next 10 years were presented. In this section, the long-range expenditures of the account are examined under the intermediate assumptions. As noted, Part B expenditures after 2007 are substantially understated. Because of its automatic financing provisions, the Part B account is expected to be adequately financed into the indefinite future, so a long-range analysis using high cost and low cost assumptions is not conducted. 
Table III.C14 shows the estimated Part B incurred expenditures under the intermediate assumptions expressed as a percentage of GDP, for selected years over the calendar-year period 2006-2080. ${ }^{35}$ The 75-year projection period fully allows for the presentation of future trends that may reasonably be expected to occur, such as the impact of the large increase in enrollees after 2010 when the baby boom generation will reach eligibility age and begin to receive benefits.

\begin{tabular}{cc}
\begin{tabular}{c} 
Table III.C14.-Part B Expenditures (Incurred Basis) \\
\multicolumn{2}{c}{ of the Gross Domestic Product } \\
(
\end{tabular} \\
\hline Calendar year & Part B expenditures as a percentage of GDP \\
\hline 2006 & $1.28 \%$ \\
2007 & 1.31 \\
2008 & 1.32 \\
2009 & 1.33 \\
2010 & 1.35 \\
2011 & 1.36 \\
2012 & 1.39 \\
2013 & 1.42 \\
2014 & 1.45 \\
2015 & 1.48 \\
2020 & 1.71 \\
2025 & 2.00 \\
2030 & 2.32 \\
2035 & 2.61 \\
2040 & 2.83 \\
2045 & 3.00 \\
2050 & 3.16 \\
2055 & 3.31 \\
2060 & 3.48 \\
2065 & 3.64 \\
2070 & 3.76 \\
2075 & 3.85 \\
2080 & 3.94 \\
\hline
\end{tabular}

Part B costs per enrollee after the initial 25-year period are assumed to increase at a rate determined by the economic model described in sections II.C and IV.C. Based on these assumptions, incurred Part B expenditures as a percentage of GDP would increase rapidly from 1.28 percent in 2006 to 3.94 percent in 2080 .

This report focuses on the 75-year period from 2006 to 2080 for the evaluation of the long-run financial status of Part B on an open-group basis (i.e., including past, current, and future participants). Table III.C15 shows that because of the automatic financing of Part B, there is no unfunded obligation.

\footnotetext{
${ }^{35}$ These estimated incurred expenditures are for benefit payments and administrative expenses combined, unlike the values in table III.C9, which express only benefit payments on a cash basis as a percentage of GDP.
} 


\section{Actuarial Analysis}

In section III.B of this report, an extended projection of HI revenues and expenditures was presented, beyond the normal 75-year projection period, to highlight the continuing financial imbalance over an infinite horizon.

Tables III.C15 and III.C16 present corresponding estimates for Part B that extend to the infinite horizon. The extension assumes no change to current law, and the demographic and economic trends used for the 75-year projection continue indefinitely except that average Part B expenditures per beneficiary are assumed to increase at the same rate as GDP per capita beginning in about 2081.

Table III.C15 shows an estimated present value of Part B expenditures through the infinite horizon of $\$ 37.7$ trillion, of which $\$ 18.8$ trillion would occur during the first 75 years. Because such amounts, calculated over extremely long-time horizons, can be difficult to interpret, they are also shown as percentages of the present value of future GDP. So expressed, the corresponding figures are 3.3 percent and 2.6 percent of GDP, respectively. The table also indicates that approximately 26 percent of expenditures for each time period would be financed through beneficiary premiums, with the remaining 74 percent paid by general revenues, as mandated by current law.

Table III.C15.-Unfunded Part B Obligations from Program Inception through the Infinite Horizon [Present values as of January 1, 2007; dollar amounts in trillions]

\begin{tabular}{|c|c|c|}
\hline & Present value & $\begin{array}{l}\text { As a } \\
\text { percentage } \\
\text { of GDP }\end{array}$ \\
\hline Unfunded obligations through the infinite horizon ${ }^{1}$ & $\$ 0.0$ & $0.0 \%$ \\
\hline Expenditures & 37.7 & 3.3 \\
\hline Income & 37.7 & 3.3 \\
\hline Beneficiary premiums & 10.0 & 0.9 \\
\hline General revenue contributions & 27.7 & 2.4 \\
\hline Unfunded obligations from program inception through $2081^{1}$ & 0.0 & 0.0 \\
\hline Expenditures & 18.8 & 2.6 \\
\hline Income & 18.8 & 2.6 \\
\hline Beneficiary premiums & 4.9 & 0.7 \\
\hline General revenue contributions & 13.9 & 1.9 \\
\hline \multicolumn{3}{|c|}{$\begin{array}{l}\text { Present value of future expenditures less income, reduced by the amount of trust fund assets at th } \\
\text { beginning of the period. }\end{array}$} \\
\hline \multicolumn{3}{|c|}{$\begin{array}{l}\text { Notes: } 1 \text { The present values of GDP for } 2007-2081 \text { and for } 2007 \text { through the infinite horizon are } \\
\$ 730.0 \text { trillion and } \$ 1,154.1 \text { trillion, respectively. See note } 2 \text { of table III.B10. } \\
\text { 2. Totals do not necessarily equal the sums of rounded components. }\end{array}$} \\
\hline
\end{tabular}

Table III.C16 shows corresponding projections separately for current versus future beneficiaries. As indicated, about 38 percent of the total, infinite-horizon cost is associated with current beneficiaries, 
with the remaining 62 percent attributable to beneficiaries becoming eligible for Part B benefits after January 1, 2007.

Table III.C16._-Unfunded Part B Obligations for Current and Future Program Participants through the Infinite Horizon [Present values as of January 1, 2007; dollar amounts in trillions]

\begin{tabular}{|c|c|c|}
\hline & $\begin{array}{c}\text { Present } \\
\text { value }\end{array}$ & $\begin{array}{c}\text { As a } \\
\text { percentage } \\
\text { of GDP }\end{array}$ \\
\hline  & $\$ 0.2$ & $0.0 \%$ \\
\hline 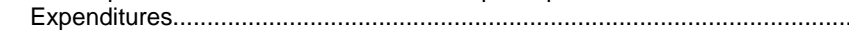 & 14.4 & 1.2 \\
\hline Income & 14.2 & 1.2 \\
\hline 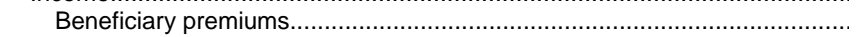 & 3.8 & 0.3 \\
\hline 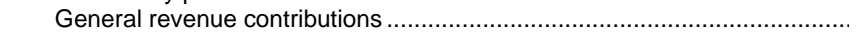 & 10.4 & 0.9 \\
\hline Less current trust fund & & \\
\hline (Income minus expenditures to date for past and current participants) ............ & 0.0 & 0.0 \\
\hline 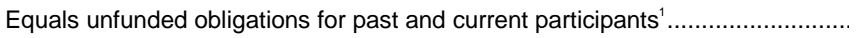 & 0.2 & 0.0 \\
\hline 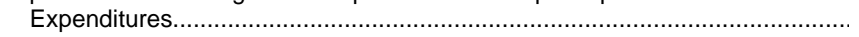 & 14.4 & 1.2 \\
\hline Income & 14.2 & 1.2 \\
\hline Beneficiary premiums......................... & 3.8 & 0.3 \\
\hline General revenue contributions ................................ & 10.4 & 0.9 \\
\hline Plus expenditures less income for future participants for the infinite horizon ....... & -0.2 & -0.0 \\
\hline 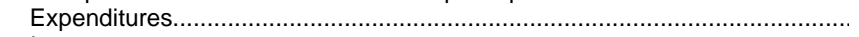 & 23.3 & 2.0 \\
\hline Income & 23.5 & 2.0 \\
\hline Beneficiary premiums....................... & 6.2 & 0.5 \\
\hline 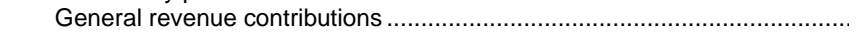 & 17.3 & 1.5 \\
\hline Equals unfunded obligations for all participants for the infinite future ................. & 0.0 & 0.0 \\
\hline 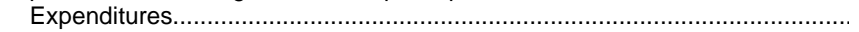 & 37.7 & 3.3 \\
\hline 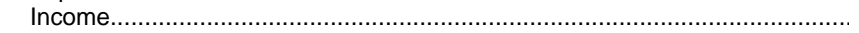 & 37.7 & 3.3 \\
\hline 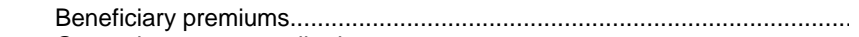 & 10.0 & 0.9 \\
\hline General revenue contributions ......................... & 27.7 & 2.4 \\
\hline
\end{tabular}

Notes: 1. The estimated present value of GDP for 2007 through the infinite horizon is $\$ 1,154.1$ trillion. See note 2 of table III.B10.

2. Totals do not necessarily equal the sums of rounded components.

Figure III.C5 compares the year-by-year Part B costs as a percentage of GDP for the current annual report with the corresponding projections from the 2006 report.

The long-range projections of Part B costs as shown in this report differ somewhat from those in the 2006 annual report. Initially, the costs are slightly lower as a result of actual historical spending in 2005 and 2006 being lower than estimated last year, offsetting the higher projected spending in 2007 resulting from the higher physician fees under the Tax Relief and Health Care Act. During 2010 through about 2025, assumed Part B growth rates are slightly greater than estimated in last year's report due to an increase in the assumption of utilization and cost of services from 2010 through 2016. Thereafter, through the end of the 75-year projection period, the growth assumptions are similar to those assumed last year. At the end of the 


\section{Actuarial Analysis}

period, the projected Part B cost as a percentage of GDP is slightly higher than estimated in last year's report.

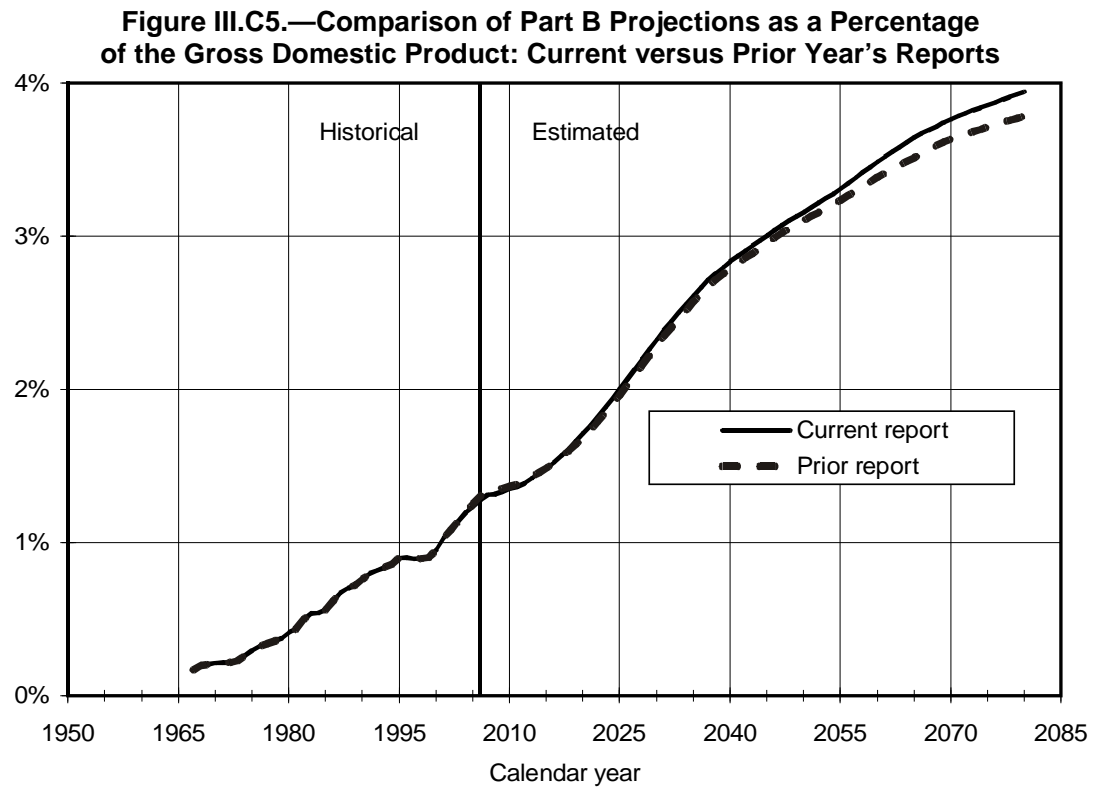

As figure III.C5 indicates, the intermediate Part B cost projections as a percentage of GDP in this report are initially lower than in last year's report, but are higher by the end of the projection. The differential starts out at -0.03 percent of GDP in 2006 and gradually increases to +0.13 percent of GDP in 2080 .

\section{Part D Account}

The Medicare Modernization Act, enacted on December 8, 2003, established within SMI two Part D accounts related to prescription drug benefits: the Medicare Prescription Drug Account and the Transitional Assistance Account. The Medicare Prescription Drug Account is used in conjunction with the broad, voluntary prescription drug benefits that commenced in 2006. The Transitional Assistance Account was used to provide transitional assistance benefits, beginning in 2004 and extending through 2005, for certain low-income beneficiaries prior to the start of the new prescription drug benefit. For simplicity, in this report both accounts are combined and referred to as the "Part D account."

The nature of the new Medicare prescription drug benefit is significantly different from the usual HI and SMI Part B fee-for- 
service benefits. In particular, beneficiaries obtain the drug benefit by voluntarily purchasing insurance policies from private stand-alone drug plans or through private Medicare Advantage health plans. The premiums established by these plans are heavily subsidized by Medicare. In addition, Medicare pays some or all of the remaining beneficiary drug premiums and cost-sharing liabilities for low-income beneficiaries. Medicare also pays special subsidies on behalf of beneficiaries retaining primary drug coverage through qualifying employer-sponsored retiree health plans. Collectively, the various Medicare drug subsidies are financed primarily by general revenues. In addition, a declining portion of the subsidy costs associated with beneficiaries who also qualify for full Medicaid benefits are financed through special payments from State governments. Beneficiaries may have their drug insurance premiums withheld from their Social Security benefits, if they wish, and then forwarded to the drug plans on their behalf. In 2006, about one-third of the enrollees in Part D drug plans exercised this option.

\section{a. Financial Operations in Calendar Year 2006}

During calendar year 2006, total Part D expenditures were approximately $\$ 47.3$ billion. General revenue was provided on an as-needed basis to cover the portion of these expenditures supported through Medicare subsidies. Total Part D receipts were $\$ 48.1$ billion, and total assets in the Part D account at the end of the calendar year were $\$ 0.8$ billion.

A statement of the revenue and expenditures of the Part D account of the SMI trust fund in calendar year 2006, and of its assets at the beginning and end of the calendar year, is presented in table III.C17. 


\section{Actuarial Analysis}

\begin{tabular}{|c|c|c|}
\hline $\begin{array}{l}\text { Total assets of the Part D account in the trust fund, beginning of } \\
\text { period. }\end{array}$ & & $\$ 0$ \\
\hline \multirow{2}{*}{\multicolumn{3}{|c|}{ Revenue: }} \\
\hline Premiums from enrollees: & & \\
\hline $\begin{array}{l}\text { Premiums deducted from Social Security benefit checks........... } \\
\text { Premiums paid directly to plans' }\end{array}$ & $\begin{array}{r}\$ 1,184,804 \\
2,265,523\end{array}$ & \\
\hline 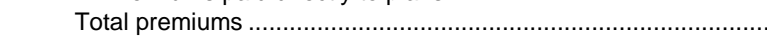 & & $3,450,327$ \\
\hline \multicolumn{3}{|l|}{ Government contributions: } \\
\hline 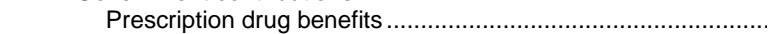 & $38,825,874$ & \\
\hline Prescription drug administrative expenses ................................... & 307,231 & \\
\hline 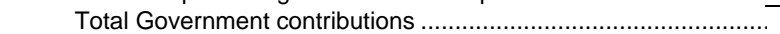 & & $39,133,106$ \\
\hline 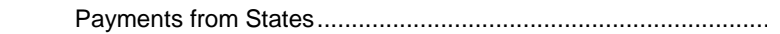 & & $5,474,223$ \\
\hline 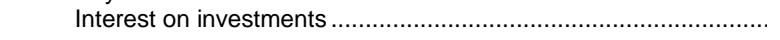 & & 12,552 \\
\hline \multicolumn{2}{|l|}{ Total revenue } & $48,070,208$ \\
\hline \multicolumn{3}{|l|}{ Expenditures: } \\
\hline \multirow{2}{*}{\multicolumn{2}{|c|}{ 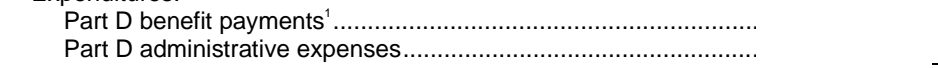 }} & $46,969,077$ \\
\hline & & 307,231 \\
\hline \multicolumn{2}{|l|}{ Total expenditures } & $47,276,309$ \\
\hline \multicolumn{2}{|l|}{ Net addition to the trust fund } & 793,899 \\
\hline \multicolumn{2}{|l|}{ Total assets of the Part D account in the trust fund, end of period........... } & $\$ 793,899$ \\
\hline \multicolumn{3}{|c|}{$\begin{array}{l}\text { Premiums paid directly to plans are not displayed on Treasury statements and are estimated. These } \\
\text { premiums have been added to the benefit payments reported on the Treasury statement to obtain an } \\
\text { estimate of total Part } D \text { benefits. Direct data on such benefit amounts are not yet available. }\end{array}$} \\
\hline \multicolumn{3}{|l|}{ Note: Totals do not necessarily equal the sums of rounded components. } \\
\hline
\end{tabular}

The Part D program began on January 1, 2006, and therefore the Part D account contained no assets as of that date. During calendar year 2006, total revenue amounted to $\$ 48.1$ billion, and total expenditures were $\$ 47.3$ billion. Thus, total assets were $\$ 0.8$ billion as of December 31, 2006.

\section{(1) Revenues}

The major sources of revenue for the Part D account are (i) contributions of the Federal Government that are authorized to be appropriated and transferred from the general fund of the Treasury, (ii) premiums paid by eligible persons who voluntarily enroll, and (iii) contributions from the States.

Of the total Part $\mathrm{D}$ revenue, $\$ 1.2$ billion represented premium amounts withheld from Social Security benefit checks or other Federal benefit payments. Total premium payments, including those paid directly to the Part D plans, are estimated to be $\$ 3.5$ billion. 
In calendar year 2006, contributions received from the general fund of the Treasury amounted to $\$ 39.1$ billion, which accounted for 81.0 percent of total revenue.

With the availability of Part D drug coverage and low-income subsidies in 2006, Medicaid is no longer the primary payer of drug costs for full-benefit dual eligibles. States are subject to a contribution requirement and must pay the Part D account in the SMI trust fund a portion of their estimated forgone drug costs for this population. Starting in 2006, States must pay 90 percent of the estimated costs, with this percentage phasing down over a 10-year period to 75 percent in 2015. For calendar year 2006, these state payments amounted to $\$ 5.5$ billion.

Another source of Part D revenue is interest received on investments held by the Part D account. Because this account holds only a very low amount of assets, and only temporarily, the interest on the investments of the account in calendar year 2006 was virtually negligible ( $\$ 13$ million).

\section{(2) Expenditures}

Part D expenditures include both the costs of prescription drugs provided by Part D plans to enrollees and Medicare payments to employer-sponsored retiree health plans on behalf of beneficiaries who obtain their primary drug coverage through such plans. Unlike Parts A and B of Medicare, not all Part D expenditures are made or supported directly from the Part D account in the SMI trust fund. In particular, a portion of these expenditures are financed by enrollee premiums that are paid directly to Part D plans and that, consequently, do not flow through the Part D account. To determine total Part D expenditures, the Part D account operations are adjusted to reflect the direct premium payments. Total expenditures are characterized as either "benefits" (representing the gross cost of enrollees' prescription drug coverage plus employer subsidy payments) or Federal administrative expenses.

All expenses incurred by the Department of Health and Human Services, the Social Security Administration, and the Department of the Treasury in administering Part D are charged to the account. Such administrative duties include making payments to Part D plans, the fraud and abuse control activities, and experiments and demonstration projects designed to determine various methods of increasing efficiency and economy in providing health care services, while maintaining the quality of these services. 


\section{Actuarial Analysis}

In addition, Congress has authorized expenditures from the trust funds for construction, rental and lease, or purchase contracts of office buildings and related facilities for use in connection with the administration of Part D. Such costs are included in the account expenditures. The net worth of facilities and other fixed capital assets, however, is not carried in the statement of Part D assets presented in this report, since the value of fixed capital assets does not represent funds available for benefit or administrative expenditures and is not, therefore, pertinent in assessing the actuarial status of the funds.

Of the $\$ 47.3$ billion in total Part $\mathrm{D}$ expenditures, $\$ 47.0$ billion represented benefits, as defined above, and the remaining $\$ 0.3$ billion of expenditures was for Federal administrative expenses. (Administrative expenses incurred by Part D plans are covered implicitly by the Medicare direct premium subsidy and reinsurance subsidy, together with enrollee premiums.)

(3) Actual experience versus prior estimates

Table III.C18 compares the actual experience in calendar year 2006 with the estimates presented in the 2005 and 2006 annual reports. A number of factors can contribute to differences between estimates and subsequent actual experience. This is especially true in the case of a new program for which the costs were largely unknown.

Table III.C18.-Comparison of Actual and Estimated Operations of the Part D Account in the SMI Trust Fund, Calendar Year 2006 [Dollar amounts in millions]

\begin{tabular}{|c|c|c|c|c|c|}
\hline \multirow[b]{3}{*}{ Item } & \multirow[b]{3}{*}{$\begin{array}{l}\text { Actual } \\
\text { amount }\end{array}$} & \multicolumn{4}{|c|}{$\begin{array}{l}\text { Comparison of actual experience with estimates for } \\
\text { calendar year } 2006 \text { published in: }\end{array}$} \\
\hline & & \multicolumn{2}{|c|}{2006 report } & \multicolumn{2}{|c|}{2005 report } \\
\hline & & $\begin{array}{c}\text { Estimated } \\
\text { amount }^{1}\end{array}$ & $\begin{array}{l}\text { Actual as a } \\
\text { percentage } \\
\text { of estimate }\end{array}$ & $\begin{array}{l}\text { Estimated } \\
\text { amount }^{1}\end{array}$ & $\begin{array}{l}\text { Actual as a } \\
\text { percentage } \\
\text { of estimate }\end{array}$ \\
\hline Premiums from enrollees & $\$ 3,450$ & $\$ 4,980$ & $69 \%$ & $\$ 8,514$ & $41 \%$ \\
\hline State transfers & 5,474 & 7,041 & 78 & 9,040 & 61 \\
\hline Government contributions & 39,133 & 46,154 & 85 & 63,599 & 62 \\
\hline Benefit payments & 46,969 & 57,513 & 82 & 80,583 & 58 \\
\hline
\end{tabular}

The Part D benefits in calendar year 2006 are significantly lower than projected last year and substantially lower than predicted 2 years ago. The difference is primarily attributable to three factors:

- Actual growth in prescription drug spending in the U.S. in 2004 and 2005 was much slower than previously expected based on prior trends. The abrupt deceleration in this past trend affected the 
starting level of Part D costs in 2006, and assumed future growth rates were adjusted accordingly.

- Expected retail discounts, manufacturer rebates, and utilization management savings, as shown in Part D plan bid data, were similar to the levels ultimately assumed for Part D plans-but were achieved immediately in 2006 rather than after several years as previously assumed. This time difference affects the entire projection period, although the impact is more significant in 2006.

- Significantly fewer beneficiaries joined Part D plans than initially estimated. The impact is particularly pronounced in 2006, since many beneficiaries who enrolled in Part D did so after the beginning of the year. Projected Part D costs are not reduced in full proportion to the reduced enrollment, however, since the average risk score of enrollees indicates that they have somewhat below-average health status and therefore higher per-person drug costs.

(4) Assets

The portion of the Part D account that is not needed to meet current expenditures for benefits and administration is invested in interest-bearing obligations of the U.S. Government.

The Social Security Act authorizes the issuance of special public-debt obligations for purchase exclusively by the account. The law requires that these special public-debt obligations shall bear interest, at a rate based on the average market yield (computed on the basis of market quotations as of the end of the calendar month immediately preceding the date of such issue), on all marketable interest-bearing obligations of the United States forming a part of the public debt that are not due or callable until after 4 years from the end of that month. Since the inception of the SMI trust fund, the assets have always been invested in special public-debt obligations. ${ }^{36}$ Table V.F10, presented in appendix F, shows the assets of the SMI trust fund, including Parts B and D, at the end of fiscal years 2005 and 2006.

As noted previously, the flexible appropriation of general revenues for Part D eliminates the need to maintain a normal contingency reserve. As a result, Part D assets are very low and are held only briefly in anticipation of immediate expenditures.

${ }^{36}$ Investments may also be made in obligations guaranteed as to both principal and interest by the United States, including certain federally sponsored agency obligations. 


\section{Actuarial Analysis}

\section{b. 10-Year Actuarial Estimates (2007-2016)}

Future operations of the Part D account are projected using the Trustees' economic and demographic assumptions, as detailed in the OASDI Trustees Report, as well as other assumptions unique to Part D. Section IV.B2 presents an explanation of the effects of the Trustees' intermediate assumptions, and of the other assumptions unique to Part D, on the estimates in this report.

Generally, the income to the Medicare Prescription Drug Account includes the beneficiary premiums described above and transfers from the general fund of the Treasury that are established annually to match each year's anticipated incurred benefit costs and other expenditures. The transfers from the Treasury are based on the calculated direct premium subsidy rate and the anticipated levels of reinsurance payments, employer subsidies, low-income subsidies, net risk-sharing payments, administrative expenses, and an amount necessary to maintain an appropriate contingency margin (if any). The beneficiary premiums and direct subsidy rate are calculated based on the national average bid amounts and are defined prior to the annual appropriation, with the average premium amounting to 25.5 percent of the expected total plan costs for basic coverage. The appropriation language provides resources for benefit payments under the Part D drug benefit program, without further Congressional action, in the event that the annual appropriation is insufficient. As a result of this authority we do not anticipate the need for a contingency margin.

Expenditures from the account include the premiums withheld from beneficiaries' Social Security or other Federal payments and transferred to the private drug plans, the direct subsidy payments, reinsurance payments, employer subsidy amounts, low-income subsidy payments, risk-sharing payments, and administrative expenses. As noted previously, these direct expenditures are adjusted to include the amount of enrollee premiums paid directly to Part D plans, thereby providing an estimate of total Part D expenditures.

The Part D cost estimates shown in this year's Trustees Report are substantially lower than those in the 2006 report. The reduction is primarily attributable to the 2007 prescription drug plan bid submissions. The average 2007 plan bid was about 10 percent lower than in 2006. This extraordinary change reflected a number of factors, including a significant drop in plans' expectations for preferred brand name drug use and an associated increase in generic 
utilization. Due to the substantial competitive pressures in Part D, and the availability of narrow risk-sharing corridors in 2007, it is possible that some plans bid over-aggressively and may not be able to achieve the performance assumed in their bids. Thus, it is necessary to make an assumption regarding the actual plan costs for 2007 versus their bid levels. If we assume a true underlying drug trend of about 6 percent from 2006 to 2007, the 2007 bids differ by roughly 16 percent from a "normal" trend level. We assume that the actual level of prescription drug spending will be roughly halfway between these two levels. Ultimately, we assume that future bids will be about 4 percent lower than actual spending.

Table III.C19 shows the estimated operations of the Part D account under the intermediate assumptions on a calendar-year basis through 2016.

\begin{tabular}{|c|c|c|c|c|c|c|c|c|c|c|}
\hline \multirow[b]{2}{*}{$\begin{array}{c}\text { Calendar } \\
\text { year }\end{array}$} & \multicolumn{5}{|c|}{ Income } & \multicolumn{3}{|c|}{ Expenditures } & \multicolumn{2}{|c|}{ Account } \\
\hline & $\begin{array}{l}\text { Premium } \\
\text { income }^{1}\end{array}$ & $\begin{array}{l}\text { General } \\
\text { revenue }^{2}\end{array}$ & $\begin{array}{c}\text { Transfers } \\
\text { from } \\
\text { States }^{3} \\
\end{array}$ & $\begin{array}{l}\text { Interest } \\
\text { and } \\
\text { other }\end{array}$ & Total & $\begin{array}{c}\text { Benefit } \\
\text { payments }^{4}\end{array}$ & $\begin{array}{c}\text { Adminis- } \\
\text { trative } \\
\text { expense }\end{array}$ & Total & $\begin{array}{c}\text { Net } \\
\text { change }\end{array}$ & $\begin{array}{c}\text { Balance } \\
\text { at end } \\
\text { of year }\end{array}$ \\
\hline \multicolumn{11}{|c|}{ Historical data: } \\
\hline 2004 & - & $\$ 0.4$ & - & - & $\$ 0.4$ & $\$ 0.4$ & - & $\$ 0.4$ & - & - \\
\hline 2005 & - & 1.1 & - & - & 1.1 & 1.1 & - & 1.1 & - & - \\
\hline 2006 & $\$ 3.5$ & 39.2 & $\$ 5.5$ & $\$ 0.0$ & 48.2 & 47.1 & $\$ 0.3$ & 47.4 & $\$ 0.8$ & $\$ 0.8$ \\
\hline \multicolumn{11}{|c|}{ Intermediate estimates: } \\
\hline 2007 & 4.0 & 39.5 & 6.6 & 0.0 & 50.1 & 49.2 & 0.9 & 50.1 & -0.0 & 0.8 \\
\hline 2008 & 5.6 & 49.4 & 6.9 & 0.0 & 61.9 & 61.0 & 0.9 & 61.9 & 0.0 & 0.8 \\
\hline 2009 & $7.4^{6}$ & 55.0 & 7.4 & 0.0 & 69.8 & 68.7 & 0.9 & 69.6 & 0.3 & 1.1 \\
\hline 2010 & $8.7^{6}$ & 61.7 & 8.0 & 0.0 & 78.4 & 77.7 & 0.9 & 78.6 & -0.2 & 0.9 \\
\hline 2011 & 11.3 & 69.2 & 8.6 & 0.0 & 89.1 & 88.1 & 0.9 & 89.0 & 0.1 & 1.0 \\
\hline 2012 & 13.5 & 78.5 & 9.3 & 0.0 & 101.4 & 100.4 & 0.9 & 101.3 & 0.1 & 1.0 \\
\hline 2013 & 15.1 & 86.6 & 10.2 & 0.0 & 112.0 & 111.0 & 0.9 & 111.9 & 0.1 & 1.1 \\
\hline 2014 & 16.9 & 96.8 & 11.2 & 0.0 & 124.8 & 123.8 & 0.9 & 124.8 & 0.1 & 1.2 \\
\hline 2015 & $19.4^{6}$ & 108.2 & 12.2 & 0.0 & 139.9 & 138.3 & 0.9 & 139.2 & 0.7 & 1.9 \\
\hline 2016 & $20.5^{6}$ & 121.0 & 13.6 & 0.0 & 155.1 & 154.7 & 0.9 & 155.6 & -0.5 & 1.4 \\
\hline
\end{tabular}

Premiums include both amounts withheld from Social Security benefit checks or other Federal benefit payments and those paid directly to Part D plans.

'Includes all government transfers, including amounts for the general subsidy, reinsurance, employer drug subsidy, low-income subsidy, administrative expenses, risk sharing, and State expenses for making low-income eligibility determinations. Includes amounts for the transitional assistance benefits in 2004 and 2005.

${ }^{3}$ With the availability of Part D drug coverage and low-income subsidies in 2006, Medicaid is no longer the primary payer for full-benefit dual eligibles. States are subject to a contribution requirement and must pay the Part D account in the SMI trust fund a portion of their estimated forgone drug costs for this population. Starting in 2006 , States must pay 90 percent of the estimated costs, with this percentage phasing down over a 10-year period to 75 percent in 2015.

${ }^{4}$ Includes payments to plans, subsidies to employer-sponsored retiree prescription drug plans, payments to States for making low-income eligibility determinations, Part D drug premiums collected from beneficiaries and transferred to Medicare Advantage plans and private drug plans, and premium amounts paid directly by enrollees to plans. Includes amounts for the transitional assistance benefits in 2004 and 2005.

${ }^{5}$ See text concerning nature of general revenue appropriations process and implications for contingency reserve assets.

${ }^{6}$ See footnote 1 of table III.A1.

Note: Totals do not necessarily equal the sums of rounded components. 


\section{Actuarial Analysis}

In table III.C20, prescription drug payment amounts are considered in the aggregate, on a per capita basis, and relative to the Gross Domestic Product (GDP). Rates of growth are shown for the next 10 years, based on the intermediate set of assumptions.

Table III.C20.-Growth in Part D Benefits (Cash Basis) through December 31, 2016

\begin{tabular}{lrrrrr}
\hline Calendar year & $\begin{array}{c}\text { Aggregate benefits } \\
\text { [billions] }\end{array}$ & $\begin{array}{l}\text { Percent } \\
\text { change }\end{array}$ & $\begin{array}{c}\text { Per capita } \\
\text { benefits }\end{array}$ & $\begin{array}{c}\text { Percent } \\
\text { change }\end{array}$ & $\begin{array}{c}\text { Part D benefits as a } \\
\text { percentage of GDP }\end{array}$ \\
\hline $\begin{array}{l}\text { Historical data: } \\
2004\end{array}$ & $\$ 0.4$ & - & & & \\
2005 & 1.1 & - & $\$ 362$ & - & $0.0 \%$ \\
2006 & 47.1 & - & 596 & - & 0.0 \\
& & & 1,596 & - & \\
Intermediate estimates: & & & & & \\
2007 & 49.2 & $4.6 \%$ & 1,590 & $-0.4 \%$ & 0.4 \\
2008 & 61.0 & 23.9 & 1,888 & 18.7 & 0.4 \\
2009 & 68.7 & 12.6 & 2,039 & 8.0 & 0.4 \\
$2010^{1}$ & 77.7 & 13.2 & 2,218 & 8.8 & 0.5 \\
$2011^{1}$ & 88.1 & 13.4 & 2,413 & 8.8 & 0.5 \\
2012 & 100.4 & 13.9 & 2,624 & 8.7 & 0.6 \\
2013 & 111.0 & 10.6 & 2,814 & 7.2 & 0.6 \\
2014 & 123.8 & 11.6 & 3,051 & 8.4 & 0.6 \\
$2015^{1}$ & 138.3 & 11.7 & 3,313 & 8.6 & 0.7 \\
$2016^{1}$ & 154.7 & 11.8 & 3,602 & 8.7 & 0.7 \\
\hline
\end{tabular}

The relatively rapid cost increases shown in table III.C20 result in part from projected further increases in Part D enrollment, changes in the distribution of enrollees by coverage category, and the expected resumption of per capita drug cost growth rates that exceed the rate of increase in other categories of medical spending. The unusually large increase in 2008 is primarily attributable to anticipated Part D payments to plans under the risk-sharing arrangement for 2007 expenditures.

In addition to the variability in economic, demographic, and health care usage and cost experience that underlies the cost projections prepared for other parts of Medicare, the intermediate projections for Part D have an added uncertainty in that they were prepared for a relatively new benefit, so there is little current experience upon which to base conclusions. As such, there remains a very substantial level of uncertainty surrounding these cost projections. High and low cost estimates have also been prepared using two alternative sets of assumptions that reflect variation from the intermediate assumptions in both the projection and the base cost calculation. The estimated operations of the Part D account for all three alternatives are summarized in table III.C21. The assumptions underlying the intermediate estimates are presented in substantial detail in section IV.B2. The assumptions used in preparing estimates under the low cost and high cost alternatives are also summarized in that section. 
Part D expenditures are estimated to grow significantly faster than GDP under the intermediate, low, and high cost assumptions.

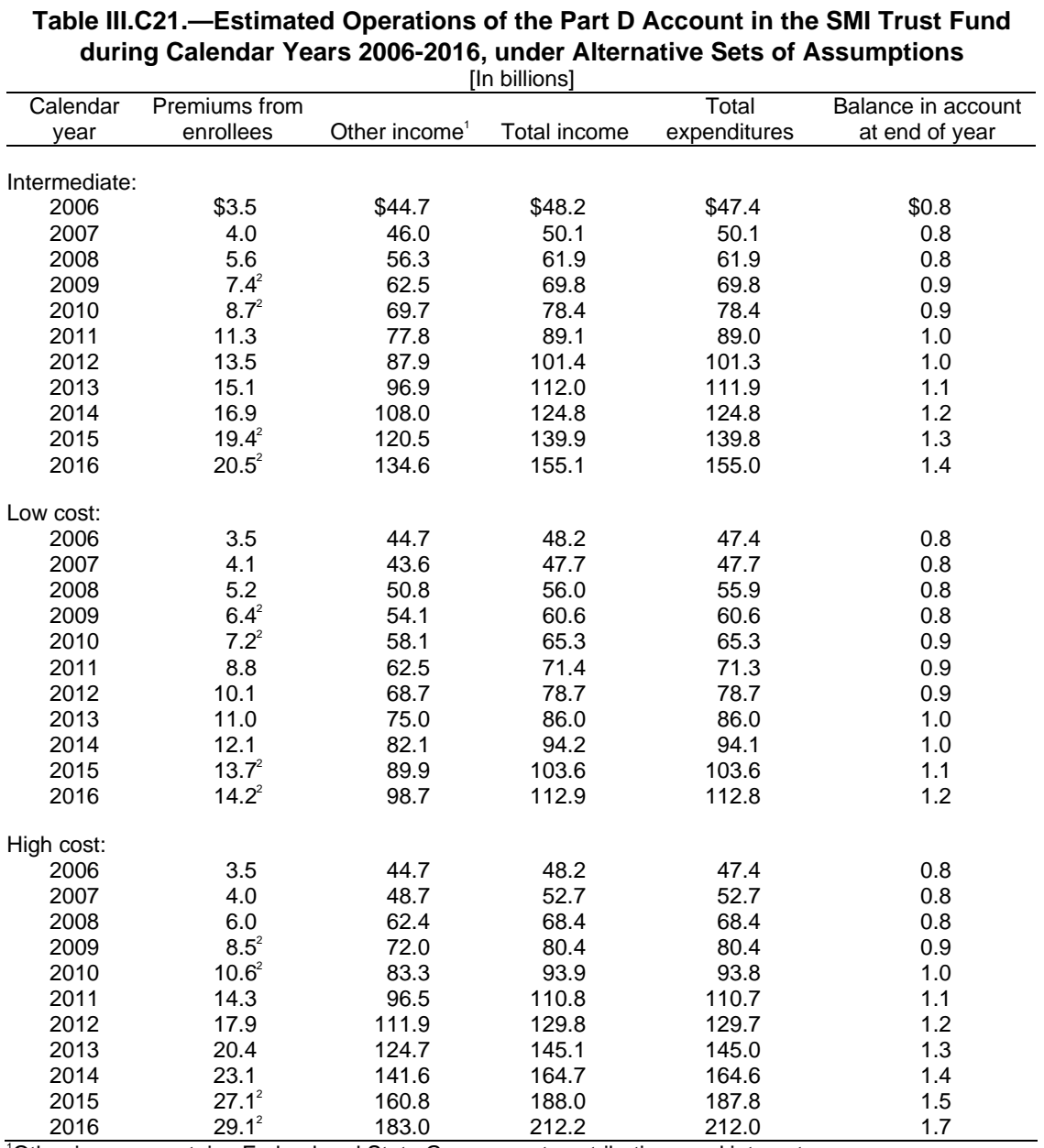

${ }^{1}$ Other income contains Federal and State Government contributions and interest.

${ }^{2}$ See footnote 1 of table III.A1.

Note: Totals do not necessarily equal the sums of rounded components.

The three sets of assumptions were selected in order to indicate the general range in which the cost might reasonably be expected to fall. The low and high cost alternatives provide for a wide range of possible experience. Actual experience is likely to fall within the range, but no assurance can be given that this will be the case, especially since the Part D benefits are a relatively new, voluntary program with which there is little actual experience. 


\section{Actuarial Analysis}

The alternative projections shown in table III.C20 illustrate two important aspects of the financial operations of the Part D account:

- Despite the widely differing assumptions underlying the three alternatives, the balance between Part D income and expenditures remains relatively stable. Under the low cost assumptions, for example, by 2016 both income and expenditures would be around 27 percent lower than projected under the intermediate assumptions. The corresponding amounts under the high cost assumptions would be around 36 percent higher than the intermediate estimates.

This result occurs because the premiums and general revenue contributions underlying the Part D financing will be reestablished annually. Thus, Part D income will automatically track Part D expenditures fairly closely, regardless of the specific economic and other conditions.

- As a result of the close matching of income and expenditures described above, together with anticipated flexibility in the appropriations of general revenues, the need for a contingency reserve to handle unanticipated fluctuations is minimal. (The next section describes this issue in more detail.)

\section{Adequacy of Part D Financing Established for Calendar Year 2007}

As noted previously, the Part D account in the SMI trust fund will be in financial balance indefinitely, as a result of the basis for program financing. Specifically, Part D expenditures are financed through the premiums paid by enrollees, special State payments to Medicare, and appropriations from the general fund of the Treasury. Moreover, the appropriation language adopted for the Part D account provides substantial flexibility in the amount of general revenues available to the account. Although a specific appropriation amount is referenced, based on estimates from the President's Budget, the appropriations language also allows indefinite budget authority for Part D in the event that the annual appropriation amount is insufficient. Thus, further Congressional action would not be required to cover a higher-than-expected level of Part D expenditures. ${ }^{37}$ Similar flexibility is anticipated for future Part $\mathrm{D}$ appropriations.

\footnotetext{
${ }^{37}$ The indefinite authority applies to all Part D outlays other than Federal administrative expenses.
} 
This basis for appropriations was used for the 2004-2005 transitional drug card subsidies. It has also been used for many years in setting appropriations for Federal matching funds for the Medicaid program.

As a consequence of this approach to appropriations for Part D, general revenues will be transferred to the account in the amount necessary to cover expenditures. The indefinite authority provision will allow such appropriations to continue even if the specific annual appropriated amount is exceeded. Consequently, no deficit will occur in the Part D account, and no contingency fund will be necessary to cover deficits.

As described in the section on the financial status of the Part B account, an appropriate level of assets should be maintained to cover the liability for claims that have been incurred but not yet reported or paid. In the case of Part $\mathrm{D}$, however, most such claims will be the responsibility of the prescription drug plans rather than the Part D program. Accordingly, the Part D account will generally not be at risk for incurred-but-unreported claim amounts, and no asset reserve will be necessary for this purpose. ${ }^{38}$

Another potential Part D liability will exist to the extent that Part D reinsurance payments and employer subsidy payments will be based on plan estimates. (These estimates are subject to actuarial review by the Office of the Actuary at the Centers for Medicare \& Medicaid Services.) Since we are assuming that actual Part D costs, as subsequently determined, will be somewhat greater than the plan bids, payment adjustments after the close of the year are expected to occur. Any settlements in favor of the plans would be made by Medicare from the following year's appropriated general revenues. Thus, creation of a reserve for payment of such settlement amounts seems unnecessary.

For these reasons, the Board of Trustees has tentatively concluded that maintenance of Part D account assets for contingency or liability purposes is unnecessary. Accordingly, evaluation of the adequacy of Part D assets is also unnecessary, and the Part D account is

\footnotetext{
${ }^{38} \mathrm{~A}$ potential exception to this principle would arise if one or more Federal "fall-back" prescription drug plans are created. Fall-back plans would be established in regions that did not have at least two prescription drug plans, and the Part D program would be at risk for the drug benefit costs. In this instance, incurred-but-unreported claim amounts would be the responsibility of the Part D program. The Part D estimates shown in this report are based on the assumption that no fall-back plans will be necessary, and no Part D account assets are included in the estimates for the purpose of covering potential incurred-but-unreported claims from fall-back plans.
} 


\section{Actuarial Analysis}

considered to be in satisfactory financial condition for 2007 (and all future years under current law) as a consequence of its basis for financing.

To the extent that actual future account transactions and appropriation measures differ from the current expectations, it may be necessary to revise this conclusion.

\section{c. Long-Range Estimates}

In section III.C3b, the expected operations of the Part D accounts over the next 10 years were presented. In this section, the long-range expenditures of the accounts are examined under the intermediate assumptions. Because of their automatic financing provisions, the Part D accounts are expected to be adequately financed into the indefinite future, so a long-range analysis using high cost and low cost assumptions is not conducted.

Table III.C22 shows the estimated Part D incurred expenditures under the intermediate assumptions expressed as a percentage of GDP, for selected years over the calendar-year period 2006-2080. ${ }^{39}$ The 75-year projection period fully allows for the presentation of future trends that may reasonably be expected to occur, such as the impact of the large increase in enrollees after 2010 when the baby boom generation will reach eligibility age and begin to receive benefits.

\footnotetext{
${ }^{39}$ These estimated incurred expenditures are for benefit payments and administrative expenses combined, unlike the values in table III.C20, which express only benefit payments on a cash basis as a percentage of GDP.
} 
SMI Financial Status

\begin{tabular}{cc}
$\begin{array}{c}\text { Table III.C22.-Part D Expenditures (Incurred Basis) } \\
\text { of the Gross Domestic Product }\end{array}$ \\
\hline Calendar year & Part D expenditures as a percentage of GDP \\
\hline 2006 & $0.36 \%$ \\
2007 & 0.38 \\
2008 & 0.41 \\
2009 & 0.45 \\
2010 & 0.48 \\
2011 & 0.52 \\
2012 & 0.56 \\
2013 & 0.60 \\
2014 & 0.64 \\
2015 & 0.68 \\
2020 & 0.93 \\
2025 & 1.20 \\
2030 & 1.43 \\
2035 & 1.58 \\
2040 & 1.70 \\
2045 & 1.80 \\
2050 & 1.90 \\
2055 & 2.00 \\
2060 & 2.09 \\
2065 & 2.18 \\
2070 & 2.24 \\
2075 & 2.30 \\
2080 & 2.35 \\
\hline
\end{tabular}

Increases in Part D costs per enrollee during the initial 25-year period are assumed to decline gradually to the rate determined by the economic model described in sections II.C and IV.C. Based on these assumptions, incurred Part D expenditures as a percentage of GDP would increase rapidly from 0.36 percent in 2006 to 2.35 percent in 2080. As actual experience becomes available for 2006 and later, both the starting cost of the drug benefit and its growth over time could prove significantly different from these projections.

This report focuses on the 75-year period from 2006 to 2080 for the evaluation of the long-run financial status of Part D on an open-group basis (i.e., including past, current, and future participants). Table III.C23 shows that because of the automatic financing of Part $\mathrm{D}$, there is no unfunded obligation.

In section III.B of this report, an extended projection of HI revenues and expenditures was presented, beyond the normal 75-year projection period, to highlight the continuing financial imbalance over an infinite horizon.

Tables III.C23 and III.C24 present corresponding estimates for Part D that extend to the infinite horizon. The extension assumes no change to current law, and the demographic and economic trends used for the 75-year projection continue indefinitely except that 


\section{Actuarial Analysis}

average Part D expenditures per beneficiary are assumed to increase at the same rate as GDP per capita beginning in about 2081.

Table III.C23 shows an estimated present value of Part D expenditures through the infinite horizon of $\$ 22.1$ trillion, of which $\$ 10.8$ trillion would occur during the first 75 years. Because such amounts, calculated over extremely long time horizons, can be difficult to interpret, they are also shown as percentages of the present value of future GDP. So expressed, the corresponding figures are 1.9 percent and 1.5 percent of GDP, respectively. The table also indicates that, for each time period, approximately 14 percent of expenditures would be financed through beneficiary premiums and 9 percent through State transfers, with the remaining 77 percent paid by general revenues, as mandated by current law.

Table III.C23.-Unfunded Part D Obligations from Program Inception through the Infinite Horizon

[Present values as of January 1,2007; dollar amounts in trillions]

\begin{tabular}{lrc}
\hline & $\begin{array}{c}\text { As a } \\
\text { percentage } \\
\text { of GDP }\end{array}$ \\
\hline Unfunded obligations through the infinite horizon ${ }^{1}$ & $\begin{array}{c}\text { Present value } \\
\text { Expenditures }\end{array}$ & $0.0 \%$ \\
Income & 22.1 & 1.9 \\
$\quad$ Beneficiary premiums & 22.1 & 1.9 \\
$\quad$ State transfers & 3.0 & 0.3 \\
$\quad$ General revenue contributions & 1.9 & 0.2 \\
& 17.1 & 1.5 \\
Unfunded obligations from program inception through 2081 & 0.0 & 0.0 \\
Expenditures & 10.8 & 1.5 \\
Income & 10.8 & 1.5 \\
$\quad$ Beneficiary premiums & 1.5 & 0.2 \\
State transfers & 1.0 & 0.1 \\
General revenue contributions & 8.4 & 1.2 \\
\hline Present value of future expenditures less income, reduced by the amount of trust fund assets at the \\
beginning of the period. & \\
Notes: 1. The present values of GDP for 2007-2081 and for 2007 through the infinite horizon are \\
$\quad$ \$730.0 trillion and \$1,154.1 trillion, respectively. See note 2 of table III.B10.
\end{tabular}

Table III.C24 shows corresponding projections separately for current versus future beneficiaries. As indicated, about 37 percent of the total, infinite-horizon cost is associated with current beneficiaries, with the remaining 63 percent attributable to beneficiaries becoming eligible for Part D benefits after January 1, 2007. 
Table III.C24.-Unfunded Part D Obligations

for Current and Future Program Participants through the Infinite Horizon [Present values as of January 1,2007; dollar amounts in trillions]

\begin{tabular}{|c|c|c|}
\hline & $\begin{array}{c}\text { Present } \\
\text { value }\end{array}$ & $\begin{array}{c}\text { As a } \\
\text { percentage } \\
\text { of GDP }\end{array}$ \\
\hline 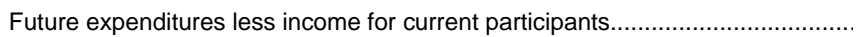 & $\$ 0.0$ & $0.0 \%$ \\
\hline 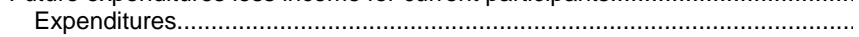 & 8.1 & 0.7 \\
\hline Income & 8.1 & 0.7 \\
\hline Beneficiary premiums. & 1.1 & 0.1 \\
\hline State transfers. & 0.7 & 0.1 \\
\hline General revenue contributions ............................................................ & 6.3 & 0.5 \\
\hline Less current trust fund & & \\
\hline (Income minus expenditures to date for past and current participants).. & 0.0 & 0.0 \\
\hline Equals unfunded obligations for past and current participants ${ }^{1}$ & 0.0 & 0.0 \\
\hline 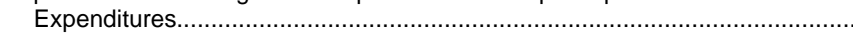 & 8.1 & 0.7 \\
\hline Income............................... & 8.1 & 0.7 \\
\hline 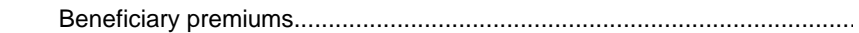 & 1.1 & 0.1 \\
\hline 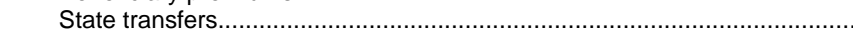 & 0.7 & 0.1 \\
\hline General revenue contributions & 6.3 & 0.5 \\
\hline Plus expenditures less income for future participants for the infinite horizon ....... & -0.0 & -0.0 \\
\hline Expenditures. & 14.0 & 1.2 \\
\hline Income & 14.0 & 1.2 \\
\hline Beneficiary premiums............................. & 1.9 & 0.2 \\
\hline 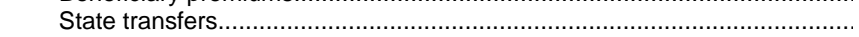 & 1.2 & 0.1 \\
\hline 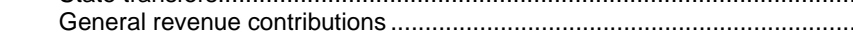 & 10.9 & 0.9 \\
\hline Equals unfunded obligations for all participants for the infinite future .................. & 0.0 & 0.0 \\
\hline 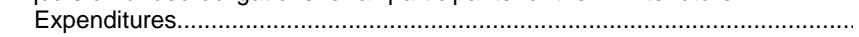 & 22.1 & 1.9 \\
\hline Income & 22.1 & 1.9 \\
\hline 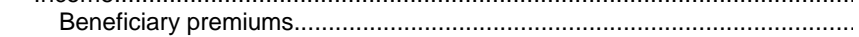 & 3.0 & 0.3 \\
\hline State transfers............................. & 1.9 & 0.2 \\
\hline General revenue contributions ......... & 17.1 & 1.5 \\
\hline
\end{tabular}

This concept is also referred to as the closed-group unfunded obligation.

Notes: 1. The estimated present value of GDP for 2007 through the infinite horizon is $\$ 1,154.1$ trillion. See note 2 of table III.B10.

2. Totals do not necessarily equal the sums of rounded components.

The long-range Part $\mathrm{D}$ projections are based on an economic model described previously for HI and SMI Part B. More information on these assumptions is available in section IV.C of this report. Section IV.B2 describes the data sources and assumptions underlying the updated Part D estimates.

It is important to note that the Trustees' Part D projections show the expected cost to the Medicare program and the income and expenditure transactions of the Part D account in the SMI trust fund. The net cost to Medicare, after accounting for premium income and State payments to Medicare, is not the same as the net cost to the Federal Government under the Medicare Modernization Act. In particular, this legislation substantially reduced Federal Medicaid outlays, thereby offsetting a portion of the increased cost to Medicare. The reduction in Medicaid outlays is not reflected in the operations of 


\section{Actuarial Analysis}

the Part D account, as shown in this report, since it is not a Medicare financial transaction.

Figure III.C6 compares the year-by-year Part D costs as a percentage of GDP for the current annual report with the corresponding projections from the 2006 report.

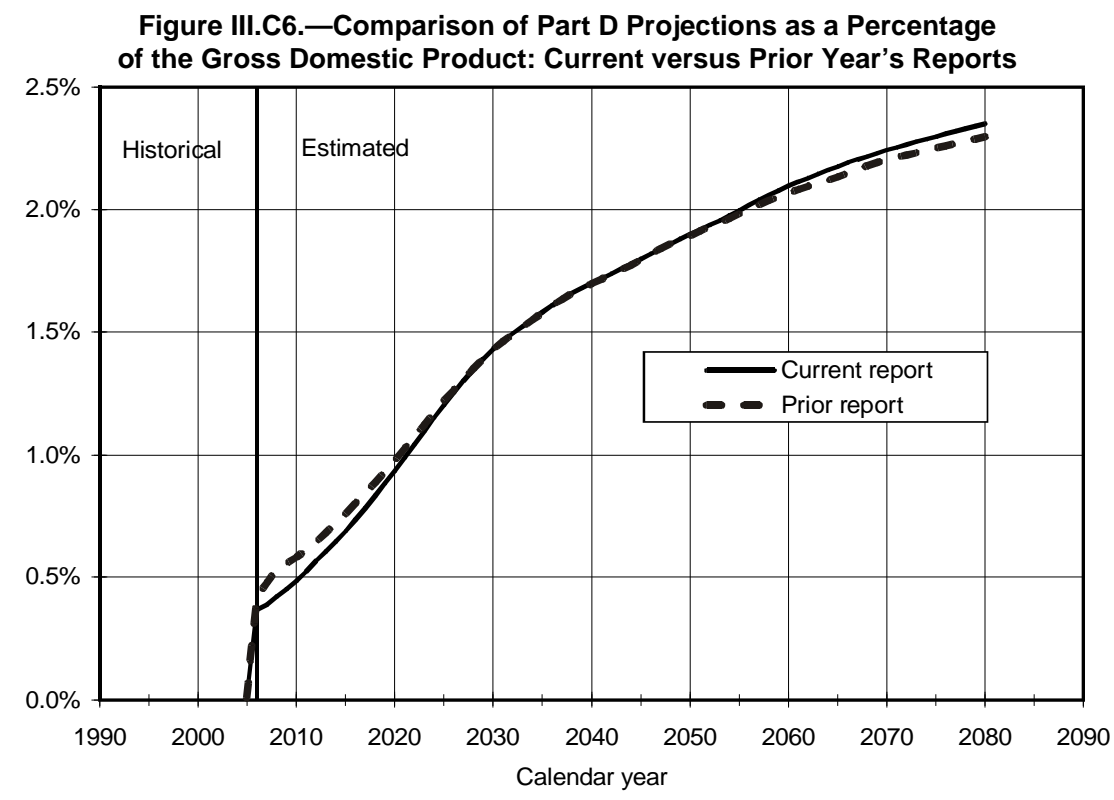

As figure III.C6 indicates, the intermediate Part D cost projections as a percentage of GDP in this report are initially lower than in last year's report, but are higher by the end of the projection. The differential starts out at -0.06 percent of GDP in 2006 and very gradually increases to +0.05 percent of GDP in 2080 .

The present values of the projected revenue and cost components of the 75-year, open-group financial obligations for HI, SMI, and OASDI are summarized in appendix table V.E2. These estimates are shown from both a trust fund perspective and a Federal Budget perspective. 


\section{ACTUARIAL METHODOLOGY AND PRINCIPAL ASSUMPTIONS FOR COST ESTIMATES FOR THE HOSPITAL INSURANCE AND SUPPLEMENTARY MEDICAL INSURANCE TRUST FUNDS}

This section describes the basic methodology and assumptions used in the estimates for the HI and SMI trust funds under the intermediate assumptions. In addition, projections of $\mathrm{HI}$ and SMI costs under two alternative sets of assumptions are presented.

The economic and demographic assumptions underlying the projections of HI and SMI costs shown in this report are consistent with those in the 2007 Annual Report of the Board of Trustees of the Federal Old-Age and Survivors Insurance and Disability Insurance Trust Funds. These assumptions are described in more detail in that report.

\section{A. HOSPITAL INSURANCE}

\section{Cost Projection Methodology}

The principal steps involved in projecting the future HI costs are (i) establishing the present cost of services provided to beneficiaries, by type of service, to serve as a projection base; (ii) projecting increases in HI payments for inpatient hospital services; (iii) projecting increases in HI payments for skilled nursing, home health, and hospice services covered; (iv) projecting increases in payments to managed care plans; and (v) projecting increases in administrative costs. The major emphasis is directed toward expenditures for fee-for-service inpatient hospital services, which accounted for approximately 64 percent of total benefits in 2006 .

\section{a. Projection Base}

To establish a suitable base from which to project the future HI costs, the incurred payments for services provided must be reconstructed for the most recent period for which a reliable determination can be made. Therefore, payments to providers must be attributed to dates of service, rather than to payment dates; in addition, the nonrecurring effects of any changes in regulations, legislation, or administration, and of any items affecting only the timing and flow of payments to providers, must be eliminated. As a result, the rates of increase in the HI incurred costs differ from the increases in cash expenditures shown in the tables in section III.B.

For those expenses still reimbursed on a reasonable-cost basis, the costs for covered services are determined on the basis of provider cost 


\section{Actuarial Methodology}

reports. Due to the time required to obtain cost reports from providers, to verify these reports, and to perform audits (where appropriate), final settlements have lagged behind the original costs by as much as several years for some providers. Additional complications are posed by changes in legislation or regulation, or in administrative or reimbursement policy, the effects of which cannot always be determined precisely.

The process of allocating the various types of HI payments made to the proper incurred period-using incomplete data and estimates of the impact of administrative actions-presents difficult problems, and the solutions to these problems can be only approximate. Under the circumstances, the best that can be expected is that the actual HI incurred cost for a recent period can be estimated within a few percent. This process increases the projection error directly, by incorporating any error in estimating the base year into all future years.

\section{b. Fee-for-Service Payments for Inpatient Hospital Costs}

Almost all inpatient hospital services covered by HI are paid under a prospective payment system. The law stipulates that the annual increase in the payment rate for each admission be related to a hospital input price index (also known as the hospital market basket), which measures the increase in prices for goods and services purchased by hospitals for use in providing care to hospital inpatients. For fiscal year 2007, the prospective payment rates have already been determined. For fiscal years 2008 and later, current statute mandates that the annual increase in the payment rate per admission equal the annual increase in the hospital input price index for those hospitals submitting required quality measure data. For this report, we assume that all hospitals will submit these data.

Increases in aggregate payments for inpatient hospital care covered under HI can be analyzed in five broad categories, all of which are presented in table IV.A1:

(1) Labor factors-the increase in the hospital input price index that is attributable to increases in hospital workers' hourly earnings (including fringe benefits);

(2) Non-labor factors-the increase in the hospital input price index that is attributable to factors other than hospital workers' hourly earnings, such as the costs of energy, food, and supplies; 
(3) Unit input intensity allowance-the amount added to or subtracted from the input price index (generally as a result of legislation) to yield the prospective payment update factor;

(4) Volume of services - the increase in total output of units of service (as measured by covered HI hospital admissions); and

(5) Other sources-a residual category, reflecting all other factors affecting hospital cost increases (such as intensity increases).

Table IV.A1 shows the estimated historical values of these principal components, as well as the projected trends used in the estimates. Unless otherwise indicated, the following discussions apply to projections under the intermediate assumptions. 
Table IV.A1.-Components of Historical and Projected Increases in HI Inpatient Hospital Payments ${ }^{1}$

ํ.ง

\begin{tabular}{|c|c|c|c|c|c|c|c|c|c|c|c|c|c|}
\hline \multirow[b]{2}{*}{$\begin{array}{c}\text { Calendar } \\
\text { year }\end{array}$} & \multirow[b]{2}{*}{$\begin{array}{l}\text { Average } \\
\text { hourly } \\
\text { earnings }\end{array}$} & \multicolumn{2}{|l|}{ Labor } & \multicolumn{3}{|c|}{ Non-labor } & \multirow[b]{2}{*}{$\begin{array}{l}\text { Input } \\
\text { price } \\
\text { index }\end{array}$} & \multirow[b]{2}{*}{$\begin{array}{l}\text { Unit input } \\
\text { intensity } \\
\text { allowance }\end{array}$} & \multicolumn{3}{|c|}{ Units of service } & \multirow[b]{2}{*}{$\begin{array}{l}\text { Other } \\
\text { sources }\end{array}$} & \multirow[b]{2}{*}{$\begin{array}{c}\mathrm{HI} \\
\text { inpatient } \\
\text { hospital } \\
\text { payments }\end{array}$} \\
\hline & & $\begin{array}{c}\text { Hospital } \\
\text { hourly } \\
\text { earnings } \\
\text { differential }\end{array}$ & $\begin{array}{l}\text { Hospital } \\
\text { hourly } \\
\text { earnings }\end{array}$ & CPI & $\begin{array}{l}\text { Hospital } \\
\text { price } \\
\text { differential }\end{array}$ & $\begin{array}{l}\text { Non-labor } \\
\text { hospital } \\
\text { prices }\end{array}$ & & & $\underset{\text { enrollment }}{\mathrm{HI}}$ & $\begin{array}{l}\text { Managed } \\
\text { care shift } \\
\text { effect }\end{array}$ & $\begin{array}{l}\text { Admission } \\
\text { incidence }\end{array}$ & & \\
\hline
\end{tabular}

Historical data:

$\begin{array}{lll}\text { Historical data. } & \\ 1997 & 3.9 \% & -2.1 \% \\ 1998 & 5.8 & -3.0 \\ 1999 & 4.9 & -1.8 \\ 2000 & 6.6 & -2.6 \\ 2001 & 4.1 & 1.2 \\ 2002 & 2.0 & 3.0 \\ 2003 & 3.5 & 0.7 \\ 2004 & 5.2 & -1.2 \\ 2005 & 3.9 & 0.0 \\ 2006 & 4.8 & -1.0\end{array}$

$2006 \quad 4.8-1.0$

\begin{tabular}{|c|c|c|c|c|c|c|c|c|c|c|c|c|c|}
\hline 2007 & 4.3 & -0.7 & 3.6 & 1.9 & 0.7 & 2.6 & 3.2 & 0.0 & 2.1 & -2.6 & 3.5 & 0.8 & 7.1 \\
\hline 2008 & 4.6 & 0.0 & 4.6 & 2.4 & 0.8 & 3.2 & 4.0 & 0.0 & 2.1 & -1.3 & -0.2 & 0.8 & 5.5 \\
\hline 2009 & 4.4 & 0.0 & 4.4 & 2.7 & 0.6 & 3.3 & 4.0 & 0.0 & 2.2 & -1.8 & -0.2 & 0.9 & 5.1 \\
\hline 2010 & 4.3 & 0.0 & 4.3 & 2.8 & 0.4 & 3.2 & 3.9 & 0.0 & 2.0 & -1.4 & -0.1 & 0.9 & 5.3 \\
\hline 2011 & 4.2 & 0.0 & 4.2 & 2.8 & 0.2 & 3.0 & 3.7 & 0.0 & 2.3 & -1.0 & -0.2 & 0.9 & 5.8 \\
\hline 2012 & 4.1 & 0.0 & 4.1 & 2.8 & 0.0 & 2.8 & 3.6 & 0.0 & 3.0 & -0.8 & -0.5 & 0.9 & 6.2 \\
\hline 2013 & 4.0 & 0.0 & 4.0 & 2.8 & 0.0 & 2.8 & 3.5 & 0.0 & 3.1 & -0.6 & -0.5 & 0.9 & 6.6 \\
\hline 2014 & 4.0 & 0.0 & 4.0 & 2.8 & 0.0 & 2.8 & 3.5 & 0.0 & 2.9 & -0.6 & -0.3 & 0.9 & 6.5 \\
\hline 2015 & 4.0 & 0.0 & 4.0 & 2.8 & 0.0 & 2.8 & 3.5 & 0.0 & 2.9 & -0.4 & -0.3 & 0.9 & 6.7 \\
\hline 2016 & 4.0 & 0.0 & 4.0 & 2.8 & 0.0 & 2.8 & 3.5 & 0.0 & 2.9 & -0.4 & -0.2 & 0.9 & 6.8 \\
\hline 2020 & 3.9 & 0.0 & 3.9 & 2.8 & 0.0 & 2.8 & 3.5 & 0.0 & 2.9 & -0.3 & 0.1 & 0.9 & 7.2 \\
\hline 2025 & 3.9 & 0.0 & 3.9 & 2.8 & 0.0 & 2.8 & 3.5 & 0.0 & 2.6 & -0.4 & 0.6 & 0.9 & 7.4 \\
\hline 2030 & 3.9 & 0.0 & 3.9 & 2.8 & 0.0 & 2.8 & 3.5 & 0.0 & 1.7 & -0.3 & 1.1 & 0.9 & 7.1 \\
\hline
\end{tabular}

'Percent increase in year indicated over previous year, on an incurred basis.

${ }^{2}$ Reflects the allowances provided for in the prospective payment update factors.

$\begin{array}{llllrrr}1.5 \% & -0.4 \% & 1.1 \% & -3.2 \% & 2.9 \% & -0.1 \% & 1.6 \% \\ 2.8 & -2.4 & 1.0 & -3.1 & 0.3 & 0.1 & -1.3 \\ 2.5 & -2.1 & 0.8 & -1.8 & 1.2 & 1.7 & 2.2 \\ 3.5 & -2.1 & 1.3 & 0.4 & -0.1 & -1.6 & 1.3 \\ 4.2 & -0.9 & 1.0 & 2.3 & 1.1 & 1.6 & 9.7 \\ 3.7 & -1.2 & 1.0 & 2.1 & 0.3 & 2.3 & 8.5 \\ 4.0 & -0.9 & 1.7 & 0.9 & -0.2 & -1.7 & 3.8 \\ 4.1 & -0.8 & 1.8 & 0.0 & -0.7 & 0.8 & 5.4 \\ 4.3 & -0.8 & 1.7 & -0.9 & 0.1 & 1.2 & 5.7 \\ 4.1 & -0.3 & 1.6 & -3.4 & -3.1 & 0.8 & -0.5\end{array}$

Note: Historical and projected data reflect the hospital input price index, which was recalibrated to a 2002 base year in 2005 . 


\section{Hospital Insurance}

Increases in hospital workers' hourly earnings can be analyzed and projected in terms of (i) the assumed increases in hourly earnings in employment in the general economy, and (ii) the difference between increases in hourly earnings in the general economy and the hospital hourly earnings used in the hospital input price index. Since HI began, the differential between hospital workers' hourly earnings and hourly earnings in the general economy has fluctuated widely, averaging about -0.7 percent since 1997 . This differential is assumed to quickly level off at zero and to remain there for the rest of the projection period.

Non-labor cost increases can similarly be analyzed in terms of a known, economy-wide price measure (the Consumer Price Index, or CPI) and a differential between the CPI and hospital-specific prices. This differential reflects price increases for non-labor goods and services that are purchased by hospitals and that do not parallel increases in the CPI. Although the price differential has fluctuated erratically in the past, it has averaged about 0.6 percent during 1997-2006. Over the short term, the hospital price differential is assumed to gradually decrease from recent levels, leveling off to zero for the remainder of the projection period.

The final input price index is calculated as a weighted average of the labor and non-labor factors described above. The weights reflect the relative use of each factor by hospitals (currently about 60 percent labor and 40 percent non-labor).

The unit input intensity allowance is generally a downward adjustment provided for by law in the prospective payment update factor; that is, it is the amount subtracted from the input price index to yield the update factor..$^{40}$ Beginning in fiscal year 2004, the law provides that increases in payments to prospective payment system hospitals for covered admissions will equal the increase in the hospital input price index for those hospitals that submit the required quality measure data. For other hospitals, the increase will be slightly smaller. For this report, we assume that all hospitals will submit these data. Thus, the unit input intensity allowance, as indicated in table IV.A1, is assumed to equal zero for all of the first 25-year projection period.

\footnotetext{
${ }^{40}$ It should be noted that the update factors are generally prescribed on a fiscal-year basis, while table IV.A1 is on a calendar-year basis. Calculations have therefore been performed to estimate the unit input intensity allowance on a calendar-year basis.
} 


\section{Actuarial Methodology}

Increases in payments for inpatient hospital services also reflect increases in the number of inpatient hospital admissions covered under HI. As shown in table IV.A1, increases in admissions are attributable to increases in both $\mathrm{HI}$ fee-for-service enrollment and admission incidence ${ }^{41}$ (admissions per beneficiary). The historical and projected increases in enrollment reflect an increase in the population aged 65 and over that is more rapid than in the total population of the United States, as well as the coverage of certain disabled beneficiaries and persons with end-stage renal disease. Increases in enrollment are expected to continue, mirroring the ongoing demographic shift into categories of the population that are eligible for HI protection.

During the 1990s, the choice of more beneficiaries to enroll in managed care plans was an offsetting effect, which is shown in the managed care shift effect column of table IV.A1. In other words, greater enrollment in managed care plans reduces the number of beneficiaries with fee-for-service Medicare coverage and thereby reduces hospital admissions paid through fee-for-service. This factor reversed during 2000-2003, as significant numbers of beneficiaries left managed care plans. More recently, with the changes introduced in the Medicare Modernization Act, more beneficiaries are again enrolling in Medicare Advantage plans. The shift is expected to continue through the projection period.

Since the beginning of the prospective payment system (PPS), increases in inpatient hospital payments from "other sources" are primarily due to three factors: (i) the changes in diagnosis-related group (DRG) coding as hospitals continue to adjust to the PPS; (ii) the trend toward treating less complicated (and thus less expensive) cases in outpatient settings, resulting in an increase in the average prospective payment per admission; and (iii) legislation affecting the payment rates. The impact of several budget reconciliation acts, sequesters as required by the Gramm-Rudman-Hollings Act, and additional legislative effects are reflected in other sources, as appropriate. The average complexity of hospital admissions (case mix) is expected to increase by 1.0 percent annually in fiscal years 2007 through 2031 as a result of an assumed continuation of the current trend toward treating less complicated cases in outpatient settings, ongoing changes in DRG coding, and the overall impact of

\footnotetext{
${ }^{41}$ For $2010-2020$, this factor is estimated to be negative, reflecting the influx of beneficiaries aged 65 (and the resulting reduction in the average age of beneficiaries) due to the retirement of the baby boom. By 2025, the aging of the baby boom is expected to increase the incidence of admissions.
} 
new technology. Additionally, part of the increase from other sources can be attributed to the increase in payments for certain costs, not included in the DRG payment, that are generally increasing at a rate slower than the input price index. Other possible sources of changes in payments include (i) a shift to more or less expensive admissions due to changes in the demographic characteristics of the covered population; (ii) changes in medical practice patterns; and (iii) adjustments in the relative payment levels for various DRGs, or addition/deletion of DRGs, in response to changes in technology.

The increases in the input price index (less any intensity allowance specified in the law), units of service, and other sources are compounded to calculate the total increase in payments for inpatient hospital services. These overall increases are shown in the last column of table IV.A1.

\section{c. Fee-for-Service Payments for Skilled Nursing Facility, Home Health Agency, and Hospice Services}

Historical experience with the number of days of care covered in skilled nursing facilities (SNFs) under HI has been characterized by wide swings. This extremely volatile experience has resulted, in part, from legislative and regulatory changes and from judicial decisions affecting the scope of coverage. Most recently, at the start of the prospective payment system (PPS) in 1998 and 1999, there were large decreases in utilization. The intermediate projections reflect modest increases in covered SNF days based on growth and aging of the population.

Increases in the average HI cost per day ${ }^{42}$ in SNFs are caused principally by increasing payroll costs for nurses and other required skilled labor. From 1991 through 1996, large rates of increase in cost per day occurred due to nursing home reform regulations. For 1997 and 1998, this increase was smaller than during the previous 6 years, but still large by historical standards. Projected rates of increase in cost per day are assumed to decline to a level slightly higher than increases in general earnings throughout the projection period. For 1998 and later, adjustments are included to reflect the implementation of the new PPS for SNFs, as required by the Balanced Budget Act of 1997. Increases in reimbursement per day also reflect implementation and expiration of special provisions from

${ }^{42}$ Cost is defined to be the total of HI reimbursement and beneficiary cost sharing. 
Actuarial Methodology

the Balanced Budget Refinement Act of 1999 and the Benefits Improvement and Protection Act of 2000.

The resulting increases in fee-for-service expenditures for SNF services are shown in table IV.A2.

\begin{tabular}{|c|c|c|c|c|c|c|c|c|c|}
\hline $\begin{array}{c}\text { Calendar } \\
\text { year }\end{array}$ & $\begin{array}{l}\text { Inpatient } \\
\text { hospital }^{2,3}\end{array}$ & $\begin{array}{c}\text { Skilled } \\
\text { nursing } \\
\text { facility }^{3}\end{array}$ & $\begin{array}{c}\text { Home } \\
\text { health } \\
\text { agency }^{3}\end{array}$ & $\begin{array}{c}\text { Managed } \\
\text { care }\end{array}$ & $\begin{array}{l}\text { Weighted } \\
\text { average }^{3,4}\end{array}$ & $\begin{array}{c}\text { HI admin- } \\
\text { istrative } \\
\text { costs }^{3,5}\end{array}$ & $\begin{array}{c}\mathrm{HI} \text { expendi- } \\
\text { tures }^{3,5}\end{array}$ & $\begin{array}{c}\mathrm{HI} \\
\text { - taxable } \\
\text { payroll }\end{array}$ & $\begin{array}{c}\text { Growth } \\
\text { rate } \\
\text { differential }^{6} \\
\end{array}$ \\
\hline \multicolumn{10}{|c|}{ Historical data: } \\
\hline 1997 & $1.6 \%$ & $16.1 \%$ & $-0.9 \%$ & $39.9 \%$ & $6.1 \%$ & $26.5 \%$ & $6.3 \%$ & $7.6 \%$ & $-1.2 \%$ \\
\hline 1998 & -1.3 & -1.6 & -44.2 & 20.1 & -4.0 & 6.3 & -3.8 & 8.0 & -11.0 \\
\hline 1999 & 2.2 & -18.3 & -39.2 & 11.4 & -1.1 & 2.9 & -1.1 & 6.7 & -7.3 \\
\hline 2000 & 1.3 & 7.5 & -29.6 & 2.5 & 0.8 & 41.3 & 1.5 & 7.9 & -6.0 \\
\hline 2001 & 9.7 & 22.2 & 47.7 & -6.0 & 9.6 & -14.0 & 9.1 & 2.3 & 6.7 \\
\hline 2002 & 8.5 & 10.7 & -4.6 & -8.5 & 5.9 & 14.4 & 6.1 & 0.4 & 5.6 \\
\hline 2003 & 3.9 & 3.5 & -12.1 & 0.1 & 3.3 & -0.5 & 3.3 & 2.7 & 0.5 \\
\hline 2004 & 5.1 & 14.3 & 9.4 & 10.5 & 7.4 & 18.3 & 7.6 & 6.1 & 1.4 \\
\hline 2005 & 5.4 & 10.9 & 7.1 & 21.0 & 8.5 & -2.6 & 8.3 & 5.3 & 2.8 \\
\hline 2006 & -0.6 & 1.9 & 3.4 & 26.9 & 4.4 & 0.0 & 4.3 & 6.5 & -2.1 \\
\hline \multicolumn{10}{|c|}{ Intermediate estimates: } \\
\hline 2007 & 7.1 & 6.3 & 6.1 & 17.2 & 8.8 & 3.7 & 8.7 & 5.3 & 3.2 \\
\hline 2008 & 5.5 & 7.1 & 7.8 & 14.6 & 7.5 & 0.8 & 7.4 & 5.6 & 1.7 \\
\hline 2009 & 5.0 & 5.4 & 6.3 & 15.4 & 7.3 & 3.0 & 7.3 & 5.4 & 1.8 \\
\hline 2010 & 5.3 & 4.6 & 5.5 & 13.6 & 7.1 & 3.1 & 7.1 & 5.1 & 1.9 \\
\hline 2011 & 5.7 & 5.1 & 5.3 & 10.3 & 6.8 & 2.8 & 6.7 & 5.0 & 1.6 \\
\hline 2012 & 6.2 & 5.4 & 5.7 & 9.4 & 6.9 & 3.4 & 6.9 & 4.7 & 2.0 \\
\hline 2013 & 6.6 & 5.7 & 6.0 & 8.9 & 7.1 & 3.5 & 7.0 & 4.5 & 2.4 \\
\hline 2014 & 6.5 & 5.8 & 6.0 & 8.8 & 7.0 & 3.5 & 7.0 & 4.4 & 2.5 \\
\hline 2015 & 6.7 & 6.0 & 6.3 & 8.2 & 7.0 & 3.6 & 7.0 & 4.5 & 2.4 \\
\hline 2016 & 6.8 & 6.2 & 6.5 & 8.5 & 7.2 & 3.8 & 7.1 & 4.5 & 2.5 \\
\hline 2020 & 7.3 & 7.2 & 7.2 & 8.5 & 7.6 & 4.4 & 7.6 & 4.3 & 3.1 \\
\hline 2025 & 7.4 & 8.1 & 7.8 & 8.8 & 7.9 & 4.7 & 7.9 & 4.2 & 3.5 \\
\hline 2030 & 7.1 & 8.5 & 7.8 & 8.3 & 7.6 & 4.6 & 7.6 & 4.2 & 3.2 \\
\hline
\end{tabular}

${ }^{1}$ Percent increase in year indicated over previous year.

${ }^{2}$ This column may differ slightly from the last column of table IV.A1, since table IV.A1 includes all persons eligible for $\mathrm{HI}$ protection while this table excludes noninsured persons.

${ }^{3}$ Costs attributable to insured beneficiaries only, on an incurred basis. Benefits and administrative costs for noninsured persons are expected to be financed through general revenue transfers and premium payments, rather than through payroll taxes.

${ }^{4}$ Includes costs for hospice care.

${ }^{5}$ Includes costs of Peer Review Organizations through 2001 and Quality Improvement Organizations beginning in 2002.

${ }^{6}$ The ratio of the increase in $\mathrm{HI}$ costs to the increase in taxable payroll. This ratio is equivalent to the percent increase in the ratio of $\mathrm{HI}$ expenditures to taxable payroll (the cost rate).

Until recently, HI experience with home health agency (HHA) payments had shown a generally upward trend, frequently with sharp increases in the number of visits from year to year. During 1989-1995, extremely large increases in the number of visits occurred. Growth slowed dramatically in 1996 and 1997, in part as a result of intensified efforts to identify fraudulent activities in this area. The growth in the benefit was also heavily affected by the enactment of the Balanced Budget Act of 1997, which introduced 


\section{Hospital Insurance}

interim per beneficiary cost limits at levels resulting in substantially lower aggregate payments. These cost limits were used until the prospective payment system was implemented in October 2000. For 1998 through 2001, data show large decreases in utilization, with utilization leveling off in 2002 and 2003. For 2004 through 2006, slightly larger increases have been observed. For 2007 and later, these increases are assumed to decrease, so more modest increases are assumed for the rest of the projection period, based on growth and aging of the population.

In addition, beginning in 1998, certain categories of HHA services were transferred from HI to SMI, but with a portion of the cost of the transferred services met through the HI trust fund during a 6-year transitional period. At the start of the HHA prospective payment system, the transferred services represented a little over one-half of all HHA services. The HHA estimates shown in this report represent the total cost to HI from (i) HI-covered HHA services, and (ii) the transitional payments to the SMI trust fund for the applicable portion of SMI HHA costs, as specified by the Balanced Budget Act of 1997. Reimbursement per episode of care $^{43}$ is assumed to increase at a slightly higher rate than increases in general earnings, but adjustments to reflect the limiting, by legislation, of HHA reimbursement per episode are included where appropriate. In particular, payments were set to be equivalent to a 15-percent reduction in the prior interim cost limits, effective October 2002. Reimbursement per episode also includes any change in the mix of services being provided. During the first year that the prospective payment system was in effect, this mix of services was much higher than anticipated. The resulting increases in fee-for-service expenditures for HHA services are shown in table IV.A2.

HI covers certain hospice care for terminally ill beneficiaries. Hospice payments are very small relative to total HI benefit payments, but they have grown rapidly in most years. This growth rate slowed dramatically in the mid-to-late 1990 s but rebounded sharply in 1999 through 2006. Although detailed hospice data are scant at this time, estimates for hospice benefit payment increases are based on mandated daily payment rates and annual payment caps, and assume a deceleration in the growth in the number of covered days. Increases in hospice payments are not shown separately in table IV.A2 due to their extremely small contribution to the weighted

${ }^{43}$ Under the HHA prospective payment system, Medicare payments are made for each episode of care, rather than for each individual home health visit. 
Actuarial Methodology

average increase for all HI types of service; they are, however, included in the average.

\section{d. Managed Care Costs}

HI payments to private health plans have generally increased significantly from the time that such plans began to participate in the Medicare program in the early 1980s. Most of the increase in expenditures has been associated with the increasing numbers of beneficiaries who have enrolled in these plans. Decreases in such enrollment occurred during 2001-2003, as a result of slow growth in Medicare capitation rates under the Balanced Budget Act of 1997; as plan costs grew at a faster rate than the capitation payments, most plans had to reduce the supplemental benefits they could offer, and a number of plans dropped out of the Medicare market. Plan participation and enrollment growth have rebounded under the Medicare Modernization Act, which raised capitation payments starting in 2004 and which introduced a competitive bidding system in 2006 and later. The Medicare managed care enrollment projections reflect more refined modeling of the growth potential in Medicare managed care enrollment. Gradually decreasing increases in Medicare Advantage plan enrollments are anticipated throughout the projection period, with an ultimate Medicare Advantage penetration rate of about 32 percent being reached by 2031 .

In its comprehensive review, the 2004 Medicare Technical Review Panel agreed that the Board of Trustees' assumption regarding the ultimate rate of beneficiary participation in Medicare Advantage plans was in a reasonable range, but recommended that the period to reach the ultimate participation rate be extended and that the participation rate be assumed to increase in even increments from the current level to the ultimate level. This recommendation is again being followed in this year's report.

\section{e. Administrative Expenses}

Historically, the cost of administering the HI trust fund has remained relatively small in comparison with benefit amounts. The ratio of administrative expenses to benefit payments has generally fallen within the range of 1 to 3 percent. The short-range projection of administrative cost is based on estimates of workloads and approved budgets for intermediaries and the Centers for Medicare \& Medicaid Services. In the long range, administrative cost increases are based on assumed increases in workloads, primarily due to growth and aging of the population, and on assumed unit cost increases of 
slightly less than the increases in average hourly earnings that are shown in table IV.A1. In addition, amounts are added to reflect the costs of administering the new MMA requirements.

\section{Financing Analysis Methodology}

Because the HI trust fund is supported by payroll taxes, HI costs must be compared on a year-by-year basis with the taxable payroll in order to analyze costs and evaluate the financing. Since the vast majority of total HI costs are related to insured beneficiaries, and since general revenue appropriations and premium payments are expected to support the uninsured segments, the remainder of this section will focus on the financing for insured beneficiaries only.

\section{a. Taxable Payroll}

Taxable payroll increases occur as a result of increases in both average covered earnings and the number of covered workers. The taxable payroll projection used in this report is based on the same economic assumptions used in the 2007 Annual Report of the Board of Trustees of the Federal Old-Age and Survivors Insurance and Disability Insurance Trust Funds. The projected increases in taxable payroll for this report, under the intermediate assumptions, are shown in table IV.A2.

\section{b. Relationship between HI Costs and Taxable Payroll}

The single most meaningful measure of cost increases, with reference to the financing of the system, is the relationship between cost increases and taxable payroll increases. If costs increase more rapidly than taxable payroll, either income rates must be increased or costs reduced (or some combination thereof) to finance the system in the future. Table IV.A2 shows the projected increases in HI costs relative to taxable payroll over the first 25-year projection period. These relative increases fluctuate, reaching 1.9 percent per year in 2010, and then increasing to a level of about 3.2 percent per year by 2030 for the intermediate assumption, as the baby boom population becomes eligible for benefits.

The result of these relative growth rates is a steady increase in the year-by-year ratios of HI expenditures to taxable payroll, as shown in table IV.A3. Under the low cost alternative, increases in HI expenditures follow a similar pattern relative to increases in taxable payroll, but at a somewhat lower rate; the rate becomes equal to the rate for taxable payroll by 2010 but then increases, reaching about 


\section{Actuarial Methodology}

1.3 percent more per year than taxable payroll by 2030 . The high cost alternative follows a comparable pattern but at a somewhat higher rate than under the intermediate assumptions, gradually becoming about 4.6 percent more than taxable payroll by 2010 and then increasing to about 5.2 percent more than taxable payroll by 2030 .

Table IV.A3.-Summary of HI Alternative Projections

\begin{tabular}{|c|c|c|c|c|c|c|c|c|}
\hline \multirow[b]{2}{*}{$\begin{array}{l}\text { Calendar } \\
\text { year }\end{array}$} & \multicolumn{4}{|c|}{$\begin{array}{c}\text { Increases in aggregate } \mathrm{HI} \\
\text { inpatient hospital payments }{ }^{1}\end{array}$} & \multicolumn{3}{|c|}{$\begin{array}{c}\text { Changes in the relationship } \\
\text { between expenditures and payroll' }\end{array}$} & \multirow{2}{*}{$\begin{array}{c}\text { Expenditures } \\
\text { as a percent } \\
\text { of taxable } \\
\text { payroll }^{3,4,5}\end{array}$} \\
\hline & $\begin{array}{c}\text { Average } \\
\text { hourly } \\
\text { earnings }\end{array}$ & $\mathrm{CPI}$ & $\begin{array}{c}\text { Other } \\
\text { factors }^{2}\end{array}$ & Total $^{3}$ & $\begin{array}{c}\mathrm{HI} \\
\text { expendi- } \\
\text { tures } \\
\end{array}$ & $\begin{array}{c}\text { Taxable } \\
\text { payroll }\end{array}$ & $\begin{array}{c}\text { Ratio of } \\
\text { expenditures } \\
\text { to payroll }\end{array}$ & \\
\hline \multicolumn{9}{|c|}{ Intermediate: } \\
\hline 2007 & $4.3 \%$ & $1.9 \%$ & $3.6 \%$ & $7.1 \%$ & $8.7 \%$ & $5.3 \%$ & $3.2 \%$ & $3.11 \%$ \\
\hline 2008 & 4.6 & 2.4 & 1.7 & 5.5 & 7.4 & 5.6 & 1.7 & 3.16 \\
\hline 2009 & 4.4 & 2.7 & 1.3 & 5.1 & 7.3 & 5.4 & 1.8 & 3.22 \\
\hline 2010 & 4.3 & 2.8 & 1.6 & 5.3 & 7.1 & 5.1 & 1.9 & 3.28 \\
\hline 2011 & 4.2 & 2.8 & 2.0 & 5.8 & 6.7 & 5.0 & 1.6 & 3.33 \\
\hline 2011 & 4.1 & 2.8 & 2.5 & 6.2 & 6.9 & 4.7 & 2.0 & 3.40 \\
\hline 2012 & 4.0 & 2.8 & 2.9 & 6.6 & 7.0 & 4.5 & 2.4 & 3.48 \\
\hline 2014 & 4.0 & 2.8 & 2.9 & 6.5 & 7.0 & 4.4 & 2.5 & 3.57 \\
\hline 2015 & 4.0 & 2.8 & 3.0 & 6.7 & 7.0 & 4.5 & 2.4 & 3.65 \\
\hline 2016 & 4.0 & 2.8 & 3.1 & 6.8 & 7.1 & 4.5 & 2.5 & 3.74 \\
\hline 2020 & 3.9 & 2.8 & 3.6 & 7.2 & 7.6 & 4.3 & 3.1 & 4.21 \\
\hline 2025 & 3.9 & 2.8 & 3.7 & 7.4 & 7.9 & 4.2 & 3.5 & 4.99 \\
\hline 2030 & 3.9 & 2.8 & 3.5 & 7.1 & 7.6 & 4.2 & 3.2 & 5.91 \\
\hline \multicolumn{9}{|l|}{ Low cost: } \\
\hline 2007 & 4.3 & 1.7 & 0.7 & 4.0 & 6.1 & 5.9 & 0.2 & 3.00 \\
\hline 2008 & 4.3 & 1.9 & 0.1 & 3.5 & 5.4 & 5.6 & -0.1 & 2.99 \\
\hline 2009 & 3.8 & 1.8 & -0.3 & 2.7 & 5.0 & 5.1 & -0.1 & 2.99 \\
\hline 2010 & 3.6 & 1.8 & 0.1 & 3.0 & 4.7 & 4.8 & 0.0 & 2.99 \\
\hline 2011 & 3.5 & 1.8 & 0.5 & 3.4 & 4.4 & 4.7 & -0.3 & 2.98 \\
\hline 2012 & 3.5 & 1.8 & 1.0 & 3.9 & 4.6 & 4.6 & 0.0 & 2.98 \\
\hline 2013 & 3.4 & 1.8 & 1.6 & 4.4 & 4.9 & 4.4 & 0.5 & 3.00 \\
\hline 2014 & 3.4 & 1.8 & 1.5 & 4.3 & 4.8 & 4.3 & 0.5 & 3.01 \\
\hline 2015 & 3.4 & 1.8 & 1.5 & 4.3 & 4.6 & 4.2 & 0.4 & 3.02 \\
\hline 2016 & 3.3 & 1.8 & 1.6 & 4.3 & 4.7 & 4.1 & 0.6 & 3.04 \\
\hline 2020 & 3.3 & 1.8 & 2.0 & 4.8 & 5.1 & 3.9 & 1.1 & 3.17 \\
\hline 2025 & 3.3 & 1.8 & 2.1 & 4.9 & 5.4 & 3.8 & 1.5 & 3.41 \\
\hline 2030 & 3.3 & 1.8 & 1.8 & 4.7 & 5.2 & 3.9 & 1.3 & 3.67 \\
\hline \multicolumn{9}{|l|}{ High cost: } \\
\hline 2007 & 3.2 & 2.6 & 6.9 & 10.1 & 11.2 & 2.9 & 8.0 & 3.27 \\
\hline 2008 & 5.5 & 2.8 & 2.6 & 7.2 & 9.1 & 5.6 & 3.3 & 3.38 \\
\hline 2009 & 4.5 & 2.9 & 3.1 & 7.1 & 9.3 & 5.7 & 3.4 & 3.49 \\
\hline 2010 & 4.0 & 4.4 & 2.8 & 7.1 & 8.8 & 4.0 & 4.6 & 3.66 \\
\hline 2011 & 7.2 & 5.7 & 2.7 & 9.5 & 10.4 & 6.8 & 3.4 & 3.78 \\
\hline 2012 & 7.1 & 5.6 & 4.4 & 11.2 & 11.9 & 8.5 & 3.1 & 3.90 \\
\hline 2013 & 5.4 & 4.7 & 5.1 & 10.5 & 10.9 & 6.1 & 4.5 & 4.08 \\
\hline 2014 & 4.6 & 3.9 & 4.8 & 9.3 & 9.8 & 5.0 & 4.6 & 4.26 \\
\hline 2015 & 4.5 & 3.8 & 4.7 & 9.2 & 9.5 & 4.9 & 4.3 & 4.45 \\
\hline 2016 & 4.5 & 3.8 & 4.8 & 9.3 & 9.6 & 4.9 & 4.5 & 4.65 \\
\hline 2020 & 4.6 & 3.8 & 5.3 & 9.8 & 10.1 & 4.8 & 5.1 & 5.65 \\
\hline 2025 & 4.6 & 3.8 & 5.4 & 10.0 & 10.4 & 4.7 & 5.5 & 7.36 \\
\hline 2030 & 4.6 & 3.8 & 5.1 & 9.6 & 10.1 & 4.7 & 5.2 & 9.59 \\
\hline
\end{tabular}

${ }^{1}$ Percent increase for the year indicated over the previous year.

${ }^{2}$ Other factors include hospital hourly earnings, hospital price input intensity, unit input intensity allowance, units of service as measured by admissions, and additional sources.

${ }^{3}$ On an incurred basis.

${ }^{4}$ Includes expenditures attributable to insured beneficiaries only. 
Hospital Insurance

${ }^{5}$ Includes hospital, SNF, HHA, managed care, and hospice expenditures; administrative costs; and costs of Quality Improvement Organizations.

\section{Projections under Alternative Assumptions}

In almost every year since the trust fund was established, average HI expenditures per beneficiary have increased substantially faster than increases in average earnings and prices in the general economy. Table IV.A2 shows the estimated past experience of HI from 1997 to 2006. As mentioned earlier, HI now makes most payments to hospitals on a prospective basis. Payments to skilled nursing facilities have been made prospectively since mid-1998, and home health reimbursement became prospective in October 2000. The prospective payment systems have made (and are expected to continue to make) HI outlays potentially less vulnerable to excessive rates of growth in the health care industry. However, there is still considerable uncertainty in projecting HI expenditures - for inpatient hospital services as well as for other types of covered services - due to the uncertainty of the underlying economic assumptions and utilization increases. Uncertainty in projecting HI expenditures also exists because of the possibility that future legislation will affect unit payment levels, particularly for inpatient hospital services. Although current law is assumed throughout the estimates shown in this report, legislation has been enacted affecting the inpatient PPS payment levels to hospitals for each of the past 22 years, and future legislation is probable.

In view of the uncertainty of future cost trends, projected HI costs have been prepared under three alternative sets of assumptions. A summary of the assumptions and results is shown in table IV.A3. Increases in the economic factors (average hourly earnings and CPI) for the three alternatives are consistent with those underlying the OASDI report.

HI costs beyond the first 25-year projection period are based on the assumption that average per beneficiary expenditures (excluding demographic impacts) will increase at a rate determined by the economic model described in sections II.C and IV.C. This rate is about 1.4 percent faster than the Gross Domestic Product (GDP) per capita in 2031, slowing down to about the same rate as GDP per capita by 2081. HI expenditures, which were 3.0 percent of taxable payroll in 2006, will increase to 5.9 percent by 2030 and to 11.7 percent by 2080 under the intermediate assumptions. Hence, if all of the projection assumptions are realized over time, the HI income rates provided in 
Actuarial Methodology

current law (3.40 percent of taxable payroll) will be grossly inadequate to support the HI cost.

During the first 25-year projection period, the low cost and high cost alternatives contain assumptions that result in HI costs increasing, relative to taxable payroll increases, approximately 2 percentage points less rapidly and 2 percentage points more rapidly, respectively, than the results under the intermediate assumptions. Costs beyond the first 25-year projection period assume that the 2-percentage-point differential gradually decreases until 2056, when HI cost increases relative to taxable payroll are approximately the same as under the intermediate assumptions. Under the low cost alternative, HI expenditures would be 3.7 percent of taxable payroll in 2030, increasing to 5.5 percent of taxable payroll by 2080 . Under the high cost alternative, HI expenditures in 2030 would increase to 9.6 percent of taxable payroll, and to 24.9 percent of taxable payroll in 2080.

\section{B. SUPPLEMENTARY MEDICAL INSURANCE}

SMI consists of Part B and, beginning in 2004, Part D. The benefits provided by each part are quite different in nature. The actuarial methodologies used to produce the estimates for each part reflect these differences and, accordingly, are presented in separate sections.

\section{Part B}

\section{a. Cost Projection Methodology}

Estimates under the intermediate assumptions are calculated separately for each category of enrollee and for each type of service. The estimates are prepared by establishing the allowed charges or costs incurred per enrollee for a recent year (to serve as a projection base) and then projecting these charges through the estimation period. The per enrollee charges are then converted to reimbursement amounts by subtracting the per enrollee values of the deductible and coinsurance. Aggregate reimbursement amounts are calculated by multiplying the per enrollee reimbursement amounts by the projected enrollment. In order to estimate cash expenditures, an allowance is made for the delay between receipt of, and payment for, the service. 
(1) Projection Base

To establish a suitable base from which to project the future Part B costs, the incurred payments for services provided must be reconstructed for the most recent period for which a reliable determination can be made. Therefore, payments to providers must be attributed to dates of service, rather than to payment dates; in addition, the nonrecurring effects of any changes in regulations, legislation, or administration, and of any items affecting only the timing and flow of payments to providers, must be eliminated. As a result, the rates of increase in the Part B incurred cost differ from the increases in cash expenditures.

\section{(a) Carrier Services}

Reimbursement amounts for physician services, durable medical equipment (DME), laboratory tests performed in physician offices and independent laboratories, and other services (such as physicianadministered drugs, free-standing ambulatory surgical center facility services, ambulance, and supplies) are paid through organizations acting for the Centers for Medicare \& Medicaid Services (CMS). These organizations, referred to as "carriers," determine whether billed services are covered under Part B and establish the allowed charges for covered services. A record of the allowed charges, the applicable deductible and coinsurance, and the amount reimbursed after reduction for coinsurance and the deductible is transmitted to CMS.

The data are tabulated on an incurred basis. As a check on the validity of the projection base, incurred reimbursement amounts are compared with cash expenditures reported by the carriers through an independent reporting system.

\section{(b) Intermediary Services}

Reimbursement amounts for institutional services under Part B are paid by the same "fiscal intermediaries" that pay for HI services. Institutional care covered under Part B includes outpatient hospital services, home health agency services, laboratory services performed in hospital outpatient departments, and other services (such as renal dialysis performed in free-standing dialysis facilities, services in outpatient rehabilitation facilities, and services in rural health clinics). 


\section{Actuarial Methodology}

Currently, there are separate payment systems for almost all the Part B institutional services. For these systems, the intermediaries determine whether billed services are covered under Part B and establish the allowed payment for covered services. A record of the allowed payment, the applicable deductible and coinsurance, and the amount reimbursed after reduction for coinsurance and the deductible is transmitted to CMS.

For those services still reimbursed on a reasonable-cost basis, the costs for covered services are determined on the basis of provider cost reports. Reimbursement for these services occurs in two stages. First, bills are submitted to the intermediaries, and interim payments are made on the basis of these bills. The second stage takes place at the close of a provider's accounting period, when a cost report is submitted and lump-sum payments or recoveries are made to correct for the difference between interim payments and final settlement amounts for providing covered services (net of coinsurance and deductible amounts). Tabulations of the bills are prepared by date of service, and the lump-sum settlements, which are reported only on a cash basis, are adjusted (using approximations) to allocate them to the time of service.

\section{(c) Managed Care Services}

Managed care plans with contracts to provide health services to Medicare beneficiaries are reimbursed directly by CMS on either a reasonable-cost or capitation basis. Comprehensive data on such direct reimbursements are available only on a cash basis. Certain approximations must be made to allocate expenses to the period when services were rendered.

(2) Fee-for-Service Payments for Aged Enrollees and Disabled Enrollees without End-Stage Renal Disease

Disabled persons with end-stage renal disease (ESRD) have per enrollee costs that are substantially higher and quite different in nature from those of most other disabled persons. Hence, Part B costs for them have been excluded from the analysis in this section and are contained in a later section. Similarly, costs associated with beneficiaries enrolled in managed care plans are discussed separately. 


\section{(a) Carrier Services}

\section{i. Physician Services}

Medicare payments for physician services are based on a fee schedule, which reflects the relative level of resources required for each service. The fee schedule amount is equal to the product of the procedure's relative value, a conversion factor, and a geographic adjustment factor. Payments are based on the lower of the actual charge and the fee schedule amount. Increases in physician fees are based on growth in the Medicare Economic Index (MEI) ${ }^{44}$ plus an update adjustment reflecting whether past growth in the volume and intensity of services met specified targets under the sustainable growth rate mechanism. Table IV.B1 shows the projected MEI increases and update adjustments for 2007 through 2016. The physician fee updates shown through 2007 are actual values. For 2008 and thereafter, the physician updates are unrealistically low, due to the requirements of the current-law sustainable growth rate system (SGR), and are extremely unlikely to actually occur. The modified update shown in column 4 reflects the growth in the MEI, the update adjustment, and legislative impacts, such as the addition of preventive services.

${ }^{44}$ The MEI is a measure of inflation in physician practice costs and general wage levels. 
Actuarial Methodology

Table IV.B1.-Components of Increases in Total Allowed Charges per Fee-for-Service Enrollee for Carrier Services

Physician fee schedule

\begin{tabular}{|c|c|c|c|c|c|c|c|c|c|}
\hline \multicolumn{6}{|c|}{ Physician fee schedule } & & & & \multirow[b]{3}{*}{$\begin{array}{l}\text { Other } \\
\text { carrier }\end{array}$} \\
\hline & $\mathrm{InCl}$ & se due & to price changes & & & & & & \\
\hline $\begin{array}{c}\text { Calendar } \\
\text { year }\end{array}$ & MEI & MPA $^{1}$ & $\begin{array}{l}\text { Physician Modified } \\
\text { update }^{2} \text { update }^{3}\end{array}$ & $\begin{array}{c}\text { Residual } \\
\text { factors }\end{array}$ & $\begin{array}{c}\text { Total } \\
\text { increase }^{4}\end{array}$ & $\mathrm{CPI}$ & DME & $\mathrm{Lab}$ & \\
\hline
\end{tabular}

Aged:

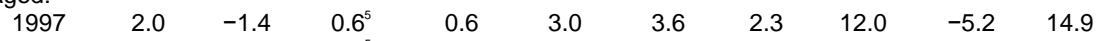

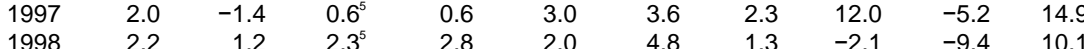

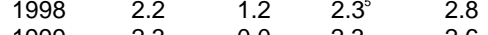

$\begin{array}{lllll}1999 & 2.3 & 0.0 & 2.3 & 2.6\end{array}$

$\begin{array}{lllll}2000 & 2.4 & 3.0 & 5.5 & 5.9 \\ 2001 & 2.1 & 3.0 & 4.8 & 5.3\end{array}$

$\begin{array}{llllr}2001 & 2.1 & 3.0 & 4.8 & 5.3 \\ 2002 & 2.6 & -7.0 & -4.8 & -4.2\end{array}$

$2003 \quad 3.0^{6} \quad-1.1^{6} \quad 1.7^{6} \quad 1.4$

$2004 \quad 2.9 \quad-1.4 \quad 1.5 \quad 3.8$

$2005 \quad 3.1 \quad-1.6 \quad 1.5 \quad 2.1$

$\begin{array}{lllll}2006 & 2.8 & -2.6 & 0.2 & 0.2\end{array}$

$\begin{array}{lllll}2007 & 2.1 & -2.1 & 0.0 & -1.4\end{array}$

$\begin{array}{lllll}2008 & 2.0 & -7.0 & -9.9^{7} & -8.2\end{array}$

$2009 \quad 2.1 \quad-7.0 \quad-5.0 \quad-7.0$

$\begin{array}{lllll}2010 & 1.7 & -7.0 & -5.4 & -5.2\end{array}$

$\begin{array}{lllll}2011 & 1.8 & -7.0 & -5.3 & -5.2\end{array}$

$\begin{array}{lllll}2012 & 1.9 & -7.0 & -5.2 & -5.1\end{array}$

$2013 \quad 2.0 \quad-7.0 \quad-5.1 \quad-5.0$

$\begin{array}{lllll}2014 & 2.1 & -7.0 & -5.0 & -5.0\end{array}$

$\begin{array}{lllll}2015 & 2.2 & -7.0 & -5.0 & -5.0\end{array}$

$\begin{array}{lllll}2016 & 2.4 & -7.0 & -4.8 & -4.8\end{array}$

$\begin{array}{ll}2.0 & 4.8 \\ 1.3 & 3.9\end{array}$

$3.6 \quad 9.6$

$4.1 \quad 9.7$

$6.1 \quad 1.7$

$4.5 \quad 6.0$

$6.0 \quad 10.0$

$3.5 \quad 5.7$

$\begin{array}{lll}5.1 & 5.2 & 3.4\end{array}$

$-9.4 \quad 10.1$

$\begin{array}{llll}2.2 & 5.0 & -0.0 & 10.7\end{array}$

$\begin{array}{llll}3.5 & 10.2 & 7.6 & 14.3 \\ 2.7 & 12.6 & 7.4 & 16.1\end{array}$

$\begin{array}{llll}2.7 & 12.6 & 7.4 & 16.1 \\ 1.4 & 12.8 & 7.0 & 17.0\end{array}$

$\begin{array}{llll}1.4 & 12.8 & 7.0 & 17.0 \\ 2.2 & 13.8 & 6.9 & 16.2\end{array}$

$\begin{array}{llll}2.6 & -0.6 & 7.6 & 7.6\end{array}$

$\begin{array}{llll}3.5 & 0.7 & 6.8 & 3.6\end{array}$

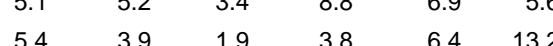

$\begin{array}{lrrrrr}7.1 & -1.6 & 2.4 & 4.2 & 5.5 & 12.1\end{array}$

$\begin{array}{llllll}6.5 & -1.0 & 2.7 & -2.1 & 7.3 & 11.7\end{array}$

$\begin{array}{llllll}3.7 & -1.7 & 2.8 & 4.4 & 7.1 & 11.0\end{array}$

$\begin{array}{llllll}3.4 & -2.0 & 2.8 & 4.4 & 6.7 & 10.7 \\ 3.1 & -2.2 & 2.8 & 5.7 & 6.0 & 9.8\end{array}$

$\begin{array}{llllll}3.1 & -2.2 & 2.8 & 5.7 & 6.0 & 9.8 \\ 3.2 & -2.1 & 2.8 & 5.7 & 6.1 & 9.2\end{array}$

$\begin{array}{llllll}3.2 & -2.1 & 2.8 & 5.7 & 6.1 & 9.2\end{array}$

$\begin{array}{llllll}3.2 & -2.0 & 2.8 & 5.8 & 6.1 & 8.6\end{array}$

$\begin{array}{llllll}3.2 & -1.9 & 2.8 & 5.8 & 6.1 & 7.9\end{array}$

Disabled (excluding ESRD):

\begin{tabular}{|c|c|c|c|c|c|c|c|c|c|c|}
\hline 1997 & 2.0 & -1.4 & $0.6^{5}$ & 0.6 & 1.8 & 2.4 & 2.3 & 14.8 & -4.2 & 8.2 \\
\hline 1998 & 2.2 & 1.2 & $2.3^{5}$ & 2.8 & 2.1 & 4.9 & 1.3 & 2.8 & -5.8 & 11.0 \\
\hline 1999 & 2.3 & 0.0 & 2.3 & 2.6 & 0.9 & 3.5 & 2.2 & 2.6 & 3.1 & 11.2 \\
\hline 2000 & 2.4 & 3.0 & 5.5 & 5.9 & 5.9 & 12.1 & 3.5 & 9.3 & 3.6 & 17.4 \\
\hline 2001 & 2.1 & 3.0 & 4.8 & 5.3 & 3.9 & 9.5 & 2.7 & 14.5 & 7.9 & 16.8 \\
\hline 2002 & 2.6 & -7.0 & -4.8 & -4.2 & 7.3 & 2.8 & 1.4 & 19.8 & 10.5 & 20.8 \\
\hline 2003 & $3.0^{6}$ & $-1.1^{6}$ & $1.7^{6}$ & 1.4 & 4.6 & 6.1 & 2.2 & 14.9 & 5.6 & 23.4 \\
\hline 2004 & 2.9 & -1.4 & 1.5 & 3.8 & 5.7 & 9.7 & 2.6 & -0.4 & 9.0 & 13.7 \\
\hline 2005 & 3.1 & -1.6 & 1.5 & 2.1 & 3.1 & 5.3 & 3.5 & 1.1 & 7.0 & 8.7 \\
\hline 2006 & 2.8 & -2.6 & 0.2 & 0.2 & 1.6 & 1.7 & 3.4 & 7.8 & 5.1 & -4.8 \\
\hline 2007 & 2.1 & -2.1 & 0.0 & -1.4 & 5.3 & 3.9 & 1.9 & 4.0 & 6.1 & 11.9 \\
\hline 2008 & 2.0 & -7.0 & $-9.9^{7}$ & -8.2 & 7.1 & -1.7 & 2.4 & 4.5 & 5.4 & 10.8 \\
\hline 2009 & 2.1 & -7.0 & -5.0 & -7.0 & 6.5 & -1.0 & 2.7 & -1.8 & 7.2 & 10.6 \\
\hline 2010 & 1.7 & -7.0 & -5.4 & -5.2 & 3.7 & -1.8 & 2.8 & 4.6 & 7.0 & 10.0 \\
\hline 2011 & 1.8 & -7.0 & -5.3 & -5.2 & 3.4 & -2.0 & 2.8 & 4.7 & 6.6 & 9.9 \\
\hline 2012 & 1.9 & -7.0 & -5.2 & -5.1 & 3.1 & -2.2 & 2.8 & 6.1 & 6.0 & 9.0 \\
\hline 2013 & 2.0 & -7.0 & -5.1 & -5.0 & 3.1 & -2.1 & 2.8 & 6.1 & 6.0 & 8.6 \\
\hline 2014 & 2.1 & -7.0 & -5.0 & -5.0 & 3.2 & -2.0 & 2.8 & 6.1 & 6.1 & 8.2 \\
\hline 2015 & 2.2 & -7.0 & -5.0 & -5.0 & 3.2 & -1.9 & 2.8 & 6.1 & 6.1 & 7.6 \\
\hline 2016 & 2.4 & -7.0 & -4.8 & -4.8 & 3.3 & -1.6 & 2.8 & 6.2 & 6.2 & 7.2 \\
\hline
\end{tabular}

${ }^{1}$ Medicare performance adjustment.

${ }^{2}$ Reflects the growth in the MEI, the update adjustment, and legislation that impacts the physician fee schedule update. The legislative impacts are -1.1 percent in 1998 and -0.2 percent in 2001-2003. For 2004 and 2005, the Medicare Modernization Act established a minimum update of 1.5 percent. For 2006, the Deficit Reduction Act froze the physician fee schedule conversion factor. The conversion factor freeze, together with refinements to the relative value units, results in an update of 0.2 percent for 2006. The conversion factor was frozen again for 2007 by the Tax Relief and Health Care Act of 2006.

${ }^{3}$ Reflects the growth in the $\mathrm{MEI}$, the update adjustment, and all legislation affecting physician servicesfor example, the addition of new preventative services enacted in 1997 and 2000. The legislative impacts would include those listed in footnote 2.

${ }^{4}$ Equals combined increases in allowed fees and residual factors.

${ }^{5}$ For this year there were separate updates for surgery, primary care, and other physician services. This value is the weighted average of these updates.

${ }^{6}$ The physician payment price changes for 2003 occurred on March 1, 2003. 
${ }^{7}$ The 2008 conversion factor is calculated as if the 2007 conversion factor had not been changed by the Tax Relief and Health Care Act of 2006.

The projected physician fee schedule expenditures should be considered unrealistically low due to the current-law structure of physician payment updates under the SGR system. The SGR requires that future physician payment increases be adjusted for past actual physician spending relative to a target spending level. The system would have led to significant reductions in physician fee schedule rates for 2003, 2004, 2005, 2006, and 2007. To avoid these reductions, the Consolidated Appropriation Resolution established a 1.7-percent update beginning in March 2003, the Medicare Modernization Act established minimum updates of 1.5 percent for 2004 and 2005, and the Deficit Reduction Act established a 0.2-percent update for 2006. ${ }^{45}$ However, the target spending level was not adjusted by any of these amendments, and, therefore, the cumulative actual physician expenditures are nearly certain to continue to exceed the SGR targets for many years.

The Tax Relief and Health Care Act (TRA) established a 0.0-percent update for 2007, increased the target spending level for 1 year, and specified that the 2008 physician fee schedule conversion factor be computed as if the 2007 physician update had not been changed by the TRA. Under current law, this situation causes projected physician updates to be about -10 percent for 2008 and about -5 percent for each of at least 8 consecutive years, beginning in 2009. The result would be a cumulative reduction in the payment rates for physician services of approximately 41 percent by 2016 . In contrast, the MEI is expected to increase by about 20 percent over the same time frame. More than 9 years of significant reductions in physician payments per service are very unlikely to occur before legislative changes intervene. (As noted, Congress has overridden the scheduled negative update for each of the past 5 years.) Despite the extremely low probability of these payment reductions actually occurring, the payment reductions are required under the current-law SGR system and are included in the physician fee schedule projections shown in this report. Therefore, the physician estimates after 2007 are of limited use for assessing the

\footnotetext{
${ }^{45}$ The Deficit Reduction Act froze the conversion factor for 2006. Changes in relative value units (RVUs), which increased the average RVU by about 0.2 percent, result in a physician fee schedule update of 0.2 percent for 2006 .
} 


\section{Actuarial Methodology}

likely future state of Part B, and these estimates should be interpreted cautiously. ${ }^{46}$

Per capita physician charges also have changed each year as a result of a number of other factors besides fee increases, including more physician visits and related services per enrollee, the aging of the Medicare population, greater use of specialists and more expensive techniques, and certain administrative actions. The fifth column of table IV.B1 shows the increases in charges per enrollee resulting from these residual factors. Because the measurement of increased allowed charges per service is subject to error, this error is included implicitly under residual causes.

Based on the increases in table IV.B1, table IV.B2 shows the estimates of the average incurred reimbursement for carrier services per fee-for-service enrollee.

${ }^{46}$ Part B projections under illustrative alternatives to the current sustainable growth rate system are shown on the CMS website at http://www.cms.hhs.gov/ ReportsTrustFunds/05_alternativePartB.asp. No endorsement of these alternatives by the Board of Trustees, CMS, or the Office of the Actuary should be inferred. 
Supplementary Medical Insurance

Table IV.B2.-Incurred Reimbursement Amounts per Fee-for-Service Enrollee for Carrier Services

\begin{tabular}{|c|c|c|c|c|c|}
\hline Calendar year & $\begin{array}{c}\text { Fee-for-service } \\
\text { enrollment } \\
\text { [millions] }\end{array}$ & $\begin{array}{c}\text { Physician fee } \\
\text { schedule }\end{array}$ & DME & Lab & Other carrier \\
\hline \multicolumn{6}{|l|}{ Aged: } \\
\hline 1997 & 27.059 & $\$ 1,037.51$ & $\$ 130.34$ & $\$ 75.23$ & $\$ 179.68$ \\
\hline 1998 & 26.289 & $1,089.33$ & 127.41 & 68.20 & 198.14 \\
\hline 1999 & 26.003 & $1,134.08$ & 133.74 & 68.35 & 219.30 \\
\hline 2000 & 26.163 & $1,248.46$ & 147.52 & 73.29 & 250.62 \\
\hline 2001 & 26.959 & $1,373.57$ & 166.49 & 78.73 & 291.31 \\
\hline 2002 & 27.686 & $1,397.76$ & 188.03 & 84.23 & 340.63 \\
\hline 2003 & 28.232 & $1,485.04$ & 214.15 & 89.84 & 396.40 \\
\hline 2004 & 28.444 & $1,639.23$ & 212.49 & 96.88 & 426.29 \\
\hline 2005 & 28.390 & $1,729.84$ & 213.67 & 103.46 & 442.54 \\
\hline 2006 & 27.532 & $1,815.63$ & 231.69 & 110.71 & 465.14 \\
\hline 2007 & 26.834 & $1,885.43$ & 242.14 & 118.00 & 522.79 \\
\hline 2008 & 26.865 & $1,851.20$ & 252.33 & 124.54 & 586.51 \\
\hline 2009 & 26.721 & $1,831.79$ & 246.96 & 133.70 & 656.01 \\
\hline 2010 & 26.655 & $1,794.94$ & 257.85 & 143.18 & 728.97 \\
\hline 2011 & 26.807 & $1,754.07$ & 269.23 & 152.76 & 807.62 \\
\hline 2012 & 27.296 & $1,709.76$ & 284.66 & 161.96 & 887.11 \\
\hline 2013 & 27.954 & $1,668.88$ & 301.01 & 171.81 & 969.28 \\
\hline 2014 & 28.574 & $1,630.01$ & 318.68 & 182.37 & $1,053.40$ \\
\hline 2015 & 29.240 & $1,592.85$ & 337.27 & 193.56 & $1,137.42$ \\
\hline 2016 & 29.932 & $1,571.57$ & 357.54 & 205.68 & $1,221.50$ \\
\hline \multicolumn{6}{|c|}{ Disabled (excluding ESRD): } \\
\hline 1997 & 3.812 & 860.86 & 177.90 & 63.98 & 149.83 \\
\hline 1998 & 3.886 & 903.74 & 182.74 & 60.23 & 166.52 \\
\hline 1999 & 3.989 & 936.88 & 187.30 & 62.06 & 184.79 \\
\hline 2000 & 4.137 & $1,055.96$ & 204.68 & 64.38 & 216.55 \\
\hline 2001 & 4.355 & $1,160.01$ & 234.68 & 69.44 & 251.95 \\
\hline 2002 & 4.563 & $1,195.45$ & 281.70 & 76.65 & 303.45 \\
\hline 2003 & 4.847 & $1,274.53$ & 323.63 & 80.91 & 374.88 \\
\hline 2004 & 5.096 & $1,405.62$ & 321.85 & 88.26 & 426.71 \\
\hline 2005 & 5.302 & $1,479.78$ & 325.59 & 94.52 & 465.42 \\
\hline 2006 & 5.380 & $1,505.33$ & 351.85 & 99.82 & 444.57 \\
\hline 2007 & 5.432 & $1,546.58$ & 370.10 & 106.41 & 500.80 \\
\hline 2008 & 5.527 & $1,517.70$ & 386.78 & 112.15 & 555.25 \\
\hline 2009 & 5.633 & $1,501.65$ & 379.75 & 120.21 & 614.60 \\
\hline 2010 & 5.746 & $1,470.98$ & 397.29 & 128.60 & 676.24 \\
\hline 2011 & 5.837 & $1,436.87$ & 415.82 & 137.09 & 743.27 \\
\hline 2012 & 5.912 & $1,400.05$ & 441.32 & 145.26 & 810.61 \\
\hline 2013 & 6.000 & $1,366.37$ & 468.30 & 154.02 & 880.72 \\
\hline 2014 & 6.086 & $1,334.30$ & 497.18 & 163.42 & 952.91 \\
\hline 2015 & 6.175 & $1,303.62$ & 527.71 & 173.39 & $1,025.62$ \\
\hline 2016 & 6.260 & $1,302.44$ & 560.36 & 184.20 & $1,099.23$ \\
\hline
\end{tabular}

ii. DME, Laboratory, and Other Carrier Services

As with physician services, over time unique fee schedules or reimbursement mechanisms have been established for virtually all other non-physician carrier services. Table IV.B1 shows the increases in the allowed charges per fee-for-service enrollee for DME, laboratory services, and other carrier services. Based on the increases in table IV.B1, table IV.B2 shows the corresponding estimates of the average incurred reimbursement for these services per fee-for-service enrollee. The fee schedules for each of these expenditure categories 


\section{Actuarial Methodology}

are updated by increases in the CPI, together with any applicable legislated limits on payment updates. In addition, per capita charges for these expenditure categories have grown as a result of a number of other factors, including increased number of services provided, the aging of the Medicare population, more expensive services, and certain administrative actions. This growth is projected based on recent past trends in growth per enrollee.

\section{(b) Intermediary Services}

Over the years, legislation has been enacted to establish new payment systems for virtually all Part B intermediary services. A fee schedule was established for tests performed in laboratories in hospital outpatient departments. The Balanced Budget Act of 1997 (BBA) implemented a prospective payment system (PPS), which began August 1, 2000, for services performed in the outpatient department of a hospital. It also implemented a PPS for home health agency services, which began October 1, 2000.

The historical and projected increases in charges and costs per feefor-service enrollee for intermediary services are shown in table IV.B3. 
Supplementary Medical Insurance

Table IV.B3.-Components of Increases in Recognized Charges and Costs per Fee-for-Service Enrollee for Intermediary Services

\begin{tabular}{|c|c|c|c|c|}
\hline Calendar year & Outpatient hospital & $\begin{array}{l}\text { Home health } \\
\text { agency }^{1}\end{array}$ & Outpatient lab & Other intermediary \\
\hline \multicolumn{5}{|l|}{ Aged: } \\
\hline 1997 & $7.4 \%$ & $1.6 \%$ & $8.7 \%$ & $11.9 \%$ \\
\hline 1998 & -1.5 & $2,990.3^{2,3}$ & 4.1 & -4.0 \\
\hline 1999 & 9.5 & $-1.4^{2,3}$ & 12.6 & -21.0 \\
\hline 2000 & -0.8 & $14.5^{3}$ & 5.3 & 19.7 \\
\hline 2001 & 12.5 & $-51.0^{3}$ & 0.7 & 14.4 \\
\hline 2002 & -1.4 & $3.1^{3}$ & 13.5 & 20.7 \\
\hline 2003 & 5.3 & $4.5^{3}$ & 7.8 & 3.9 \\
\hline 2004 & 11.0 & 14.6 & 8.3 & 15.3 \\
\hline 2005 & 10.7 & 16.2 & 8.0 & 17.2 \\
\hline 2006 & 13.5 & 6.3 & 12.5 & 8.8 \\
\hline 2007 & 9.9 & 8.6 & 7.1 & 9.9 \\
\hline 2008 & 10.0 & 7.5 & 3.5 & -2.7 \\
\hline 2009 & 9.7 & 6.6 & 7.4 & 6.1 \\
\hline 2010 & 9.1 & 5.5 & 7.1 & 5.8 \\
\hline 2011 & 7.8 & 4.6 & 6.8 & 5.5 \\
\hline 2012 & 7.0 & 3.8 & 6.2 & 5.2 \\
\hline 2013 & 7.1 & 3.5 & 6.2 & 5.1 \\
\hline 2014 & 7.0 & 3.7 & 6.3 & 5.1 \\
\hline 2015 & 7.0 & 3.9 & 6.3 & 5.1 \\
\hline 2016 & 7.1 & 4.0 & 6.3 & 5.1 \\
\hline \multicolumn{5}{|c|}{ Disabled (excluding ESRD): } \\
\hline 1997 & 6.1 & - & 5.7 & 18.5 \\
\hline 1998 & -3.5 & $-^{2,3}$ & 0.8 & -1.3 \\
\hline 1999 & 8.8 & $-1.5^{2,3}$ & 14.3 & -12.9 \\
\hline 2000 & 2.0 & $14.0^{3}$ & 7.4 & -15.6 \\
\hline 2001 & 13.4 & $-44.2^{3}$ & 7.3 & 0.7 \\
\hline 2002 & 3.9 & $4.7^{3}$ & 13.9 & 21.9 \\
\hline 2003 & 5.1 & $5.0^{3}$ & 6.4 & -2.9 \\
\hline 2004 & 13.0 & 14.3 & 10.3 & 22.6 \\
\hline 2005 & 11.7 & 17.3 & 10.2 & 14.9 \\
\hline 2006 & 8.0 & 5.9 & 9.3 & 12.4 \\
\hline 2007 & 9.8 & 8.2 & 7.0 & 9.8 \\
\hline 2008 & 9.9 & 8.2 & 3.4 & -3.2 \\
\hline 2009 & 9.7 & 7.4 & 7.3 & 5.8 \\
\hline 2010 & 9.1 & 6.0 & 7.1 & 5.9 \\
\hline 2011 & 7.8 & 5.2 & 6.7 & 5.8 \\
\hline 2012 & 7.0 & 5.0 & 6.2 & 5.8 \\
\hline 2013 & 7.1 & 4.8 & 6.2 & 5.8 \\
\hline 2014 & 7.0 & 4.8 & 6.3 & 5.9 \\
\hline 2015 & 7.0 & 4.8 & 6.2 & 5.8 \\
\hline 2016 & 7.1 & 4.8 & 6.3 & 5.9 \\
\hline
\end{tabular}

${ }^{1}$ From July 1, 1981 to December 31, 1997, home health agency (HHA) services were almost exclusively provided by Part A. However, for those Part B enrollees not entitled to Part A, the coverage of these services was provided by Part B. During that time, since all Part B disabled enrollees were entitled to Part A, their coverage of these services was provided by Part $A$.

${ }^{2}$ Effective January 1,1998, the coverage of a majority of HHA services for those individuals entitled to Part A and enrolled in Part B was transferred from Part A to Part B. As a result, as of January 1, 1998, there was a large increase in Part B expenditures for these services for the aged enrollees, and Part $B$ coverage for these services resumed for disabled enrollees.

${ }^{3}$ Does not reflect the impact of adjustment for monies transferred from the Part A trust fund for HHA costs, as provided for by the Balanced Budget Act of 1997.

Based on the increases in table IV.B3, table IV.B4 shows the estimates of the incurred reimbursement for the various intermediary services per fee-for-service enrollee. Each of these expenditure 
Actuarial Methodology

categories is projected on the basis of recent past trends in growth per enrollee, together with applicable legislated limits on payment updates.

\begin{tabular}{|c|c|c|c|c|c|}
\hline Calendar year & $\begin{array}{c}\text { Fee-for-service } \\
\text { enrollment } \\
\text { [millions] }\end{array}$ & $\begin{array}{c}\text { Outpatient } \\
\text { hospital }\end{array}$ & $\begin{array}{c}\text { Home health } \\
\text { agency }\end{array}$ & Outpatient lab & $\begin{array}{c}\text { Other } \\
\text { intermediary }\end{array}$ \\
\hline \multicolumn{6}{|l|}{ Aged: } \\
\hline 1997 & 27.059 & $\$ 296.75$ & $\$ 8.89$ & $\$ 46.64$ & $\$ 155.93$ \\
\hline 1998 & 26.289 & 277.23 & $274.78^{1}$ & 48.54 & 146.04 \\
\hline 1999 & 26.003 & 292.92 & $270.85^{1}$ & 54.68 & 120.60 \\
\hline 2000 & 26.163 & 297.41 & $310.16^{1}$ & 57.56 & 146.73 \\
\hline 2001 & 26.959 & 396.89 & $151.98^{1}$ & 57.94 & 168.24 \\
\hline 2002 & 27.686 & 396.10 & $156.67^{1}$ & 65.74 & 206.24 \\
\hline 2003 & 28.232 & 444.50 & $163.78^{1}$ & 70.85 & 211.35 \\
\hline 2004 & 28.444 & 509.45 & 187.68 & 76.76 & 242.01 \\
\hline 2005 & 28.390 & 579.69 & 218.12 & 82.89 & 281.90 \\
\hline 2006 & 27.532 & 678.63 & 231.88 & 93.25 & 306.07 \\
\hline 2007 & 26.834 & 755.62 & 251.91 & 99.89 & 344.60 \\
\hline 2008 & 26.865 & 840.52 & 270.73 & 103.37 & 335.08 \\
\hline 2009 & 26.721 & 932.07 & 288.64 & 110.98 & 355.54 \\
\hline 2010 & 26.655 & $1,027.34$ & 304.62 & 118.87 & 376.21 \\
\hline 2011 & 26.807 & $1,118.76$ & 318.63 & 126.91 & 396.86 \\
\hline 2012 & 27.296 & $1,208.53$ & 330.65 & 134.75 & 417.35 \\
\hline 2013 & 27.954 & $1,305.58$ & 342.30 & 143.14 & 438.77 \\
\hline 2014 & 28.574 & $1,409.20$ & 355.05 & 152.12 & 461.28 \\
\hline 2015 & 29.240 & $1,520.27$ & 368.73 & 161.64 & 484.66 \\
\hline 2016 & 29.932 & $1,640.92$ & 383.66 & 171.90 & 509.60 \\
\hline \multicolumn{6}{|c|}{ Disabled (excluding ESRD): } \\
\hline 1997 & 3.812 & 316.04 & - & 53.18 & 160.50 \\
\hline 1998 & 3.886 & 289.89 & $182.05^{1}$ & 53.62 & 154.51 \\
\hline 1999 & 3.989 & 304.92 & $179.26^{1}$ & 61.28 & 140.42 \\
\hline 2000 & 4.137 & 322.54 & $204.34^{1}$ & 65.80 & 119.98 \\
\hline 2001 & 4.355 & 436.17 & $114.01^{1}$ & 70.61 & 124.94 \\
\hline 2002 & 4.563 & 456.21 & $119.34^{1}$ & 80.46 & 155.01 \\
\hline 2003 & 4.847 & 503.57 & $125.31^{1}$ & 85.60 & 147.66 \\
\hline 2004 & 5.096 & 584.12 & 143.26 & 94.43 & 179.26 \\
\hline 2005 & 5.302 & 666.98 & 168.02 & 104.05 & 202.50 \\
\hline 2006 & 5.380 & 742.12 & 177.90 & 113.74 & 227.26 \\
\hline 2007 & 5.432 & 825.20 & 192.57 & 121.75 & 259.95 \\
\hline 2008 & 5.527 & 917.47 & 208.35 & 125.94 & 251.38 \\
\hline 2009 & 5.633 & $1,017.10$ & 223.76 & 135.15 & 266.13 \\
\hline 2010 & 5.746 & $1,120.48$ & 237.29 & 144.71 & 281.76 \\
\hline 2011 & 5.837 & $1,219.51$ & 249.66 & 154.46 & 298.20 \\
\hline 2012 & 5.912 & $1,316.74$ & 262.08 & 163.97 & 315.42 \\
\hline 2013 & 6.000 & $1,422.07$ & 274.70 & 174.15 & 333.83 \\
\hline 2014 & 6.086 & $1,534.52$ & 287.90 & 185.06 & 353.48 \\
\hline 2015 & 6.175 & $1,655.04$ & 301.65 & 196.62 & 374.22 \\
\hline 2016 & 6.260 & $1,785.92$ & 316.02 & 209.08 & 396.49 \\
\hline
\end{tabular}

${ }^{1}$ See footnote 3 of table IV.B3

As indicated in table IV.B4, expenditures for outpatient hospital services are expected to increase significantly due to provisions in the BBA, the Balanced Budget Refinement Act of 1999, and the Benefits Improvement and Protection Act of 2000 that reduce beneficiaries' coinsurance payments but maintain the same total payment to the 
hospital. The result is that Medicare pays a larger portion of the total outpatient hospital costs.

(3) Fee-for-Service Payments for Persons with End-Stage Renal Disease

Most persons with ESRD are eligible to enroll for Part B coverage. For analytical purposes, enrollees with ESRD who are also eligible as Disability Insurance beneficiaries are included in this section because their per enrollee costs are both higher and different in nature from those of most other disabled persons. Specifically, most of the Part B reimbursements for these persons are for kidney transplants and renal dialysis.

The estimates under the intermediate assumptions reflect the unique payment mechanism through which ESRD services are reimbursed under Medicare. Also, the estimates assume a continued increase in enrollment. The historical and projected enrollment and costs for Part B benefits are shown in table IV.B5.

Table IV.B5.-Enrollment and Incurred Reimbursement for End-Stage Renal Disease

\begin{tabular}{|c|c|c|c|c|}
\hline \multirow[b]{2}{*}{ Calendar year } & \multicolumn{2}{|c|}{ Average enrollment [thousands] } & \multicolumn{2}{|c|}{ Reimbursement [millions] } \\
\hline & Disabled ESRD & ESRD only & Disabled ESRD & ESRD only \\
\hline 1997 & 83 & 77 & $\$ 1,478$ & $\$ 1,443$ \\
\hline 1998 & 88 & 78 & 1,377 & 1,279 \\
\hline 1999 & 92 & 80 & 1,500 & 1,296 \\
\hline 2000 & 97 & 82 & 1,559 & 1,290 \\
\hline 2001 & 103 & 85 & 1,854 & 1,431 \\
\hline 2002 & 107 & 88 & 2,091 & 1,704 \\
\hline 2003 & 113 & 90 & 2,411 & 1,740 \\
\hline 2004 & 117 & 91 & 2,743 & 1,854 \\
\hline 2005 & 120 & 93 & 3,145 & 2,017 \\
\hline 2006 & 121 & 95 & 3,490 & 2,204 \\
\hline 2007 & 122 & 97 & 3,715 & 2,360 \\
\hline 2008 & 124 & 98 & 3,750 & 2,360 \\
\hline 2009 & 127 & 99 & 4,001 & 2,505 \\
\hline 2010 & 130 & 101 & 4,268 & 2,652 \\
\hline 2011 & 132 & 101 & 4,526 & 2,794 \\
\hline 2012 & 134 & 102 & 4,783 & 2,927 \\
\hline 2013 & 137 & 103 & 5,074 & 3,066 \\
\hline 2014 & 140 & 103 & 5,385 & 3,212 \\
\hline 2015 & 143 & 104 & 5,716 & 3,364 \\
\hline 2016 & 146 & 104 & 6,073 & 3,526 \\
\hline
\end{tabular}

(4) Managed Care Costs

Part B experience with managed care payments has generally shown a strong upward trend. However, in 2001, 2002, and 2003, there was a reduction in the number of Medicare beneficiaries choosing to enroll in managed care plans for the reasons given previously in the HI methodology section. In 2004, 2005, and 2006, the number of Medicare enrollees who selected a managed care plan to provide their 


\section{Actuarial Methodology}

Medicare benefits increased, reflecting increased payments to these plans under the MMA. Capitated plans currently account for approximately 95 percent of all Part B managed care enrollees. For capitated plans, per capita payment amounts have grown, following legislative changes and the same trend as fee-for-service per capita cost growth, based on the formula in the law to calculate capitation amounts. The projection of future per capita amounts follows the requirements of the MMA and the BBA in regard to the Medicare Advantage capitation amounts, which increase at rates based on the per capita growth for all of Medicare and, beginning in 2006, on the amounts bid by Medicare Advantage plans. Table IV.B6 shows the estimated number of Part B beneficiaries enrolled in a managed care plan and the aggregate incurred reimbursements associated with those enrollees.

Table IV.B6.-Enrollment and Incurred Reimbursement for Managed Care

\begin{tabular}{cccc}
\hline Calendar year & $\begin{array}{c}\text { Average enrollment } \\
\text { [millions] }\end{array}$ & $\begin{array}{c}\text { Percentage of total } \\
\text { enrollment }\end{array}$ & \begin{tabular}{c} 
Reimbursement [millions] \\
\hline 1997
\end{tabular} $5^{4.414}$ \\
1998 & 6.416 & $13.1 \%$ & $\$ 10,746$ \\
1999 & 6.857 & 15.8 & $15,839^{1}$ \\
2000 & 6.856 & 16.9 & $17,653^{1}$ \\
2001 & 6.166 & 16.9 & $18,620^{1}$ \\
2002 & 5.538 & 13.3 & $17,565^{1}$ \\
2003 & 5.302 & 12.2 & $17,517^{1}$ \\
2004 & 5.375 & 12.1 & $17,234^{1}$ \\
2005 & 5.794 & 12.9 & 19,473 \\
2006 & 7.143 & 16.4 & 22,940 \\
2007 & 8.240 & 18.9 & 32,014 \\
2008 & 8.865 & 20.9 & 37,365 \\
2009 & 9.713 & 22.5 & 42,047 \\
2010 & 10.424 & 23.7 & 48,138 \\
2011 & 11.024 & 24.6 & 54,298 \\
2012 & 11.637 & 25.3 & 59,601 \\
2013 & 12.211 & 25.8 & 65,202 \\
2014 & 12.790 & 26.3 & 71,036 \\
2015 & 13.337 & 26.7 & 77,328 \\
2016 & 13.906 & 27.1 & 83,866 \\
& & & 91,120 \\
\hline
\end{tabular}

'See footnote 3 of table IV.B3.

In 2006, there was a substantial increase in Medicare Advantage enrollment, as the provisions of the MMA gave higher payments to Medicare Advantage plans. The higher payments provide incentives for expansion of coverage areas and for the provision of additional benefits to plan enrollees. In addition, preferred provider plan demonstrations were conducted from 2003 through 2005 that increased total managed care enrollment for those years. In its comprehensive review, the 2004 Medicare Technical Review Panel agreed that the Board of Trustees' assumption regarding the ultimate rate of beneficiary participation is in a reasonable range, but recommended that the period to reach the ultimate beneficiary participation rate be extended and that the beneficiary participation 
rate be assumed to increase in even increments from the current level to the ultimate level. This recommendation is again being followed in this report.

\section{(5) Administrative Expenses}

The ratio of Part $\mathrm{B}$ administrative expenses to benefit payments has declined to about 2 percent in recent years and is projected to continue to decline in future years. Projections of administrative costs are based on estimates of changes in average annual wages.

\section{b. Summary of Aggregate Reimbursement Amounts on a Cash Basis under the Intermediate Assumptions}

Table IV.B7 shows aggregate historical and projected reimbursement amounts on a cash basis under the intermediate assumptions, by type of service. The difference between reimbursement amounts on a cash versus incurred basis results from the lag between the time of service and the time of payment. This lag has been gradually decreasing. 


\begin{tabular}{|c|c|c|c|c|c|c|c|c|c|c|c|c|c|}
\hline \multirow[b]{2}{*}{$\begin{array}{c}\text { Calendar } \\
\text { year }\end{array}$} & \multicolumn{5}{|c|}{ Carrier } & \multicolumn{5}{|c|}{ Intermediary } & \multirow[b]{2}{*}{ Total FFS } & \multirow[b]{2}{*}{$\begin{array}{c}\text { Managed } \\
\text { care }\end{array}$} & \multirow[b]{2}{*}{$\begin{array}{c}\text { Total } \\
\text { Part B }\end{array}$} \\
\hline & $\begin{array}{c}\text { Physician } \\
\text { fee schedule }\end{array}$ & DME & Lab & Other & Total & Hospital & Lab & $\begin{array}{c}\text { Home health } \\
\text { agency }\end{array}$ & Other & Total & & & \\
\hline \multicolumn{14}{|c|}{ Historical data: } \\
\hline 1997 & $\$ 31,898$ & $\$ 4,236$ & $\$ 2,385$ & $\$ 5,586$ & $\$ 44,105$ & $\$ 9,358$ & $\$ 1,503$ & $\$ 239$ & $\$ 6,575$ & $\$ 17,674$ & $\$ 61,779$ & $\$ 10,962$ & $\$ 72,740$ \\
\hline 1998 & 32,449 & 4,037 & 2,087 & 5,940 & 44,514 & 8,712 & 1,541 & $6,169^{1}$ & 6,381 & 22,804 & $67,318^{1}$ & $15,338^{1}$ & $82,656^{1}$ \\
\hline 1999 & 33,354 & 4,279 & 2,078 & 6,451 & 46,163 & 8,790 & 1,680 & $6,792^{1}$ & 5,773 & $23,036^{1}$ & $69,199^{1}$ & $17,702^{1}$ & $86,901^{1}$ \\
\hline 2000 & 36,963 & 4,718 & 2,226 & 7,408 & 51,315 & 8,435 & 1,770 & $9,169^{1}$ & 6,208 & $25,582^{1}$ & $76,897^{1}$ & $18,358^{1}$ & $95,256^{1}$ \\
\hline 2001 & 42,034 & 5,439 & 2,436 & 8,904 & 58,813 & 12,767 & 1,936 & $4,513^{1}$ & 7,119 & $26,336^{1}$ & $85,149^{1}$ & $17,560^{1}$ & $102,709^{1}$ \\
\hline 2002 & 44,824 & 6,529 & 2,788 & 10,873 & 65,014 & 13,569 & 2,235 & $5,019^{1}$ & 8,709 & $29,531^{1}$ & $94,545^{1}$ & $17,497^{1}$ & $112,042^{1}$ \\
\hline 2003 & 48,326 & 7,534 & 2,983 & 12,933 & 71,775 & 15,293 & 2,479 & $5,095^{1}$ & 9,687 & $32,555^{1}$ & $104,331^{1}$ & $17,250^{1}$ & $121,581^{1}$ \\
\hline 2004 & 54,085 & 7,724 & 3,316 & 14,188 & 79,314 & 17,424 & 2,732 & 5,853 & 10,856 & 36,865 & 116,179 & 18,672 & 134,851 \\
\hline 2005 & 57,740 & 7,906 & 3,551 & 15,319 & 84,516 & 20,210 & 2,954 & 7,094 & 12,176 & 42,433 & 126,949 & 22,012 & 148,961 \\
\hline 2006 & 58,351 & 8,404 & 3,734 & 15,174 & 85,662 & 23,847 & 3,394 & 7,163 & 14,105 & 48,509 & 134,170 & 31,460 & 165,630 \\
\hline \multicolumn{14}{|c|}{ Intermediate estimates: } \\
\hline 2007 & 59,618 & 8,613 & 3,873 & 16,838 & 88,943 & 24,479 & 3,329 & 7,702 & 14,126 & 49,636 & 138,579 & 37,365 & 175,944 \\
\hline 2008 & 59,085 & 9,012 & 4,101 & 18,917 & 91,115 & 28,016 & 3,564 & 8,295 & 14,305 & 54,180 & 145,295 & 42,047 & 187,342 \\
\hline 2009 & 58,163 & 8,895 & 4,393 & 21,127 & 92,578 & 31,082 & 3,815 & 8,852 & 15,018 & 58,768 & 151,346 & 48,138 & 199,485 \\
\hline 2010 & 57,181 & 9,259 & 4,711 & 23,479 & 94,631 & 34,332 & 4,096 & 9,367 & 15,893 & 63,688 & 158,319 & 54,298 & 212,617 \\
\hline 2011 & 56,251 & 9,749 & 5,062 & 26,151 & 97,212 & 37,686 & 4,406 & 9,883 & 16,835 & 68,809 & 166,022 & 59,601 & 225,622 \\
\hline 2012 & 55,746 & 10,471 & 5,457 & 29,182 & 100,856 & 41,400 & 4,756 & 10,448 & 17,909 & 74,512 & 175,368 & 65,202 & 240,570 \\
\hline 2013 & 55,634 & 11,323 & 5,917 & 32,590 & 105,463 & 45,710 & 5,162 & 11,078 & 19,139 & 81,090 & 186,553 & 71,036 & 257,589 \\
\hline 2014 & 55,476 & 12,237 & 6,410 & 36,156 & 110,278 & 50,356 & 5,597 & 11,749 & 20,436 & 88,138 & 198,417 & 77,328 & 275,745 \\
\hline 2015 & 55,391 & 13,234 & 6,949 & 39,895 & 115,469 & 55,486 & 6,074 & 12,482 & 21,828 & 95,869 & 211,338 & 83,866 & 295,204 \\
\hline 2016 & 55,939 & 14,329 & 7,543 & 43,797 & 121,608 & 61,174 & 6,596 & 13,283 & 23,334 & 104,387 & 225,995 & 91,120 & 317,115 \\
\hline
\end{tabular}




\section{c. Projections under Alternative Assumptions}

Part B cash expenditures for the low cost and high cost alternatives were developed by modifying the growth rates estimated under the intermediate assumptions. Beginning in the middle of calendar year 2006, the low cost and high cost incurred benefits for the following 4 quarters reflect some variation relative to the intermediate assumptions. Thereafter, the low cost and high cost alternatives contain assumptions that result in incurred benefits increasing, relative to the Gross Domestic Product (GDP), 2 percent less rapidly and 2 percent more rapidly, respectively, than the results under the intermediate assumptions. Administrative expenses under the low cost and the high cost alternatives are projected on the basis of their respective wage series growth. Based on the above methodology, cash expenditures as a percentage of GDP were calculated for all three sets of assumptions and are displayed in table IV.B8.

\begin{tabular}{cccc}
\multicolumn{2}{c}{$\begin{array}{c}\text { Table IV.B8.-Part B Cash Expenditures as a Percentage } \\
\text { of the Gross Domestic Product for Calendar Years 2006-2016 }\end{array}$} \\
\cline { 2 - 4 } Calendar year & Intermediate assumptions & Low cost & Alternatives \\
\hline 2006 & $1.27 \%$ & $1.27 \%$ & High cost \\
2007 & 1.29 & 1.26 & $1.27 \%$ \\
2008 & 1.31 & 1.26 & 1.35 \\
2009 & 1.32 & 1.25 & 1.44 \\
2010 & 1.34 & 1.24 & 1.48 \\
2011 & 1.36 & 1.23 & 1.53 \\
2012 & 1.38 & 1.22 & 1.58 \\
2013 & 1.41 & 1.22 & 1.65 \\
2014 & 1.44 & 1.23 & 1.72 \\
2015 & 1.47 & 1.23 & 1.80 \\
2016 & 1.51 & 1.24 & 1.88 \\
\hline
\end{tabular}

\section{Part D}

The voluntary prescription drug benefit, which started on January 1, 2006, presents challenges for projecting its costs. Except for limited specific drugs, Medicare has no historical experience in covering outpatient prescription drugs - and many provisions of the reimbursement mechanism are without precedent. Data on Part D plan bid submissions for 2006 and 2007 are now available, as is actual Part D enrollment for 2006. These new data sources have been used for the Part D projections shown in this report.

\section{a. Participation Rates}

All individuals enrolled in Medicare Part A or Part B are eligible to enroll in the voluntary prescription drug benefit. However, 
Actuarial Methodology

individuals for whom Medicare is the secondary payer are not assumed to enroll in Part D.

\section{(1) Employer-Sponsored Plans}

There are several options for employer-sponsored plans to benefit from the Part D program. One option is the retiree drug subsidy, in which Medicare will subsidize qualifying employer-sponsored plans a portion of their qualifying retiree drug expenses, which are determined without regard to plan reimbursements. About 25 percent of beneficiaries enrolled in Part D were covered by this subsidy in 2006. This proportion is assumed to grade down to about 11 percent in 2016.

Other options for an employer-sponsored plan are to enroll in an employer/union-only group welfare plan, wrap around an existing Part D plan, or become a prescription drug plan itself. The subsidies for these types of arrangements will generally be calculated in the same way as for other Part D plans. It is expected that such plans will offer additional benefits beyond the standard Part D benefit package, resulting in lower Part $\mathrm{D}$ reinsurance payments. About 5 percent of beneficiaries enrolled in Part D were covered by these employer-sponsored plans in 2006, grading up to about 12 percent in 2016.

\section{(2) Low-Income Subsidy}

Qualifying low-income beneficiaries can receive additional Part D subsidies to help finance premium and cost-sharing payments. Subsidies are estimated for beneficiaries who apply for this assistance and meet the income and asset requirements. (Beneficiaries qualified for both Medicare and Medicaid are automatically enrolled in plans with premiums below the low-income premium benchmarks within their regions.) The estimated number of low-income enrollees is about 30 percent of the total beneficiaries enrolled in Part D from 2006 to 2016.

\section{(3) Other Part D Beneficiaries}

Medicare beneficiaries who are not qualified for the low-income subsidy and who are not covered by employer plans can choose to enroll in any plan they wish. Once enrolled, they will pay for premiums and any applicable deductible, coinsurance, and/or copayment. After accounting for the enrollees discussed above and those Part D eligibles who are receiving creditable coverage through 
another source (such as the Federal Employees Health Benefits Program, TRICARE for Life, the Veterans Administration, and the Indian Health Service), about 63 percent of the remaining beneficiaries eligible for Part D enrolled by May 15, 2006 (the end of the initial open enrollment period). We are projecting this rate to grow to 75 percent by 2012 . Table IV.B9 provides a summary of the estimated average enrollment in Part $\mathrm{D}$, by category.

\begin{tabular}{|c|c|c|c|c|c|c|c|}
\hline \multicolumn{8}{|c|}{$\begin{array}{c}\text { Table IV.B9._-Part D Enrollment } \\
{[\text { [n millions] }}\end{array}$} \\
\hline \multirow[b]{2}{*}{$\begin{array}{l}\text { Calendar } \\
\text { year }\end{array}$} & \multirow[b]{2}{*}{$\begin{array}{l}\text { Employer } \\
\text { subsidy }^{1}\end{array}$} & \multicolumn{4}{|c|}{ Low-income subsidy } & \multirow[b]{2}{*}{$\begin{array}{c}\text { All } \\
\text { others }\end{array}$} & \multirow[b]{2}{*}{ Total } \\
\hline & & $\begin{array}{l}\text { Medicaid } \\
\text { full dual } \\
\text { eligible }\end{array}$ & $\begin{array}{l}\text { Other, } \\
\text { with full } \\
\text { subsidy }\end{array}$ & $\begin{array}{l}\text { Other, with } \\
\text { partial } \\
\text { subsidy }\end{array}$ & Total & & \\
\hline \multicolumn{8}{|c|}{ Historical data: } \\
\hline 2006 & 6.9 & 6.3 & 2.6 & 0.3 & 9.1 & 13.5 & 29.5 \\
\hline \multicolumn{8}{|c|}{ Intermediate estimates } \\
\hline 2007 & 6.9 & 6.0 & 3.1 & 0.3 & 9.4 & 14.6 & 31.0 \\
\hline 2008 & 6.2 & 6.1 & 3.4 & 0.4 & 9.9 & 16.2 & 32.3 \\
\hline 2009 & 5.6 & 6.2 & 3.7 & 0.4 & 10.3 & 17.8 & 33.7 \\
\hline 2010 & 5.0 & 6.3 & 3.9 & 0.4 & 10.7 & 19.3 & 35.0 \\
\hline 2011 & 4.5 & 6.5 & 4.1 & 0.4 & 11.0 & 21.0 & 36.5 \\
\hline 2012 & 4.1 & 6.7 & 4.2 & 0.5 & 11.3 & 22.8 & 38.3 \\
\hline 2013 & 4.2 & 6.9 & 4.3 & 0.5 & 11.7 & 23.5 & 39.4 \\
\hline 2014 & 4.3 & 7.1 & 4.5 & 0.5 & 12.0 & 24.2 & 40.6 \\
\hline 2015 & 4.5 & 7.3 & 4.6 & 0.5 & 12.4 & 24.9 & 41.7 \\
\hline 2016 & 4.6 & 7.5 & 4.7 & 0.5 & 12.7 & 25.6 & 42.9 \\
\hline
\end{tabular}

\section{b. Cost Projection Methodology}

(1) Projection Base

(a) Drug Benefit Payments

The 2003 Medicare Current Beneficiary Survey (MCBS) provides the base data for the projection of Part $D$ expenses. The MCBS is a survey of about 12,000 beneficiaries that collects data on person-specific health care utilization, expenses, and sources of payment, including prescription drugs. The MCBS drug expenses were adjusted to correct for survey misreporting. Due to the nature of drug administration in the institutional setting, the MCBS cannot determine drug expenses for institutionalized beneficiaries; hence, drug expenses for this group were imputed. The data were standardized to a full-retail cost level by removing the estimated effects of rebates and discounts.

The data were separated by source of payment-that is, fee-forservice and managed care-to more closely align the MCBS 


\section{Actuarial Methodology}

population data with the Part D bid population data. Specifically, the fee-for-service and managed care MCBS populations align with the Part D stand-alone prescription drug plans and Medicare Advantage plans, respectively.

The adjusted 2003 MCBS drug costs were updated to 2007 through 2016 by the past and projected increases in per capita drug expenses from the National Health Expenditure Accounts. These growth rates are shown in table IV.B10. Since insurance coverage influences the spending level for covered services and drugs (that is, individuals with increased insurance coverage for drugs would tend to increase their drug expenses), the MCBS drug expenses were adjusted to reflect differences in drug coverage between the Part $\mathrm{D}$ benefit and the existing coverage reported in the MCBS.

Table IV.B10 displays the key factors affecting Part D expenditure estimates. Prescription drug plans are expected to negotiate significant retail price discounts and manufacturer rebates and to manage drug utilization. In addition, these plans incur administrative costs for plan operation and earn profits. Since drug expenses grow faster than administrative costs, the administrative expenses as a percentage of benefit and costs slowly decrease over time.

Table IV.B10.-Key Factors for Part D Expenditure Estimates

\begin{tabular}{|c|c|c|c|c|}
\hline Calendar year & $\begin{array}{l}\text { Annual per capita } \\
\text { drug cost increase }^{1}\end{array}$ & $\begin{array}{l}\text { Cost management } \\
\text { and discounts }\end{array}$ & $\begin{array}{c}\text { Manufacturer } \\
\text { rebates }\end{array}$ & $\begin{array}{c}\text { Plan administrative } \\
\text { expenses and } \\
\text { profits }^{2}\end{array}$ \\
\hline \multicolumn{5}{|c|}{ Intermediate estimates: } \\
\hline 2006 & $6.0 \%$ & $21.0 \%$ & $5.2 \%$ & $11.5 \%$ \\
\hline 2007 & 6.7 & 22.0 & 4.6 & 11.3 \\
\hline 2008 & 7.2 & 22.0 & 4.6 & 11.0 \\
\hline 2009 & 7.7 & 22.0 & 4.6 & 10.8 \\
\hline 2010 & 8.0 & 22.0 & 4.6 & 10.6 \\
\hline 2011 & 8.2 & 22.0 & 4.6 & 10.4 \\
\hline 2012 & 8.5 & 22.0 & 4.6 & 10.3 \\
\hline 2013 & 8.6 & 22.0 & 4.6 & 10.0 \\
\hline 2014 & 8.7 & 22.0 & 4.6 & 9.7 \\
\hline 2015 & 8.8 & 22.0 & 4.6 & 9.4 \\
\hline 2016 & 9.0 & 22.0 & 4.6 & 9.1 \\
\hline \multicolumn{5}{|c|}{$\begin{array}{l}{ }^{1} \text { The per capita drug increase is based on the underlying pre-MMA growth rate used for the National } \\
\text { Health Expenditure (NHE) projections. The final NHE prescription drug projections, published } \\
\text { February } 21,2007 \text {, reflect this underlying growth rate adjusted for the impact of beneficiaries joining a } \\
\text { Part D plan. } \\
{ }^{2} \text { Expressed as a percentage of plan benefit payments. }\end{array}$} \\
\hline
\end{tabular}

\section{(b) Drug Benefit Categories}

Projected drug expenses are allocated to the beneficiary premium, direct subsidy, and reinsurance subsidy by the benefit formula specifications (deductible, coinsurance, initial benefit limit, and 
catastrophic threshold) for beneficiaries in prescription drug plans and Medicare Advantage drug plans. Low-income beneficiaries receive additional subsidies to help finance premium and cost-sharing payments. Subsidies are estimated for beneficiaries who meet the income and asset requirements.

The statute specifies that the base beneficiary premium is equal to 25.5 percent of the sum of the national average monthly bid amount ${ }^{47}$ and the estimated catastrophic reinsurance. The actual premium is greater, dollar for dollar, for plans with bids above the national average and lower for plans with lower bids. The estimated average premium amount is based on the base beneficiary premium with an adjustment to reflect enrollees' tendency to select plans with below-average premiums.

\section{(2) 2006 and 2007 Drug Bid Data}

The estimation of drug benefit payments, as described above using the MCBS data and the NHE projection factors, was supplemented by actual data from the actuarial bid submissions of Part D plans for 2006 and 2007. These data represent the plans' expectations of costs for pharmacy expenses (including discounts, rebates, and utilization management savings) and administrative costs (including profit margins).

\section{(a) Cost Management}

Prescription drug plans negotiate retail price discounts and manufacturer rebates and manage drug utilization. Based on the information from the plan bids, it is now estimated that plans achieved an average savings of 21 percent from retail discounts and utilization management in 2006. This average savings increased to 22 percent in 2007 and is estimated to remain at this level through 2016. In 2006 and 2007, the average rebate was estimated by plans to be 5.2 percent and 4.6 percent, respectively. It is estimated to remain at about 4-5 percent through 2016, as shown in table IV.B10. ${ }^{48}$

\footnotetext{
${ }^{47}$ In 2006, the national average bid was calculated as an unweighted average. Ultimately, it will be a weighted average, using plan enrollments as weights. The current demonstration program to transition between the two calculations is assumed to continue and to be complete in 2011.

${ }^{48}$ These are average rebate percentages across all prescription drugs. Generic drugs, which represent somewhat over 50 percent of all Part D drug use, typically do not carry manufacturer rebates. Many brand-name prescription drugs carry substantial rebates, often as much as 20-30 percent.
} 
Actuarial Methodology

(b) Administrative Expenses

For 2006 and 2007, the plans' expected administrative costs and projected profit margins are used to determine administrative expenses. These expenses are projected forward with wage increases and reduced by about 1 percent in each of the next 2 years to account for the phasing-out of start-up costs. The plan gains are projected using the per capita benefit trend.

\section{(c) Plan Benefits}

In addition, 2006 and 2007 Part D bid information, weighted by actual enrollment, has been incorporated in the baseline. As predicted and modeled in late 2005, Part D beneficiaries tended to enroll in the plans with the lowest premiums in 2006. The impact of this preference was reflected in the 2007 bids; that is, many plans that had above-average premiums in 2006 submitted much more competitive bids for 2007. Overall, average claims costs in the 2007 bids were 10 percent lower than the claims costs projected in the 2006 bids. The lower claims costs could be attributed to aggressive bidding to achieve market share, as noted above, and to other factors, including lower prescription drug trends in general, managed pharmacy programs that promote the use of more cost-efficient drugs, and branded drugs losing patent protection, increasing generic drug utilization as a result.

The results of the reduction of the 2007 bids over the 2006 bids were a national average bid amount and base beneficiary premium that were 13 percent and 15 percent lower, respectively, than in 2006. Conceptually, the projections in the 2007 Part D bids were consistent with the NHE assumptions with respect to the impact of fewer newto-market brand drugs, more new-to-market generic drugs, and lower cost growth trends. However, a quantitative comparison of the MCBS results, updated using the NHE growth assumptions, with the 2006 and 2007 bid data supports projections that are about midway between the level of the 2006 and 2007 bids.

The average 2007 plan bid was about 10 percent lower than in 2006 . Assuming a true underlying drug trend from 2006 to 2007 of about 6 percent, the 2007 bids differ by roughly 16 percent from a "normal" trend level. We assumed that the actual level of prescription drug spending will be roughly halfway between these two levels. Ultimately, we assumed that future bids will be about 4 percent lower than actual spending. 


\section{(d) Risk Sharing}

Risk corridor payments were estimated based on the projected level of expenditures compared to the expected level of expenditures included in the plan bids. Each plan's differential was allocated to the appropriate risk corridor using the statutory formula and the risk corridor thresholds for each year, and the risk-sharing percentages within each threshold layer. Risk corridor payments or receipts were calculated for each plan and then aggregated to develop the aggregate net risk corridor payments.

Since we are assuming that the plan bids are lower than the actual costs for the entire projection period, we are estimating net risk corridor payments to plans for each year.

\section{(e) Per Capita Reimbursements}

Table IV.B11 shows estimated enrollments and per capita reimbursements for beneficiaries in private prescription drug plans, low-income beneficiaries, and beneficiaries in employer-sponsored retiree health plans.

Table IV.B11.—Incurred Reimbursement Amounts per Enrollee for Part D Expenditures

\begin{tabular}{|c|c|c|c|c|c|c|c|}
\hline \multirow[b]{3}{*}{$\begin{array}{c}\text { Calendar } \\
\text { year }\end{array}$} & \multicolumn{5}{|c|}{ Private plans (PDPs and MA-PDs) } & \multirow{2}{*}{\multicolumn{2}{|c|}{ Employer plans }} \\
\hline & \multicolumn{3}{|c|}{ All beneficiaries } & \multicolumn{2}{|c|}{ Low-income } & & \\
\hline & $\begin{array}{c}\text { Enroll- } \\
\text { ment } \\
\text { (millions) }\end{array}$ & $\begin{array}{c}\text { Direct } \\
\text { subsidy }\end{array}$ & $\begin{array}{l}\text { Reinsur- } \\
\text { ance }\end{array}$ & $\begin{array}{c}\text { Enroll- } \\
\text { ment } \\
\text { (millions) }\end{array}$ & $\begin{array}{c}\text { Low- } \\
\text { income } \\
\text { subsidy }\end{array}$ & $\begin{array}{c}\text { Enroll- } \\
\text { ment } \\
\text { (millions) }\end{array}$ & $\begin{array}{c}\text { Employer } \\
\text { subsidy }\end{array}$ \\
\hline \multicolumn{8}{|c|}{ Historical data: } \\
\hline \multicolumn{8}{|c|}{ Intermediate estimates: } \\
\hline 2007 & 24.0 & 735.38 & 399.52 & 9.4 & $1,779.00$ & 6.9 & 585.18 \\
\hline 2008 & 26.1 & 770.37 & 415.06 & 9.9 & $1,908.92$ & 6.2 & 626.53 \\
\hline 2009 & 28.1 & 822.87 & 435.73 & 10.3 & $2,047.06$ & 5.6 & 673.95 \\
\hline 2010 & 30.0 & 882.14 & 459.57 & 10.7 & $2,203.28$ & 5.0 & 727.43 \\
\hline 2011 & 32.0 & 947.58 & 486.43 & 11.0 & $2,379.51$ & 4.5 & 786.62 \\
\hline 2012 & 34.2 & $1,034.99$ & 516.04 & 11.3 & $2,577.89$ & 4.1 & 852.57 \\
\hline 2013 & 35.2 & $1,117.46$ & 560.29 & 11.7 & $2,796.84$ & 4.2 & 925.36 \\
\hline 2014 & 36.2 & $1,207.74$ & 609.02 & 12.0 & $3,037.72$ & 4.3 & $1,005.34$ \\
\hline 2015 & 37.3 & $1,307.24$ & 662.79 & 12.4 & $3,303.67$ & 4.5 & $1,093.22$ \\
\hline 2016 & 38.3 & $1,417.19$ & 722.40 & 12.7 & $3,598.34$ & 4.6 & $1,187.52$ \\
\hline
\end{tabular}

c. Summary of Aggregate Reimbursement Amounts on a Cash Basis under the Intermediate Assumptions

Table IV.B12 shows aggregate projected reimbursements to plans and employers by type of payment. Since most payments would be made as they are incurred, cash and incurred are generally about the same. 
Actuarial Methodology

Table IV.B12.-Aggregate Reimbursement Amounts on a Cash Basis for Part D [In billions]

\begin{tabular}{|c|c|c|c|c|c|c|c|}
\hline $\begin{array}{c}\text { Calendar } \\
\text { year }\end{array}$ & Premiums $^{1}$ & $\begin{array}{c}\text { Direct } \\
\text { subsidy }\end{array}$ & Reinsurance & $\begin{array}{l}\text { Low- } \\
\text { income } \\
\text { subsidy }\end{array}$ & $\begin{array}{c}\text { Employer } \\
\text { subsidy }\end{array}$ & $\begin{array}{c}\text { Risk } \\
\text { sharing }^{2}\end{array}$ & Total \\
\hline $\begin{array}{l}\text { Historical } \\
2006\end{array}$ & $\$ 3.5$ & $\$ 17.3$ & $\$ 8.6$ & $\$ 15.1$ & $\$ 2.1$ & $\$ 0.3$ & $\$ 47.0$ \\
\hline \multicolumn{8}{|c|}{ Intermediate estimates: } \\
\hline 2007 & 4.0 & 17.7 & 7.9 & 16.9 & 3.9 & -1.2 & 49.2 \\
\hline 2008 & 5.6 & 20.1 & 10.9 & 18.9 & 4.3 & 1.2 & 61.0 \\
\hline 2009 & 7.1 & 23.1 & 12.4 & 21.2 & 3.8 & 1.1 & 68.7 \\
\hline 2010 & 9.3 & 26.5 & 14.0 & 23.7 & 3.7 & 0.9 & 77.7 \\
\hline 2011 & 10.9 & 30.3 & 15.9 & 26.4 & 3.6 & 0.8 & 88.1 \\
\hline 2012 & 13.4 & 35.4 & 18.1 & 29.4 & 3.5 & 0.6 & 100.4 \\
\hline 2013 & 15.0 & 39.4 & 19.7 & 32.7 & 3.8 & 0.5 & 111.0 \\
\hline 2014 & 16.8 & 43.8 & 22.0 & 36.5 & 4.2 & 0.5 & 123.8 \\
\hline 2015 & 19.3 & 48.7 & 24.7 & 40.9 & 4.7 & 0.6 & 138.3 \\
\hline 2016 & 20.4 & 54.3 & 27.6 & 45.8 & 5.3 & 0.7 & 154.6 \\
\hline
\end{tabular}

\section{d. Projections under Alternative Assumptions}

Part D expenditures for the low cost and high cost alternatives were developed by modifying the estimates under the intermediate assumptions. The 2007 per capita estimates increased by about 9 percent under the high cost scenario and decreased by about 9 percent under the low cost scenario. For years after 2006, the growth assumptions decreased 2 percentage points per year under the low cost scenario and increased 2 percentage points per year under the high cost scenario.

The 2007 base modifications include the following:

- \pm 5 percent for how well the MCBS-based projections, coupled with the 2007 plan bids, represent Medicare beneficiaries' drug expenses in 2007. The high cost scenario increases the spending by 5 percent, and the low cost scenario decreases the spending by 5 percent.

- \pm 2 percent for the average retail discount that drug plans negotiate. The high cost scenario decreases the average discount by 2 percent, and the low cost scenario increases the average discount by 2 percent.

- \pm 2 percent for the average manufacturer rebate that drug plans negotiate. The high cost scenario decreases the average rebate by 
2 percent, and the low cost scenario increases the average rebate by 2 percent.

For the projections beyond 2007, the drug per capita increases from the NHE projections are increased by 2 percent for the high cost scenario and decreased by 2 percent for the low cost scenario. In addition, assumptions regarding employer-sponsored plan participation, participation in the low-income subsidies, and the participation rate for individuals who do not qualify for the low-income subsidy or receive coverage through an employersponsored retiree plan vary in the alternative scenarios. Table IV.B13 compares these varying assumptions.

Table IV.B13.-Part D Assumptions under Alternative Scenarios for Calendar Years 2006-2016

\begin{tabular}{|c|c|c|c|}
\hline \multirow[b]{2}{*}{ Calendar year } & \multirow[b]{2}{*}{ Intermediate assumptions } & \multicolumn{2}{|c|}{ Alternatives } \\
\hline & & Low cost & High cost \\
\hline \multicolumn{4}{|c|}{ Percentage of beneficiaries enrolled in subsidized employer-sponsored plans } \\
\hline 2006 & $16.0 \%$ & $16.0 \%$ & $16.0 \%$ \\
\hline 2007 & 16.0 & 16.0 & 16.0 \\
\hline 2008 & 14.1 & 14.9 & 13.3 \\
\hline 2009 & 12.4 & 13.8 & 11.0 \\
\hline 2010 & 10.9 & 12.8 & 9.1 \\
\hline 2011 & 9.6 & 11.9 & 7.6 \\
\hline 2012 & 8.4 & 11.1 & 6.3 \\
\hline 2013 & 8.4 & 11.1 & 6.3 \\
\hline 2014 & 8.4 & 11.1 & 6.3 \\
\hline 2015 & 8.4 & 11.1 & 6.3 \\
\hline 2016 & 8.4 & 11.1 & 6.3 \\
\hline \multicolumn{4}{|c|}{ Low-income participation as a percentage of beneficiaries } \\
\hline 2006 & 21.1 & 21.1 & 21.1 \\
\hline 2007 & 21.3 & 20.8 & 21.7 \\
\hline 2008 & 21.9 & 21.0 & 22.8 \\
\hline 2009 & 22.4 & 21.1 & 23.8 \\
\hline 2010 & 22.8 & 21.0 & 24.6 \\
\hline 2011 & 23.0 & 20.8 & 25.3 \\
\hline 2012 & 23.0 & 20.8 & 25.3 \\
\hline 2013 & 23.0 & 20.8 & 25.3 \\
\hline 2014 & 23.0 & 20.8 & 25.3 \\
\hline 2015 & 23.0 & 20.8 & 25.3 \\
\hline 2016 & 23.0 & 20.8 & 25.3 \\
\hline \multicolumn{4}{|c|}{ Percentage of non-employer, non-low-income beneficiaries enrolled } \\
\hline 2006 & 52.8 & 52.8 & 52.8 \\
\hline 2007 & 67.0 & 66.0 & 68.0 \\
\hline 2008 & 68.6 & 65.8 & 71.4 \\
\hline 2009 & 70.2 & 65.6 & 74.8 \\
\hline 2010 & 71.8 & 65.4 & 78.2 \\
\hline 2011 & 73.4 & 65.2 & 81.6 \\
\hline 2012 & 75.0 & 65.0 & 85.0 \\
\hline 2013 & 75.0 & 65.0 & 85.0 \\
\hline 2014 & 75.0 & 65.0 & 85.0 \\
\hline 2015 & 75.0 & 65.0 & 85.0 \\
\hline 2016 & 75.0 & 65.0 & 85.0 \\
\hline
\end{tabular}


Actuarial Methodology

Table IV.B14 compares Part D expenditures as a percentage of the Gross Domestic Product under the intermediate, low, and high cost alternatives.

\begin{tabular}{cccc}
\multicolumn{4}{c}{$\begin{array}{c}\text { Table IV.B14.-Part D Cash Expenditures as a Percentage } \\
\text { of the Gross Domestic Product for Calendar Years 2006-2016 }\end{array}$} \\
\cline { 3 - 3 } Calendar year & Intermediate assumptions & Low cost & Alternatives \\
\hline & & & High cost \\
2006 & $0.36 \%$ & $0.36 \%$ & $0.36 \%$ \\
2007 & 0.36 & 0.34 & 0.39 \\
2008 & 0.43 & 0.38 & 0.48 \\
2009 & 0.45 & 0.39 & 0.53 \\
2010 & 0.49 & 0.41 & 0.60 \\
2011 & 0.53 & 0.42 & 0.66 \\
2012 & 0.57 & 0.45 & 0.71 \\
2013 & 0.60 & 0.47 & 0.75 \\
2014 & 0.64 & 0.49 & 0.81 \\
2015 & 0.69 & 0.52 & 0.87 \\
2016 & 0.73 & 0.54 & 0.94 \\
\hline
\end{tabular}

\section{LONG-RANGE MEDICARE COST GROWTH ASSUMPTIONS}

The prior two sections have described the detailed assumptions and methodology underlying the projected expenditures for HI and SMI (Parts B and D) during 2007 through 2016. These projections are made for individual categories of Medicare-covered services, such as inpatient hospital care and physicians' services.

As the projection horizon lengthens, it becomes increasingly difficult to anticipate changes in the delivery of health care, the development of new medical technologies, and other factors that will affect future health care cost increases. Thus, for the long range, Medicare projections after the first 10 years are made in aggregate for each of HI, SMI Part B, and SMI Part D, rather than preparing for each individual category of service. Moreover, starting with the $25^{\text {th }}$ year of the projection, all Medicare expenditures are assumed to increase at a common rate (before demographic impacts), in recognition of the uncertainty described above and the small likelihood that one category of expense could continue to grow indefinitely at significantly faster rates of growth than those for other services.

Based on a recommendation by the 2000 Medicare Technical Review Panel, the increase in average expenditures per beneficiary for the $25^{\text {th }}$ through $75^{\text {th }}$ years of the projection was assumed in the 2001 through 2005 Trustees Reports to equal the growth in per capita GDP plus 1 percentage point, prior to demographic effects. For the infinitehorizon projections, the Trustees have assumed the same growth rate 
as per capita GDP for the $76^{\text {th }}$ and later years (again, prior to demographic impacts).

Beginning with the 2006 report, the Board of Trustees adopted a refinement of these long-range growth assumptions. The refinement provides a smoother and more realistic transition from current Medicare cost growth rates, which have been significantly above the level of GDP growth, to the ultimate assumed level of GDP plus zero percent for the indefinite future. The year-by-year growth patterns are based on a stylized economic model that makes assumptions about (i) continuing improvements in medical technology, (ii) the extent to which new medical technology either increases health care costs or reduces them, and (iii) society's relative preference for improved health versus consumption of other goods and services. The model is based on a computable general equilibrium (CGE) methodology and uses a single agent to represent demand for medical care at the national level. The model does not directly project Medicare spending. Consistent with past Trustees Report assumptions, however, the new projection assumes that overall health care spending per capita and Medicare spending per beneficiary grow at the same rate after the $25^{\text {th }}$ year of the projection.

Due to data limitations, this economic model cannot be used to independently project long-range health cost growth rates. It is a refinement to the existing growth assumptions rather than a replacement, and accordingly the intermediate growth assumption generated by the economic model is determined in such a way that the average rate of cost growth in the long range is consistent with the prior "GDP plus 1 percent" assumption. Specifically, the model parameters are selected (i) to reproduce the past (1977) and projected (2016) levels of total U.S. health expenditures as a share of GDP, (ii) to be within the reasonable range of existing research studies on income and price elasticities, and (iii) to result in the same 75-year HI actuarial balance as calculated under the "GDP plus 1 percent" assumption.

With this latter constraint, the assumed per beneficiary growth rate from the economic model for all Medicare services in 2031 is about 1.4 percentage points above the level of GDP growth for that year. This differential gradually declines to about 0.8 percent in 2051 and to less than 0.2 percent in 2081. Compared to the assumptions used prior to the 2006 report, the new growth assumption is initially higher but subsequently lower than the constant "GDP plus 1 percent" assumption. For the infinite horizon, the assumed growth rate of GDP plus zero percent is essentially unchanged. Following 


\section{Actuarial Methodology}

prior practice, in between the $10^{\text {th }}$ and $25^{\text {th }}$ years of the projection the growth rates are assumed to grade smoothly into the long-range growth rates from the economic model.

The new cost growth assumptions thus follow a smoother path over the next 75 years than did the prior assumptions. Under the new assumptions, projected HI and SMI costs are initially somewhat higher than they would have been with the prior assumption, but later in the projection period they are lower. For example, the HI cost in 2031 is estimated to be 6.10 percent of taxable payroll. If the "GDP plus 1 percent" assumption had been used, the corresponding estimate would be 5.93 percent. In 2081, however, the new cost rate of 11.79 percent is significantly lower than the 13.39 -percent rate under the prior assumption. As noted, the 75-year actuarial balance is the same under either set of assumptions. Similar patterns of difference result for the SMI Part B and Part D projections.

The theory behind this model is that, should medical technology continue to increase rapidly, and expensively, in the future, then eventually society would be unwilling and unable to devote a steadily increasing share of its income to obtaining better health. Such unwillingness could be expressed in a number of ways consistent with current law, such as private and public health plans' refusal to adopt expensive new technologies that offer only marginal health improvement over existing techniques, or the inability on the part of individuals to afford health insurance premiums or cost-sharing payments.

The economic model implicitly reflects such constraints in a general way but does not attempt to explicitly model the actual mechanisms by which cost growth would be slowed. Because the model is tied through the actuarial balance calculation to the underlying "GDP plus 1 percent" assumption for the first 75 years, it effectively assumes a similar degree of cost constraint that has been assumed as part of the prior assumption. ${ }^{49}$

As recommended by both the 2000 and 2004 Medicare Technical Review Panels, the Trustees and their staffs are continuing to pursue research into these issues, with the goal of developing an economic model that will directly estimate long-range health cost growth rates. The economic model introduced in this report offers a useful, although limited, step in this direction.

${ }^{49}$ The rationale for the "GDP plus 1 percent" assumption is described in the report of the 2000 Medicare Technical Review Panel, available at http://www.cms.hhs.gov/ReportsTrustFunds/downloads/TechnicalPanelReport2000.pdf. Further discussion of this assumption is included in the 2004 Medicare Technical Review Panel's report, at http://www.aspe.hhs.gov/health/medpanel/. 


\section{APPENDICES}

\section{A. MEDICARE AMENDMENTS SINCE THE 2006 REPORT}

Since the 2006 annual report was transmitted to Congress on May 1, 2006, one law has been enacted that has a significant effect on the Medicare trust funds.

The Tax Relief and Health Care Act of 2006 (Public Law 109-432, enacted on December 20,2006) included a number of provisions affecting the HI and SMI programs. The more important provisions, from an actuarial standpoint, are described in the following paragraphs. Certain provisions with a relatively minor financial impact on the HI and SMI programs, but which are important from a policy perspective, are described as well.

\section{Provisions Affecting both HI and SMI}

- The capitalization of the Medicare Advantage Regional Plan Stabilization Fund is reduced from $\$ 10$ billion to $\$ 3.5$ billion. The date on which funds would initially be available is changed from January 1, 2007 to January 1, 2012.

\section{Provisions Affecting HI Only}

- Certain hospital wage index reclassifications are extended for 6 months. The Medicare Payment Advisory Commission is required to submit a report by June 30, 2007 on the wage index classification system applied under Medicare prospective payment systems, including alternative methodologies to compute the wage index. The Secretary is required to submit one or more proposals to revise the wage index adjustment under the inpatient hospital prospective payment system (IPPS) in the FY 2009 proposed rule to update the IPPS.

\section{Provisions Affecting SMI Only}

- For 2007, the physician fee schedule conversion factor is the same as the 2006 conversion factor, rather than decreasing by 5.0 percent as would have otherwise occurred.

- For 2008, the physician fee schedule conversion factor will be computed as if the 2007 conversion factor had not been changed by the Tax Relief and Health Care Act.

- From July 1, 2007 through December 31, 2007, physicians and other professionals who successfully report data on applicable 


\section{Appendices}

quality measures will be eligible for lump sum bonus incentive payments for this period. The bonus payments will be 1.5 percent of allowed charges for covered services billed by the physician during the 6 -month reporting period, but limited by a cap on the total amount of bonus payments per physician.

- A Physician Assistance and Quality Improvement Fund is established and may draw up to $\$ 1.35$ billion from the SMI trust fund. The Secretary is required to spend the funds for physician payment and quality improvement initiatives, including applying the funds to future physician updates.

- The floor of 1.0 for the geographic practice cost index that is applied to the work component of the physician fee schedule payment amount, which was established by the Medicare Modernization Act (MMA), is extended for services furnished from January 1, 2007 through December 31, 2007.

- For dialysis services for 2006 , the composite rate component of the basic case-mix adjusted prospective payment system is extended until April 1, 2007. The composite rate component for services on or after April 1, 2007 is updated by 1.6 percent above the 2006 rate.

- Direct payments for the technical component for certain pathology services, as provided for by the MMA, are extended for 2007.

- The increase factor to the hospital outpatient department fee schedule will be reduced by 2.0 percentage points in 2009 for subsection (d) hospitals that fail to report quality measures selected by the Secretary.

- Exceptions to the financial limits on therapy services, as established by the Deficit Reduction Act of 2005 (DRA), are extended until December 31, 2007.

- In 2007, the payments for the administration of a Part D covered vaccine are made from Part B. Beginning in 2008, the administration costs will be paid by Part $\mathrm{D}$. 
Per Beneficiary Cost

\section{B. AVERAGE MEDICARE EXPENDITURES PER BENEFICIARY}

Table V.B1 shows historical average per beneficiary expenditures for HI and SMI, as well as projected costs for calendar years 2007 through 2016 under the intermediate assumptions.

For both HI and SMI Part B, costs increased very rapidly in the early years when Medicare was still a new program and as a result of the rapid inflation of the 1970 s and early 1980 s. In addition, the costbased reimbursement mechanisms in place provided relatively little incentive for efficiency in the provision of health care. Growth in average HI expenditures moderated dramatically following the introduction of the inpatient hospital prospective payment system in fiscal year 1984 but accelerated again in the late 1980s and early 1990s due to rapid growth in skilled nursing and home health expenditures. During this same period, SMI Part B average costs generally continued to increase at relatively fast rates but slowed somewhat in the early 1990s with the implementation of physician fee reform legislation.

Expenditure growth moderated again during the late 1990s due to the effects of further legislation, including the Balanced Budget Act of 1997 (BBA), and efforts to control fraud and abuse. In addition, historically low levels of general and medical inflation helped reduce Medicare payment updates. HI per beneficiary costs actually decreased in 1998, 1999, and 2000, in part because of such BBA mandates as a reduction in payment updates to providers and a shift in home health benefits from HI to SMI Part B, and because of a decline in utilization of services. 
Appendices

Table V.B1.-HI and SMI Average per Beneficiary Costs

\begin{tabular}{|c|c|c|c|c|c|c|c|c|}
\hline \multirow{3}{*}{$\begin{array}{c}\text { Calendar } \\
\text { year }\end{array}$} & \multicolumn{4}{|c|}{ Average per beneficiary costs } & \multicolumn{4}{|c|}{ Average percent change $^{1}$} \\
\hline & \multirow[b]{2}{*}{$\mathrm{HI}$} & \multicolumn{2}{|c|}{ SMI } & \multirow[b]{2}{*}{ Total } & \multirow[b]{2}{*}{$\mathrm{HI}$} & \multicolumn{2}{|c|}{ SMI } & \multirow[b]{2}{*}{ Total } \\
\hline & & Part B & Part D & & & Part B & Part D & \\
\hline \multicolumn{9}{|c|}{ Historical data: } \\
\hline 1970 & $\$ 255$ & $\$ 101$ & - & $\$ 356$ & $13.4 \%$ & $14.8 \%$ & - & $13.8 \%$ \\
\hline 1975 & 462 & 180 & - & 642 & 12.6 & 12.2 & - & 12.5 \\
\hline 1980 & 895 & 390 & - & 1,285 & 14.1 & 16.7 & - & 14.9 \\
\hline 1985 & 1,554 & 768 & - & 2,322 & 11.7 & 14.5 & - & 12.6 \\
\hline 1990 & 1,963 & 1,304 & - & 3,267 & 4.8 & 11.2 & - & 7.1 \\
\hline 1995 & 3,130 & 1,823 & 一 & 4,953 & 9.8 & 6.9 & 一 & 8.7 \\
\hline 2000 & 3,272 & 2,381 & - & 5,653 & 0.9 & 5.5 & - & 2.7 \\
\hline 2001 & 3,559 & 2,646 & - & 6,205 & 8.8 & 11.1 & - & 9.8 \\
\hline 2002 & 3,743 & 2,922 & 一 & 6,664 & 5.2 & 10.4 & 一 & 7.4 \\
\hline 2003 & 3,733 & 3,209 & - & 6,942 & -0.2 & 9.8 & - & 4.2 \\
\hline 2004 & 4,039 & 3,450 & - & 7,489 & 8.2 & 7.5 & - & 7.9 \\
\hline 2005 & 4,268 & 3,759 & - & 8,027 & 5.7 & 9.0 & - & 7.2 \\
\hline 2006 & 4,410 & 4,121 & $\$ 1,690$ & 10,221 & 3.3 & 9.6 & - & 27.3 \\
\hline \multicolumn{9}{|c|}{ Intermediate estimates: } \\
\hline 2007 & 4,687 & 4,328 & 1,590 & 10,606 & 6.3 & 5.0 & $-5.9 \%$ & 3.8 \\
\hline 2008 & 4,948 & 4,522 & 1,888 & 11,359 & 5.6 & 4.5 & 18.7 & 7.1 \\
\hline 2009 & 5,203 & 4,718 & 2,039 & 11,960 & 5.1 & 4.3 & 8.0 & 5.3 \\
\hline 2010 & 5,463 & 4,939 & 2,218 & 12,621 & 5.0 & 4.7 & 8.8 & 5.5 \\
\hline 2011 & 5,702 & 5,140 & 2,413 & 13,256 & 4.4 & 4.1 & 8.8 & 5.0 \\
\hline 2012 & 5,920 & 5,338 & 2,624 & 13,882 & 3.8 & 3.8 & 8.7 & 4.7 \\
\hline 2013 & 6,143 & 5,552 & 2,814 & 14,509 & 3.8 & 4.0 & 7.2 & 4.5 \\
\hline 2014 & 6,388 & 5,783 & 3,051 & 15,222 & 4.0 & 4.2 & 8.4 & 4.9 \\
\hline 2015 & 6,644 & 6,026 & 3,313 & 15,983 & 4.0 & 4.2 & 8.6 & 5.0 \\
\hline 2016 & 6,919 & 6,300 & 3,602 & 16,821 & 4.1 & 4.5 & 8.7 & 5.2 \\
\hline
\end{tabular}

On average, annual increases in per beneficiary costs have been greater for SMI Part B than for HI during the previous 3 decades-by approximately 1.0 percent, 4.7 percent, and 1.0 percent per year in the $1970 \mathrm{~s}, 1980 \mathrm{~s}$, and $1990 \mathrm{~s}$, respectively. This trend continued through 2003, in part because of the shift of certain home health services from HI to SMI Part B, which was completed in 2003. For 2005 and 2006, the SMI Part B increase was higher than the HI increase in part as a result of unusually rapid increases in the volume and intensity of physician services. The comparison is expected to reverse in 2007, due to an assumed return to the historical trend in HI hospital admission rates, from their below-average level in 2006, and frozen Part B payment rates for physician and certain other services.

For the period 2008-2016, the projected SMI Part B increases are substantially understated as a result of the current-law physician updates. Under the Sustainable Growth Rate system (SGR), the physician payment update is projected to be -10 percent in 2008 and about -5 percent for all years, 2009-2016. Legislation to prevent or ameliorate such an outcome is highly likely. Note that the large 
growth in the 1970s and 1980s is not expected to recur for either HI or SMI Part B, due to more moderate inflation rates and the conversion of Medicare's remaining cost-based reimbursement mechanisms to prospective payment systems as part of the Balanced Budget Act of 1997, and because of the physician updates under the SGR.

Although SMI Part D coverage began in 2004, the most significant prescription drug provisions did not start until 2006. Accordingly, for purposes of this discussion, only the per beneficiary expenditures for 2006 and later will be included. As table V.B1 indicates, the per beneficiary costs are expected to decrease in 2007, primarily as a result of the pattern of bids submitted by private plans in 2006 and 2007 . Since the 2007 bids were roughly 10 percent lower than the 2006 bids, the assumption is that private plans overbid in 2006 and underbid in 2007. Since actual spending is expected to be less than the bids in 2006, the net risk corridor payments made in 2007 are expected to be negative. For 2008, we are expecting the net risk corridor payments to be positive because the 2007 plans bids are assumed to be lower than actual drug spending.

On the other hand, average annual increases in Part D per beneficiary costs are expected to be between 3 to 5 percent greater than for HI or SMI Part B for the period 2008-2016. With the inclusion of the Part D costs in the total, overall Medicare per beneficiary cost growth is expected to be roughly 0.5 percent higher over the 2007-2016 period than it otherwise would be. 


\section{Appendices}

\section{MEDICARE COST SHARING AND PREMIUM AMOUNTS}

HI beneficiaries who use covered services may be subject to deductible and coinsurance requirements. A beneficiary is responsible for an inpatient hospital deductible amount, which is deducted from the amount payable by the HI trust fund to the hospital, for inpatient hospital services furnished in a spell of illness. When a beneficiary receives such services for more than 60 days during a spell of illness, he or she is responsible for a coinsurance amount equal to one-fourth of the inpatient hospital deductible for each of days 61-90 in the hospital. After 90 days in a spell of illness, each individual has 60 lifetime reserve days of coverage, for which the coinsurance amount is equal to one-half of the inpatient hospital deductible. A beneficiary is responsible for a coinsurance amount equal to one-eighth of the inpatient hospital deductible for each of days 21-100 of skilled nursing facility services furnished during a spell of illness.

Most persons aged 65 and older and many disabled individuals under age 65 are insured for HI benefits without payment of any premium. The Social Security Act provides that certain aged and disabled persons who are not insured may voluntarily enroll, subject to the payment of a monthly premium. In addition, since 1994, voluntary enrollees may qualify for a reduced premium if they have at least 30 quarters of covered employment.

Table V.C1 shows the historical levels of the HI deductible, coinsurance amounts, and premiums, as well as projected values for future years based on the intermediate set of assumptions used in estimating the operations of the trust funds. Certain anomalies in these values resulted from specific trust fund features in particular years (for example, the effect of the Medicare Catastrophic Coverage Act of 1988 on 1989 values). The values listed in the table for future years are estimates, and the actual amounts are likely to be somewhat different as experience emerges. 
Cost Sharing and Premiums

Table V.C1.-HI Cost Sharing and Premium Amounts

\begin{tabular}{|c|c|c|c|c|c|c|}
\hline \multirow[b]{2}{*}{ Year } & \multirow[b]{2}{*}{$\begin{array}{l}\text { Inpatient hospital } \\
\text { deductible }^{1}\end{array}$} & \multicolumn{2}{|c|}{ Inpatient coinsurance ${ }^{1}$} & \multirow[b]{2}{*}{$\begin{array}{c}\text { SNF coinsurance } \\
\text { days }^{1}\end{array}$} & \multicolumn{2}{|c|}{ Monthly premium } \\
\hline & & Days $61-90$ & $\begin{array}{c}\text { Lifetime } \\
\text { reserve days }\end{array}$ & & Standard $^{2}$ & Reduced $^{1}$ \\
\hline \multicolumn{7}{|c|}{ Historical data: } \\
\hline 1967 & $\$ 40$ & $\$ 10$ & - & $\$ 5.00$ & - & - \\
\hline 1968 & 40 & 10 & $\$ 20$ & 5.00 & - & - \\
\hline 1969 & 44 & 11 & 22 & 5.50 & - & - \\
\hline 1970 & 52 & 13 & 26 & 6.50 & - & - \\
\hline 1971 & 60 & 15 & 30 & 7.50 & - & - \\
\hline 1972 & 68 & 17 & 34 & 8.50 & - & - \\
\hline 1973 & 72 & 18 & 36 & 9.00 & $\$ 33$ & - \\
\hline 1974 & 84 & 21 & 42 & 10.50 & 36 & - \\
\hline 1975 & 92 & 23 & 46 & 11.50 & 40 & - \\
\hline 1976 & 104 & 26 & 52 & 13.00 & 45 & - \\
\hline 1977 & 124 & 31 & 62 & 15.50 & 54 & - \\
\hline 1978 & 144 & 36 & 72 & 18.00 & 63 & - \\
\hline 1979 & 160 & 40 & 80 & 20.00 & 69 & - \\
\hline 1980 & 180 & 45 & 90 & 22.50 & 78 & - \\
\hline 1981 & 204 & 51 & 102 & 25.50 & 89 & - \\
\hline 1982 & 260 & 65 & 130 & 32.50 & 113 & - \\
\hline 1983 & 304 & 76 & 152 & 38.00 & 113 & - \\
\hline 1984 & 356 & 89 & 178 & 44.50 & 155 & - \\
\hline 1985 & 400 & 100 & 200 & 50.00 & 174 & - \\
\hline 1986 & 492 & 123 & 246 & 61.50 & 214 & - \\
\hline 1987 & 520 & 130 & 260 & 65.00 & 226 & - \\
\hline 1988 & 540 & 135 & 270 & 67.50 & 234 & - \\
\hline $1989^{3}$ & 560 & - & - & 25.50 & 156 & - \\
\hline 1990 & 592 & 148 & 296 & 74.00 & 175 & - \\
\hline 1991 & 628 & 157 & 314 & 78.50 & 177 & - \\
\hline 1992 & 652 & 163 & 326 & 81.50 & 192 & - \\
\hline 1993 & 676 & 169 & 338 & 84.50 & 221 & - \\
\hline 1994 & 696 & 174 & 348 & 87.00 & 245 & $\$ 184$ \\
\hline 1995 & 716 & 179 & 358 & 89.50 & 261 & 183 \\
\hline 1996 & 736 & 184 & 368 & 92.00 & 289 & 188 \\
\hline 1997 & 760 & 190 & 380 & 95.00 & 311 & 187 \\
\hline 1998 & 764 & 191 & 382 & 95.50 & 309 & 170 \\
\hline 1999 & 768 & 192 & 384 & 96.00 & 309 & 170 \\
\hline 2000 & 776 & 194 & 388 & 97.00 & 301 & 166 \\
\hline 2001 & 792 & 198 & 396 & 99.00 & 300 & 165 \\
\hline 2002 & 812 & 203 & 406 & 101.50 & 319 & 175 \\
\hline 2003 & 840 & 210 & 420 & 105.00 & 316 & 174 \\
\hline 2004 & 876 & 219 & 438 & 109.50 & 343 & 189 \\
\hline 2005 & 912 & 228 & 456 & 114.00 & 375 & 206 \\
\hline 2006 & 952 & 238 & 476 & 119.00 & 393 & 216 \\
\hline 2007 & 992 & 248 & 496 & 124.00 & 410 & 226 \\
\hline \multicolumn{7}{|c|}{ Intermediate estimates: } \\
\hline 2008 & 1,040 & 260 & 520 & 130.00 & 421 & 232 \\
\hline 2009 & 1,092 & 273 & 546 & 136.50 & 442 & 243 \\
\hline 2010 & 1,148 & 287 & 574 & 143.50 & 463 & 255 \\
\hline 2011 & 1,204 & 301 & 602 & 150.50 & 483 & 266 \\
\hline 2012 & 1,260 & 315 & 630 & 157.50 & 501 & 276 \\
\hline 2013 & 1,320 & 330 & 660 & 165.00 & 519 & 285 \\
\hline 2014 & 1,380 & 345 & 690 & 172.50 & 539 & 296 \\
\hline 2015 & 1,444 & 361 & 722 & 180.50 & 560 & 308 \\
\hline 2016 & 1,512 & 378 & 756 & 189.00 & 582 & 320 \\
\hline
\end{tabular}

${ }^{1}$ Amounts shown are effective for calendar years.

${ }^{2}$ Amounts shown for 1967-1982 are for the 12-month periods ending June 30; amounts shown for 1983 are for the period July 1, 1982 through December 31, 1983; amounts shown for 1984 and later are for calendar years.

${ }^{3}$ Anomalies in the 1989 values are due to the Medicare Catastrophic Coverage Act of 1988. Most of the provisions of the Act were repealed the following year. 


\section{Appendices}

The Federal Register notice announcing the HI deductible and coinsurance amounts for 2007 included an estimate of the aggregate cost to HI beneficiaries for the changes in the deductible and coinsurance amounts from 2006 to 2007 . At the time the notice was published, it was estimated that in 2007 there would be 8.85 million inpatient deductibles paid at $\$ 992$ each, 2.30 million inpatient days subject to coinsurance at $\$ 248$ per day (for hospital days 61 through 90), 1.08 million lifetime reserve days subject to coinsurance at $\$ 496$ per day, and 38.03 million extended care days subject to coinsurance at $\$ 124$ per day. Similarly, it was estimated that in 2006 there would be 8.91 million deductibles paid at $\$ 952$ each, 2.31 million days subject to coinsurance at $\$ 238$ per day (for hospital days 61 through 90), 1.08 million lifetime reserve days subject to coinsurance at $\$ 476$ per day, and 37.08 million extended care days subject to coinsurance at $\$ 119$ per day. Therefore, the total increase in cost to beneficiaries was estimated to be $\$ 640$ million, due to (i) the increase in the inpatient deductible and coinsurance amounts, and (ii) the change in the number of deductibles and daily coinsurance amounts paid.

Table V.C2 displays the SMI cost-sharing and premium amounts for Parts B and D. The projected values for future years are based on the intermediate set of assumptions used in estimating the operations of the Part B and Part D accounts. As a result, these values are estimates, and the actual amounts are likely to be somewhat different as experience emerges. In particular, the Part B premiums reflect the substantial-and improbable-reductions in physician payment rates for 2008 through at least 2016 under the sustainable growth rate system. If these unrealistic physician payment updates are overridden by new legislation-as has happened for each of the past 5 years-then future Part B premiums and Part B deductibles will reflect the impact of any legislative changes..$^{50}$

\footnotetext{
${ }^{50}$ Projected Part B premiums and deductibles under two illustrative alternatives to current law are shown on the CMS website at http://www.cms.hhs.gov/ ReportsTrustFunds/05_alternativePartB.asp. No endorsement of these alternatives by the Board of Trustees, CMS, or the Office of the Actuary should be inferred.
} 
Cost Sharing and Premiums

Table V.C2.-SMI Cost Sharing and Premium Amounts

\begin{tabular}{|c|c|c|c|c|c|c|}
\hline \multirow[b]{2}{*}{ Calendar year } & \multicolumn{2}{|c|}{ Part B } & \multicolumn{4}{|c|}{ Part D } \\
\hline & $\begin{array}{l}\text { Standard } \\
\text { monthly } \\
\text { premium }\end{array}$ & $\begin{array}{c}\text { Annual } \\
\text { deductible }^{2}\end{array}$ & $\begin{array}{c}\text { Base } \\
\text { beneficiary } \\
\text { premium }\end{array}$ & Deductible & $\begin{array}{l}\text { Initial benefit } \\
\text { limit }\end{array}$ & $\begin{array}{l}\text { Catastrophic } \\
\text { threshold }\end{array}$ \\
\hline 1967 & $\$ 3.00$ & $\$ 50$ & - & - & - & - \\
\hline 1968 & 4.00 & 50 & - & - & - & - \\
\hline 1969 & 4.00 & 50 & - & - & - & - \\
\hline 1970 & 4.00 & 50 & - & - & - & - \\
\hline 1971 & 5.30 & 50 & - & - & - & - \\
\hline 1972 & 5.60 & 50 & - & - & - & - \\
\hline 1973 & 5.80 & 60 & - & - & - & - \\
\hline 1974 & $6.30^{3}$ & 60 & - & - & - & - \\
\hline 1975 & 6.70 & 60 & - & - & - & - \\
\hline 1976 & 6.70 & 60 & - & - & - & - \\
\hline 1977 & 7.20 & 60 & - & - & - & - \\
\hline 1978 & 7.70 & 60 & - & - & - & - \\
\hline 1979 & 8.20 & 60 & - & - & - & - \\
\hline 1980 & 8.70 & 60 & - & - & - & - \\
\hline 1981 & 9.60 & 60 & - & - & - & - \\
\hline 1982 & 11.00 & 75 & - & - & - & - \\
\hline 1983 & 12.20 & 75 & - & - & - & - \\
\hline 1984 & 14.60 & 75 & - & - & - & - \\
\hline 1985 & 15.50 & 75 & - & - & - & - \\
\hline 1986 & 15.50 & 75 & - & - & - & - \\
\hline 1987 & 17.90 & 75 & - & - & - & - \\
\hline 1988 & 24.80 & 75 & - & - & - & - \\
\hline $1989^{4}$ & 31.90 & 75 & - & - & - & - \\
\hline 1990 & 28.60 & 75 & - & - & - & - \\
\hline 1991 & 29.90 & 100 & - & - & - & - \\
\hline 1992 & 31.80 & 100 & - & - & - & - \\
\hline 1993 & 36.60 & 100 & - & - & - & - \\
\hline 1994 & 41.10 & 100 & - & - & - & - \\
\hline 1995 & 46.10 & 100 & - & - & - & - \\
\hline 1996 & 42.50 & 100 & - & - & - & - \\
\hline 1997 & 43.80 & 100 & - & - & - & - \\
\hline 1998 & 43.80 & 100 & - & - & - & - \\
\hline 1999 & 45.50 & 100 & - & - & - & - \\
\hline 2000 & 45.50 & 100 & - & - & - & - \\
\hline 2001 & 50.00 & 100 & - & - & - & - \\
\hline 2002 & 54.00 & 100 & - & - & - & - \\
\hline 2003 & 58.70 & 100 & - & - & - & - \\
\hline 2004 & 66.60 & 100 & - & - & - & - \\
\hline 2005 & 78.20 & 110 & - & - & - & - \\
\hline 2006 & 88.50 & 124 & $\$ 32.20$ & $\$ 250$ & $\$ 2,250$ & $\$ 3,600$ \\
\hline 2007 & 93.50 & 131 & 27.35 & 265 & 2,400 & 3,850 \\
\hline \multicolumn{7}{|c|}{ Intermediate estimates: } \\
\hline 2008 & 96.40 & 135 & 30.56 & 285 & 2,540 & 4,050 \\
\hline 2009 & 97.30 & 136 & 33.09 & 305 & 2,730 & 4,350 \\
\hline 2010 & 101.70 & 142 & 35.91 & 325 & 2,940 & 4,700 \\
\hline 2011 & 105.90 & 148 & 39.02 & 355 & 3,170 & 5,100 \\
\hline 2012 & 110.00 & 154 & 42.87 & 380 & 3,430 & 5,500 \\
\hline 2013 & 114.40 & 160 & 46.41 & 415 & 3,730 & 5,950 \\
\hline 2014 & 119.00 & 166 & 50.29 & 450 & 4,050 & 6,450 \\
\hline 2015 & 124.00 & 173 & 54.46 & 490 & 4,400 & 7,050 \\
\hline 2016 & 129.40 & 181 & 59.29 & 530 & 4,780 & 7,650 \\
\hline
\end{tabular}

${ }^{1}$ Amounts shown for 1967-1982 are for the 12-month periods ending June 30; amounts shown for 1983 are for the period July 1, 1982 through December 31, 1983; amounts shown for 1984 and later are for calendar years.

${ }^{2}$ Prior to the Medicare Modernization Act (MMA), the Part B deductible was fixed by statute and had only occasionally been adjusted. The MMA raised the deductible to $\$ 110$ in 2005 and specified that it be indexed by average per beneficiary Part B expenditures thereafter. 


\section{Appendices}

${ }^{3}$ In accordance with limitations on the costs of health care imposed under Phase III of the Economic Stabilization program, the standard premium rates for July and August 1973 were set at $\$ 5.80$ and $\$ 6.10$, respectively. Effective September 1973 , the rate increased to $\$ 6.30$.

${ }^{4}$ Anomalies in the 1989 values are due to the Medicare Catastrophic Coverage Act of 1988 . Most of the provisions of the Act were repealed the following year.

The Part B monthly premiums displayed in table V.C2 are the standard premium rates paid by most Part B enrollees. However, there are three provisions that alter the premium rate for certain Part B enrollees. First, there is a premium surcharge for those beneficiaries who enroll after their initial enrollment period. Second, beginning in 2007, there is a higher "income-related" premium for those individuals whose modified adjusted gross income exceeds a specified threshold. Those individuals exceeding the threshold will pay premiums covering $35,50,65$, or 80 percent of the average program cost for aged beneficiaries, depending on their income level, compared to the standard premium covering 25 percent. Table V.C3 displays these Part B income-related premium amounts for 2007-2016, based on the intermediate set of assumptions.

Table V.C3.-Part B Income-Related Premium Amounts'

\begin{tabular}{|c|c|c|c|c|}
\hline \multirow[b]{2}{*}{ Calendar year } & \multicolumn{4}{|c|}{ Ultimate percentage of program costs represented by premium } \\
\hline & $35 \%$ & $50 \%$ & $65 \%$ & $80 \%$ \\
\hline Historical data: & $\$ 105.80$ & $\$ 124.40$ & $\$ 142.90$ & $\$ 161.40$ \\
\hline \multicolumn{5}{|c|}{ Intermediate estimates: } \\
\hline 2008 & 122.20 & 160.90 & 199.70 & 238.40 \\
\hline 2009 & 136.20 & 194.50 & 252.90 & 311.20 \\
\hline 2010 & 142.40 & 203.40 & 264.40 & 325.40 \\
\hline 2011 & 148.20 & 211.70 & 275.20 & 338.70 \\
\hline 2012 & 154.00 & 220.00 & 286.00 & 352.00 \\
\hline 2013 & 160.10 & 228.70 & 297.30 & 365.90 \\
\hline 2014 & 166.50 & 237.90 & 309.30 & 380.60 \\
\hline 2015 & 173.50 & 247.90 & 322.30 & 396.60 \\
\hline 2016 & 181.20 & 258.80 & 336.40 & 414.10 \\
\hline
\end{tabular}

In 2007 the initial threshold is $\$ 80,000$ for an individual tax return and $\$ 160,000$ for a joint return. The thresholds will be indexed to inflation in subsequent years. These higher income-related premiums will be phased in over the 3-year period 2007-2009.

Part B premiums may also vary from the standard rate because a "hold-harmless" provision lowers the premium rate for certain individuals who have their premiums deducted from their Social Security checks. On an individual basis, this provision limits the dollar increase in the Part B premium to the dollar increase in the individual's Social Security check. As a result, the person affected pays a lower Part B premium, and the net amount of the individual's Social Security check does not decrease despite the greater increase in the premium. 


\section{Cost Sharing and Premiums}

Most services under Part B are subject to an annual deductible and coinsurance. The annual deductible has been set in statute through 2005. Thereafter, it increases with the increase in the Part B aged actuarial rate to approximate the growth in per capita Part B expenditures. After meeting the deductible, the beneficiary pays an amount equal to the product of the coinsurance percentage and the remaining allowed charges. The coinsurance percentage is 20 percent except for outpatient psychiatric services, which have a 50-percent coinsurance, and most services currently reimbursed under the outpatient hospital prospective payment system (OPPS). Under the OPPS, the coinsurance percentage varies by service but currently falls in the range of 20-50 percent. The OPPS coinsurance percentages will gradually decrease over time until they reach 20 percent for each OPPS service. For those services not subject to either the deductible or coinsurance (clinical lab tests, home health agency services, and some preventive care services), the beneficiary pays nothing.

The Part D average premiums displayed in table V.C2 are the estimated base beneficiary premiums. For 2006, the base beneficiary premium was calculated based on a national average plan bid that gave each bid an equal weight. The actual premium that a beneficiary pays varies according to the plan in which the beneficiary is enrolled. Some pay lower premiums than those displayed in table V.C2, and others pay more. The average premium rate that beneficiaries paid in 2006 was roughly $\$ 23$. In 2007 , the national average was calculated under a transitional demonstration program using 80 percent of the equally weighted bids and 20 percent of the enrollment-weighted average bid. As a result of this calculation, the average premium rate paid by beneficiaries fell to about $\$ 22$. This transition is assumed to occur through 2010. By 2011, we assume that the national average bid will be the enrollment-weighted average bid and that the estimated average premium rate paid by beneficiaries will, therefore, be similar to the base beneficiary premium.

As with Part B, there is a late enrollment penalty for those beneficiaries enrolling after their initial enrollment period. Furthermore, there are premium and cost-sharing subsidies for those beneficiaries with incomes less than 150 percent of the Federal poverty level and with assets in 2006 less than $\$ 10,000$ for an individual and $\$ 20,000$ for a couple. The asset figures are indexed in subsequent years by the CPI. 


\section{Appendices}

Under standard Part D coverage, there is an initial deductible. After meeting the deductible, the beneficiary pays 25 percent of the remaining costs up to the initial benefit limit. Beyond this limit, the beneficiary pays all the drug costs until his or her total out-of-pocket expenditures reach the catastrophic threshold. (Included in this total are the deductible and coinsurance payments for expenses up to the initial benefit limit.) Thereafter, the beneficiary pays the greater of (i) 5 percent of the drug cost, or (ii) $\$ 2$ for generic or preferred multiple-source drugs or $\$ 5$ for preferred single-source drugs. The latter copayment amounts from 2006 are indexed annually by per enrollee Part D average costs. Beneficiaries qualifying for the Part D low-income subsidy pay substantially reduced premium and cost-sharing amounts. Many Part D plans offer alternative coverage that differs from the standard coverage described above. In fact, the majority of beneficiaries have not enrolled in the standard benefit design, but rather in plans with low or no deductibles, flat payments for covered drugs, and, in some cases, partial coverage in the coverage gap. 
Supplemental Assessment of Uncertainty

\section{SUPPLEMENTARY ASSESSMENT OF UNCERTAINTY IN PART B COST PROJECTIONS}

This appendix presents an additional way to help assess the uncertainty of Part B cost projections. It is intended to supplement the traditional methods of examining such uncertainty and to illustrate the potential value of stochastic techniques. The analysis offered here uses statistical methods to help quantify the range and likelihood of future Part B costs and trust fund assets and should be viewed as a tentative application of stochastic techniques to the Part B financial projections, subject to refinement over time as more data become available.

\section{Background}

Financial projections, including those for Medicare, are necessarily uncertain because the future is unknown. Medicare projections depend on numerous assumptions, as outlined in sections II.D and IV.B.1 of this report. Variations between actual future cost factors (for example, growth in the utilization of medical services) and the corresponding assumptions will almost always cause future costs to vary from the estimate.

Uncertainty in Medicare costs is traditionally illustrated by using three alternative sets of assumptions (intermediate, high cost, and low cost). The high cost alternative assumes a faster growth rate in Part B expenditures in every year. Similarly, the low cost alternative assumes slower growth rates in all years. These growth differentials are set deterministically, to illustrate the impact on Part B costs of sustained faster or slower growth that could reasonably be expected to occur. Using the traditional methodology alone, it is not possible to quantify the probability of either outcome or the likelihood of a future result outside of the range defined by the high cost and low cost alternatives.

From time to time, expert panels of actuaries and economists convene to review the assumptions and methodology underlying the Medicare and Social Security Trustees Reports. Several of the past expert panels have recommended consideration of alternative analytical techniques to supplement the current methodology for assessing the uncertainty in cost projections and to add insight into the potential range of future variation. The 1991 Advisory Council Technical Panel on Social Security recommended the "development of methods to quantify the uncertainty of short- and long-range forecasts, both for particular assumptions and projections." Similarly, the 1994-95 


\section{Appendices}

Advisory Council Technical Panel recommended that "stochastic analysis should be used to examine more explicitly the probabilities of alternative projections." The 1999 Social Security Advisory Board Technical Panel agreed, stating that they "follow previous panels in strongly recommending efforts toward stochastic modeling or similar techniques that are better able to capture the interrelationships among assumptions." They added, "what we seek is a method of displaying to policy makers and the public just how uncertain is some average cost outcome or date of exhaustion of the Trust Funds, and what are the probabilities that events will be close to or far away from that result." In their review of the Trustees Reports, the 2000 Medicare Technical Review Panel recommended the continued use of stochastic methods for Medicare and noted that "although stochastic modeling is complicated, it can result in enhanced insight into the uncertainty associated with health care cost projections."

The projections shown in this appendix represent the application of such techniques to the short-range Part B cost projections.

\section{Methodology}

For health care cost projections, the most critical assumption is generally the rate of increase in average per beneficiary medical costs. ${ }^{51}$ In the past there have been wide variations in such growth rates for Part B. The statistical methods employed here (also referred to as "stochastic" projection techniques) measure past variation in per beneficiary growth rates relative to the average and assume that similar variation will occur in the future, relative to the intermediate growth rate assumptions for the short-range projection period.

Past variations in benefit expenditure growth rates are examined separately by service type (for example, physician, hospital, and home health) and by eligibility category (aged, disabled, or end-stage renal disease), using data from the first quarter of 1991 through the third quarter of 2006. For each future year, these variations are combined statistically to develop a measure of variation in total Part B benefit expenditures per beneficiary. ${ }^{52}$ Individual 10-year projection scenarios

\footnotetext{
${ }^{51}$ Such cost increases reflect changes in (i) the prices of specific medical services, (ii) the utilization of services, and (iii) the average complexity or "intensity" of services.

${ }^{52}$ For this calculation, variation in each service category is weighted by the expected level of benefit expenditures per beneficiary for that category for the year. The calculation also reflects the "covariances" among the different categories-for example, the probability that a faster-than-average increase in physician expenditures would be associated with an above-average increase in spending for diagnostic laboratory tests, outpatient hospital procedures, and other services.
} 
Supplemental Assessment of Uncertainty

are generated by randomly selecting each year's per beneficiary Part B cost increase from a frequency distribution of increases based on past variation and the intermediate growth rate assumption for the given year. ${ }^{53}$ Two thousand short-range scenarios are generated and benefit expenditures are projected for each individual scenario. A distribution of the resulting cost projections is calculated and used to assess the possible variation in future expenditure levels and trust fund operations.

The stochastic approach provides several potential benefits to supplement the traditional projections. This method provides an estimated probability of occurrence for various possible outcomes, rather than just an illustrative outcome. For example, the likelihood that Part B expenditures would exceed a specified level within 10 years can be estimated using stochastic techniques. Similarly, the likelihood of an abrupt decline in assets in the Part B account of the SMI trust fund can be evaluated using these techniques, as illustrated in section V.D3 of this appendix.

The projections shown in this appendix should be considered only as an attempt to augment the traditional projections that are made for Part B. The method presented, like any projection model, is only a tool; it can provide useful-but limited-information regarding an unknowable future. Stochastic techniques can improve our understanding of possible future developments but cannot "guarantee" any specific outcome. In particular:

- The stochastic techniques used here rely heavily on past experience. The future may differ from the past in fundamental ways that generally cannot be anticipated or reflected in a statistical model. For example, much of the past experience underlying the statistical model is drawn from years that precede implementation of the Part B outpatient hospital prospective payment system (which started in August 2000). The range of future variation in outpatient hospital expenditures (and total Part B costs) may therefore differ from what is reflected in the model. A similar and potentially much more serious limitation is that available past experience does not include a catastrophe such as a bird flu pandemic. The stochastic forecast, consequently, does not reflect such a possibility.

\footnotetext{
${ }^{53}$ These future increases are assumed to be normally distributed, based on the near-normality of past increases about their average.
} 


\section{Appendices}

- Actual Part B payment operations are very complex. The stochastic model used is a simplification of real-world relationships and may not be sufficiently sophisticated to match future behavior. Many possible models could be used; the one employed here may not be the best model possible (if there indeed is a unique "best" model).

- The model is based on the underlying data. A limited number of years of data are available, and the data can be subject to problems, such as measurement errors or inconsistent definitions over time. Any such problems would, of course, affect the model.

- Potential variations in costs due to factors other than growth in per beneficiary expenditures are not considered. For example, longer life expectancies or variations in net immigration could affect the total number of Part B beneficiaries and therefore total expenditures.

- Finally, the methodology described here models future expenditure uncertainty on the assumption that the intermediate assumptions produce the most likely future year-by-year cost increases. Actual future growth rates could, on average, differ from these assumptions.

For these reasons, the stochastic projections shown in this appendix should be viewed cautiously and used with awareness of their limitations. ${ }^{54}$ Many refinements to the methodology are possible. For example, the assumed average future cost increases could be allowed to differ from the increases of the intermediate assumptions. Also, separate cost increases could be generated by type of service rather than in aggregate. Other factors, such as the demographic assumptions, could be allowed to vary rather than just the per beneficiary Part B cost increases.

\section{Results}

The shaded region in figure V.D1 illustrates the range within which future Part B benefit expenditures are estimated to occur 95 percent of the time, based on the stochastic projections. In other words, actual future expenditures in a given year would be expected to exceed the

\footnotetext{
${ }^{54}$ Many of these limitations also apply to the traditional projection methods used in the annual Trustees Report and, indeed, to virtually any estimation technique. Different methods have different relative advantages and disadvantages. Use of multiple techniques has the potential to improve our overall understanding of possible future developments.
} 
upper bound only 2.5 percent of the time or to fall below the lower bound 2.5 percent of the time. ${ }^{55}$

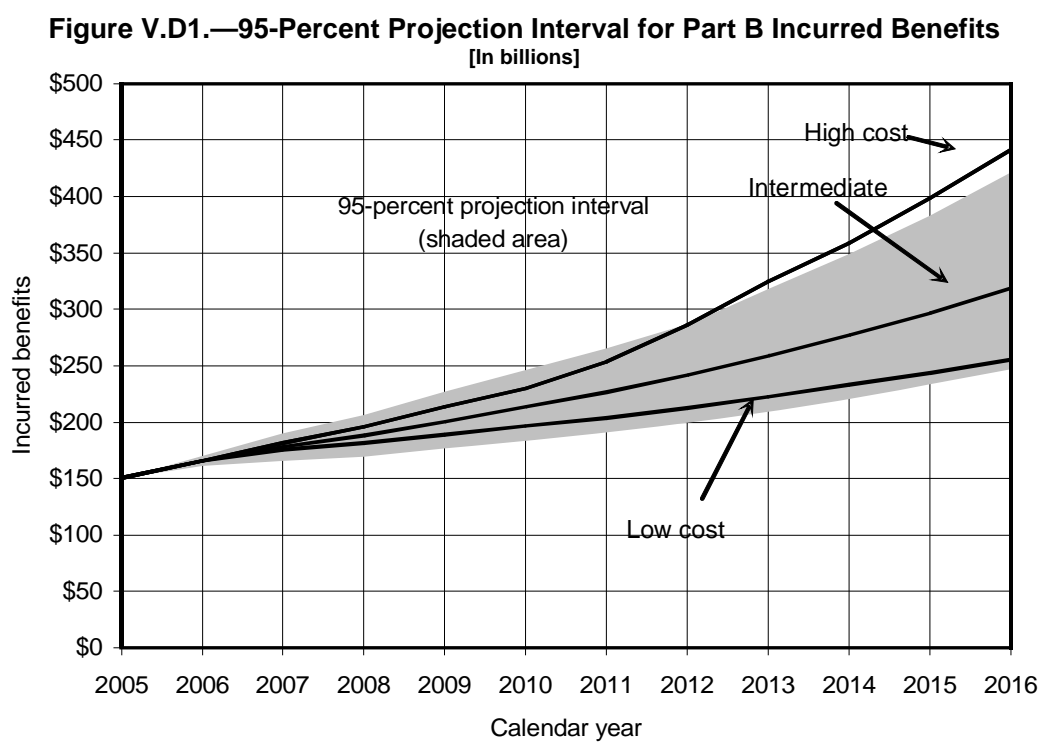

For comparison, the benefit levels projected under the intermediate, high cost, and low cost alternatives are also shown in figure V.D1. With both projection methodologies, the range of benefits widens as the projections move further into the future, reflecting increasing uncertainty. The high cost alternative is initially well below the upper bound for the 95-percent stochastic projection interval but passes the upper bound by 2013 and stays above it through the remainder of the 10-year projection period. In contrast, the low cost alternative exceeds the lower bound for the 95-percent interval initially and nearly reaches the boundary by 2016 . The intermediate estimate is similar to the 50th percentile of the stochastic distribution, as one would anticipate because the stochastic analysis is tied to the intermediate assumptions as the expected case.

The levels of Part B benefits corresponding to various percentiles from the stochastic benefit distribution are shown in table V.D1. The percentiles represent the estimated probabilities that actual future Part B expenditures in a given year would be less than or equal to the expenditure amount shown. For example, the stochastic projections suggest a 5-percent probability that expenditures would be

\footnotetext{
${ }^{55}$ These estimated probabilities apply to a given projection year and not to all years simultaneously. Based on the stochastic model, the probability of costs exceeding the upper 95-percent limit in all 10 years would be substantially smaller than 2.5 percent.
} 
Appendices

$\$ 256.7$ billion or less in 2016. Similarly, there is an estimated 50-50 probability that expenditures in 2016 would be lower-or higher-than the 50th-percentile projection of $\$ 316.6$ billion (also known as the median projection).

Table V.D1.-Estimated Incurred Part B Benefit Expenditures, by Percentile of Projection Distribution

[In billions]

\begin{tabular}{crrrrr}
\multicolumn{5}{c}{$\left[\begin{array}{l}\text { [n billions] } \\
\text { Calendar year }\end{array}\right.$} & \multicolumn{5}{c}{ Percentiles } \\
\cline { 2 - 6 } 2006 & $\$ 161.4$ & 5.0 & 50.0 & 95.0 & 97.5 \\
2007 & 166.0 & 162.2 & $\$ 165.7$ & $\$ 169.2$ & $\$ 170.0$ \\
2008 & 169.5 & 172.2 & 178.1 & 188.0 & 190.1 \\
2009 & 176.5 & 180.1 & 188.3 & 203.9 & 206.6 \\
2010 & 183.5 & 187.3 & 200.6 & 221.7 & 226.9 \\
2011 & 191.1 & 197.2 & 213.1 & 240.4 & 246.4 \\
2012 & 199.6 & 206.4 & 226.7 & 258.6 & 265.3 \\
2013 & 209.5 & 217.1 & 240.8 & 280.1 & 286.6 \\
2014 & 220.2 & 228.3 & 257.8 & 302.5 & 310.6 \\
2015 & 233.9 & 241.9 & 294.6 & 328.9 & 339.2 \\
2016 & 247.1 & 256.7 & 316.6 & 356.2 & 367.1 \\
\hline
\end{tabular}

Note: Intermediate estimates are similar to the $50^{\text {th }}$-percentile benefits. See section IV.B for specific expenditure projections under the intermediate assumptions.

Table V.D2 presents the stochastic percentiles that correspond to the traditional intermediate, high, and low cost projections. For example, based on the stochastic model, the estimated probability that Part B expenditures in 2008 would be less than the low cost projection is 24.9 percent. Similarly, the estimated probability that costs would be at or below the high cost projection in 2011 is 91.6 percent.

As noted before, these probabilities are estimated, based on the statistical methods described in the previous section, and are subject to the various limitations inherent in such methods. Accordingly, the estimates provide a reasonable guide to possible outcomes but could be invalidated by unanticipated changes.

Table V.D2.-Percentiles of Part B Benefit Expenditure Distribution Corresponding to Low, Intermediate, and High Cost Estimates

\begin{tabular}{cccc}
\hline Calendar year & Low cost & Intermediate & High cost \\
\hline 2006 & $50.6 \%$ & $50.6 \%$ & $50.6 \%$ \\
2007 & 32.8 & 49.2 & 70.7 \\
2008 & 24.9 & 48.3 & 78.7 \\
2009 & 18.5 & 49.0 & 84.2 \\
2010 & 14.4 & 50.8 & 85.3 \\
2011 & 10.0 & 49.8 & 91.6 \\
2012 & 8.3 & 52.1 & 97.4 \\
2013 & 7.5 & 51.2 & 98.3 \\
2014 & 6.5 & 51.9 & 98.9 \\
2015 & 5.7 & 52.2 & 99.0 \\
2016 & 4.6 & 52.3 & 99.2 \\
\hline
\end{tabular}

The comparison of projection results in figure V.D1 and table V.D2 indicates that the lower range of the 95-percent stochastic projection is initially lower than the level of the low cost alternatives. Over the 
Supplemental Assessment of Uncertainty

10-year projection period, the difference between the levels becomes smaller. Similarly, the upper range of the 95-percent stochastic projection is initially higher than the level of the high cost alternatives. Toward the end of the 10-year projection period, however, the level of the high cost alternative is higher than the upper range of the 95-percent stochastic projection. This result illustrates the different natures of the two projection methodologies. The high and low cost alternatives assume expenditure increases of roughly 2 percent higher or lower, respectively, than the intermediate assumption in every year. ${ }^{56}$ In contrast, Part B growth rates under the stochastic projection can vary randomly by as much as 8 percentage points higher or lower than the intermediate assumption for a specific year. Thus, the stochastic projections suggest that the uncertainty of future Part B expenditures is somewhat greater over the next few years than illustrated by the traditional alternative projections. Over longer periods, however, the probability diminishes that Part B costs would increase 2 percent faster (or slower) than the intermediate assumption in every year. The stochastic model estimates that, by the end of the 10-year period, the likelihood of costs exceeding the high cost projection is small ( 0.8 percent) and that the probability of falling below the low cost alternative is also small (4.6 percent).

The statistical methodology described in this appendix can also be used to help assess the adequacy of financing and assets for the Part B account of the SMI trust fund. As noted elsewhere in this report, Part B is considered to be automatically in financial balance because premium and general revenue financing levels are reestablished annually to match expected expenditures for the following year. Thus, in contrast to OASDI and HI, where financing can be changed only through legislation, Part B should always be adequately financed so long as premiums and general revenue levels are accurately set and an adequate trust fund balance is maintained. In this regard, the stochastic methods used in this appendix can help determine if an unexpected major change in Part B expenditure levels is likely and whether such a change could jeopardize asset adequacy prior to the next premium determination. This assessment can be used to evaluate the sufficiency of existing procedures for setting premiums and the adequacy of traditional trust fund reserve targets.

The assets of the Part B account of the SMI trust fund should be sufficient at any time to cover the costs of covered services that have

${ }^{56} \mathrm{~A}$ more detailed description of the high and low cost assumptions is given in section IV.B. 


\section{Appendices}

been performed but not yet reimbursed (referred to as "incurred but unpaid" claims). In addition, assets should be sufficient to prevent account depletion in the event of unexpectedly high expenditures. The adequacy of the Part B account of the SMI trust fund for these purposes is generally measured by comparing the account's assets minus liabilities (for the incurred but unpaid claims) with expenditures for the following year, as described in more detail in section III.C2. Premium rates and matching general fund transfers are set each year based on estimates of the following 2 years' expenditures. ${ }^{57}$ The sensitivity of the asset reserve ratio to above- or below- average expenditure growth over the 2 years can be evaluated using the stochastic projections.

The estimated financial status of the Part B account of the SMI trust fund, based on the stochastic projections, is shown in figure V.D2. This graph displays the 95-percent projection interval for the ratio of trust fund assets less liabilities at the end of a year to the following year's expenditures. The results show a reasonable range of surplus values over the 10 -year period, reflecting the annual redetermination of Part B premiums and general revenue financing. If expenditure levels begin to drift away from expectations, financing is adjusted for the following year, thereby minimizing the degree to which fund assets would depart from desired levels. The figure also illustrates (i) the past decline in the reserve ratio attributable primarily to several years of legislation increasing Part B costs after the financing had been determined for the year, and (ii) the intentional movement from the existing financial status toward the desired reserve level of approximately 15 to 20 percent of the following year's expenditures.

Figure V.D2 also indicates the current level of assets less liabilities. Adverse experience or further legislation to increase physician payments would be financed by further large increases in the Part B premium and general revenue transfers, offset somewhat by the modest level of Part B assets.

The stochastic projections shown in figure V.D2 suggest that the target reserve level and annual redetermination of Part B financing should be sufficient to prevent the assets of the Part B account of the SMI trust fund from falling below acceptable levels. The lower bound of the 95-percent range remains in the vicinity of 10 percent after 2007. Thus, with a target fund ratio of 15 to 20 percent, faster-than-

\footnotetext{
${ }^{57}$ Expenditures in the following year determine the level of assets and liabilities at the end of that year; expenditures in the second year are used in the denominator of the trust fund reserve ratio and thus affect the level of this ratio.
} 
expected expenditure growth appears unlikely to result in actual levels below 10 percent. The supplementary assessment of uncertainty, based on the statistical approach shown in this appendix, supports the existing standards for ensuring fund solvency.

Figure V.D2.-95-Percent Projection Interval for Financing Status of Part B Account of SMI Trust Fund

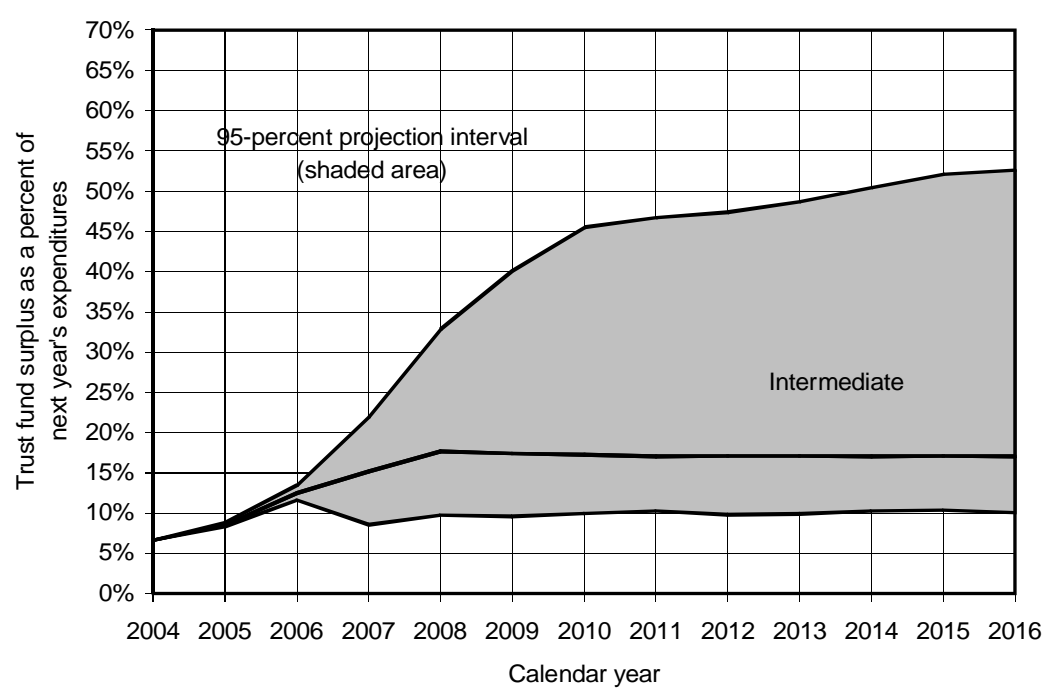

As noted previously, Part B financing is set for a future year based on projections of benefit expenditures. For example, the monthly premium and corresponding general fund transfers for 2007 were set in 2006 based on projections of benefit expenditures for 2007 and 2008. In practice, however, the actual benefit levels are likely to differ from those expected when the financing is determined. Although a specific reserve asset level is anticipated, the subsequent actual level will invariably differ. Figure V.D3 shows an estimated frequency distribution for such disparities, to assess their magnitude and likelihood. The estimation error for a given year is defined as the net surplus ratio at the end of the year, based on the stochastic projection, minus the expected surplus ratio at the time that financing is established. The frequency distribution shows the probabilities of various differences from the expected trust fund status.

The stochastic analysis suggests that, on average, 95 percent of the estimation errors would be expected to fall between about -9 percent and 11 percent. The largest adverse differences generated by the stochastic projections were in the vicinity of -14 percent. These results are also consistent with the traditional reserve level target of 


\section{Appendices}

15 to 20 percent. They further indicate that the expected reserve ratio of 15.2 percent (at the end of 2007) is now at the low end of the adequate range.

Figure V.D3.-Frequency Distribution of Estimation Errors for Part B Account of SMI Trust Fund Surplus Ratio (Stochastic "Actual" minus Estimated Surplus as a Percentage of Next Year's Expenditures)

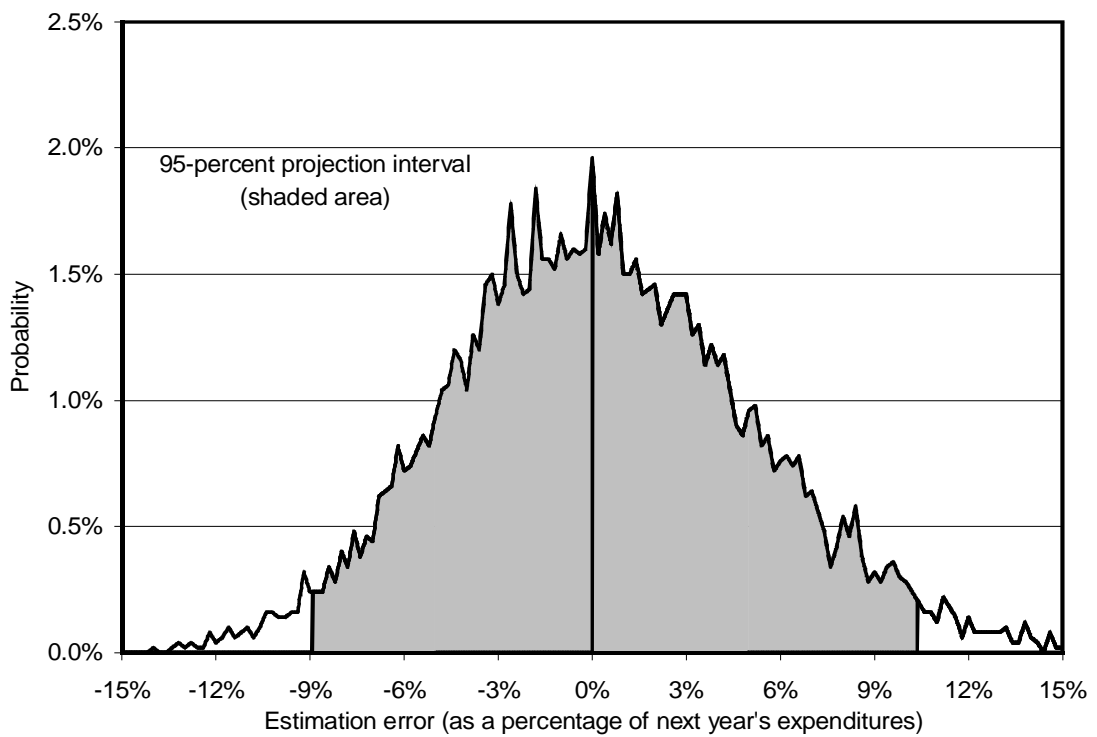

\section{Summary}

The stochastic approach presented in this appendix is intended to supplement the traditional projection methods used to evaluate the financial status of the Part B account of the SMI trust fund. The approach can help quantify the uncertainty of future Part B cost projections but is subject to further refinement. The results suggest that the range of variation defined by the traditional high and low cost alternatives is initially somewhat narrower than the range determined by the tentative application of stochastic modeling but about the same at the end of the 10-year projection period. The projections support the view that future Part B costs could vary substantially from the intermediate projection, due to variations in future annual cost increases. The statistical analysis also reinforces the conclusions that the current methods of establishing Part B premiums and general revenue financing should prevent depletion of the trust fund, even under conditions of sustained adverse cost experience, and that the level of Part B assets in 2007 is expected to reach the low end of the adequate level for the first time since 2002. 


\section{E. MEDICARE AND SOCIAL SECURITY TRUST FUNDS AND THE FEDERAL BUDGET}

The financial operations of Medicare and Social Security can be viewed in the context of the programs' trust funds or in the context of the overall Federal Budget. The financial status of the trust funds differs fundamentally from the impact of these programs on the budget, and the relationship between these two perspectives is often misunderstood. Each perspective is appropriate and important for its intended purpose; this appendix attempts to clarify their roles and relationship.

By law, the annual reports of the Medicare and Social Security Boards of Trustees to Congress focus on the financial status of the programs' trust funds-that is, whether these funds have sufficient revenues and assets to enable the payment of benefits and administrative expenses. This "trust fund perspective" is important, because the existence of trust fund assets provides the statutory authority to make such payments without the need for an appropriation from Congress. Medicare and Social Security benefits can be paid only if the relevant trust fund has sufficient income or assets.

The trust fund perspective does not encompass the interrelationship between the Medicare and Social Security trust funds and the overall Federal Budget. The budget is a comprehensive display of all Federal activities, whether financed through trust funds or from the general fund of the Treasury. This broader focus may appropriately be termed the "budget perspective" or "government-wide perspective" and is officially presented in the Budget of the United States Government and in the Financial Report of the United States Government.

The majority of Medicare and Social Security costs are financed through payroll taxes, income taxes on Social Security benefits, Medicare premiums, and special State payments to Medicare. In addition to these "earmarked" receipts from workers, employers, beneficiaries, and States, Medicare and Social Security rely on Federal general fund revenues for some of their financing (principally for the SMI trust fund), and the trust funds are credited with interest payments on their accumulated assets as well. The financial status of a trust fund appropriately considers all sources of financing provided under current law for that fund, including the availability of trust fund assets that can be used to meet program expenditures. From the budget perspective, however, general fund transfers and interest 


\section{Appendices}

payments to the trust funds, and asset redemptions, represent a draw on other Federal resources for which there is no earmarked source of revenue from the public.

In the past, general fund and interest payments for Medicare and Social Security were relatively small. These amounts have increased substantially over the last 2 decades, however, and the expected rapid future growth of Medicare and Social Security will make their interaction with the Federal Budget increasingly important. As the difference between earmarked and total trust fund revenues grows, the financial operations of Social Security and Medicare can appear markedly different depending on which of the two perspectives is used. $^{58}$

\section{Illustration with Actual Data for 2006}

The trust fund and budget perspectives can be illustrated with actual data on Federal financial operations for fiscal year 2006, as shown in table V.E1. The first three columns show revenues and expenditures for HI, SMI, and OASDI, respectively, and the fourth column is the sum of these three columns. The fifth column shows total revenues and expenditures for all other government programs (including the general fund account of the Treasury), and the final column is the sum of the "Combined" and "Other Government" columns. Earmarked revenues from the public are shown separately from revenues from other government accounts (general revenue transfers and interest credits). Note that the transfers and interest credits received by the trust funds appear in total as negative entries under the "Other Government" column and are thus offsetting when summed for the total budget in the final column. These two intragovernmental transactions are key to the differences between the two perspectives.

\footnotetext{
${ }^{58} \mathrm{~A}$ more complete treatment of this topic can be found in the 2006 Financial Report of the United States Government at www.fms.treas.gov/fr/ and in a Treasury report entitled "Social Security and Medicare Trust Funds and the Federal Budget: An Expanded Exposition," available at www.treas.gov/offices/economicpolicy/social_security.html. Additional information is available in a Health Care Financing Review article entitled "Medicare Financial Status, Budget Impact, and Sustainability: Which Concept Is Which?", available at http://www.cms.hhs.gov/HealthCareFinancingReview/02_2005_Edition.asp.
} 


\begin{tabular}{|c|c|c|c|c|c|c|}
\hline \multirow[b]{2}{*}{ Revenue and expenditures categories } & \multirow[b]{2}{*}{$\mathrm{HI}$} & \multicolumn{2}{|c|}{ Trust funds } & \multirow{2}{*}{\multicolumn{2}{|c|}{$\begin{array}{c}\text { Other } \\
\text { Combined government }\end{array}$}} & \multirow[b]{2}{*}{ Total $^{1}$} \\
\hline & & SMI & OASDI & & & \\
\hline $\begin{array}{l}\text { Revenues from public: } \\
\text { Payroll and benefit taxes } \\
\text { Premiums } \\
\text { Other taxes, fees, and payments }{ }^{3}\end{array}$ & $\begin{array}{r}\$ 190.7 \\
3.7 \\
- \\
\end{array}$ & $\begin{array}{r}-\overline{-} \\
\$ 44.2 \\
3.6\end{array}$ & $\begin{array}{r}\$ 636.4 \\
- \\
\end{array}$ & $\begin{array}{r}\$ 827.1 \\
47.9 \\
3.6 \\
\end{array}$ & $\begin{array}{r}- \\
\$ 1,529.8 \\
\end{array}$ & $\begin{array}{r}\$ 827.1 \\
47.9 \\
1,533.4 \\
\end{array}$ \\
\hline Total & 194.4 & 47.9 & 636.4 & 878.7 & $1,529.8$ & $2,408.5$ \\
\hline Total expenditures to public ${ }^{4}$ & 184.9 & 195.5 & 548.5 & 928.9 & $1,727.2$ & $2,656.2$ \\
\hline Net Results for Budget Perspective & 9.5 & -147.7 & 87.9 & -50.3 & -197.4 & -247.7 \\
\hline $\begin{array}{l}\text { Revenues from other government } \\
\text { accounts: } \\
\text { Transfers } \\
\text { Interest credits }\end{array}$ & $\begin{array}{r}0.5 \\
15.4 \\
\end{array}$ & $\begin{array}{r}162.6 \\
1.5 \\
\end{array}$ & $\begin{array}{l}-0.3 \\
97.7 \\
\end{array}$ & $\begin{array}{l}162.8 \\
114.5\end{array}$ & $\begin{array}{l}-162.8 \\
-114.5\end{array}$ & $\begin{array}{l}0.0 \\
0.0\end{array}$ \\
\hline Total & 15.9 & 164.1 & 97.4 & 277.3 & -277.3 & 0.0 \\
\hline $\begin{array}{l}\text { Net Results for Trust Fund Perspective } \\
{ }^{1} \text { This column is the sum of the preceding } t \\
\text { figure } \$ 247.7 \text { billion was the total Federal } \\
{ }^{2} \text { Includes Part D premiums paid directly to } \\
\text { are estimated. } \\
{ }^{3} \text { Includes Part D State transfers. } \\
{ }^{4} \text { The OASDI figure includes } \$ 3.8 \text { billion tra }\end{array}$ & $\begin{array}{l}\text { 25.4 } \\
\text { two colun } \\
\text { Budget d } \\
\text { to plans, } \\
\text { ansferred }\end{array}$ & $\begin{array}{l}16.4 \\
\text { mns and } \\
\text { deficit for } \\
\text { which ar } \\
\text { to the Ra }\end{array}$ & $\begin{array}{l}\text { 185.2 } \\
\text { shows dat } \\
\text { fiscal year } \\
\text { enot displ } \\
\text { ilroad Reti }\end{array}$ & $\begin{array}{l}\frac{227.0}{\text { ta for the tote }} \\
\text { 2006. } \\
\text { layed on Tre } \\
\text { tirement Boa }\end{array}$ & $\begin{array}{l}\frac{\mathbf{n} / \mathbf{a}}{\text { tal Federal Bu }} \\
\text { easury staten } \\
\text { ard. }\end{array}$ & $\begin{array}{l}\text { n/a } \\
\text { udget. The } \\
\text { ments and }\end{array}$ \\
\hline $\begin{array}{l}\text { Notes: } 1 \text {. For comparison, } \mathrm{HI} \text { taxable } \mathrm{p} \\
\$ 5,038 \text { billion, and } \$ 13,245 \text { bill } \\
\text { 2. Totals do not necessarily equa } \\
\text { 3. "n/a" indicates not applicable. }\end{array}$ & $\begin{array}{l}\text { payroll, O } \\
\text { llion, resp } \\
\text { al the sum }\end{array}$ & $\begin{array}{l}\text { ASDI ta } \\
\text { eectively, } \\
\text { ns of rour }\end{array}$ & $\begin{array}{l}\text { able payr } \\
\text { n } 2006 . \\
\text { ded comp }\end{array}$ & $\begin{array}{l}\text { roll, and GD } \\
\text { ponents. }\end{array}$ & P were $\$ 6,2$ & 290 billion, \\
\hline
\end{tabular}

The trust fund perspective reflects both categories of revenues for each trust fund. For HI, revenues from the public plus transfers/credits from other government accounts exceeded total expenditures by $\$ 25.4$ billion in 2006 , as shown at the bottom of the first column. ${ }^{59}$ For the SMI trust fund, the statutory revenues from beneficiary premiums, State transfers, general revenue transfers, and interest earnings collectively exceeded expenditures by $\$ 16.4$ billion in 2006. Note that the general revenue transfers from other government accounts are appropriately viewed as financial resources from the trust fund perspective, since they are available under

\footnotetext{
${ }^{59}$ Surpluses of revenues from the public over expenditures to the public are invested in special Treasury securities and thereby represent a loan from the trust funds to the general fund of the Federal Government. These loans reduce the amount that the general fund has to borrow from the public to finance a deficit (or likewise increase the amount of debt paid off if there is a surplus). Interest is credited to the trust funds while the securities are being held. Trust fund securities can be redeemed at any time if needed to help meet program expenditures. Thus, the accumulation of fund assets creates budget commitments for future years when interest earnings and asset redemptions are used to meet expenditures.
} 


\section{Appendices}

current law to help meet trust fund outlays. For OASDI, total trust fund revenues from all sources (including $\$ 97.7$ billion in interest payments) exceeded total expenditures by $\$ 185.2$ billion.

From the government-wide or budget perspective, only earmarked revenues received from the public-taxes on payroll and benefits, plus premiums-and expenditures made to the public are important for the final balance. ${ }^{60}$ For HI, the difference between such revenues ( $\$ 194.4$ billion) and total expenditures made to the public ( $\$ 184.9$ billion) was $\$ 9.5$ billion in 2006 , indicating that $\mathrm{HI}$ had a small, positive effect on the overall budget in 2006. For SMI, beneficiary premiums and State payments to Part D of Medicare are the only source of revenues from the public and represent only about 25 percent of total expenditures. The remaining $\$ 147.7$ billion in 2006 outlays represented a substantial net draw on the Federal Budget in that year. ${ }^{61}$ For OASDI, the difference between revenues from the public ( $\$ 636.4$ billion) and total expenditures ( $\$ 548.5$ billion) was $\$ 87.9$ billion, indicating that OASDI had a large, positive effect on the overall budget last year.

Thus, from the trust fund perspective, HI, SMI, and OASDI had significant annual surpluses in 2006. From the budget perspective, HI and OASDI made positive contributions to the Federal Budget, though by an amount smaller than the respective trust fund surpluses, and SMI had a net draw on the budget. HI, SMI, and OASDI collectively had a large trust fund surplus of $\$ 227.0$ billion in fiscal year 2006, but a significant net draw of $\$ 50.3$ billion on the budget.

It is important to recognize that each viewpoint is appropriate for its intended purpose but that one perspective cannot be used to answer questions related to the other. In the case of SMI, under current-law financing the trust fund will always be in balance and there will always be a net draw on the Federal Budget. In the case of HI, trust fund surpluses in a given year may occur with either a positive or negative direct impact on the budget for that year. Conversely, a positive or negative budget impact from HI offers minimal insight

\footnotetext{
${ }^{60}$ For this purpose, "the public" includes State Governments since they are outside of the Federal Government.

${ }^{61}$ Three types of trust fund transactions comprised this net budget obligation: $\$ 162.6$ billion was drawn in the form of general revenue transfers, and another $\$ 1.5$ billion in interest payments, and $\$ 16.4$ billion was transferred from the trust fund to the general fund through the purchase of special-issue Treasury securities in an amount equal to the trust fund surplus for the year.
} 
into whether its trust fund has sufficient total revenues and assets to permit payment of benefits.

The next section illustrates the magnitude of the long-range difference between projected expenditures and revenues for Medicare and Social Security, under both the trust fund and budget perspectives.

\section{Future Obligations of the Trust Funds and the Budget}

Table V.E2 collects from the Medicare and OASDI Trustees Reports the present values of projected future revenues and expenditures over the next 75 years under current law. For HI and OASDI, tax revenues from the public are projected to fall short of statutory expenditures by $\$ 11.9$ trillion and $\$ 6.8$ trillion, respectively, in present value terms. ${ }^{62}$

Table V.E2.-Present Values of Projected Revenue and Cost Components of 75-Year Open-Group Obligations for HI, SMI, and OASDI (In trillions, as of January 1, 2007)

\begin{tabular}{|c|c|c|c|c|}
\hline Revenue and expenditure categories & $\mathrm{HI}$ & SMI & OASDI & Combined \\
\hline \multicolumn{5}{|l|}{ Revenues from public: } \\
\hline Payroll and benefit taxes & $\$ 11.1$ & - & $\$ 34.1$ & $\$ 45.2$ \\
\hline Premiums & 0.0 & $\$ 6.4$ & - & 6.4 \\
\hline Other taxes and fees ${ }^{1}$ & - & 1.0 & 一 & 1.0 \\
\hline Total & 11.1 & 7.4 & 34.1 & 52.6 \\
\hline Total expenditures to public & 23.0 & 29.6 & 40.9 & 93.5 \\
\hline Net Results for Budget Perspective & -11.9 & -22.3 & -6.8 & -40.9 \\
\hline \multicolumn{5}{|l|}{$\begin{array}{l}\text { Revenues from other government } \\
\text { accounts: }\end{array}$} \\
\hline Transfers & 0.0 & 22.3 & 0.0 & 22.3 \\
\hline Interest credits & $\mathrm{n} / \mathrm{a}$ & $\mathrm{n} / \mathrm{a}$ & $\mathrm{n} / \mathrm{a}$ & $\mathrm{n} / \mathrm{a}$ \\
\hline Total & 0.0 & 22.3 & 0.0 & 22.3 \\
\hline Trust fund assets on January 1, 2007 & 0.3 & 0.0 & 2.0 & 2.4 \\
\hline Net Results for Trust Fund Perspective & -11.6 & 0.0 & -4.7 & -16.3 \\
\hline
\end{tabular}

${ }^{1}$ Includes Part D State transfers.

Notes: 1. For comparison, the present values of $\mathrm{HI}$ taxable payroll, OASDI taxable payroll, and GDP are $\$ 335.3$ trillion, $\$ 259.8$ trillion, and $\$ 730.0$ trillion, respectively, over the next 75 years. This present value of GDP is calculated using HI-specific interest discount factors and differs slightly from the corresponding amount shown in the OASDI Trustees Report.

2. Medicare present values are calculated using HI-specific discount factors, while OASDI amounts use OASDI-specific discount factors.

3. Totals do not necessarily equal the sums of rounded components.

4. "n/a" indicates not applicable.

5. "0.0" indicates an amount of less than $\$ 50$ billion.

${ }^{62}$ Interest income is not a factor in this table, as dollar amounts are in present value terms. 


\section{Appendices}

From the budget perspective, these are the additional amounts that would be needed in order to pay HI and OASDI benefits and other costs at the level scheduled under current law over the next 75 years. From the trust fund perspective, the amounts needed are smaller by the value of the accumulated assets in the respective trust funds$\$ 0.3$ trillion for HI and $\$ 2.0$ trillion for OASDI-that could be drawn down to cover a part of the projected shortfall in tax revenues. Two points about this comparison are important to note:

- Other than asset redemptions and interest payments, no provision exists under current law to address the projected HI and OASDI financial imbalances. Once assets are exhausted, expenditures cannot be made except to the extent covered by ongoing tax receipts. In this extreme-and politically unlikelysituation, further transfers from the general fund would require new legislation.

- Accordingly, from a trust fund perspective, the long-range $\mathrm{HI}$ and OASDI deficits reflect the net imbalance after trust fund assets have been redeemed. From a government-wide perspective, the deficits represent the cost of redeeming those assets plus the additional legislative authorization that would be required to fully satisfy future scheduled benefit payments. ${ }^{63}$

The situation for SMI is somewhat different. SMI expenditures for Part B and Part D are projected to exceed premium revenues by $\$ 22.3$ trillion. General fund transfers of this amount will be needed to keep the SMI trust fund solvent for the next 75 years, and these transfers represent a formal budget requirement under current law. From the trust fund perspective, the present value of projected total premiums and general revenues equals the present value of future expenditures.

From the 75-year budget perspective, the present value of the additional resources that would be needed to meet projected expenditures, at current-law levels for the three programs combined, is $\$ 40.9$ trillion. ${ }^{64}$ To put this very large figure in perspective, it would

\footnotetext{
${ }^{63}$ In practice, the long-range HI and OASDI deficits could be addressed by reducing expenditures, increasing payroll or other earmarked tax revenues, implementing a general revenue subsidy, or some combination of such measures. For Medicare, in particular, legislation has frequently been enacted to slow the growth of expenditures. ${ }^{64} \mathrm{As}$ noted previously, the long-range HI and OASDI financial imbalances could instead be partially addressed by expenditure reductions, thereby reducing the need for additional revenues. Similarly, SMI expenditure reductions would reduce the need for general fund transfers.
} 
represent 5.6 percent of the present value of projected GDP over the same period ( $\$ 730$ trillion). The components of the $\$ 40.9$-trillion total are as follows:

\begin{tabular}{|c|c|c|}
\hline $\begin{array}{l}\text { Unfunded HI and OASDI obligations } \\
\text { (trust fund perspective) }^{65}\end{array}$ & $\$ 16.3$ trillion & $(2.2 \%$ of GDP) \\
\hline $\mathrm{HI}$ and OASDI asset redemptions ........................ & $\$ 2.4$ trillion & $(0.3 \%$ of GDP $)$ \\
\hline $\begin{array}{l}\text { SMI Part B and Part D general } \\
\text { revenue financing }\end{array}$ & $\$ 22.3$ trillion & ( $3.1 \%$ of GDP) \\
\hline
\end{tabular}

These resource needs would be in addition to the payroll taxes, benefit taxes, and premium payments scheduled under current law. As noted, the asset redemptions and SMI general revenue transfers represent formal budget commitments under current law, but no provision exists for covering the HI and OASDI trust fund deficits once assets are exhausted.

\footnotetext{
${ }^{65}$ Additional revenues and/or expenditure reductions totaling $\$ 16.3$ trillion, together with $\$ 2.4$ trillion in asset redemptions, would cover the projected financial imbalance but would leave the HI and OASDI trust funds exhausted at the end of the 75-year period. The long-range actuarial deficit for HI and OASDI includes a cost factor to allow for a normal level of fund assets. See section III.B3 in this report, and section IV.B4 in the OASDI Trustees Report, for the numerical relationship between the actuarial deficit and the "unfunded obligations" of each program.
} 


\section{Appendices}

\section{F. FISCAL YEAR HISTORICAL DATA AND PROJECTIONS THROUGH 2016}

Tables V.F1, V.F2, and V.F3 present detailed operations of the HI trust fund, along with Part B and Part D of the SMI trust fund, for fiscal year 2006. These tables are similar to the calendar-year operation tables displayed in sections III.B and III.C.

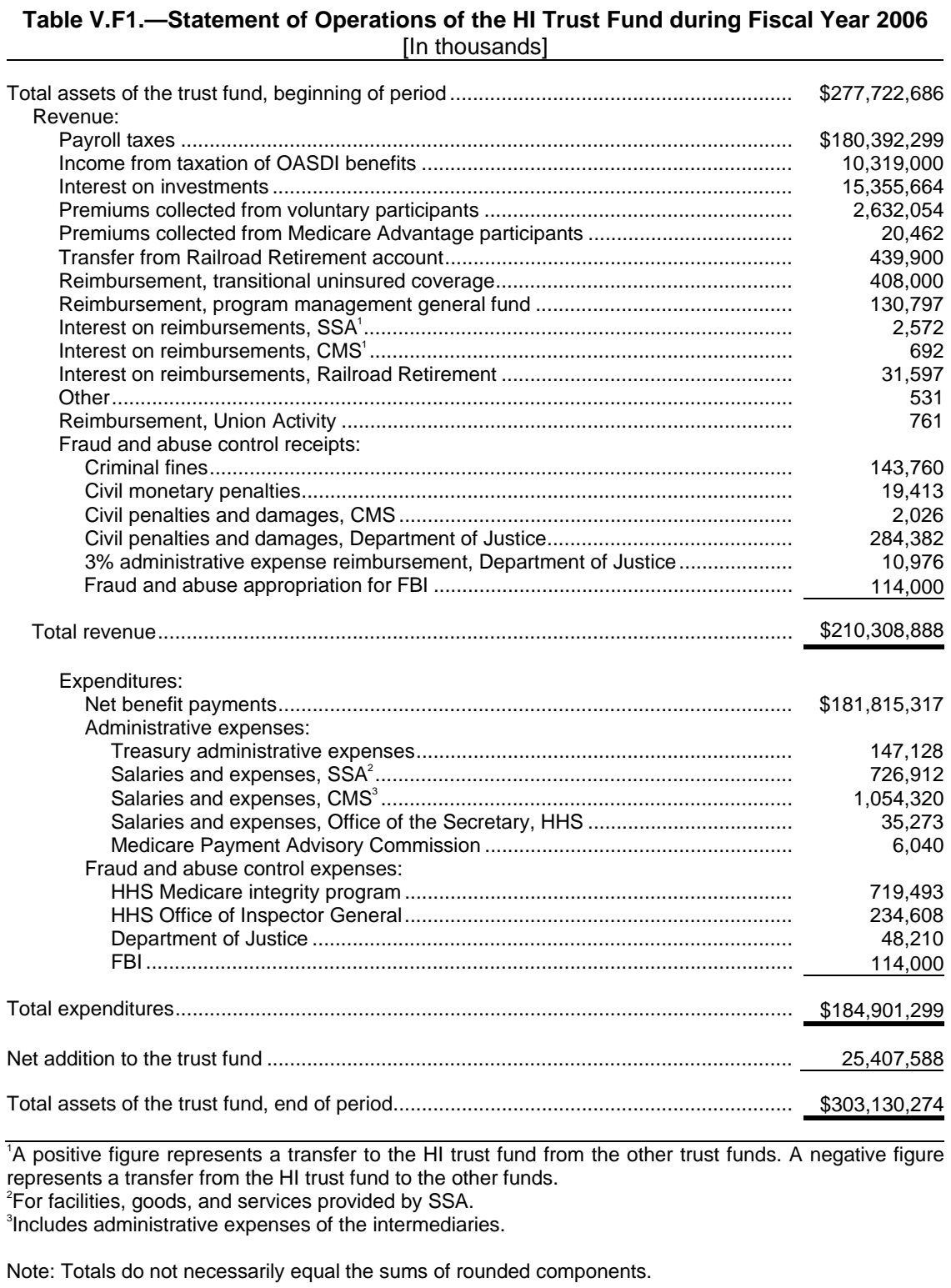




\section{Fiscal Year Operations and Projections}

Table V.F2.-Statement of Operations of the Part B Account in the SMI Trust Fund during Fiscal Year 2006

[In thousands]

\footnotetext{
Total assets of the Part B account in the trust fund, beginning of period...

Revenue:

Premiums from enrollees:

Enrollees aged 65 and over.

Disabled enrollees under age 65

$\$ 35,605,915$ $6,022,601$

Premiums collected from Medicare Advantage participants

Government contributions:

Enrollees aged 65 and over.....

Disabled enrollees under age 65

Total Government contributions

Other

Interest on investments...

Total revenue.

$\$ 16,884,504$

Expenditures:

Net Part B benefit payments

Administrative expenses:

Transfer to Medicaid ${ }^{1}$

Treasury administrative expense

Salaries and expenses, $\mathrm{CMS}^{2}$

Salaries and expenses, SSA

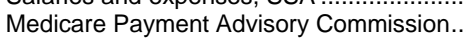

Railroad Retirement administrative expenses.....................

Transitional assistance administrative expenses

Prescription drug administrative expenses .................................. 337,118

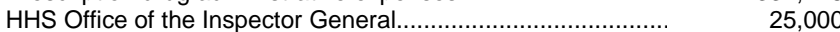

Total administrative expenses

$3,299,250$

Total expenditures

$161,647,274$

Net addition to the trust fund

$15,707,243$

Total assets of the Part B account in the trust fund, end of period..........

$\$ 32,591,747$

${ }^{1}$ Represents amount transferred from the Part B account in the SMI trust fund to Medicaid to pay the Part B premium for certain qualified individuals, as legislated by the Balanced Budget Act of 1997.

${ }^{2}$ Includes administrative expenses of the carriers and intermediaries.

Note: Totals do not necessarily equal the sums of rounded components.
} 


\section{Appendices}

Table V.F3-Statement of Operations of the Part D Account in the SMI Trust Fund during Fiscal Year 2006 [In thousands]

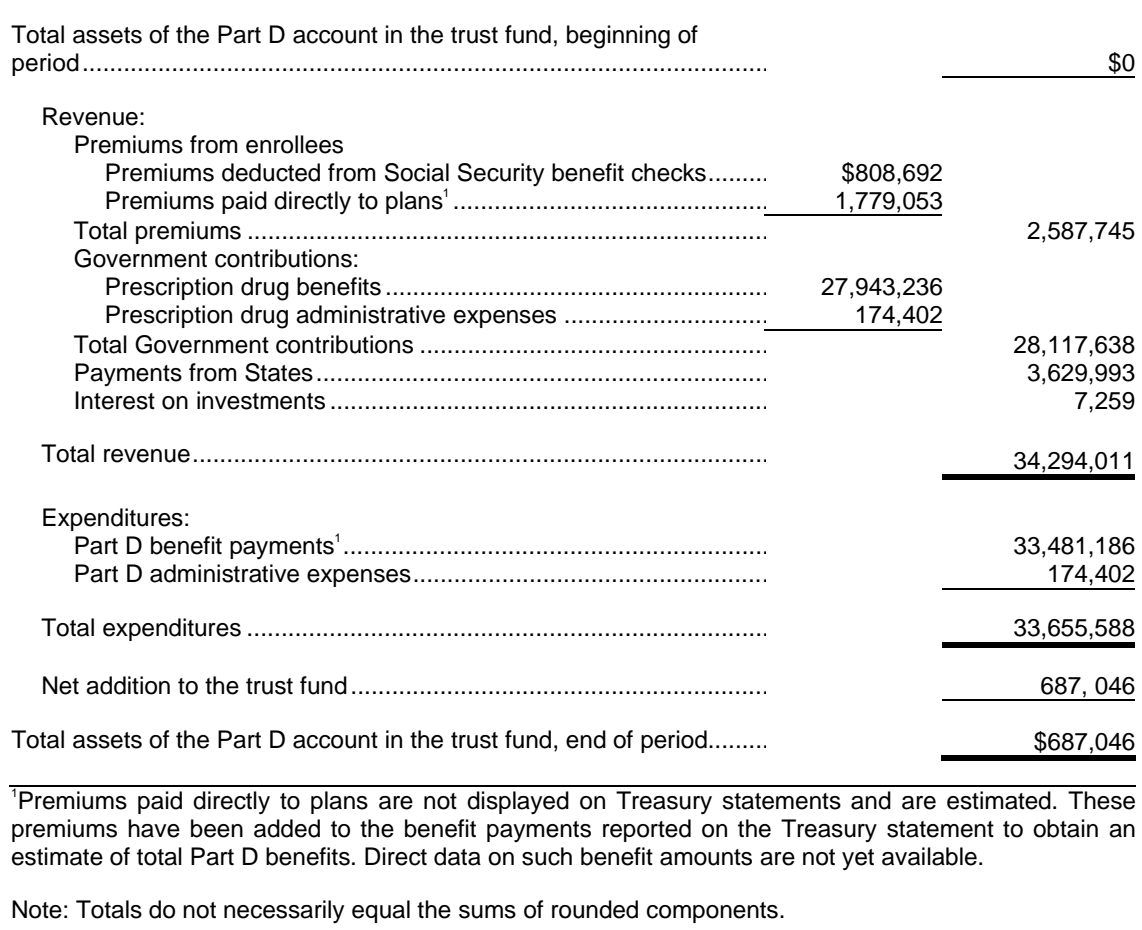

${ }^{1}$ Premiums paid directly to plans are not displayed on Treasury statements and are estimated. These premiums have been added to the benefit payments reported on the Treasury statement to obtain an estimate of total Part $D$ benefits. Direct data on such benefit amounts are not yet available.

Note: Totals do not necessarily equal the sums of rounded components.

Tables V.F4, V.F5, V.F6, V.F7, and V.F8 present estimates of the fiscal year operations of total Medicare, the HI trust fund, the SMI trust fund, the Part B account in the SMI trust fund, and the Part D account in the SMI trust fund, respectively. These tables correspond to the calendar-year trust fund operation tables shown in section III. 
Fiscal Year Operations and Projections

Table V.F4.-Total Medicare Income, Expenditures, and Trust Fund Assets during Fiscal Years 1970-2016

\begin{tabular}{|c|c|c|c|c|}
\hline Fiscal year & Total income & Total expenditures & $\begin{array}{c}\text { Net change in } \\
\text { assets }\end{array}$ & $\begin{array}{c}\text { Assets at end of } \\
\text { year }\end{array}$ \\
\hline \multicolumn{5}{|l|}{ Historical data: } \\
\hline 1970 & $\$ 7.5$ & $\$ 7.1$ & $\$ 0.3$ & $\$ 2.7$ \\
\hline 1975 & 16.9 & 14.8 & 2.1 & 11.3 \\
\hline 1980 & 35.7 & 35.0 & 0.7 & 19.0 \\
\hline 1985 & 75.5 & 71.4 & 4.1 & 31.9 \\
\hline 1990 & 125.7 & 109.7 & 16.0 & 110.2 \\
\hline 1995 & 173.0 & 180.1 & -7.1 & 143.4 \\
\hline 2000 & 248.9 & 219.3 & 29.6 & 214.0 \\
\hline 2001 & 266.3 & 241.2 & 25.2 & 239.2 \\
\hline 2002 & 285.5 & 256.9 & 28.6 & 267.8 \\
\hline 2003 & 286.0 & 277.8 & 8.2 & 275.9 \\
\hline 2004 & 307.6 & 301.5 & 6.1 & 282.1 \\
\hline 2005 & 349.4 & 336.9 & 12.5 & 294.6 \\
\hline 2006 & 422.2 & 380.4 & 41.8 & 336.4 \\
\hline \multicolumn{5}{|c|}{ Intermediate estimates: } \\
\hline 2007 & 455.7 & 437.0 & 18.7 & 355.1 \\
\hline 2008 & 488.9 & 470.6 & 18.4 & 373.5 \\
\hline 2009 & 517.3 & 505.4 & 11.9 & 385.4 \\
\hline 2010 & 552.3 & 544.7 & 7.6 & 393.0 \\
\hline 2011 & 595.8 & 601.9 & -6.1 & 387.0 \\
\hline 2012 & 624.7 & 613.5 & 11.2 & 398.1 \\
\hline 2013 & 672.0 & 678.2 & -6.3 & 391.9 \\
\hline 2014 & 715.9 & 730.8 & -14.9 & 377.0 \\
\hline 2015 & 762.7 & 787.4 & -24.6 & 352.4 \\
\hline 2016 & 826.9 & 877.0 & -50.2 & 302.2 \\
\hline
\end{tabular}


Table V.F5.-Operations of the HI Trust Fund during Fiscal Years 1970-2016

\begin{tabular}{|c|c|c|c|c|c|c|c|c|c|c|c|c|c|}
\hline & & & & & & {$[\ln \mathrm{bi}$} & illions] & & & & & & \\
\hline & & & & Incor & & & & & & xpenditures & & Trus & st fund \\
\hline $\begin{array}{l}\text { Fiscal } \\
\text { year }^{1}\end{array}$ & $\begin{array}{c}\text { Payroll } \\
\text { taxes }\end{array}$ & $\begin{array}{c}\text { Income } \\
\text { from } \\
\text { taxation of } \\
\text { benefits }\end{array}$ & $\begin{array}{c}\text { Railroad } \\
\text { Retirement } \\
\text { account } \\
\text { transfers } \\
\end{array}$ & $\begin{array}{l}\text { Reimburse- } \\
\text { ment for } \\
\text { uninsured } \\
\text { persons }\end{array}$ & $\begin{array}{c}\begin{array}{c}\text { Premiums } \\
\text { from }\end{array} \\
\text { voluntary } \\
\text { enrollees }\end{array}$ & $\begin{array}{c}\text { Payments } \\
\text { for military } \\
\text { wage } \\
\text { credits }\end{array}$ & $\begin{array}{l}\text { Interest } \\
\text { and } \\
\text { other }{ }^{2,3} \\
\end{array}$ & Total & $\begin{array}{c}\text { Benefit } \\
\text { payments }^{3,4}\end{array}$ & $\begin{array}{l}\text { Adminis- } \\
\text { trative } \\
\text { expenses }^{5}\end{array}$ & Total & $\begin{array}{c}\text { Net } \\
\text { change }\end{array}$ & $\begin{array}{l}\text { Balance at } \\
\text { end of year }\end{array}$ \\
\hline Historica & data: & & & & & & & & & & & & \\
\hline 1970 & $\$ 4.8$ & - & $\$ 0.1$ & $\$ 0.6$ & - & $\$ 0.0$ & $\$ 0.1$ & $\$ 5.6$ & $\$ 4.8$ & $\$ 0.1$ & $\$ 5.0$ & $\$ 0.7$ & $\$ 2.7$ \\
\hline 1975 & 11.3 & - & 0.1 & 0.5 & $\$ 0.0$ & 0.0 & 0.6 & 12.6 & 10.4 & 0.3 & 10.6 & 2.0 & 9.9 \\
\hline 1980 & 23.2 & - & 0.2 & 0.7 & 0.0 & 0.1 & 1.1 & 25.4 & 23.8 & 0.5 & 24.3 & 1.1 & 14.5 \\
\hline 1985 & 46.5 & - & 0.4 & 0.8 & 0.0 & 0.1 & 3.2 & 50.9 & 47.8 & 0.8 & 48.7 & $4.1^{6}$ & 21.3 \\
\hline 1990 & 70.7 & - & 0.4 & 0.4 & 0.1 & 0.1 & 7.9 & 79.6 & 65.9 & 0.8 & 66.7 & 12.9 & 95.6 \\
\hline 1995 & 98.1 & $\$ 3.9$ & 0.4 & 0.5 & 1.0 & 0.1 & 11.0 & 114.8 & 113.6 & 1.3 & 114.9 & -0.0 & 129.5 \\
\hline 2000 & 137.7 & 8.8 & 0.5 & 0.5 & 1.4 & 0.0 & 10.8 & 159.7 & $127.9^{7}$ & 2.4 & 130.3 & 29.4 & 168.1 \\
\hline 2001 & 151.9 & 4.9 & 0.5 & 0.5 & 1.4 & $-1.2^{8}$ & 13.0 & 171.0 & $139.4^{7}$ & 2.4 & 141.7 & 29.3 & 197.4 \\
\hline 2002 & 151.6 & 10.9 & 0.4 & 0.4 & 1.5 & 0.0 & 14.9 & 179.8 & $145.6^{7}$ & 2.5 & 148.0 & 31.7 & 229.1 \\
\hline 2003 & 149.8 & 8.3 & 0.4 & 0.4 & 1.6 & 0.0 & 15.2 & 175.8 & $151.3^{7}$ & 2.5 & 153.8 & 22.0 & 251.1 \\
\hline 2004 & 153.4 & 8.6 & 0.4 & 0.4 & 1.8 & 0.2 & 16.0 & 180.8 & 164.1 & 2.9 & 167.0 & 13.8 & 264.9 \\
\hline 2005 & 169.0 & 8.8 & 0.4 & 0.3 & 2.3 & 0.0 & 16.2 & 196.9 & 181.3 & 2.9 & 184.1 & 12.8 & 277.7 \\
\hline 2006 & 180.4 & 10.3 & 0.5 & 0.4 & 2.6 & 0.0 & 16.1 & 210.3 & 181.8 & 3.1 & 184.9 & 25.4 & 303.1 \\
\hline Intermec & ate estima & ates: & & & & & & & & & & & \\
\hline 2007 & 188.3 & 10.7 & 0.5 & 0.5 & 2.8 & 0.0 & 16.6 & 219.3 & 204.2 & 3.1 & 207.3 & 12.0 & 315.1 \\
\hline 2008 & 198.4 & 12.1 & 0.5 & 0.5 & 2.9 & 0.0 & 17.0 & 231.5 & 217.2 & 3.0 & 220.2 & 11.2 & 326.3 \\
\hline 2009 & 209.2 & 13.7 & 0.5 & 0.3 & 3.1 & 0.0 & 17.4 & 244.2 & 233.5 & 3.1 & 236.7 & 7.5 & 333.9 \\
\hline 2010 & 221.1 & 15.3 & 0.5 & 0.3 & 3.3 & 0.0 & 17.8 & 258.3 & 250.3 & 3.2 & 253.5 & 4.8 & 338.6 \\
\hline 2011 & 232.8 & 17.1 & 0.6 & 0.3 & 3.6 & 0.0 & 18.0 & 272.3 & 272.7 & 3.3 & 276.0 & -3.7 & 334.9 \\
\hline 2012 & 243.4 & 19.1 & 0.6 & 0.3 & 3.8 & 0.0 & 18.0 & 285.1 & 280.4 & 3.4 & 283.8 & 1.3 & 336.2 \\
\hline 2013 & 254.4 & 21.5 & 0.6 & 0.3 & 4.0 & 0.0 & 17.7 & 298.5 & 305.8 & 3.5 & 309.3 & -10.8 & 325.3 \\
\hline 2014 & 265.3 & 23.8 & 0.6 & 0.3 & 4.2 & 0.0 & 17.0 & 311.2 & 327.3 & 3.7 & 331.0 & -19.7 & 305.6 \\
\hline 2015 & 276.5 & 26.1 & 0.6 & 0.3 & 4.5 & 0.0 & 15.8 & 323.8 & 350.1 & 3.8 & 353.9 & -30.1 & 275.4 \\
\hline 2016 & 291.4 & 28.6 & 0.7 & 0.3 & 4.7 & 0.0 & 14.1 & 339.7 & 383.1 & 3.9 & 387.0 & -47.3 & 228.1 \\
\hline
\end{tabular}


'Fiscal years 1970 and 1975 consist of the 12 months ending on June 30 of each year; fiscal years 1980 and later consist of the 12 months ending on September 30 of each year.

${ }^{2}$ Other income includes recoveries of amounts reimbursed from the trust fund that are not obligations of the trust fund, receipts from the fraud and abuse control program, and a small amount of miscellaneous income.

${ }^{3}$ See footnote 2 of table III.B4.

${ }^{4}$ Includes costs of Peer Review Organizations from 1983 through 2001 (beginning with the implementation of the prospective payment system on October 1, 1983) and costs of Quality Improvement Organizations beginning in 2002.

Includes costs of experiments and demonstration projects. Beginning in 1997, includes fraud and abuse control expenses, as provided for by Public Law 104-191.

${ }^{6}$ Includes repayment of loan principal, from the OASI trust fund, of $\$ 1.8$ billion.

${ }^{7}$ For 1998 to 2003, includes monies transferred to the SMI trust fund for home health agency costs, as provided for by Public Law 105-33.

${ }^{8}$ Includes the lump-sum general revenue adjustment of $-\$ 1.2$ billion, as provided for by section 151 of Public Law 98-21.

Note: Totals do not necessarily equal the sums of rounded components. 


\section{Appendices}

Table V.F6.-Operations of the SMI Trust Fund (Cash Basis) during Fiscal Years 1970-2016

[In billions]

\begin{tabular}{|c|c|c|c|c|c|c|c|c|c|c|}
\hline & \multicolumn{5}{|c|}{ Income } & \multicolumn{3}{|c|}{ Expenditures } & \multicolumn{2}{|c|}{ Trust fund } \\
\hline & $\begin{array}{c}\text { Premium } \\
\text { income }\end{array}$ & $\begin{array}{c}\text { General } \\
\text { revenue }^{2}\end{array}$ & $\begin{array}{c}\text { Transfers } \\
\text { from } \\
\text { States }\end{array}$ & $\begin{array}{l}\text { Interest } \\
\text { and } \\
\text { other }^{3,4}\end{array}$ & Total & $\begin{array}{c}\text { Benefit } \\
\text { payments }\end{array}$ & $\begin{array}{l}\text { Adminis- } \\
\text { trative } \\
\text { expense }\end{array}$ & Total & $\begin{array}{c}\text { Net } \\
\text { change }\end{array}$ & $\begin{array}{l}\text { Balanc } \\
\text { at enc } \\
\text { of yea }\end{array}$ \\
\hline \multicolumn{11}{|c|}{ Historical data: } \\
\hline 1970 & $\$ 0.9$ & $\$ 0.9$ & - & $\$ 0.0$ & $\$ 1.9$ & $\$ 2.0$ & $\$ 0.2$ & $\$ 2.2$ & $-\$ 0.3$ & $\$ 0.1$ \\
\hline 1975 & 1.9 & 2.3 & - & 0.1 & 4.3 & 3.8 & 0.4 & 4.2 & 0.2 & 1.4 \\
\hline 1980 & 2.9 & 6.9 & - & 0.4 & 10.3 & 10.1 & 0.6 & 10.7 & -0.5 & 4.5 \\
\hline 1985 & 5.5 & 17.9 & - & 1.2 & 24.6 & 21.8 & 0.9 & 22.7 & 1.8 & 10.6 \\
\hline 1990 & $11.5^{7}$ & 33.2 & - & $1.4^{7}$ & $46.1^{7}$ & 41.5 & $1.5^{7}$ & $43.0^{7}$ & $3.1^{7}$ & $14.5^{7}$ \\
\hline 1995 & 19.2 & 37.0 & - & 1.9 & 58.2 & 63.5 & 1.7 & 65.2 & -7.0 & 13.9 \\
\hline 2000 & 20.5 & 65.6 & - & 3.2 & 89.2 & $87.2^{8}$ & 1.8 & 89.0 & 0.2 & 45.9 \\
\hline 2001 & 22.3 & 69.8 & - & 3.2 & 95.3 & $97.5^{8}$ & 2.0 & 99.5 & -4.1 & 41.8 \\
\hline 2002 & 24.4 & 78.3 & - & 3.0 & 105.7 & $107.0^{8}$ & 1.8 & 108.8 & -3.1 & 38.7 \\
\hline 2003 & 26.8 & 80.9 & - & 2.5 & 110.2 & $121.7^{8}$ & 2.4 & 124.1 & -13.9 & 24.8 \\
\hline 2004 & 30.3 & 94.5 & - & 1.7 & 126.6 & 131.5 & 2.8 & 134.3 & -7.7 & 17.1 \\
\hline 2005 & 35.9 & 115.2 & - & 1.4 & 152.5 & 149.8 & 2.9 & 152.7 & -0.2 & 16.9 \\
\hline 2006 & 44.2 & 162.6 & $\$ 3.6$ & 1.5 & 211.9 & 192.1 & 3.5 & 195.5 & 16.4 & 33.3 \\
\hline \multicolumn{11}{|c|}{ Intermediate estimates: } \\
\hline 2007 & 49.9 & 177.4 & 7.1 & 2.0 & 236.4 & 225.9 & 3.8 & 229.7 & 6.7 & 40.0 \\
\hline 2008 & 54.6 & 193.6 & 6.8 & 2.5 & 257.5 & 246.4 & 3.9 & 250.3 & 7.1 & 47.2 \\
\hline 2009 & 58.9 & 204.1 & 7.3 & 2.9 & 273.1 & 264.7 & 4.1 & 268.7 & 4.4 & 51.6 \\
\hline 2010 & 63.8 & 219.2 & 7.8 & 3.2 & 294.0 & 287.0 & 4.2 & 291.2 & 2.8 & 54.4 \\
\hline 2011 & 69.5 & 242.1 & 8.4 & 3.4 & 323.5 & 321.5 & 4.4 & 325.8 & -2.3 & 52.1 \\
\hline 2012 & 75.7 & 251.1 & 9.2 & 3.7 & 339.6 & 325.2 & 4.5 & 329.8 & 9.9 & 62.0 \\
\hline 2013 & 81.9 & 277.7 & 10.0 & 3.9 & 373.5 & 364.3 & 4.7 & 368.9 & 4.6 & 66.5 \\
\hline 2014 & 88.4 & 301.2 & 10.9 & 4.2 & 404.7 & 395.0 & 4.8 & 399.8 & 4.9 & 71.4 \\
\hline 2015 & 95.4 & 327.0 & 11.9 & 4.5 & 439.0 & 428.5 & 5.0 & 433.5 & 5.5 & 76.9 \\
\hline 2016 & 103.3 & 365.8 & 13.2 & 4.9 & 487.2 & 484.9 & 5.1 & 490.0 & -2.8 & 74.1 \\
\hline
\end{tabular}

Fiscal years 1970 and 1975 consist of the 12 months ending on June 30 of each year; fiscal years 1980 and later consist of the 12 months ending on September 30 of each year.

${ }^{2}$ Includes Part B general fund matching payments, Part D subsidy costs, and certain interest-adjustment items.

${ }^{3}$ Other income includes recoveries of amounts reimbursed from the trust fund that are not obligations of the trust fund and other miscellaneous income.

${ }^{4}$ See footnote 2 of table III.B4.

${ }^{5}$ See footnote 5 of table III.C1.

${ }^{6}$ The financial status of SMI depends on both the assets and the liabilities of the trust fund (see table III.C12).

${ }^{7}$ Includes the impact of the Medicare Catastrophic Coverage Act of 1988 (Public Law 100-360).

${ }^{8}$ Benefit payments less monies transferred from the $\mathrm{HI}$ trust fund for home health agency costs, as provided for by the Balanced Budget Act of 1997.

Note: Totals do not necessarily equal the sums of rounded components. 
Fiscal Year Operations and Projections

Table V.F7.-Operations of the Part B Account in the SMI Trust Fund (Cash Basis) during Fiscal Years 1970-2016

\begin{tabular}{|c|c|c|c|c|c|c|c|c|c|}
\hline \multirow[b]{2}{*}{$\begin{array}{l}\text { Fiscal } \\
\text { year }^{1}\end{array}$} & \multicolumn{4}{|c|}{ Income } & \multicolumn{3}{|c|}{ Expenditures } & \multicolumn{2}{|c|}{ Account } \\
\hline & $\begin{array}{c}\text { Premium } \\
\text { income }\end{array}$ & $\begin{array}{l}\text { General } \\
\text { revenue }^{2}\end{array}$ & $\begin{array}{c}\text { Interest } \\
\text { and other }\end{array}$ & Total & $\begin{array}{c}\text { Benefit } \\
\text { payments }^{4,5}\end{array}$ & $\begin{array}{l}\text { Adminis- } \\
\text { trative } \\
\text { expense }\end{array}$ & Total & $\begin{array}{c}\text { Net } \\
\text { change }\end{array}$ & $\begin{array}{c}\text { Balance a } \\
\text { end of } \\
\text { year }^{6}\end{array}$ \\
\hline \multicolumn{10}{|c|}{ Historical data: } \\
\hline 1970 & $\$ 0.9$ & $\$ 0.9$ & $\$ 0.0$ & $\$ 1.9$ & $\$ 2.0$ & $\$ 0.2$ & $\$ 2.2$ & $-\$ 0.3$ & $\$ 0.1$ \\
\hline 1975 & 1.9 & 2.3 & 0.1 & 4.3 & 3.8 & 0.4 & 4.2 & 0.2 & 1.4 \\
\hline 1980 & 2.9 & 6.9 & 0.4 & 10.3 & 10.1 & 0.6 & 10.7 & -0.5 & 4.5 \\
\hline 1985 & 5.5 & 17.9 & 1.2 & 24.6 & 21.8 & 0.9 & 22.7 & 1.8 & 10.6 \\
\hline 1990 & $11.5^{7}$ & 33.2 & $1.4^{7}$ & $46.1^{7}$ & 41.5 & $1.5^{7}$ & $43.0^{7}$ & $3.1^{7}$ & $14.5^{7}$ \\
\hline 1995 & 19.2 & 37.0 & 1.9 & 58.2 & 63.5 & 1.7 & 65.2 & -7.0 & 13.9 \\
\hline 2000 & 20.5 & 65.6 & 3.2 & 89.2 & $87.2^{8}$ & 1.8 & 89.0 & 0.2 & 45.9 \\
\hline 2001 & 22.3 & 69.8 & 3.2 & 95.3 & $97.5^{8}$ & 2.0 & 99.5 & -4.1 & 41.8 \\
\hline 2002 & 24.4 & 78.3 & 3.0 & 105.7 & $107.0^{8}$ & 1.8 & 108.8 & -3.1 & 38.7 \\
\hline 2003 & 26.8 & 80.9 & 2.5 & 110.2 & $121.7^{8}$ & 2.4 & 124.1 & -13.9 & 24.8 \\
\hline 2004 & 30.3 & 94.5 & 1.7 & 126.6 & 131.5 & 2.8 & 134.3 & -7.7 & 17.1 \\
\hline 2005 & 35.9 & 114.0 & 1.4 & 151.3 & 148.6 & 2.9 & 151.5 & -0.2 & 16.9 \\
\hline 2006 & 41.6 & 134.3 & 1.5 & 177.4 & 158.3 & 3.3 & 161.6 & 15.7 & 32.6 \\
\hline \multicolumn{10}{|c|}{ Intermediate estimates: } \\
\hline 2007 & 46.0 & 137.5 & 2.0 & 185.5 & 175.8 & 3.0 & 178.8 & 6.7 & 39.3 \\
\hline 2008 & 49.4 & 143.8 & 2.4 & 195.7 & 185.5 & 3.1 & 188.6 & 7.1 & 46.4 \\
\hline 2009 & 52.1 & 148.8 & 2.9 & 203.7 & 196.2 & 3.2 & 199.3 & 4.4 & 50.8 \\
\hline 2010 & 55.3 & 157.1 & 3.2 & 215.6 & 209.5 & 3.3 & 212.8 & 2.8 & 53.6 \\
\hline 2011 & 58.8 & 166.9 & 3.4 & 229.1 & 227.2 & 3.5 & 230.7 & -1.6 & 52.0 \\
\hline 2012 & 62.8 & 178.2 & 3.6 & 244.6 & 231.9 & 3.6 & 235.5 & 9.1 & 61.1 \\
\hline 2013 & 67.2 & 190.6 & 3.9 & 261.7 & 253.5 & 3.7 & 257.2 & 4.5 & 65.6 \\
\hline 2014 & 71.9 & 203.9 & 4.2 & 280.0 & 271.3 & 3.9 & 275.2 & 4.8 & 70.4 \\
\hline 2015 & 77.1 & 218.3 & 4.5 & 299.8 & 290.4 & 4.0 & 294.4 & 5.4 & 75.8 \\
\hline 2016 & 82.7 & 234.1 & 4.8 & 321.7 & 319.3 & 4.2 & 323.5 & -1.8 & 74.0 \\
\hline
\end{tabular}

${ }^{1}$ Fiscal years 1970 and 1975 consist of the 12 months ending on June 30 of each year; fiscal years 1980 and later consist of the 12 months ending on September 30 of each year.

${ }^{2}$ General fund matching payments, plus certain interest-adjustment items.

${ }^{3}$ Other income includes recoveries of amounts reimbursed from the trust fund that are not obligations of the trust fund and other miscellaneous income.

${ }^{4}$ See footnote 2 of table III.B4

${ }^{5}$ See footnote 5 of table III.C1.

${ }^{6}$ The financial status of Part B depends on both the assets and the liabilities of the trust fund (see table III.C12).

${ }^{7}$ Includes the impact of the Medicare Catastrophic Coverage Act of 1988 (Public Law 100-360).

${ }^{8}$ Benefit payments less monies transferred from the $\mathrm{HI}$ trust fund for home health agency costs, as provided for by the Balanced Budget Act of 1997.

Note: Totals do not necessarily equal the sums of rounded components. 


\section{Appendices}

Table V.F8.-Operations of the Part D Account in the SMI Trust Fund (Cash Basis) during Fiscal Years 2004-2016

[In billions]

\begin{tabular}{|c|c|c|c|c|c|c|c|c|c|c|}
\hline \multirow[b]{2}{*}{$\begin{array}{l}\text { Fiscal } \\
\text { year }\end{array}$} & \multicolumn{5}{|c|}{ Income } & \multicolumn{3}{|c|}{ Expenditures } & \multicolumn{2}{|c|}{ Account } \\
\hline & $\begin{array}{l}\text { Premium } \\
\text { income }\end{array}$ & $\begin{array}{l}\text { General } \\
\text { revenue }^{1}\end{array}$ & $\begin{array}{c}\text { Transfers } \\
\text { from } \\
\text { States }^{2}\end{array}$ & $\begin{array}{l}\text { Interest } \\
\text { and } \\
\text { other }\end{array}$ & Total & $\begin{array}{c}\text { Benefit } \\
\text { payments }^{3}\end{array}$ & $\begin{array}{l}\text { Adminis- } \\
\text { trative } \\
\text { expense }\end{array}$ & Total & $\begin{array}{c}\text { Net } \\
\text { change }\end{array}$ & $\begin{array}{c}\text { Balance } \\
\text { at end of } \\
\text { year }\end{array}$ \\
\hline
\end{tabular}

\begin{tabular}{|c|c|c|c|c|c|c|c|c|c|c|}
\hline \multicolumn{11}{|c|}{ Historical data: } \\
\hline 2004 & - & $\$ 0.2$ & - & - & $\$ 0.2$ & $\$ 0.2$ & - & $\$ 0.2$ & - & - \\
\hline 2005 & - & 1.2 & - & - & 1.2 & 1.2 & - & $\begin{array}{r}\psi 0.2 \\
1.2\end{array}$ & - & 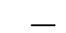 \\
\hline 2006 & $\$ 2.6$ & 28.2 & $\$ 3.6$ & $\$ 0.0$ & 34.4 & 33.6 & $\$ 0.2$ & 33.8 & $\$ 0.6$ & $\$ 0.6$ \\
\hline \multicolumn{11}{|c|}{ Intermediate estimates: } \\
\hline 2007 & $\$ 3.9$ & 39.9 & $\$ 7.1$ & $\$ 0.0$ & 50.9 & 50.1 & $\$ 0.9$ & 50.9 & 0.0 & \\
\hline 2008 & 5.2 & 49.8 & 6.8 & 0.0 & 61.8 & 60.9 & 0.9 & 61.7 & 0.0 & 0.7 \\
\hline 2009 & 6.7 & 55.4 & 7.3 & 0.0 & 69.4 & 68.5 & 0.9 & 69.4 & 0.0 & 0.7 \\
\hline 2010 & 8.5 & 62.1 & 7.8 & 0.0 & 78.4 & 77.5 & 0.9 & 78.4 & 0.0 & \\
\hline 2011 & 10.7 & 75.3 & 8.4 & 0.0 & 94.4 & 94.3 & 0.9 & 95.2 & -0.8 & \\
\hline 2012 & 13.0 & 72.9 & 9.2 & 0.0 & 95.1 & 93.4 & 0.9 & 94.3 & 0.8 & \\
\hline 2013 & 14.7 & 87.1 & 10.0 & 0.0 & 111.8 & 110.8 & 0.9 & 111.7 & 0.1 & \\
\hline 2014 & 16.4 & 97.3 & 10.9 & 0.0 & 124.7 & 123.7 & 0.9 & 124.6 & 0.1 & \\
\hline 2015 & 18.4 & 108.8 & 11.9 & 0.0 & 139.1 & 138.1 & 0.9 & 139.0 & 0.1 & \\
\hline 2016 & 20.5 & 131.7 & 13.2 & 0.0 & 165.5 & 165.6 & 0.9 & 165.6 & -1.0 & \\
\hline
\end{tabular}

${ }^{1}$ Includes all government transfers including amounts for the general subsidy, reinsurance, employer drug subsidy, low-income subsidy, administrative expenses, risk sharing, and State expenses for making low-income eligibility determinations. Includes amounts for the Transitional Assistance program of $\$ 0.2$,

$\$ 1.1$, and $\$ 0.1$ billion in 2004-2006, respectively.

${ }^{2}$ See footnote 3 of table III.C18.

${ }^{3}$ Includes payments to plans, subsidies to employer retiree prescription drug plans, payments to States for making low-income eligibility determinations, and Part D drug premiums collected from beneficiaries and transferred to Medicare Advantage plans and private drug plans. Includes amounts for the Transitional Assistance program of $\$ 0.2, \$ 1.1$, and $\$ 0.1$ billion in 2004-2006, respectively.

Note: Totals do not necessarily equal the sums of rounded components.

Table V.F9 shows the total assets of the HI trust fund and their distribution at the end of fiscal years 2005 and 2006. The assets at the end of fiscal year 2006 totaled $\$ 303.1$ billion: $\$ 302.2$ billion in the form of U.S. Government obligations and an undisbursed balance of $\$ 0.9$ billion. 


\section{Fiscal Year Operations and Projections}

Table V.F9._Assets of the HI Trust Fund, by Type, at the End of Fiscal Years 2005 and $2006^{1}$

\begin{tabular}{|c|c|c|}
\hline & September 30, 2005 & September 30, 2006 \\
\hline \multicolumn{3}{|c|}{ Investments in public-debt obligations sold only to the trust funds (special issues): } \\
\hline 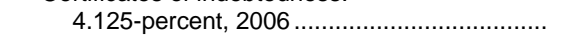 & $\$ 2,257,231,000.00$ & \\
\hline 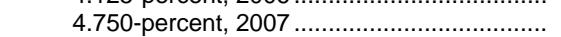 & 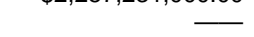 & $\$ 7,999,547,000.00$ \\
\hline 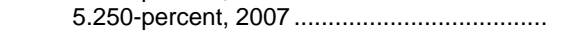 & & $1,360,946,000.00$ \\
\hline \multicolumn{3}{|l|}{ Bonds: } \\
\hline 3.500-percent, $2007 \ldots \ldots \ldots \ldots$ & $1,491,940,000.00$ & \\
\hline 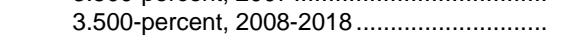 & $31,937,208,000.00$ & $31,937,208,000.00$ \\
\hline 4.125 -percent, $2007 \ldots \ldots \ldots \ldots \ldots \ldots \ldots \ldots \ldots \ldots \ldots \ldots \ldots \ldots \ldots \ldots \ldots \ldots \ldots \ldots \ldots \ldots \ldots$ & $987,939,000.00$ & \\
\hline 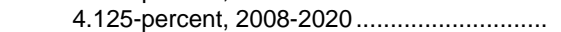 & $30,661,202,000.00$ & $30,661,202,000.00$ \\
\hline 4.625-percent, $2007 \ldots \ldots \ldots \ldots$ & $977,468,000.00$ & \\
\hline 4.625-percent, $2008-2020 \ldots$ & $28,570,115,000.00$ & $28,570,115,000.00$ \\
\hline 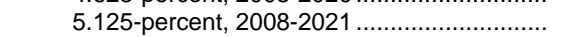 & & $35,028,868,000.00$ \\
\hline 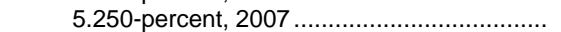 & $2,028,429,000.00$ & \\
\hline 5.250 -percent, $2008-2017 \ldots$ & $33,427,108,000.00$ & $33,427,108,000.00$ \\
\hline 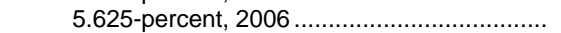 & $945,225,000.00$ & \\
\hline 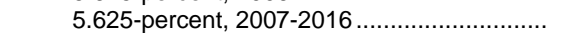 & $36,159,654,000.00$ & $36,159,654,000.00$ \\
\hline 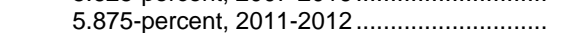 & $8,754,457,000.00$ & $8,754,457,000.00$ \\
\hline 6.000 -percent, $2012-2014 \ldots$ & $20,598,023,000.00$ & $20,598,023,000.00$ \\
\hline 6.250 -percent, $2006 \ldots \ldots \ldots \ldots$ & $363,198,000.00$ & \\
\hline 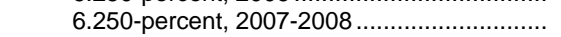 & $8,911,323,000.00$ & $8,911,323,000.00$ \\
\hline 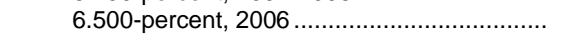 & $2,009,146,000.00$ & \\
\hline 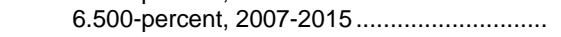 & $35,834,732,000.00$ & $35,834,732,000.00$ \\
\hline 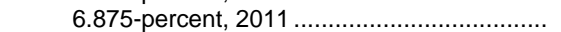 & $2,166,172,000.00$ & $2,166,172,000.00$ \\
\hline 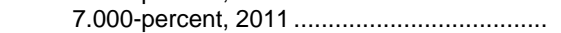 & $3,368,466,000.00$ & $3,368,466,000.00$ \\
\hline 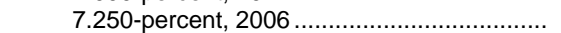 & $225,129,000.00$ & \\
\hline 7.250-percent, $2007-2009$ & $9,223,516,000.00$ & $9,223,516,000.00$ \\
\hline 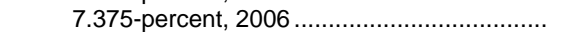 & $867,961,000.00$ & \\
\hline 7.375-percent, $2007 \ldots \ldots \ldots$ & $8,184,929,000.00$ & $8,184,929,000.00$ \\
\hline 8.125-percent, $2006 \ldots$. & $7,316,968,000.00$ & \\
\hline Total investments ......... & $\$ 277,267,539,000.00$ & $\$ 302,186,266,000.00$ \\
\hline Undisbursed balance ${ }^{2}$ & $455,146,827.07$ & $944,007,971.03$ \\
\hline Total assets.... & $\$ 277,722,685,827.07$ & $\$ 303,130,273,971.03$ \\
\hline
\end{tabular}

The effective annual rate of interest earned by the assets of the HI trust fund during the 12 months ending on December 31, 2006 was 5.4 percent. Interest on special issues is paid semiannually on June 30 and December 31. The interest rate on public-debt obligations issued for purchase by the trust fund in June 2006 was 5.125 percent, payable semiannually.

Table V.F10 shows a comparison of the total assets of the SMI trust fund, Parts B and D combined, and their distribution at the end of fiscal years 2005 and 2006. At the end of 2006, assets totaled $\$ 33.3$ billion: $\$ 33.1$ billion in the form of U.S. Government obligations and an undisbursed balance of $\$ 0.2$ billion. 


\section{Appendices}

Table V.F10.-Assets of the SMI Trust Fund, by Type, at the End of Fiscal Years 2005 and $2006^{1}$

September 30, $2005 \quad$ September 30, 2006

Investments in public-debt obligations sold only to the trust funds (special issues): Certificates of indebtedness:
4.750-percent, 2007
5.000-percent, 2007
5.250-percent, 2007
Bonds:
4.125-percent, 2008
4.125-percent, 2009
5.125-percent, 2008-2011
5.250-percent, 2016
5.625-percent, 2016
5.875-percent, 2013
6.000-percent, 2013-2014
6.500-percent, 2013-2015
6.875-percent, 2012

.

Total investments

Undisbursed balance ${ }^{2}$.

Total assets

.

Total assets

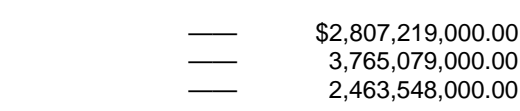

$\$ 1,484,237,000.00$

$2,570,352,000.00$

$297,753,000.00$

$1,822,107,000.00$

$2,526,588,000.00$

$3,462,146,000.00$

$3,110,670,000.00$

$1,929,853,000.00$

$2,463,548,000.00$

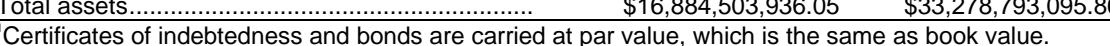

$\$ 17,203,706,000.00$

$-319,202,063.95$

$170,774,000.00$

$2,570,352,000.00$

$8,134,902,000.00$

$297,753,000.00$

$1,822,107,000.00$

$2,526,588,000.00$

$3,462,146,000.00$

$3,110,670,000.00$

$1,929,853,000.00$

$\$ 16,884,503,936.05$

$\$ 33,060,991,000.00$

$217,802,095.86$ ${ }^{2}$ Negative figures represent an extension of credit against securities to be redeemed within the following few days.

The effective annual rate of interest earned by the assets of the SMI trust fund for the 12 months ending on December 31, 2006 was 5.1 percent. Interest on special issues is paid semiannually on June 30 and December 31. The interest rate on special issues purchased by the account in June 2006 was 5.125 percent, payable semiannually. 
Glossary

\section{G. GLOSSARY}

Actuarial balance. The difference between the summarized income rate and the summarized cost rate over a given valuation period.

Actuarial deficit. A negative actuarial balance.

Actuarial rates. One-half of the Part B expected monthly cost for each aged enrollee (for the aged actuarial rate) and one-half of the expected monthly cost for each disabled enrollee (for the disabled actuarial rate) for the duration the rate is in effect.

Actuarial status. A measure of the adequacy of the financing as determined by the difference between assets and liabilities at the end of the periods for which financing was established.

Administrative expenses. Expenses incurred by the Department of Health and Human Services and the Department of the Treasury in administering HI and SMI and the provisions of the Internal Revenue Code relating to the collection of contributions. Such administrative expenses, which are paid from the HI and SMI trust funds, include expenditures for contractors to determine costs of, and make payments to, providers, as well as salaries and expenses of the Centers for Medicare \& Medicaid Services.

Aged enrollee. An individual, aged 65 or over, who is enrolled in $\mathrm{HI}$ or SMI.

Allowed charge. Individual charge determined by a carrier for a covered Part B medical service or supply.

Annual out-of-pocket threshold. The amount of out-of-pocket expenses that must be paid before significantly reduced beneficiary cost sharing is effective. Amounts paid by a third-party insurer are not included in testing this threshold, but amounts paid by State or Federal assistance programs are included.

Assets. Treasury notes and bonds guaranteed by the Federal Government, and cash held by the trust funds for investment purposes.

Assumptions. Values relating to future trends in certain key factors that affect the balance in the trust funds. Demographic assumptions include fertility, mortality, net immigration, marriage, divorce, retirement patterns, disability incidence and termination rates, and 


\section{Appendices}

changes in the labor force. Economic assumptions include unemployment, average earnings, inflation, interest rates, and productivity. Three sets of economic assumptions are presented in the Trustees Report:

(1) The low cost alternative, with relatively rapid economic growth, low inflation, and favorable (from the standpoint of program financing) demographic conditions;

(2) The intermediate assumptions, which represent the Trustees' best estimates of likely future economic and demographic conditions; and

(3) The high cost alternative, with slow economic growth, more rapid inflation, and financially disadvantageous demographic conditions.

See also "Hospital assumptions."

Average market yield. A computation that is made on all marketable interest-bearing obligations of the United States. It is computed on the basis of market quotations as of the end of the calendar month immediately preceding the date of such issue.

Baby boom. The period from the end of World War II through the mid-1960s marked by unusually high birth rates.

Base estimate. The updated estimate of the most recent historical year.

Beneficiary. A person enrolled in HI or SMI. See also "Aged enrollee" and "Disabled enrollee."

Benefit payments. The amounts disbursed for covered services after the deductible and coinsurance amounts have been deducted.

Benefit period. An alternate name for "spell of illness."

Board of Trustees. A Board established by the Social Security Act to oversee the financial operations of the Federal Hospital Insurance Trust Fund and the Federal Supplementary Medical Insurance Trust Fund. The Board is composed of six members, four of whom serve automatically by virtue of their positions in the Federal Government: the Secretary of the Treasury, who is the Managing Trustee; the Secretary of Labor; the Secretary of Health and Human Services; and the Commissioner of Social Security. The other two members, John L. Palmer and Thomas R. Saving, are public representatives initially appointed by President William J. Clinton on October 28, 2000, and reappointed by President George W. Bush on April 18, 2006. The 
Administrator of the Centers for Medicare \& Medicaid Services (CMS) serves as Secretary of the Board of Trustees.

Bond. A certificate of ownership of a specified portion of a debt due by the Federal Government to holders, bearing a fixed rate of interest.

Callable. Subject to redemption upon notice, as is a bond.

Carrier. A private or public organization under contract to CMS to administer the Part B benefits under Medicare. Also referred to as "contractors," these organizations determine coverage and benefit amounts payable and make payments to physicians, suppliers, and beneficiaries.

Case mix index. A relative weight that captures the average complexity of certain Medicare services.

Cash basis. The costs of the service when payment was made rather than when the service was performed.

Certificate of indebtedness. A short-term certificate of ownership (12 months or less) of a specified portion of a debt due by the Federal Government to individual holders, bearing a fixed rate of interest.

Closed-group population. Includes all persons currently participating in the program as either taxpayers or beneficiaries, or both. See also "Open-group population."

Coinsurance. Portion of the costs for covered services paid by the beneficiary after meeting the annual deductible. See also "Hospital coinsurance" and "SNF coinsurance."

Consumer Price Index (CPI). A measure of the average change in prices over time in a fixed group of goods and services. In this report, all references to the CPI relate to the CPI for Urban Wage Earners and Clerical Workers (CPI-W).

Contingency. Funds included in the SMI trust fund to serve as a cushion in case actual expenditures are higher than those projected at the time financing was established. Since the financing is set prospectively, actual experience may be different from the estimates used in setting the financing.

Contingency margin. An amount included in the actuarial rates to provide for changes in the contingency level in the SMI trust fund. 
Appendices

Positive margins increase the contingency level, and negative margins decrease it.

Contribution base. See "Maximum tax base."

Contributions. See "Payroll taxes."

Cost rate. The ratio of $\mathrm{HI}$ cost (or outgo or expenditures) on an incurred basis during a given year to the taxable payroll for the year. In this context, the outgo is defined to exclude benefit payments and administrative costs for those uninsured persons for whom payments are reimbursed from the general fund of the Treasury, and for voluntary enrollees, who pay a premium to be enrolled.

Covered earnings. Earnings in employment covered by HI.

Covered employment. All employment and self-employment creditable for Social Security purposes. Almost every kind of employment and self-employment is covered under HI. In a few employment situations - for example, religious orders under a vow of poverty, foreign affiliates of American employers, or State and local governments - coverage must be elected by the employer. However, effective July 1991, coverage is mandatory for State and local employees who are not participating in a public employee retirement system. All new State and local employees have been covered since April 1986. In a few situations-for instance, ministers or selfemployed members of certain religious groups - workers can opt out of coverage. Covered employment for HI includes all Federal employees (whereas covered employment for OASDI includes some, but not all, Federal employees).

Covered Part D drugs. Prescription drugs covered under the Medicaid program plus insulin-related supplies and smoking cessation agents. Drugs covered in Parts A and B of Medicare will continue to be covered there, rather than in Part D.

Covered services. Services for which HI or SMI pays, as defined and limited by statute. Covered HI services are provided by hospitals (inpatient care), skilled nursing facilities, home health agencies, and hospices. Covered SMI Part B services include most physician services, care in outpatient departments of hospitals, diagnostic tests, durable medical equipment, ambulance services, and other health services that are not covered by HI. See "Covered Part D drugs" for SMI Part D. 
Covered worker. A person who has earnings creditable for Social Security purposes on the basis of services for wages in covered employment and/or on the basis of income from covered self-employment. The number of HI covered workers is slightly larger than the number of OASDI covered workers because of different coverage status for Federal employment. See "Covered employment."

Creditable prescription drug coverage. Prescription drug coverage that meets or exceeds the actuarial value of Part D coverage provided through a group health plan or otherwise.

Dedicated financing sources. The sum of HI payroll taxes, HI share of income taxes on Social Security benefits, Part D state transfers, and beneficiary premiums. This amount is used in the test of excess general revenue Medicare funding.

Deductible. The annual amount payable by the beneficiary for covered services before Medicare makes reimbursement. See also "Inpatient hospital deductible."

Deemed wage credit. See "Non-contributory or deemed wage credits."

Demographic assumptions. See "Assumptions."

Diagnosis-related groups (DRGs). A classification system that groups patients according to diagnosis, type of treatment, age, and other relevant criteria. Under the inpatient hospital prospective payment system, hospitals are paid a set fee for treating patients in a single DRG category, regardless of the actual cost of care for the individual.

Direct subsidy. The amount paid to the prescription drug plans representing the difference between the plan's risk-adjusted bid and the beneficiary premium for basic coverage.

Disability. For Social Security purposes, the inability to engage in substantial gainful activity by reason of any medically determinable physical or mental impairment that can be expected to result in death or to last for a continuous period of not less than 12 months. Special rules apply for workers aged 55 or older whose disability is based on blindness. The law generally requires that a person be disabled continuously for 5 months before he or she can qualify for a disabled-worker cash benefit. An additional 24 months is necessary to qualify for benefits under Medicare. 
Appendices

Disability Insurance (DI). See "Old-Age, Survivors, and Disability Insurance (OASDI)."

Disabled enrollee. An individual under age 65 who has been entitled to disability benefits under Title II of the Social Security Act or the Railroad Retirement system for at least 2 years and who is enrolled in HI or SMI.

DRG Coding. The DRG categories used by hospitals on discharge billing. See also "Diagnosis-related groups (DRGs)."

Durable medical equipment (DME). Items such as iron lungs, oxygen tents, hospital beds, wheelchairs, and seat lift mechanisms that are used in the patient's home and are either purchased or rented.

Earnings. Unless otherwise qualified, all wages from employment and net earnings from self-employment, whether or not taxable or covered.

Economic assumptions. See "Assumptions."

Economic stabilization program. A legislative program during the early 1970 s that limited price increases.

Employer subsidy. The amount paid to the sponsors of qualifying employment-based retiree prescription drug plans. This amount subsidizes a portion of actual drug expenditures between specified coverage limits and is determined without regard to actual employer plan payments.

End-stage renal disease (ESRD). Permanent kidney failure.

Extended care services. In the context of this report, an alternate name for "skilled nursing facility services."

Fallback prescription drug plan. Prescription drug coverage provided by plans bearing no risk. One fallback plan will be approved in regions that do not have a choice of at least two at-risk plans.

Federal Insurance Contributions Act (FICA). Provision authorizing taxes on the wages of employed persons to provide for OASDI and HI. The tax is paid in equal amounts by covered workers and their employers. 
Financial interchange. Provisions of the Railroad Retirement Act providing for transfers between the trust funds and the Social Security Equivalent Benefit Account of the Railroad Retirement program in order to place each trust fund in the same position as if railroad employment had always been covered under Social Security.

Fiscal year. The accounting year of the U.S. Government. Since 1976, each fiscal year has begun October 1 of the prior calendar year and ended the following September 30. For example, fiscal year 2007 began October 1, 2006 and will end September 30, 2007.

Fixed capital assets. The net worth of facilities and other resources.

Frequency distribution. An exhaustive list of possible outcomes for a variable, and the associated probability of each outcome. The sum of the probabilities of all possible outcomes from a frequency distribution is 100 percent.

General fund of the Treasury. Funds held by the U.S. Treasury, other than revenue collected for a specific trust fund (such as HI or SMI) and maintained in a separate account for that purpose. The majority of this fund is derived from individual and business income taxes.

General revenue. Income to the $\mathrm{HI}$ and SMI trust funds from the general fund of the Treasury. Only a very small percentage of total HI trust fund income each year is attributable to general revenue.

Gramm-Rudman-Hollings Act. The Balanced Budget and Emergency Deficit Control Act of 1985.

Gross Domestic Product (GDP). The total dollar value of all goods and services produced in a year in the United States, regardless of who supplies the labor or property.

High cost alternative. See "Assumptions."

Home health agency (HHA). A public agency or private organization that is primarily engaged in providing the following services in the home: skilled nursing services, other therapeutic services (such as physical, occupational, or speech therapy), and home health aide services. 


\section{Appendices}

Hospice. A provider of care for the terminally ill; delivered services generally include home health care, nursing care, physician services, medical supplies, and short-term inpatient hospital care.

Hospital assumptions. These include differentials between hospital labor and non-labor indices compared with general economy labor and non-labor indices; rates of admission incidence; the trend toward treating less complicated cases in outpatient settings; and continued improvement in DRG coding.

Hospital coinsurance. For the 61st through 90th day of hospitalization in a benefit period, a daily amount for which the beneficiary is responsible, equal to one-fourth of the inpatient hospital deductible; for lifetime reserve days, a daily amount for which the beneficiary is responsible, equal to one-half of the inpatient hospital deductible (see "Lifetime reserve days").

Hospital input price index. An alternate name for "hospital market basket."

Hospital Insurance (HI). The Medicare trust fund that covers specified inpatient hospital services, posthospital skilled nursing care, home health services, and hospice care for aged and disabled individuals who meet the eligibility requirements. Also known as Medicare Part A.

Hospital market basket. The cost of the mix of goods and services (including personnel costs but excluding nonoperating costs) comprising routine, ancillary, and special care unit inpatient hospital services.

Income rate. The ratio of income from tax revenues on an incurred basis (payroll tax contributions and income from the taxation of OASDI benefits) to the HI taxable payroll for the year.

Incurred basis. The costs based on when the service was performed rather than when the payment was made.

Independent laboratory. A free-standing clinical laboratory meeting conditions for participation in the Medicare program and billing through a carrier.

Initial coverage limit. The amount up to which the coinsurance applies under the standard prescription drug benefit. 
Inpatient hospital deductible. An amount of money that is deducted from the amount payable by Medicare Part A for inpatient hospital services furnished to a beneficiary during a spell of illness.

Inpatient hospital services. These services include bed and board, nursing services, diagnostic or therapeutic services, and medical or surgical services.

Interest. A payment for the use of money during a specified period.

Interfund borrowing. The borrowing of assets by a trust fund (OASI, DI, HI, or SMI) from another of the trust funds when one of the funds is in danger of exhaustion. Interfund borrowing was authorized only during 1982-1987.

Intermediary. A private or public organization that is under contract to CMS to determine costs of, and make payments to, providers for HI and certain SMI Part B services.

Intermediate assumptions. See "Assumptions."

Late enrollment penalty. Additional beneficiary premium amounts for those who either do not enroll in Part D at the first opportunity or fail to maintain other creditable coverage for more than 63 days.

Lifetime reserve days. Under $\mathrm{HI}$, each beneficiary has 60 lifetime reserve days that he or she may opt to use when regular inpatient hospital benefits are exhausted. The beneficiary pays one-half of the inpatient hospital deductible for each lifetime reserve day used.

Long range. The next 75 years.

Low cost alternative. See "Assumptions."

Low-income beneficiaries. Individuals meeting income and assets tests who are eligible for prescription drug coverage subsidies to help finance premiums and out-of-pocket payments.

Managed care. Includes Health Maintenance Organizations (HMOs), Competitive Medical Plans (CMPs), and other plans that provide health services on a prepayment basis, which is based on either cost or risk, depending on the type of contract the plans have with Medicare. See also "Medicare Advantage."

Market basket. See "Hospital market basket." 
Appendices

Maximum tax base. Annual dollar amount above which earnings in employment covered under HI are not taxable. Beginning in 1994, the maximum tax base was eliminated under HI.

Maximum taxable amount of annual earnings. See "Maximum tax base."

Medicare. A nationwide, federally administered health insurance program authorized in 1965 to cover the cost of hospitalization, medical care, and some related services for most people over age 65 . In 1972, coverage was extended to people receiving Social Security Disability Insurance payments for 2 years and to people with end-stage renal disease. In 2006, prescription drug coverage was added as well. Medicare consists of two separate but coordinated trust funds: Hospital Insurance (HI, or Part A) and Supplementary Medical Insurance (SMI). The SMI trust fund is composed of three separate accounts: the Part B account, the Part D account, and the Transitional Assistance Account. Almost all persons who are aged 65 and over or disabled and who are entitled to HI are eligible to enroll in Part B and Part D on a voluntary basis by paying monthly premiums. Health insurance protection is available to Medicare beneficiaries without regard to income.

Medicare Advantage (formerly called Medicare+Choice). An expanded set of options, established by the Medicare Modernization Act, for the delivery of health care under Medicare. Most Medicare beneficiaries can choose to receive benefits through the original fee-for-service program or through one of the following Medicare Advantage plans: (i) coordinated care plans (such as Health Maintenance Organizations, Provider Sponsored Organizations, and Preferred Provider Organizations); (ii) Medical Savings Account (MSA)/High Deductible plans (through a demonstration available to up to 390,000 beneficiaries); or (iii) private fee-for-service plans.

Medicare Advantage Prescription Drug Plan (MA-PDP). Prescription drug coverage provided by Medicare Advantage plans.

Medicare Economic Index (MEI). An index often used in the calculation of the increases in the prevailing charge levels that help to determine allowed charges for physician services. In 1992 and later, this index is considered in connection with the update factor for the physician fee schedule.

Medicare Payment Advisory Commission (MedPAC). A commission established by Congress in the Balanced Budget Act of 
1997 to replace the Prospective Payment Assessment Commission and the Physician Payment Review Commission. MedPAC is directed to provide the Congress with advice and recommendations on policies affecting the Medicare program.

Medicare Prescription Drug Account. The separate account within the SMI trust fund to manage revenues and expenditures of the Part D drug benefit.

Military service wage credits. Credits recognizing that military personnel receive other cash payments and wages in kind (such as food and shelter) in addition to their basic pay. Noncontributory wage credits of $\$ 160$ were provided for each month of active military service from September 16, 1940 through December 31, 1956. For years after 1956, the basic pay of military personnel is covered under the Social Security program on a contributory basis. In addition to contributory credits for basic pay, noncontributory wage credits of $\$ 300$ were granted for each calendar quarter in which a person received pay for military service from January 1957 through December 1977. Deemed wage credits of $\$ 100$ were granted for each $\$ 300$ of military wages, up to a maximum of $\$ 1,200$ per calendar year, from January 1978 through December 2001. See also "Quinquennial military service determinations and adjustments."

National average monthly bid. The weighted average of all drug bids including all of the bids from PDPs and the drug portion of bids from MA-PDPs.

Noncontributory or deemed wage credits. Wages and wages in kind that were not subject to the HI tax but are deemed as having been. Deemed wage credits exist for the purposes of (i) determining HI eligibility for individuals who might not be eligible for HI coverage without payment of a premium were it not for the deemed wage credits; and (ii) calculating reimbursement due the HI trust fund from the general fund of the Treasury. The first purpose applies in the case of providing coverage to persons during the transitional periods when HI began and when it was expanded to cover Federal employees; both purposes apply in the cases of military service wage credits and deemed wage credits granted for the internment of persons of Japanese ancestry during World War II.

Old-Age, Survivors, and Disability Insurance (OASDI). The Social Security programs that pay for (i) monthly cash benefits to retired-worker (old-age) beneficiaries, their spouses and children, and survivors of deceased insured workers (OASI); and (ii) monthly cash 


\section{Appendices}

benefits to disabled-worker beneficiaries and their spouses and children, and for providing rehabilitation services to the disabled (DI).

Open-group population. Includes all persons who will ever participate in the program as either taxpayers or beneficiaries, or both. See also "Closed-group population."

Outpatient hospital. Part of the hospital providing services covered by SMI Part B, including services in an emergency room or outpatient clinic, ambulatory surgical procedures, medical supplies such as splints, laboratory tests billed by the hospital, etc.

Part A. The Medicare Hospital Insurance trust fund.

Part A premium. A monthly premium paid by or on behalf of individuals who wish for and are entitled to voluntary enrollment in Medicare HI. These individuals are those who are aged 65 and older, are uninsured for social security or railroad retirement, and do not otherwise meet the requirements for entitlement to Part A. Disabled individuals who have exhausted other entitlement are also qualified. These individuals are those not now entitled but who have been entitled under section 226(b) of the Act, who continue to have the disabling impairment upon which their entitlement was based, and whose entitlement ended solely because the individuals had earnings that exceeded the substantial gainful activity amount (as defined in section 223(d)(4) of the Act).

Part B. The account within the Medicare Supplementary Medical Insurance trust fund that pays for a portion of the costs of physicians' services, outpatient hospital services, and other related medical and health services for voluntarily enrolled aged and disabled individuals.

Part B premium. The monthly amount paid by those individuals who have voluntarily enrolled in Part B. Most enrollees pay the standard premium amount, which currently represents approximately 25 percent of the average program costs for an aged beneficiary. Beneficiaries with high income are also required to pay an income-related monthly adjustment amount starting in 2007, and those who enroll late are required to pay a penalty. In addition, beneficiaries who are affected by the hold-harmless provision pay a lower premium. See section V.C for more details about the Part B premium.

Part C. See "Medicare Advantage." 
Part D. The account within the Medicare Supplementary Medical Insurance trust fund that pays private plans to provide prescription drug coverage.

Participating hospitals. Those hospitals that participate in the Medicare program.

Pay-as-you-go financing. A financing scheme in which taxes are scheduled to produce just as much income as required to pay current benefits, with trust fund assets built up only to the extent needed to prevent exhaustion of the fund by random fluctuations.

Payroll taxes. Taxes levied on the gross wages of workers.

PDP regions. Regional areas that are fully serviced by prescription drug plans.

Peer Review Organization (PRO). A group of practicing physicians and other health care professionals paid by the Federal Government to review the care given to Medicare patients. Starting in 2002, these organizations are called Quality Improvement Organizations.

Percentile. A number that corresponds to one of the equal divisions of the range of a variable in a given sample and that characterizes a value of the variable as not exceeded by a specified percentage of all the values in the sample. For example, a score higher than 97 percent of those attained is said to be in the $97^{\text {th }}$ percentile.

Prescription Drug Plans (PDPs). Stand-alone prescription drug plans offered to beneficiaries in traditional fee-for-service Medicare and to beneficiaries in Medicare Advantage plans that do not offer a prescription drug benefit.

Present value. The present value of a future stream of payments is the lump-sum amount that, if invested today, together with interest earnings would be just enough to meet each of the payments as it fell due. At the time of the last payment, the invested fund would be exactly zero.

Projection error. Degree of variation between estimated and actual amounts.

Prospective payment system (PPS). A method of reimbursement in which Medicare payment is made based on a predetermined, fixed 


\section{Appendices}

amount. The payment amount for a particular service is derived based on the classification system of that service (for example, DRGs for inpatient hospital services).

Provider. Any organization, institution, or individual who provides health care services to Medicare beneficiaries. Hospitals (inpatient services), skilled nursing facilities, home health agencies, and hospices are the providers of services covered under Medicare Part A. Physicians, ambulatory surgical centers, and outpatient clinics are some of the providers of services covered under Medicare Part B.

Quality Improvement Organization (QIO). See "Peer Review Organization."

Quinquennial military service determination and adjustments. Prior to the Social Security Amendments of 1983, quinquennial determinations (that is, estimates made once every 5 years) were made of the costs arising from the granting of deemed wage credits for military service prior to 1957; annual reimbursements were made from the general fund of the Treasury to the HI trust fund for these costs. The Social Security Amendments of 1983 provided for (i) a lump-sum transfer in 1983 for (a) the costs arising from the pre-1957 wage credits, and (b) amounts equivalent to the HI taxes that would have been paid on the deemed wage credits for military service for 1966 through 1983, inclusive, if such credits had been counted as covered earnings; (ii) quinquennial adjustments to the pre-1957 portion of the 1983 lump-sum transfer; (iii) general fund transfers equivalent to $\mathrm{HI}$ taxes on military deemed wage credits for 1984 and later, to be credited to the fund on July 1 of each year; and (iv) adjustments as deemed necessary to any previously transferred amounts representing HI taxes on military deemed wage credits.

Railroad Retirement. A Federal insurance program similar to Social Security designed for workers in the railroad industry. The provisions of the Railroad Retirement Act provide for a system of coordination and financial interchange between the Railroad Retirement program and the Social Security program.

Real-wage differential. The difference between the percentage increases, before rounding, in (i) the average annual wage in covered employment, and (ii) the average annual CPI.

Reasonable-cost basis. The calculation to determine the reasonable cost incurred by individual providers when furnishing covered 
services to beneficiaries. The reasonable cost is based on the actual cost of providing such services, including direct and indirect costs of providers, and excluding any costs that are unnecessary in the efficient delivery of services covered by a health insurance program.

Reinsurance subsidy. Payments to the prescription drug plans in the amount of 80 percent of drug expenses that exceed the annual out-of-pocket threshold.

Residual factors. Factors other than price, including volume of services, intensity of services, and age/sex changes.

Risk corridor. Triggers that are set to protect prescription drug plans from unexpected losses and that allow the government to share in unexpected gains.

Self-employment. Operation of a trade or business by an individual or by a partnership in which an individual is a member.

Self-Employment Contributions Act (SECA). Provision authorizing taxes on the net income of most self-employed persons to provide for OASDI and HI.

Sequester. The reduction of funds to be used for benefits or administrative costs from a Federal account, based on the requirements specified in the Gramm-Rudman-Hollings Act.

Short range. The next 10 years.

Skilled nursing facility (SNF). An institution that is primarily engaged in providing skilled nursing care and related services for residents who require medical or nursing care, or that is engaged in the rehabilitation of injured, disabled, or sick persons.

SNF coinsurance. For the 21st through 100th day of extended care services in a benefit period, a daily amount for which the beneficiary is responsible, equal to one-eighth of the inpatient hospital deductible.

Social Security Act. Public Law 74-271, enacted on August 14, 1935, with subsequent amendments. The Social Security Act consists of 20 titles, four of which have been repealed. The HI and SMI trust funds are authorized by Title XVIII of the Social Security Act. 


\section{Appendices}

Special public-debt obligation. Securities of the U.S. Government issued exclusively to the OASI, DI, HI, and SMI trust funds and other Federal trust funds. Sections 1817(c) and 1841(a) of the Social Security Act provide that the public-debt obligations issued for purchase by the HI and SMI trust funds, respectively, shall have maturities fixed with due regard for the needs of the funds. The usual practice in the past has been to spread the holdings of special issues, as of every June 30, so that the amounts maturing in each of the next 15 years are approximately equal. Special public-debt obligations are redeemable at par at any time.

Spell of illness. A period of consecutive days, beginning with the first day on which a beneficiary is furnished inpatient hospital or extended care services, and ending with the close of the first period of 60 consecutive days thereafter in which the beneficiary is in neither a hospital nor a skilled nursing facility.

Standard prescription drug coverage. Prescription drug coverage that includes a deductible, coinsurance up to an initial coverage limit, and protection against high out-of-pocket expenditures by having reduced coinsurance provisions for individuals exceeding the out-ofpocket threshold.

Stochastic model. An analysis involving a random variable. For example, a stochastic model may include a frequency distribution for one assumption. From the frequency distribution, possible outcomes for the assumption are selected randomly for use in an illustration.

Summarized cost rate. The ratio of the present value of expenditures to the present value of the taxable payroll for the years in a given period. In this context, the expenditures are on an incurred basis and exclude costs for those uninsured persons for whom payments are reimbursed from the general fund of the Treasury, and for voluntary enrollees, who pay a premium in order to be enrolled. The summarized cost rate includes the cost of reaching and maintaining a "target" trust fund level, known as a contingency fund ratio. Because a trust fund level of about 1 year's expenditures is considered to be an adequate reserve for unforeseen contingencies, the targeted contingency fund ratio used in determining summarized cost rates is 100 percent of annual expenditures. Accordingly, the summarized cost rate is equal to the ratio of (i) the sum of the present value of the outgo during the period, plus the present value of the targeted ending trust fund level, plus the beginning trust fund level, to (ii) the present value of the taxable payroll during the period. 
Summarized income rate. The ratio of (i) the present value of the tax revenues incurred during a given period (from both payroll taxes and taxation of OASDI benefits), to (ii) the present value of the taxable payroll for the years in the period.

Supplementary Medical Insurance (SMI). The Medicare trust fund composed of the Part B account, the Part D account, and the Transitional Assistance Account. The Part B account pays for a portion of the costs of physicians' services, outpatient hospital services, and other related medical and health services for voluntarily enrolled aged and disabled individuals. The Part D account pays private plans to provide prescription drug coverage, beginning in 2006. The Transitional Assistance Account paid for transitional assistance under the prescription drug card program in 2004 and 2005 .

Supplemental prescription drug coverage. Coverage in excess of the standard prescription drug coverage.

Sustainable growth rate. A system for establishing goals for the rate of growth in expenditures for physicians' services.

Tax rate. The percentage of taxable earnings, up to the maximum tax base, that is paid for the HI tax. Currently, the percentages are 1.45 for employees and employers, each. The self-employed pay 2.9 percent.

Taxable earnings. Taxable wages and/or self-employment income under the prevailing annual maximum taxable limit.

Taxable payroll. A weighted average of taxable wages and taxable self-employment income. When multiplied by the combined employeeemployer tax rate, it yields the total amount of taxes incurred by employees, employers, and the self-employed for work during the period.

Taxable self-employment income. Net earnings from self-employment-generally above $\$ 400$ and below the annual maximum taxable amount for a calendar or other taxable year-less any taxable wages in the same taxable year.

Taxable wages. Wages paid for services rendered in covered employment up to the annual maximum taxable amount. 


\section{Appendices}

Taxation of benefits. Beginning in 1994, up to 85 percent of an individual's or a couple's OASDI benefits is potentially subject to Federal income taxation under certain circumstances. The revenue derived from taxation of benefits in excess of 50 percent, up to 85 percent, is allocated to the HI trust fund.

Taxes. See "Payroll taxes."

Term insurance. A type of insurance that is in force for a specified period of time.

Test of Long-Range Close Actuarial Balance. Summarized income rates and cost rates are calculated for each of 66 valuation periods within the full 75-year long-range projection period under the intermediate assumptions. The first of these periods consists of the next 10 years. Each succeeding period becomes longer by 1 year, culminating with the period consisting of the next 75 years. The long-range test is met if, for each of the 66 time periods, the actuarial balance is not less than zero or is negative by, at most, a specified percentage of the summarized cost rate for the same time period. The percentage allowed for a negative actuarial balance is 5 percent for the full 75-year period and is reduced uniformly for shorter periods, approaching zero as the duration of the time periods approaches the first 10 years. The criterion for meeting the test is less stringent for the longer periods in recognition of the greater uncertainty associated with estimates for more distant years. This test is applied to HI trust fund projections made under the intermediate assumptions.

Test of Short-Range Financial Adequacy. The conditions required to meet this test are as follows: (i) If the trust fund ratio for a fund exceeds 100 percent at the beginning of the projection period, then it must be projected to remain at or above 100 percent throughout the 10-year projection period; (ii) alternatively, if the fund ratio is initially less than 100 percent, it must be projected to reach a level of at least 100 percent within 5 years (and not be depleted at any time during this period), and then remain at or above 100 percent throughout the rest of the 10-year period. This test is applied to HI trust fund projections made under the intermediate assumptions.

Transitional assistance. An interim benefit for 2004 and 2005 that provided up to $\$ 600$ per year to assist low-income beneficiaries who had no drug insurance coverage with prescription drug purchases. This benefit also paid the enrollment fee in the Medicare Prescription Drug Discount Card program. 
Transitional Assistance Account. The separate account within the SMI trust fund that managed revenues and expenditures for the transitional assistance drug benefit in 2004 and 2005.

Trust fund. Separate accounts in the U. S. Treasury, mandated by Congress, whose assets may be used only for a specified purpose. For the HI and SMI trust funds, monies not withdrawn for current benefit payments and administrative expenses are invested in interest-bearing Federal securities, as required by law; the interest earned is also deposited in the trust funds.

Trust fund ratio. A short-range measure of the adequacy of the HI and SMI trust fund level; defined as the assets at the beginning of the year expressed as a percentage of the outgo during the year.

Unit input intensity allowance. The amount added to, or subtracted from, the hospital input price index to yield the prospective payment system update factor.

Valuation period. A period of years that is considered as a unit for purposes of calculating the status of a trust fund.

Voluntary enrollees. Certain individuals, aged 65 or older or disabled, who are not otherwise entitled to Medicare and who opt to obtain coverage under Part A by paying a monthly premium.

Year of exhaustion. The first year in which a trust fund is unable to pay benefits when due because the assets of the fund are exhausted. 
List of tables

\section{TABLES}

II.B1. - Medicare Data for Calendar Year 2006 ...............................5

II.C1._ Ultimate Assumptions .......................................................

II.E1. - Estimated Operations of the HI Trust Fund under Intermediate Assumptions, Calendar Years 2006-2016.....15

II.F1.- Estimated Operations of the SMI Trust Fund under Intermediate Assumptions, Calendar Years 2006-2016.....22

III.A1.- Total Medicare Income, Expenditures, and Trust Fund Assets during Calendar Years 1970-2016 ...........................30

III.A2.- $\mathrm{Hl}$ and SMI Incurred Expenditures as a Percentage of the Gross Domestic Product ....................................................33

III.A3._ Medicare Enrollment ...............................................................34

III.A4.- Medicare Sources of Income as a Percentage of Total

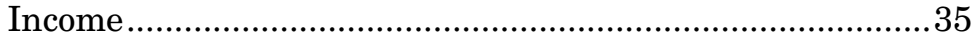

III.A5.- Comparative Growth Rates of Medicare, Private Health Insurance, and National Health Expenditures....................38

III.B1.- Statement of Operations of the HI Trust Fund during Calendar Year 2006

III.B2._ Tax Rates and Maximum Tax Bases .................................. 42

III.B3.- Comparison of Actual and Estimated Operations of the HI Trust Fund, Calendar Year 2006.....................................45

III.B4.- Operations of the HI Trust Fund during Calendar Years 1970-2016

III.B5.- Estimated Operations of the HI Trust Fund during Calendar Years 2006-2016, under Alternative Sets of Assumptions

III.B6.- Ratio of Assets at the Beginning of the Year to Expenditures during the Year for the HI Trust Fund .........53

III.B7.- - HI Cost and Income Rates...................................................56

III.B8.- HI Actuarial Balances under Three Sets of Assumptions..61

III.B9.- Components of 75 Year HI Actuarial Balance under Intermediate Assumptions (2007 2081)...............................62

III.B10.- Unfunded HI Obligations from Program Inception through the Infinite Horizon

III.B11.-Unfunded HI Obligations for Current and Future Program Participants through the Infinite Horizon............67

III.B12.-Change in the 75-Year Actuarial Balance since the 2006 Report.

III.B13.-Estimated HI Income Rates, Cost Rates, and Actuarial Balances, Based on Intermediate Estimates with Various Real-Wage Assumptions 
III.B14.-Estimated HI Income Rates, Cost Rates, and Actuarial Balances, Based on Intermediate Estimates with Various CPI-Increase Assumptions

III.B15.-Estimated HI Income Rates, Cost Rates, and Actuarial Balances, Based on Intermediate Estimates with Various Real-Interest Assumptions....

III.B16.-Estimated HI Income Rates, Cost Rates, and Actuarial Balances, Based on Intermediate Estimates with Various Health Care Cost Growth Rate Assumptions ........74

III.C1.- Operations of the SMI Trust Fund (Cash Basis) during Calendar Years 1970-2016

III.C2.- SMI Expenditures (Incurred Basis) as a Percentage of the Gross Domestic Product ...................................................77

III.C3.- Average Annual Rates of Growth in SMI and the Economy

III.C4.- SMI General Revenues as a Percentage of Personal and Corporate Federal Income Taxes

III.C5.- Statement of Operations of the Part B Account in the SMI Trust Fund during Calendar Year 2006

III.C6.- Standard Part B Monthly Premium Rates, Actuarial Rates, and Premium Rates as a Percentage of Part B Cost

III.C7.- Comparison of Actual and Estimated Operations of the Part B Account in the SMI Trust Fund, Calendar Year 2006.

III.C8.- Operations of the Part B Account in the SMI Trust Fund (Cash Basis) during Calendar Years 1970-2016 .......90

III.C9.- Growth in Part B Benefits (Cash Basis) through December 31, 2016.

III.C10.-Estimated Operations of the Part B Account in the SMI Trust Fund during Calendar Years 2006-2016, under Alternative Sets of Assumptions.....

III.C11.-Estimated Part B Income and Expenditures (Incurred Basis) for Financing Periods through December 31, 2007

III.C12.- Summary of Estimated Part B Assets and Liabilities as of the End of the Financing Period, for Periods through December 31, 2007.

III.C13.-Actuarial Status of the Part B Account in the SMI Trust Fund under Three Cost Sensitivity Scenarios for Financing Periods through December 31, 2007.

III.C14.-Part B Expenditures (Incurred Basis) as a Percentage of the Gross Domestic Product 
List of tables

III.C15.-Unfunded Part B Obligations from Program Inception through the Infinite Horizon

III.C16.-Unfunded Part B Obligations for Current and Future Program Participants through the Infinite Horizon..........105

III.C17.-Statement of Operations of the Part D Account in the SMI Trust Fund during Calendar Year 2006

III.C18.-Comparison of Actual and Estimated Operations of the Part D Account in the SMI Trust Fund, Calendar Year 2006.

III.C19.-Operations of the Part D Account in the SMI Trust Fund (Cash Basis) during Calendar Years 2004-2016 .....113

III.C20.-Growth in Part D Benefits (Cash Basis) through December 31, 2016 .

III.C21.-Estimated Operations of the Part D Account in the SMI Trust Fund during Calendar Years 2006-2016, under Alternative Sets of Assumptions...

III.C22.-Part D Expenditures (Incurred Basis) as a Percentage of the Gross Domestic Product ...........................................119

III.C23.-Unfunded Part D Obligations from Program Inception through the Infinite Horizon.

III.C24.- Unfunded Part D Obligations for Current and Future Program Participants through the Infinite Horizon..........121

IV.A1.- Components of Historical and Projected Increases in HI Inpatient Hospital Payments ........................................... 126

IV.A2.- Relationship between Increases in HI Expenditures and Increases in Taxable Payroll ..............................................130

IV.A3.- Summary of HI Alternative Projections ..............................134

IV.B1.- Components of Increases in Total Allowed Charges per Fee-for-Service Enrollee for Carrier Services......................140

IV.B2.- Incurred Reimbursement Amounts per Fee-for-Service Enrollee for Carrier Services ..............................................143

IV.B3.- Components of Increases in Recognized Charges and Costs per Fee-for-Service Enrollee for Intermediary

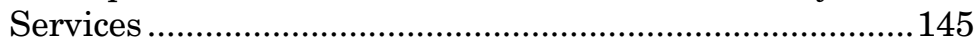

IV.B4.- Incurred Reimbursement Amounts per Fee-for-Service Enrollee for Intermediary Services ....................................146

IV.B5. - Enrollment and Incurred Reimbursement for End-Stage Renal Disease

IV.B6.- Enrollment and Incurred Reimbursement for Managed Care.....

IV.B7.- - Aggregate Reimbursement Amounts on a Cash Basis .....150

IV.B8.- Part B Cash Expenditures as a Percentage of the Gross Domestic Product for Calendar Years 2006-2016

IV.B9._- Part D Enrollment ..........................................................153 
IV.B10.-Key Factors for Part D Expenditures Estimates .. 154

IV.B11.- Incurred Reimbursement Amounts per Enrollee for Part D Expenditures

IV.B12.-Aggregate Reimbursements on a Cash Basis for Part D..158

IV.B13.-Part D Assumptions under Alternative Scenarios for Calendar Years 2006-2016

IV.B14.-Part D Cash Expenditures as a Percentage of the Gross Domestic Product for Calendar Years 20062016 ..............160

V.B1.- HI and SMI Average per Beneficiary Costs ......................166

V.C1.- HI Cost Sharing and Premium Amounts ...........................169

V.C2.- SMI Cost Sharing and Premium Amounts........................171

V.C3.- Part B Income-Related Premium Amounts....................... 172

V.D1.- Estimated Incurred Part B Benefit Expenditures, by Percentile of Projection Distribution

V.D2.- Percentiles of Part B Benefit Expenditure Distribution Corresponding to Low, Intermediate, and High Cost Estimates....

V.E1.- Annual Revenues and Expenditures for Medicare and Social Security Trust Funds and the Total Federal

Budget, Fiscal Year 2006

V.E2.- Present Values of Projected Revenue and Cost Components of 75-Year Open-Group Obligations for HI, SMI, and OASDI

V.F1.- Statement of Operations of the HI Trust Fund during Fiscal Year 2006

V.F2.- Statement of Operations of the Part B Account in the SMI Trust Fund during Fiscal Year 2006

V.F3.- Statement of Operations of the Part D Account in the SMI Trust Fund during Fiscal Year 2006

V.F4.- Total Medicare Income, Expenditures, and Trust Fund Assets during Fiscal Years 1970-2016

V.F5.- Operations of the HI Trust Fund during Fiscal Years 1970-2016

V.F6.- Operations of the SMI Trust Fund (Cash Basis) during Fiscal Years 1970-2016.

V.F7.- Operations of the Part B Account in the SMI Trust Fund (Cash Basis) during Fiscal Years 1970-2016

V.F8.- Operations of the Part D Account in the SMI Trust Fund (Cash Basis) during Fiscal Years 2004-2016...........200

V.F9.- Assets of the HI Trust Fund, by Type, at the End of Fiscal Years 2005 and 2006 199

V.F10.- Assets of the SMI Trust Fund, by Type, at the End of Fiscal Years 2005 and 2006 .201 
List of Figures

\section{FIGURES}

II.D1. - Medicare Expenditures as a Percentage of the Gross Domestic Product

II.D2.- Medicare Sources of Non-Interest Income and Expenditures as a Percentage of the Gross Domestic Product.

II.E1.- Long-Range HI Income and Cost as a Percentage of Taxable Payroll, Intermediate Assumptions.

II.E2.- HI Trust Fund Balance at Beginning of Year as a Percentage of Annual Expenditures

II.F1.- SMI Expenditures and Premiums as a Percentage of the Gross Domestic Product.

III.A1.— Projected Difference between Total Medicare Outlays and Dedicated Financing Sources, as a Percentage of Total Outlays.....

III.B1.- HI Expenditures and Income .............................................47

III.B2.- HI Trust Fund Balance at Beginning of Year as a Percentage of Annual Expenditures .

III.B3.- Estimated HI Cost and Income Rates as a Percentage of Taxable Payroll .......................................................................57

III.B4._- Workers per HI Beneficiary..............................................59

III.B5.- - Present Value of Cumulative HI Taxes Less Expenditures through Year Shown, Evaluated under Current Law Tax Rates and Legislated Expenditures

III.B6.- Comparison of HI Cost and Income Rate Projections: Current versus Prior Year's Reports

III.C1.- Comparison of Average Monthly SMI Benefits, Premiums, and Cost-Sharing to the Average Monthly Social Security Benefit............................................................ 80

III.C2.- Part B Aged and Disabled Monthly Per Capita Income.....86

III.C3.- Premium Income as a Percentage of Part B Expenditures ........................................................................92

III.C4.- Actuarial Status of the Part B Account in the SMI Trust Fund through Calendar Year 2006 ...................................102

III.C5.- Comparison of Part B Projections as a Percentage of the Gross Domestic Product: Current versus Prior Year's Reports

III.C6.- Comparison of Part D Projections as a Percentage of the Gross Domestic Product: Current versus Prior Year's Reports

V.D1.- 95-Percent Projection Interval for Part B Incurred Benefits 
List of Figures

V.D2.- 95-Percent Projection Interval for Financing Status of Part B Account of SMI Trust Fund .....................................183

V.D3.- Frequency Distribution of Estimation Errors for Part B Account of SMI Trust Fund Surplus Ratio........................ 184 
Appendices

\section{STATEMENT OF ACTUARIAL OPINION}

It is my opinion that (1) the techniques and methodology used herein to evaluate the financial status of the Federal Hospital Insurance Trust Fund and the Federal Supplementary Medical Insurance Trust Fund are based upon sound principles of actuarial practice and are generally accepted within the actuarial profession; and (2) the principal assumptions used and the resulting actuarial estimates are, individually and in the aggregate, reasonable for the purpose of evaluating the financial status of the trust funds under current law, taking into consideration the past experience and future expectations for the population, the economy, and the program.

In past reports, and again this year, the Board of Trustees has emphasized the strong likelihood that actual Part B expenditures will exceed the projections under current law, due to further legislative action to avoid substantial reductions in the Medicare physician fee schedule. While the Part B projections in this report are reasonable in their portrayal of future costs under current law, they are not reasonable as an indication of actual future costs. Current law would require physician fee reductions totaling an estimated 41 percent over the next 9 years—an implausible result.

The Trustees have also noted the uncertainty associated with the cost of the new Medicare prescription drug benefit. The availability of the 2006 and 2007 bid submissions by the private plans offering this coverage, together with data on beneficiary enrollment in 2006, has helped narrow the range of uncertainty. Nonetheless, this range remains substantial, as illustrated by the Part D projections under alternative assumptions. The projection uncertainty should continue to decline over the next few years as actual expenditure data under this new program become available.

Richard S. Foster

Fellow, Society of Actuaries

Member, American Academy of Actuaries

Chief Actuary, Centers for Medicare \& Medicaid Services 